\title{
Rational Design of Triplet Sensitizers for the Transfer of Excited State Photochemistry from UV to Visible
}

\author{
Luke D. Elliott, ${ }^{*[a]}$ Surajit Kayal, ${ }^{[b]}$ Michael W. George ${ }^{[b, c]}$ and Kevin Booker-Milburn*[a] \\ [a] School of Chemistry, University of Bristol, Cantock's Close, Bristol, BS8 1TS; [b] School of Chemistry, University of \\ Nottingham, University Park, Nottingham, UK, NG7 2RD; [c] Department of Chemical and Environmental Engineering, The \\ University of Nottingham Ningbo China, Ningbo 315100, China orcid.org/0000-0002-7844-1696
}

\begin{abstract}
Time Dependent Density Functional Theory (TD-DFT) has been used to assist the design and synthesis of a series thioxanthone triplet sensitizers. Calculated energies of the triplet excited state $\left(\mathrm{E}_{\mathrm{T}}\right)$ informed both the type and position of auxochromes placed on the thioxanthone core, enabling fine-tuning of the UV-Vis absorptions and associated triplet energies. The calculated results were highly consistent with experimental observation in both the order of the $\lambda_{\max }$ and $\mathrm{E}_{\mathrm{T}}$ values. The synthesised compounds were then evaluated for their efficacies as triplet sensitizers in a variety of UV and visible light preparative photochemical reactions. The results of this study exceeded expectations; in particular [2+2] cycloaddition chemistry that had previously been sensitized in the UV was found to undergo cycloaddition at $455 \mathrm{~nm}$ (blue) with a 2 to 9 -fold increase in productivity (g/h) relative to input power. This study demonstrates the ability of powerful modern computational methods to aid the design of successful and productive triplet sensitized photochemical reactions.
\end{abstract}

\section{INTRODUCTION}

Excited state photochemistry ${ }^{1}$ involves the formation of bonds by the reaction of molecules in an electronically excited state. Its purest embodiment occurs without catalysts or reagents by irradiation with UV light, most commonly in the region of 250-400 $\mathrm{nm}$. This 'reagentless' approach to synthesis is highly desirable in an ever more economic and green focused society. Reactions typically occur from either the lowest energy excited singlet $\left(\mathrm{S}_{1}\right)$ or triplet $\left(T_{1}\right)$ states, the latter accessed via intersystem crossing (ISC) from the singlet. These 'electronic isomers' of the ground state species can react in exotic ways to give rapid access to complex or highly strained species with favorable properties for drug discovery ${ }^{2}$ or further reactivity. ${ }^{3}$ Unfortunately the overall efficiency, and hence synthetic utility, of a photochemical reaction is often dependent on the lifetime of these states relative to the rate of chemical reaction, which in turn is determined by the physical properties of the compound. Therefore, many interesting photochemical reactions may remain of academic curiosity due to poor yields and low-productivities. Whilst the short-lived $\mathrm{S}_{1}$ state is inherently difficult to control, the much longer lifetime of the $T_{1}$ state can be exploited to significantly enhance the overall quantum efficiency of a reaction.

Since the early $1960 \mathrm{~s}^{4}$ it has been understood that photosensitizers can enable population of the $T_{1}$ excited state of a substrate by energy transfer even though the substrate does not absorb at the sensitizer absorbing wavelength (Figure 1A). As a result a number of photochemical reactions have been enabled by sensitization when direct irradiation has been ineffective. ${ }^{5}$ The ideal triplet sensitizer has a strong extinction coefficient to allow for efficient light absorption at low concentrations, a relatively small $\mathrm{S}_{1}-\mathrm{T}_{1}$ energy difference for irradiation at the longest wavelength, ISC close to unity for maximum quantum efficiency and a long lived $T_{1}$ state for efficient energy transfer to a ground state species. All these features can circumvent the most common causes for a low productivity in a photochemical reaction. Furthermore, where the singlet and triplet manifolds have different reaction outcomes it is possible to switch between $S_{1}$ and $T_{1}$ chemistry by addition of a sensitizer. ${ }^{6}$

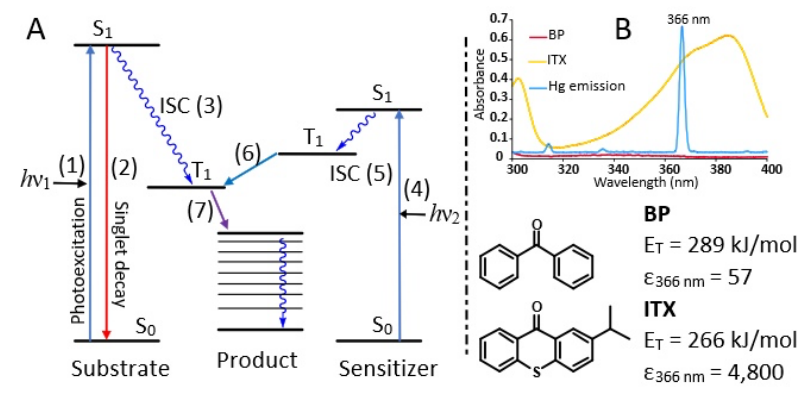

Figure 1. (A) Simplified Jablonski diagram of a triplet mediated photochemical reaction: (1) Direct excitation of substrate to $S_{1}$; (2) Singlet decay by radiative and non-radiative processes; (3) ISC to reactive $\mathrm{T}_{1}$; (4) Photoexcitation of sensitizer; (5) Rapid ISC to $\mathrm{T}_{1}$; (6) Triplet energy transfer to substrate; (7) Chemical reaction and relaxation to ground state. (B) UV absorption of BP and ITX at $1 \times 10^{-4} \mathrm{M}$, overlaid with UVA emission from medium pressure $\mathrm{Hg}$ lamp.

In addition to an energy transfer pathway, sensitizers have also allowed for efficient scale-up of photo-initiated processes by alternative methods. ${ }^{7}$ For example, in recent years there has been explosive growth in the development of photoredox catalysis, ${ }^{8}$ i.e. organic or organometallic catalysts that upon photoexcitation act as powerful one-electron oxidants or reductants in a variety of bond forming processes. Modification of a ligand on a 
transition metal complex ${ }^{9}$ or substituents on an organic dye ${ }^{10}$ allows the redox potential to be fine-tuned to match that of a substrate. Within this recent work it has been found that some of the organometallic photoredox catalysts can alternatively function as classic triplet sensitizers in, for example [2+2] photocycloadditions. ${ }^{11}$ However, the possibility that transition metal photocatalysts can react via either electron or energy transfer can make determination of the mode of activation difficult as highlighted in a recent study on eniminium [2+2] cycloaddition using laser flash photolysis. $^{12}$

Herein we report the rational design of a family of triplet sensitizers for chemical synthesis ${ }^{13}$ that share a common chromophore, but individually cover a range of triplet energies. From our experience of photochemical synthesis in the UV, we were inspired to design a range of organic sensitizers that would span the $350-450 \mathrm{~nm}$ region.

A key goal of the present study was to see if it was possible to move useful UV chemistry into the visible ( $\geq 400 \mathrm{~nm}$ ) with similar or better productivities to match readily available high intensity LED light sources. It should be noted that use of sensitizers can result in practical issues, especially if energy transfer is inefficient or the sensitizer has a low extinction coefficient ( $\varepsilon$ ). In these instances high sensitizer concentrations/equivalents are required (e.g. acetophenone \& acetone), often resulting in degradation, purification and separation issues. With this in mind we considered the design of highly absorbing sensitizers that could be used in low molar equivalences and be stable to high UV/Vis powers $(\geq 500 \mathrm{~W})$. Traditionally, sensitizer screens involve a range of chromophores with different triplet energies, but very different absorption characteristics (cf. BP and ITX, Figure 1B). A sensitizer series based around single chromophore is therefore highly desirable for consistency and reliability.

Scheme 1. Scale-up of $[2+2]$ photocycloadditions using thioxanthone sensitization.

Booker-Milburn \& Elliott 2016

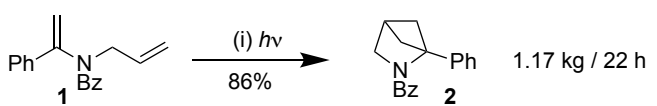<smiles>O=C1OC(=O)C2=C1CCCC2</smiles>

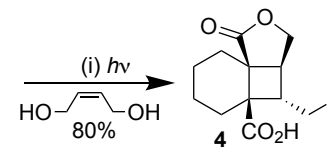
$1.54 \mathrm{~kg} / 9.3 \mathrm{~h}$ Kappe 2019<smiles>CC1=CC(=O)OC1=O</smiles>

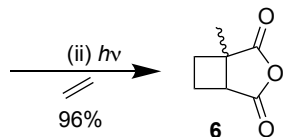

$0.10 \mathrm{~kg} / 10 \mathrm{~h}$

(i) $1 \%$ ITX, MeCN, 3kW Hg-lamp, PTFR (ii) $2.5 \% \mathrm{TX}$, EtOAc, $375 \mathrm{~nm}$ Corning $\mathrm{G} 1$

In 2016 as part of a campaign to enable the scale-up of UV photochemistry using flow-reactors we designed a parallel tube flow reactor (PTFR) ${ }^{14}$ which displayed productivities of between $1-8 \mathrm{~kg} /$ day for a range of photochemical reactions in the UV (Scheme 1). The large-scale examples in Scheme 1 required a triplet sensitizer to enable a productivity increase to multi-kg/day quantities. Of a number of sensitizers screened, isopropylthioxanthone (ITX) was demonstrably superior in terms of productivity at exceptionally low loadings $(1 \%)$. The isopropyl derivative proved to be more soluble than the parent thioxanthone, making bulk purification by trituration easier. The high extinction coefficient of ITX (Figure 1B) is important for its excellent sensitization properties at the $1 \%$ loadings used, and remarkably we found no sensitizer degradation was observed despite the very powerful $3 \mathrm{~kW}$ Hg-UV lamp employed.

In 2019 Kappe $^{15}$ reported a study of maleimide and maleic anhydride [2+2] cycloadditions (UVA) using a variety of known sensitizers chosen for their matching triplet energies. They also observed that thioxanthone proved to be a superior sensitizer where the substrate triplet energy was a suitable match. In the visible region, Bach $^{16}$ has shown that thioxanthone can be used as a sensitizer by irradiation at the tail of the absorption using 420 $\mathrm{nm}$ light. Jockush and Sivaguru ${ }^{17}$ have shown that 2,2'-bromo thioxanthone induces a moderate $(\sim 15 \mathrm{~nm})$ bathochromic shift enabling sensitized cycloadditions with near UV light (395$405 \mathrm{~nm})$. However, photolabile halo derivatives $(\mathrm{Cl}, \mathrm{Br}, \mathrm{I})$ can be problematic due to the potential of photodehalogenation. ${ }^{18} \mathrm{~A}$ further advantage of thioxanthone over other common sensitizers, such as BP is the nature of the reactive triplet state. For TX this is $\left(\pi, \pi^{*}\right)$ whilst for BP it is (n, $\left.\pi^{*}\right)$ making TX less likely to take part in competing $\mathrm{H}$-atom abstractions which are well documented for BP and derivatives. ${ }^{19}$

\section{RESULTS and DISCUSSION}

DFT Informed Sensitizer Design. It was our aim to induce predictable shifts in absorbance by substituting thioxanthone with a range of auxochromes that electronically modify the UV/Vis absorption of a chromophore. Rather than embark on a time consuming hit-and-miss synthetic approach, we opted to use timedependent density functional theory (TD-DFT) to calculate the triplet energies for a range of auxochrome substituted thioxanthone derivatives. This would enable the selection of potential sensitizer candidates to be made before synthesis. In terms of substituents we chose a balance between those that are known auxochromes and would likely be photochemically robust. Based on prior experience with substituted benzophenones and acetophenones we narrowed down the auxochrome choice to fluoroand methoxy-substituents.

Initial TD-DFT calculations of thioxanthone derivatives bearing these two auxochromes were highly informative in predicting a sensitizer series spanning a broad range of triplet energies. Once a range of nine candidates were selected from these computational studies, they were then synthesized using an Ullman coupling/Friedel Crafts approach (see SI). 


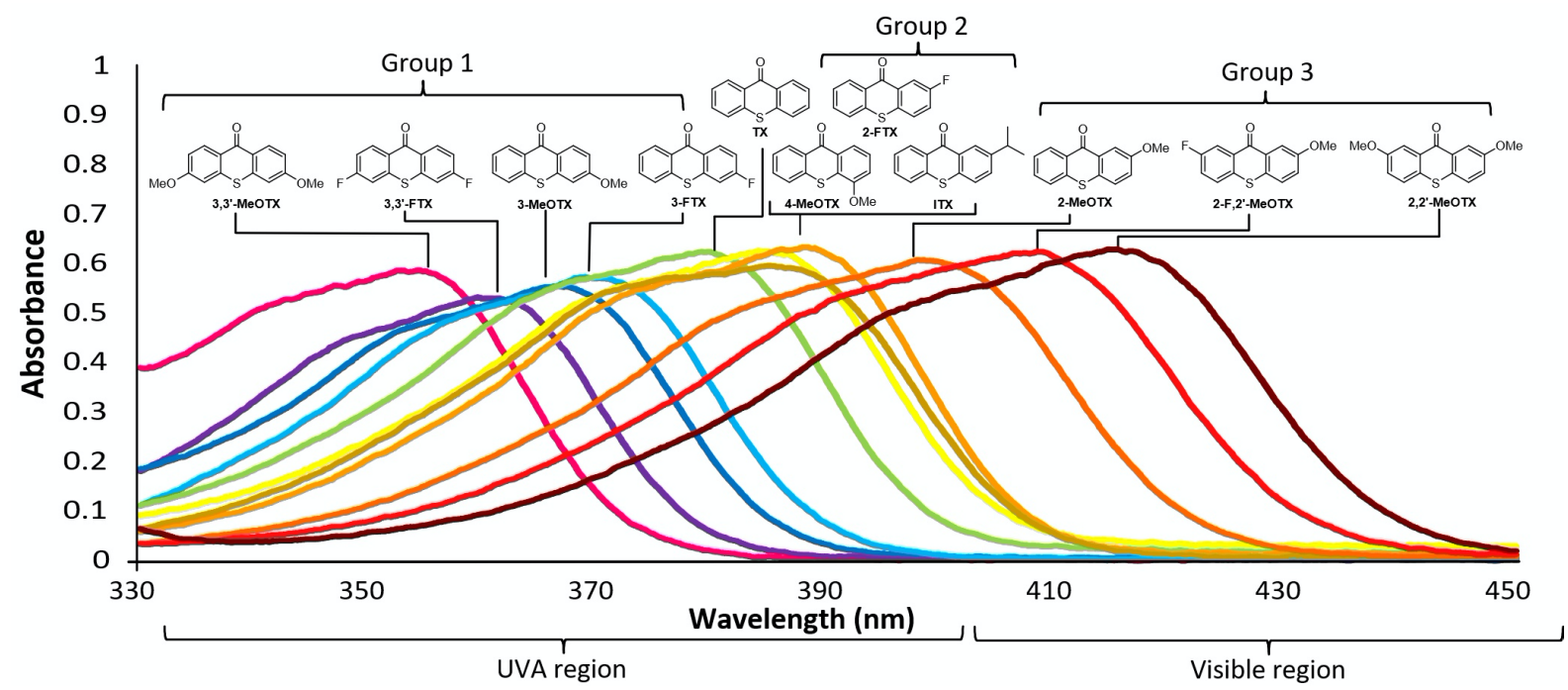

Figure 2. UV-Vis absorption spectra for the synthesized thioxanthone sensitizer series including the parent commercially available thioxanthone and 2-isopropyl thioxanthone. All were run at a concentration of $1 \times 10^{-4} \mathrm{M}$ in acetonitrile.

Photophysical Characterisation. The UV-Vis absorption of the nine synthesized thioxanthone derivatives (plus TX and ITX) are represented in Figure 2 as a composite spectrum for comparison. The placement of these auxochromes has the desired effect of shifting the UV-Vis absorption relative to the parent thioxanthone core. In the UV-Vis spectra, substituents in the 2-position induce a bathochromic shift whilst 3-substituents induce a hypsochromic shift compared to the parent thioxanthone, in excellent agreement with DFT. The effect is more pronounced for the $\mathrm{MeO}$ derivatives (compared to F) and the effect is additive. The sensitizer absorption energies can be split into three distinct groups. Absorbing at shorter wavelengths, and hence higher energies than the parent thioxanthone, are the series of 3-substituted thioxanthones (Group 1). Within this group a clear energy order is apparent with 3,3'-MeOTX $>3,3^{\prime}$-FTX
$>3$-MeOTX > 3-FTX. Absorbing at slightly longer wavelength, and hence lower energy than TX are the 2-FTX and 2iPrTX derivatives along with 4-MeOTX (Group 2). These absorbances are clustered close together but an expansion of the weak tail end at longer wavelengths suggests ITX $>2$-FTX $\geq$ 4-MeOTX. The absorbances of the Group 2 series, along with TX begin to overlap with the visible region of the spectrum above $400 \mathrm{~nm}$. Absorbing at significantly longer wavelengths are the series of 2-MeO derivatives with a clear energy order 2MeOTX > 2-F,2'-MeOTX > 2,2'-MeOTX (Group 3). This moves the lowest energy absorption bands well into the visible region and is expected to enhance their efficiency as visible light active triplet sensitizers with readily available and powerful LED sources (e.g. $36 \mathrm{~W}$ at $455 \mathrm{~nm}$ ).

Table 1. Calculated and measured photophysical parameters for substituted thioxanthone derivatives

\begin{tabular}{|c|c|c|c|c|c|c|c|c|}
\hline Entry & $\mathrm{TX}$ & $\lambda_{\max }(\mathrm{nm})^{\mathrm{a}}$ & $\begin{array}{c}\mathrm{E}_{\mathrm{T} \text { (Calc. })^{\mathrm{b}}} \\
(\mathrm{kJ} / \mathrm{mol})\end{array}$ & $\begin{array}{l}\mathrm{E}_{\mathrm{T}(\mathrm{Calc} .)^{\mathrm{c}}} \\
(\mathrm{kJ} / \mathrm{mol})\end{array}$ & $\begin{array}{l}\mathrm{E}_{\mathrm{T} \text { (Meas.) }}{ }^{\mathrm{d}} \\
(\mathrm{kJ} / \mathrm{mol})\end{array}$ & $\tau_{\mathrm{s}}^{\mathrm{g}}$ & $\tau_{\mathrm{T}}^{\mathrm{h}}$ & $\Phi_{I S C}{ }^{i}$ \\
\hline 1 & 3,3'-MeOTX & 354 & 292 & 289 & $298^{\mathrm{e}}$ & $10 \pm 3 \mathrm{ps}$ & $862 \pm 40 \mathrm{~ns}$ & 0.93 \\
\hline 2 & 3,3'-FTX & 362 & 290 & 285 & $289^{\mathrm{e}}$ & $10.5 \pm 1.8 \mathrm{ps}$ & $456 \pm 25 \mathrm{~ns}$ & 0.92 \\
\hline 3 & 3-MeOTX & 367 & 284 & 279 & $283^{\mathrm{e}}$ & $31 \pm 4 \mathrm{ps}$ & $867 \pm 50 \mathrm{~ns}$ & $>0.9$ \\
\hline 4 & 3-FTX & 370 & 282 & 277 & $282^{\mathrm{e}}$ & $21 \pm 3 \mathrm{ps}$ & $520 \pm 25 \mathrm{~ns}$ & 0.83 \\
\hline 5 & $\mathrm{TX}\left(\mathrm{R} / \mathrm{R}^{\prime}=\mathrm{H}\right)$ & 380 & 274 & 268 & $274^{\mathrm{e}}$ & $70 \mathrm{ps}^{20}$ & $760 \pm 30 \mathrm{~ns}$ & $0.76^{17}$ \\
\hline 6 & $\operatorname{ITX}\left(\mathrm{R}^{\prime}=\mathrm{H}, \mathrm{R}=2-^{-i} \mathrm{Pr}\right)$ & 385 & 270 & 263 & $266^{\mathrm{e}}$ & $220 \pm 8 \mathrm{ps}$ & $880 \pm 50 \mathrm{~ns}$ & 0.86 \\
\hline 7 & 2-FTX & 388 & 263 & 257 & $261^{\mathrm{e}}$ & $270 \pm 10 \mathrm{ps}$ & $585 \pm 20 \mathrm{~ns}$ & 0.81 \\
\hline 8 & 4-MeOTX & 385 & 267 & 260 & $263^{\mathrm{e}}$ & $1.9 \pm 0.4 \mathrm{~ns}$ & $1.8 \pm 0.3 \mu \mathrm{s}$ & 0.70 \\
\hline 9 & 2-MeOTX & 399 & 252 & 245 & $242^{\mathrm{f}}$ & $3.3 \pm 0.2 \mathrm{~ns}$ & $1.7 \pm 0.6 \mu \mathrm{s}$ & 0.83 \\
\hline 10 & 2-F,2'-MeOTX & 408 & 242 & 235 & $235^{\mathrm{f}}$ & $9.1 \pm 0.7 \mathrm{~ns}$ & $1.2 \pm 0.2 \mu \mathrm{s}$ & 0.62 \\
\hline 11 & 2,2'-MeOTX & 415 & 235 & 227 & $231^{\mathrm{f}}$ & $6.2 \pm 0.5 \mathrm{~ns}$ & $863 \pm 60 \mathrm{~ns}$ & 0.66 \\
\hline
\end{tabular}

${ }^{\mathrm{a}}$ Longest wavelength absorption maximum $(\mathrm{MeCN}) ;{ }^{\mathrm{b}}$ Calculated $\mathrm{E}_{\mathrm{T}}$, no solvent model, B3LYP 6-31G $(\mathrm{d}, \mathrm{p}) ;{ }^{\mathrm{c}}$ Calculated $\mathrm{E}_{\mathrm{T}}$, no solvent model, B3LYP 6-31+G (d,p); ${ }^{\mathrm{d}}$ Measured $\mathrm{E}_{\mathrm{T}}$ (Phosphorescence, ${ }^{\mathrm{e}} \mathrm{MCH}$ glass, $77 \mathrm{~K} ;{ }^{\mathrm{f}}$ 2-MeTHF glass, $77 \mathrm{~K}$ ); ${ }^{\mathrm{g}}$ Singlet lifetime measured with TRIR, $\mathrm{CD}_{3} \mathrm{CN}$; ${ }^{\mathrm{h}}$ Triplet lifetime measured with TRIR, $\mathrm{CD}_{3} \mathrm{CN}$; i $\mathrm{ISC}$ quantum yield calculated from bleach recovery kinetics 
The TD-DFT calculated triplet energies for the thioxanthone derivatives are summarized in Table 1 along with the corresponding $\lambda_{\max }$ and $\mathrm{E}_{\mathrm{T}}$ as measured by phosphorescence emission spectroscopy. Gratifyingly the TD-DFT calculated triplet energies corresponded well with the order of the observed absorption $\lambda_{\max }$ and measured $\mathrm{E}_{\mathrm{T}}$ values. The three lowest energy (group 3) derivatives displayed overlapping fluorescence and phosphorescence in $\mathrm{MCH}$ at $77 \mathrm{~K}$ which hampered the estimation of the triplet energy. The analysis of the emission spectra of these compounds in 2-MeTHF at $77 \mathrm{~K}$ more readily allowed estimation of the triplet energy (Table 1, entries 9-11). The thioxanthone derivatives span a remarkably wide range of triplet energies from approximately 230 to $290 \mathrm{~kJ} / \mathrm{mol}$. As a point of reference, benzophenone has a triplet energy of $289 \mathrm{~kJ} / \mathrm{mol}^{21}$ thioxanthone $274 \mathrm{~kJ} / \mathrm{mol}^{22}$ and $\left(\operatorname{Ir}\left[\mathrm{dF}\left(\mathrm{CF}_{3}\right) \text { ppy }\right]_{2}(\mathrm{dtbpy})\right) \mathrm{PF}_{6}$ is $255 \mathrm{~kJ} / \mathrm{mol}^{23}$

Also shown in Table 1 are the singlet and triplet lifetimes, as measured using ps and ns time-resolved infrared spectroscopy (TRIR) as this structurally sensitive technique allows characterisation and dynamics of both the singlet and triplet species, together with an estimation of the triplet quantum yield in one convenient measurement at room temperature. These measurements showed a large variation in singlet state lifetime with the different thioxanthone derivatives. The higher energy derivatives with substituents in the 3-position have much shorter singlet state lifetimes before undergoing ISC to the triplet state. These singlet lifetimes are approximately $1000 \times$ shorter lived than the lowest energy derivatives (entries 8-11).

Consistent with previous computational studies of thioxanthone ${ }^{24}$ DFT calculations predicted the lowest excited singlet state $\left(\mathrm{S}_{1}\right)$ was of $\pi \pi^{*}$ character and $\mathrm{S}_{2}$ was $n \pi *$ in polar solvents $(\mathrm{MeCN})$. The $\mathrm{T}_{1}$ states were calculated to be of $\pi \pi^{*}$ character, regardless of solvent polarity. There was a strong correlation between the measured singlet state lifetime and the $\mathrm{S}_{2}\left(n \pi^{*}\right)-\mathrm{S}_{1}\left(\pi \pi^{*}\right)$ energy difference (See SI). The smaller the energy difference, the faster the rate of ISC to the triplet state. This could possibly be due to increased involvement of the $n \pi^{*}$ state, when it is sufficiently close in energy, allowing faster ISC to the triplet states due to El-Sayed's rule. ${ }^{25}$ This has previously been observed in the case of 1-azathioxanthones which were investigated as antenna chromophores in lanthanide (III) based dyes. $^{26}$ Triplet quantum yields $\left(\Phi_{\text {ISC }}\right)$ were estimated using bleach recovery kinetics. These were generally between $80-$ $90 \%$, but the two lowest energy derivatives, along with 4-MeOTX, were measured at just $60-70 \%$.

Sensitizer Evaluation in Alkene Isomerisation. We first assessed the performance of these sensitizers in the simple isomerization of trans-alkenes to photostationary cis/trans mixtures (Figure 3). Using the pure trans-isomers of both $\beta$-Me styrene $\left(\mathrm{E}_{\mathrm{T}(E)}=249 \mathrm{kJmol}^{-1}, \mathrm{E}_{\mathrm{T}(Z)}=275 \mathrm{kJmol}^{-1}\right)^{21}$ and methyl cinnamate $\left(E_{\mathrm{T}}=229 \mathrm{kJmol}^{-1}\right)^{21}$ each of the 10 sensitizers were investigated in turn for their ability to effect a photostationary cis/trans isomer mixture. To allow rapid screening of the whole sensitizer series with minimal material usage, $0.5 \mathrm{ml}$ samples $(0.2 \mathrm{M}, 5 \%$ sensitizer $)$ in deuterated acetonitrile were irradiated in NMR tubes placed next to a $9 \mathrm{~W}$ PL-S low pressure UVA lamp. Multiple samples could be irradiated at once and the reaction was monitored by periodic ${ }^{1} \mathrm{H}-\mathrm{NMR}$ analysis. Pleasingly, for all 10 -sensitizers isomerization to a photostationary state was observed within a similar reaction time (30-45 mins), implying equally efficient overall energy transfer rates. These results immediately demonstrated that the full range of thioxanthone sensitizers can all act as effective sensitizers if the triplet energy is sufficiently high.

Higher energy Group 1 sensitizers gave essentially 1:1 isomerized mixtures in both cases. Slight enrichment in the cisisomer was observed for the medium energy Group 2. Significant enrichment in the cis-isomer was observed for the lower energy Group 3 which reached a maximum of 5:1 for $\beta$-Me styrene and 2:1 for methyl cinnamate when 2-F,2'-MeOTX was used. Although initially a surprise, this is a known trend observed by others and can be attributed to selective sensitization of the trans-isomer with lower energy sensitizers. ${ }^{27}$ The subsequent drop in cis/trans ratio for the lowest energy sensitizer was also noted in the earliest studies and the unusual behaviour observed for low energy triplet sensitizers has been attributed to non-vertical triplet energy transfer. ${ }^{28}$ Recently there has been renewed interest in the use of organic/organometallic sensitizers for enrichment of cis-styrenes by selective isomerization of trans. $^{29}$

$$
\begin{gathered}
\text { Trans } \\
\mathrm{R}=\mathrm{Me}, \beta-\mathrm{Me} \text { styrene; } \mathrm{R}=\mathrm{CO}_{2} \mathrm{Me} \text {, Methyl cinnamate }
\end{gathered}
$$

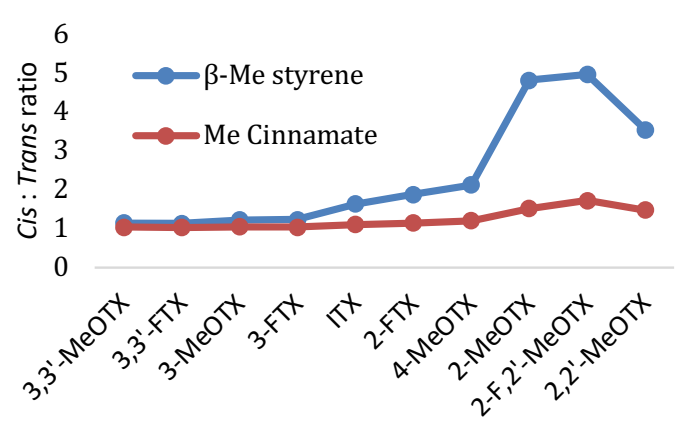

Figure 3. Photostationary cis/trans ratios of $\beta$-Me styrene and methyl cinnamate with the full range of substituted TX sensitizers at $366 \mathrm{~nm}$ (low-pressure UVA lamp).

Sensitizer Evaluation in Preparative Photochemistry. To investigate the effectiveness of the sensitizer set on a preparative scale, reactions were screened for the intra- and intermolecular [2+2] cycloadditions shown in Figure 4 using a 125 $\mathrm{W}$ medium pressure Hg-lamp and a $150 \mathrm{ml}$ immersion well batch reactor. Despite the large predicted triplet energy range, the intramolecular cross [2+2] (Reaction A) showed only moderate variation of productivity across the sensitizer range. This was maintained, even in the case of lowest energy derivative $\left(2,2^{\prime}-\mathrm{MeOTX}\right)$. The final yields, as determined by quantitative NMR all exceeded $90 \%$ at full conversion.

The intermolecular [2+2] of THPA and propargyl alcohol $(\text { Reaction } \mathrm{B})^{30}$ also proceeded with a similar productivity of 22$26 \mathrm{mmol} / \mathrm{h}$ with the first six highest energy sensitizers. The productivity then drops off sharply to $8 \mathrm{mmol} / \mathrm{h}$ with $4-\mathrm{Me}-$ OTX. This is presumably when the triplet energy of the sensitizer falls below that of THPA. At full conversion the [2+2] yields all reached around $75 \%$, which is typical for this reaction. 
(A)<smiles>C=CCNC(=C)c1ccccc1</smiles>

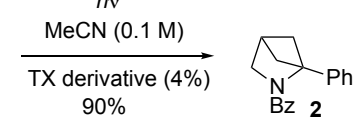

(B)<smiles>O=C1C2=C(CCCC2)C(=O)[O+]1C#CCO</smiles>
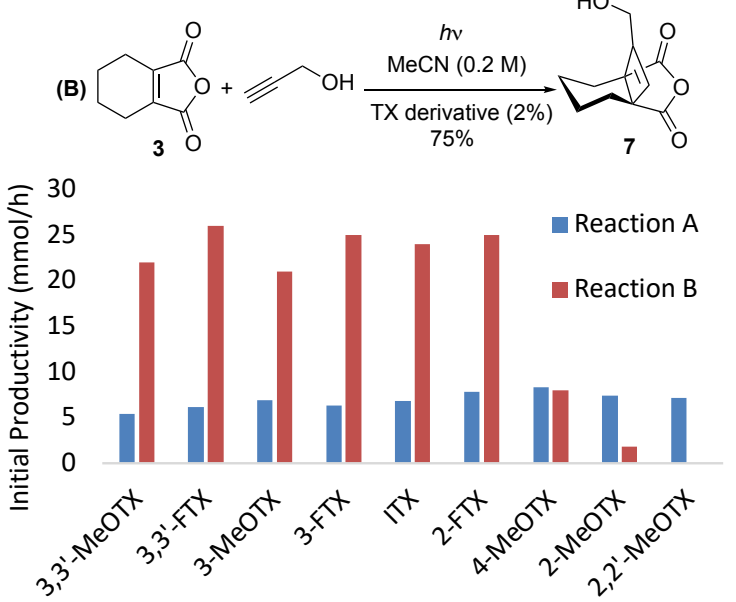

Figure 4. Initial productivities of intra- and intermolecular [2+2] cycloadditions (A) and (B) with a $150 \mathrm{ml}$ immersion well batch reactor and $125 \mathrm{~W} \mathrm{Hg}$ lamp

Reactions (A) and (B) are both well-studied and reliable triplet sensitized photochemical reactions. To further test the synthetic use of the sensitizer set, a reaction was investigated which is more sensitive to variations in reaction conditions (Figure 5). Reaction (C) is a novel cross [2+2] / retro-Mannich sequence giving $\gamma$-amino acid derivative $10{ }^{31}$ In all cases the initial productivity was around $3 \mathrm{mmol} / \mathrm{h}$ but there was a large variation in yield across the sensitizer series, with the higher energy sensitizers giving the greatest yields. 3,3'-MeOTX stands out as giving the highest isolated yield of $66 \%$. Conversely, the lowest energy sensitizer (2,2'-MeOTX) resulted in almost full degradation of the reaction mixture within a short period of time. It is possible that the lower energy sensitizers could be undergoing electron transfer from the electron rich enamine or amine intermediate. ${ }^{32}$

(C)
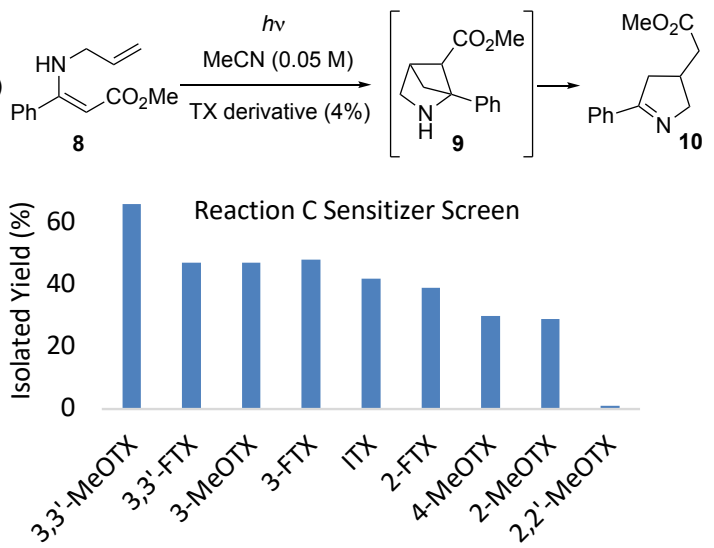

Figure 5. Isolated yields of [2+2] / retro-Mannich product $\mathbf{1 0}$

The above examples were optimized on a preparative scale with a $150 \mathrm{ml}$ batch reactor due to the ready availability of the starting materials. In cases where the photochemical precursor synthesis is more difficult, it was prudent to screen irradiation conditions on a small scale to save material and prevent unnecessary wastage of the sensitizer. The NMR technique described above was used for optimisation of the cycloaddition of amino acrylate 11 (Reaction D), which had previously been carried out under acetophenone sensitisation. ${ }^{33}$ Nearly all the TX sensitizers proved to be very effective in the conversion of enamide 11 (Figure 6). However, unlike the related styrene reaction (Reaction A), the lowest energy sensitizers became ineffective $\left(\mathrm{E}_{\mathrm{T}}<2\right.$-FTX).

The unoptimized cross [2+2] of the enamide 13 to 14 represented a more complex multi-chromophore system and proved to be consistently low yielding, requiring long reaction times, with both benzophenone and ITX sensitizers (Reaction E, Table 2, Entry 1\&2). Using the NMR tube irradiation method we were able to screen the full sensitizer series in deuterated acetonitrile, using just $0.5 \mathrm{mmol}$ of enamide 13. It was found that there was a large variation in yield and productivity across the sensitizer range. The maximum yield was limited to just above $50 \%$ and obtained with the highest energy sensitizer 3,3'MeOTX. Moving down in triplet energy it can be seen that the yields and productivity drop off rapidly (Figure 6).

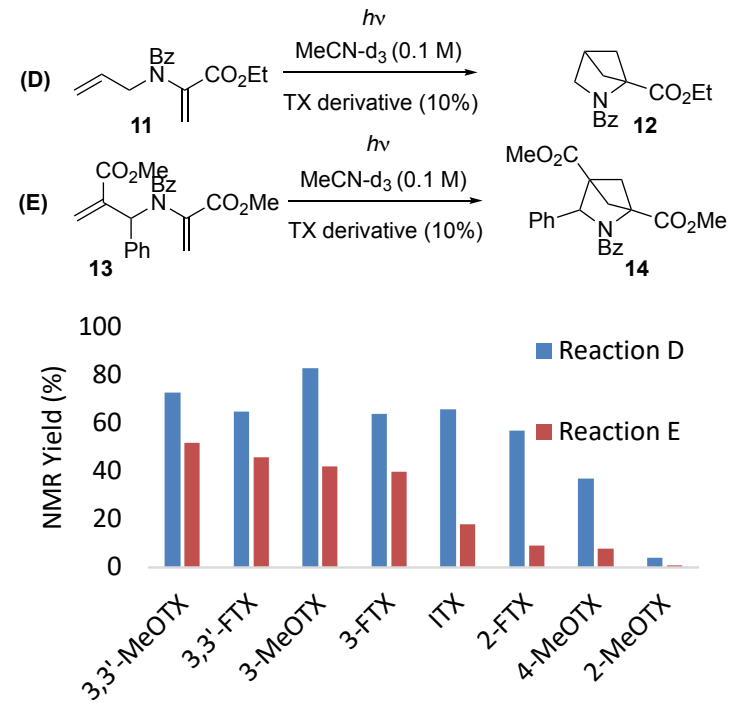

Figure 6. $0.5 \mathrm{ml}$ NMR tube sensitizer screen $(366 \mathrm{~nm})$ for rapid optimization of reactions (D) and (E). Yield determined by adiponitrile internal standard after $15 \mathrm{~min}$ (D) and $30 \mathrm{~min}$ (E)

The value of this rapid NMR method can be seen in the translation of the screening results to the scale-up of Reaction E (Table 2). Using the conventional benzophenone sensitizer gave just over $1 \mathrm{~g}$ of $\mathbf{1 4}$ after $9 \mathrm{~h}$ irradiation. Conversely using the 3,3'-MeOTX sensitizer identified from above we were able to prepare $5.8 \mathrm{~g}$ of product in $7 \mathrm{~h}$ and in the same yield as identified from screening. This result is of significance since the DFT calculations indicate both benzophenone and 3,3'-MeOTX share very similar triplet energies, yet 3,3'-MeOTX is a far superior sensitizer. Both 3-FTX and ITX showed the same drop off in yield and productivity as observed in the NMR screening reactions. 
Table 2. Preparative scale reactions using $125 \mathrm{~W}$ mediumpressure $\mathrm{Hg}$-lamp in a $150 \mathrm{ml}$ batch reactor

\begin{tabular}{llllll} 
Entry & Sensitizer & $\begin{array}{l}\text { Conc. } \\
(\mathrm{M})\end{array}$ & $\begin{array}{l}\text { Time } \\
(\mathrm{h})\end{array}$ & Yield & Mass $(\mathrm{g})$ \\
\hline 1 & $\mathrm{BP}$ & 0.05 & 9 & 46 & 1.3 \\
2 & ITX & 0.05 & 12 & 38 & 1.1 \\
3 & $3-\mathrm{FTX}$ & 0.05 & 5 & 51 & 1.45 \\
4 & $3,3^{\prime}-\mathrm{MeOTX}$ & 0.1 & 3 & 56 & 3.2 \\
5 & $3,3^{\prime}-\mathrm{MeOTX}$ & 0.2 & 7 & 51 & 5.8 \\
\hline
\end{tabular}

Development of a Visible Light Reactor for Preparative Photochemistry. We then turned our attention to the Group 3 sensitizers, which due to their longer wavelengths of absorption ( $>400 \mathrm{~nm}$ ) should be capable of facilitating triplet state photochemistry in the visible region. Our aim was to enable preparative scale photochemistry with low sensitizer loadings ( $\leq 1 \mathrm{~mol} \%$ ) using readily available powerful visible light LED sources. Reported visible light mediated photoredox reactions are often driven by a $40 \mathrm{~W}$ Kessil lamp or a flexible LED strip placed side-on and a few centimetres away from a vial containing the reaction solution. The overall light capture is poor and as a result the reactions are often left on overnight to drive a successful reaction to completion (Figure 7A). The sideon method of irradiation is necessary since the vials are stirred over a magnetic stirrer and there is no room below for a commercial light source. A successful $(4 \times 1.1 \mathrm{~W})$ device for addressing this problem was recently described by McMillan et $a b^{34}$ for optimizing photoredox chemistry and has been commercialised and utilised in a number of labs worldwide.

For our present triplet sensitizer focussed chemistry we required significantly higher-powered devices to take productivities from $\mathrm{mg} / \mathrm{h}$ to multi-grams $/ \mathrm{h}$. We have recently shown that excited state photochemistry can be scaled-up predictably with increasing lamp power since the reactions are often photon limited and have a linear relationship with photon-flux. ${ }^{35}$

Our past experience with the design of UV flow reactors for excited state photochemistry ${ }^{14,35,36}$ demonstrated that much higher productivity levels ( $\geq \mathrm{kg}$ per day) could be achieved if careful attention was paid to light capture by the photosylate. We therefore sought to engineer a visible light system for sensitised photochemistry at input powers of at least $30 \mathrm{~W}$, which could exploit the high-power density of modern visible LED's in conjunction with readily available lab components such as hotplate stirrer (Figure 7B). To achieve this, we designed a high-intensity blue light reactor system based around chip-onboard (COB) LEDs with peak emissions at $455 \mathrm{~nm}$. As these COBs have an output of $36 \mathrm{~W}$ from a circular area of only 22 $\mathrm{mm}$ diameter, they are ideal for delivering a high photon flux to a standard round bottom flask $(50-100 \mathrm{ml})$. Figures $7 \mathrm{C}$ and D show a $36 \mathrm{~W}$ COB attached to a standard magnetic stirrer in close proximity to a round bottom flask. The magnetic stirrer surface acts as a heat sink and a small fan prevents hot air stagnating around the flask.
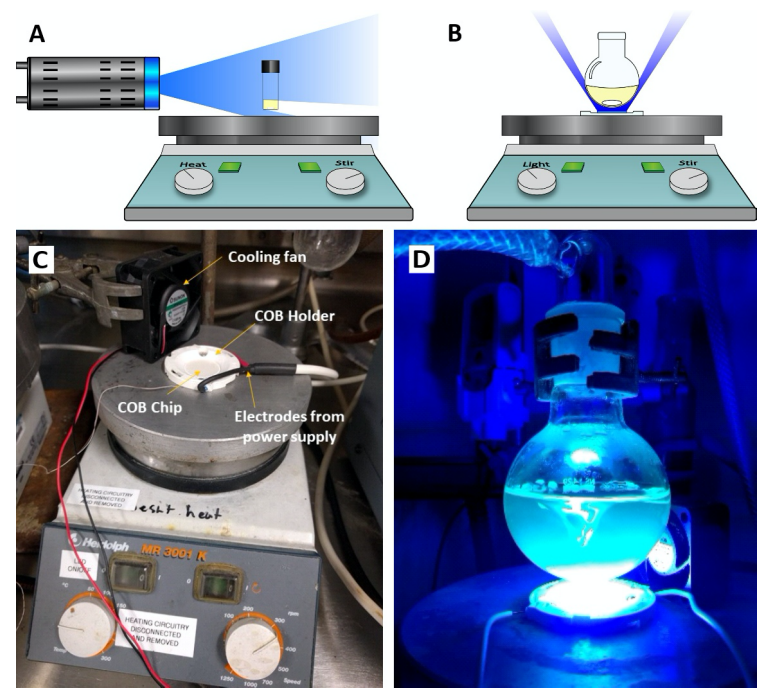

Figure 7. (A) Inefficient side-on irradiation with external lamp over magnetic stirrer. (B) Novel integrated COB LED and magnetic stirrer for maximum light capture. (C) Prototype $455 \mathrm{~nm} 36$ W COB reactor system. (D) Trial reaction, demonstrating irradiation of a stirred vessel

Scale-up of Triplet Sensitized Photochemistry with Visible Light. Simple alkene [2+2] cycloadditions cannot be achieved by direct UV irradiation as alkene absorption is normally $\leq 200 \mathrm{~nm}$. Conjugated alkenes such as styrene undergo sensitized photochemistry from an easily accessible triplet. The cinnamyl alcohol derived diene $\mathbf{1 5}$ was chosen as a test substrate. Yoon ${ }^{11 a}$ was the first to demonstrate that this substrate underwent [2+2] cycloaddition to the cyclobutene ether $\mathbf{1 6}$ in $80 \%$ yield after irradiation with white light $(23 \mathrm{~W})$ for $28 \mathrm{~h}$ with $1 \mathrm{~mol} \%\left(\operatorname{Ir}\left[\mathrm{dF}\left(\mathrm{CF}_{3}\right) \text { ppy }\right]_{2}(\mathrm{dtbpy})\right) \mathrm{PF}_{6}$ catalyst. We repeated this useful reaction using 2,2'-MeOTX ( $1 \mathrm{~mol} \%)$ as sensitizer in a MeCN solution of $15(0.5 \mathrm{M})$ with the $455 \mathrm{~nm} 36 \mathrm{~W}$ COB reactor. Remarkably, after just $3 \mathrm{~h}$ irradiation (Table 3, Entry 1) the reaction was complete allowing for the isolation of $1.5 \mathrm{~g}$ $(89 \%)$ of $16(0.5 \mathrm{~g} / \mathrm{h})$. The aza analogue $17^{37}$ performed even better, providing a high yield (87\%) of the bicyclic amine $\mathbf{1 8}$ with a productivity of $1.43 \mathrm{~g} / \mathrm{h}$.

Interestingly, Oderinde et al recently reported ${ }^{37 b}$ that the cycloaddition of 17 proceeded using $450 \mathrm{~nm}$ irradiation $(34 \mathrm{~W})$ and 5 mole $\%\left(\operatorname{Ir}\left[\mathrm{dF}_{(}\left(\mathrm{CF}_{3}\right) \text { ppy }\right]_{2}(\mathrm{dtbpy})\right) \mathrm{PF}_{6}$ to give $152 \mathrm{mg}$ of 18 in over $24 \mathrm{~h}$. As a like for like comparison this demonstrates that, in conjunction with the $36 \mathrm{~W}$ COB reactor, 2,2'-MeOTX at just $1 \mathrm{~mol} \%$ loading is over 225 times more productive $(\mathrm{g} / \mathrm{h})$. As this is the most commonly ${ }^{11}$ used Iridium based sensitizer for cycloaddition, 2,2'-MeOTX and related sensitizers may find use as convenient and low cost alternatives.

The intramolecular cross [2+2] cycloaddition of amino styrenes has previously been carried out by us in the UV at high 
concentrations (0.1-0.4 M) with a $400 \mathrm{~W}$ Hg lamp, ITX sensitizer in a Pyrex immersion well batch reactor. ${ }^{3 \mathrm{a}}$ In this work we first chose to study these reactions with the visible light absorbing Group 3 sensitizers using the blue $36 \mathrm{~W}$ COB and enamide 1. As can be seen from Figure 8 all three sensitizers ( $1 \mathrm{~mol} \%)$ were highly effective at $455 \mathrm{~nm}$. In particular 2,2'-MeOTX gave complete conversion to 2 in under $2 \mathrm{~h}(0.5 \mathrm{M})$, presumably due to the more optimal overlap of the absorption bands with the emission of the COB at $455 \mathrm{~nm}$.

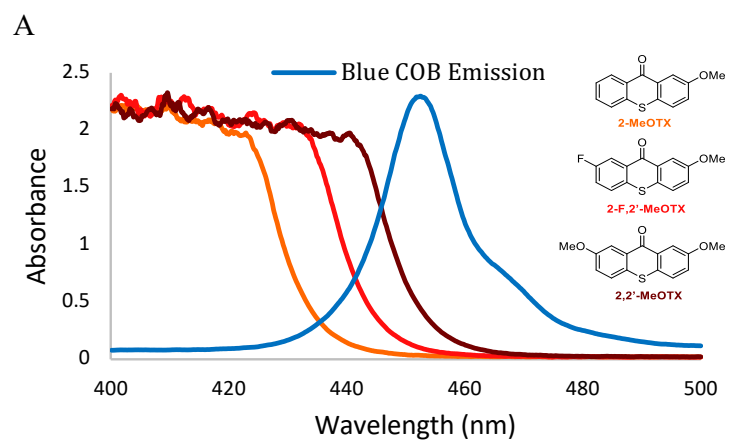

B

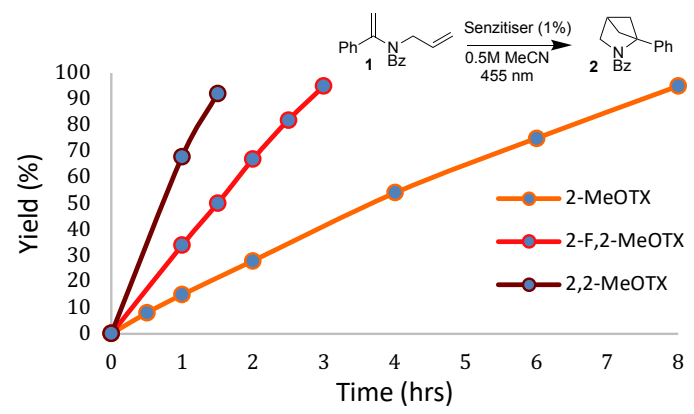

Figure 8. A comparison of (A) UV-Vis absorption spectra and (B) reaction profiles for 3-different visible light sensitizers at 455 $\mathrm{nm}$ with the blue COB LED reactor.

We then undertook a preparative study of 5 different enamides using the absorption matched 2,2'-MeOTX/COB system (Table 3, entries 3-7). In all cases this proved to be a remarkably efficient combination, with their productivities exceeding all expectations e.g. up to $6 \mathrm{~g} / \mathrm{h}$ of 20. To put this in context, for entries 4 and 7, a single $36 \mathrm{~W}$ COB system approached the productivity of the much larger and more powerful $400 \mathrm{~W}$ Hg lamp. For this reaction class the visible light COB 12,2 '-MeOTX combination was $6-9 \times$ more energy efficient than the ITX/Hg lamp reaction. Unlike the NH cinnamate 8 the Boc protected derivative $\mathbf{2 5}$ undergoes cycloaddition without degradation with the low energy sensitizer 2,2'-MeOTX. Compared to the UV conditions this reaction also showed a $9 \times$ increase in energy efficiency when carried out with 2,2'-MeOTX and the blue $\mathrm{COB}$ reactor.

Moving away from styrene chromophores we studied the performance of the alkoxy-maleimide 27 which proved to be a productive cycloaddition using a $125 \mathrm{~W}$ Hg UV lamp when irradiated directly (no sensitizer). Pleasingly, carrying out the same reaction at $455 \mathrm{~nm}$ with 2,2 '-MeOTX gave the product $\mathbf{2 8}$ but with more than twice the energy efficiency (productivity per W). Finally, the well-studied Cookson's dione ${ }^{38} \mathbf{3 0}$ was produced in high yield at $455 \mathrm{~nm}$ with 2,2'-MeOTX and with more than twice the productivity per $\mathrm{W}$ compared to the customary direct irradiation with UV. As with all the other examples the reaction was repeated with $455 \mathrm{~nm}$ in the absence of sensitizer and surprisingly was observed to proceed with identical productivity $(6 \mathrm{~g} / \mathrm{h})$. This interesting observation has not been previously reported in the literature and close inspection of the UV-Vis spectra of the pale yellow starting dione revealed a weak, but significant absorption tail overlapping with the output of the $455 \mathrm{~nm}$ COB. This move to the visible should prove to be a useful observation for a variety of Cookson's dione type cycloadditions $^{39}$ which have previously thought to have been restricted to the UV.

\section{CONCLUSION}

This study has demonstrated that modern DFT methods can be used to inform the design (pre-synthesis) of a family of thioxanthone sensitizers that span the UV-Vis region $(300-450 \mathrm{~nm})$. Based on this design 9 previously untested sensitizers were synthesised and their DFT calculated triplet energies $\left(\mathrm{E}_{\mathrm{T}}\right)$ found to be in excellent agreement with those measured by phosphoresce. A rapid NMR screening method was developed to test the efficacy of the entire sensitizer range and proved very effective in optimizing conditions for the scale-up of [2+2] cycloadditions. A new $36 \mathrm{~W}$ COB reactor system was developed for the optimal visible light $(455 \mathrm{~nm})$ irradiation of stirred vessels. The lower triplet energy sensitizers were found to perform as outstanding sensitizers at $455 \mathrm{~nm}$ for a variety of photocycloaddition reactions previously attempted in the UV. For example, on a W per W basis the 2,2'-MeOTX sensitizer, at just $1 \%$ loading, proved to be 2-9 times more productive than the corresponding UV reactions. Furthermore, for the same power input 2,2'-MeOTX outperformed Iridium based visible light sensitization of [2+2] cycloadditions by over 200 times $(\mathrm{g} / \mathrm{h})$. These outstanding results pave the way for the rational computational design of low-cost, non-metal based organic sensitizers. This should enable the transfer of a range of useful preparative photochemical reactions from the UV to the visible region of the spectra, where modern, compact, powerful and efficient LED based sources are available. 
Table 3. Visible light 2,2'-MeOTX triplet sensitized [2+2] cycloadditions of alkenes with a $36 \mathrm{~W} 455 \mathrm{~nm}$ COB and comparison to ITX sensitized process in UV

\begin{tabular}{|c|c|c|c|c|c|c|c|}
\hline & & & & \multicolumn{2}{|c|}{$36 \mathrm{~W}$ Blue / 2,2'-MeOTX } & \multirow{2}{*}{$\begin{array}{c}\text { UV/ ITX } \\
\text { Productivity } \\
\text { g/h }(\mathrm{mg} / \mathrm{h} / \mathrm{W})\end{array}$} & \multirow[b]{2}{*}{$\begin{array}{c}\text { Efficiency } \\
\text { Blue vs. UV }\end{array}$} \\
\hline \# & Starting Material & Product & $\begin{array}{c}\text { Time } \\
\mathrm{h}\end{array}$ & Yield \% (g) & $\begin{array}{l}\text { Productivity } \\
\mathrm{g} / \mathrm{h}(\mathrm{mg} / \mathrm{h} / \mathrm{W})\end{array}$ & & \\
\hline 1 & V & & 3 & 89 (1.54) & $0.51(14.2)$ & $0.85(6.8)$ & $2.1 \times$ \\
\hline 2 & & & 5 & $87(7.13)$ & $1.43(39.7)$ & $1.15(9.2)$ & $4.3 \times$ \\
\hline 3 & & & 3 & $83(6.58)$ & $2.19(60.8)$ & $3.89(9.7)$ & $6.3 x$ \\
\hline 4 & & & 1.5 & $91(9.05)$ & $6.03(167.5)$ & $7.11(17.8)$ & $9.4 \times$ \\
\hline 5 & & & 3.5 & $88(7.78)$ & $2.22(61.7)$ & $3.51(8.8)$ & $7.0 \times$ \\
\hline 6 & & & 6 & $68(5.87)$ & $0.98(27.2)$ & $1.98(5.0)$ & $5.5 x$ \\
\hline 7 & & & 3.75 & $84(7.98)$ & $2.13(59.2)$ & $2.63(6.6)$ & $9.0 \times$ \\
\hline 8 & & & 1.5 & $92(2.38)$ & $1.59(44.1)$ & $2.38(19.0)^{\mathrm{a}}$ & $2.3 x$ \\
\hline 9 & & & 0.4 & $92(2.41)$ & $6.0(166.7)$ & $9.52(76.2)^{\mathrm{a}}$ & $2.2 x$ \\
\hline & & 30 & & & & & \\
\hline
\end{tabular}

${ }^{a} U V$ results $(125 \mathrm{~W})$ using no sensitizer

\section{ASSOCIATED CONTENT}

\section{Supporting Information}

The Supporting Information is available free of charge at https://pubs.acs.org/doi/xxxxxxx

Experimental and spectral details for all new compounds and all reactions reported (PDF)

\section{AUTHOR INFORMATION}

\section{Corresponding Authors}

Luke D. Elliott - [a] School of Chemistry, Cantocks's Close, University of Bristol, Bristol, UK, BS8 1TS; Email: luke.elliott@bristol.ac.uk

Kevin I. Booker-Milburn - [a] School of Chemistry, Cantocks's Close, University of Bristol, Bristol, UK, BS8 1TS; orcid.org/0000-0001-6789-6882; Email: k.booker-milburn@bristol.ac.uk

\section{Authors}

Surajit Kayal- [b] School of Chemistry, University of Nottingham, University Park, Nottingham, UK, NG7 2RD; orcid.org/0000-0002-4239-455X; Email: Surajit.Kayal@nottingham.ac.uk

Michael W. George- $[\mathrm{b}]$ School of Chemistry, University of Nottingham, University Park, Nottingham, UK, NG7 2RD; [c] Department of Chemical and Environmental Engineering, The University of Nottingham Ningbo China, Ningbo 315100 , China orcid.org/0000-0002-7844-1696;

Email: Mike.George@nottingham.ac.uk

\section{ACKNOWLEDGMENT}

We thank the EPSRC for funding (EP/P013341/1; EP/L003325/1). We thank Dr. Hazel Sparkes for X-ray crystallography of compounds $\mathbf{2 5}$ and $\mathbf{2 6}$ and Dr Xue Zhong Sun for helpful discussions and assistance with the TRIR measurements.

\section{REFERENCES}

(1) (a) Hoffmann, N. Photochemical Reactions as Key Steps in Organic Synthesis. Chem. Rev. 2008, 108, 1052-1103. (b) Bach, T.; Hehn, J. P. Photochemical Reactions as Key Steps in Natural Product Synthesis. Angew. Chem. Int. Ed. 2011, 50, 1000-1045. (c) Kärkäs, M. D.; 
Porco, Jr., J. A.; Stephenson, C. R. J. Photochemical Approaches to Complex Chemotypes: Applications in Natural Product Synthesis. Chem. Rev. 2016, 116, 9683-9747. (d) Poplata, S.; Tröster, A.; Zou, Y-Q.; Bach, T. Recent Advances in the Synthesis of Cyclobutanes by Olefin [2 + 2] Photocycloaddition Reactions. Chem. Rev. 2016, 116, 9748-9815. (e) Remy, R.; Bochet, C. G. Arene-Alkene Cycloaddition. Chem. Rev. 2016, 116, 9816-9849.

(2) Cox, B.; Booker-Milburn, K. I.; Elliott, L. D.; Robertson-Ralph, M.; Zdorichemko, V. Escaping from Flatland: [2 + 2] Photocycloaddition; Conformationally Constrained $\mathrm{sp}^{3}$-rich Scaffolds for Lead Generation. ACS Med. Chem. Lett. 2019, 10, 1512-1517

(3) (a) Elliott, L. D.; Booker-Milburn, K. I. Photochemically Produced Aminocyclobutanes as Masked Dienes in Thermal Electrocyclic Cascade Reactions. Org. Lett. 2019, 21, 1463-1466. (b) Donnelly, B. L.; Elliott, L. D.; Willis, C.; Booker-Milburn, K. I. Sequential Photochemical and Prins Reactions for the Diastereoselective Synthesis of Tricyclic Scaffolds. Angew. Chem. Int. Ed. 2019, 58, 9095-9098

(4) Hammond, G. S.; Turro, N. J.; Leermakers, P. A. The Mechanisms of Photoreactions in Solution. IX. Energy Transfer from the Triplet States of Aldehydes and Ketones to Unsaturated Compounds. $J$. Phys. Chem. 1962, 66, 1144-1147

(5) Denisenko, A. V.; Druzhenko, T.; Skalenko, Y.; Samoilenko, M.; Grygorenko, O. O.; Zozulya, S.; Mykhailiuk, P. K. Photochemical Synthesis of 3-Azabicyclo[3.2.0]heptanes: Advanced Building Blocks for Drug Discovery. J. Org. Chem. 2017, 82, 9627-9636.

(6) (a) Engel, P. S.; Schexnayder, M. A.; Ziffer, H.; Seeman, J. I. Effect of $\alpha$-methyl groups on the photochemistry of 3,4,5,6,7,8-hexahydronaphthalen-2(1H)-one. J. Am. Chem. Soc. 1974, 96, 924-925. (b) Roscini, C.; Cubbage, K. L.; Berry, M.; Orr-Ewing, A. J.; Booker-Milburn, K. I. Reaction Control in Synthetic Organic Photochemistry: Switching between [5+2] and [2+2] Modes of Cycloaddition. Angew. Chem. Int. Ed. 2009, 48, 8716-8720

(7) (a) Ravelli, D.; Protti, S.; Neri, P.; Fagnoni, M.; Albini, A. Photochemical technologies assessed: the case of rose oxide. Green Chem. 2011, 13, 1876. (b) Beatty, J. W.; Douglas, J. J.; Miller, R.; McAtee, R. C.; Cole, K. P.; Stephenson, C. R. J. Photochemical Perfluoroalkylation with Pyridine $N$-Oxides: Mechanistic Insights and Performance on a Kilogram Scale. Chem. 2016, 1, 456-472. (c) Harper, K. C.; Moschetta, E. G.; Bordawekar, S. V.; Wittenberger, S. J. A Laser Driven Flow Chemistry Platform for Scaling Photochemical Reactions with Visible Light. ACS Cent. Sci. 2019, 5, 109-115

(8) (a) Prier, C. K.; Rankic, D. A.; MacMillan, D. W. C. Visible Light Photoredox Catalysis with Transition Metal Complexes: Applications in Organic Synthesis. Chem. Rev. 2013, 113, 5322-5363. (b) Romero, N. A.; Nicewicz, D. A. Organic Photoredox Catalysis. Chem. Rev. 2016, 116, 10075-10166. (c) Shaw, M. H.; Twilton, J.; MacMillan, D. W. C. Photoredox Catalysis in Organic Chemistry. J. Org. Chem. 2016, 81, 6898-6926. (d) Twilton, J.; Le, C.; Zhang, P.; Shaw, M. H.; Evans, R. W.; MacMillan, D. W. C. The merger of transition metal and photocatalysis. Nat. Rev. Chem. 2017, 1, 0052

(9) (a) Rillema, D. P.; Allen, G.; Meyer, T. J.; Conrad, D. Redox properties of ruthenium(II) tris chelate complexes containing the ligands 2,2'-bipyrazine, 2,2'-bipyridine, and 2,2'-bipyrimidine. Inorg. Chem. 1983, 22, 1617-1622. (b) Lowry, M. S.; Hudson, W. R.; Pascal, Jr., R. A.; Bernhard, S. Accelerated Luminophore Discovery through Combinatorial Synthesis. J. Am. Chem. Soc. 2014, 126, 14129-14135. (c) Singh, A.; Teegardin, K.; Kelly, M.; Prasad, K. S.; Krishnan, S.; Weaver, J. D. Facile synthesis and complete characterization of homoleptic and heteroleptic cyclometalated Iridium(III) complexes for photocatalysis. J. Organomet. Chem. 2015, 776, 51-59

(10) (a) Clennan, E. L.; Liao, C. Synthesis, Characterization, Photophysics and Photochemistryof Pyrylogen Electron Transfer Sensitizers. Photochem. Photobiol. 2014, 90, 344-357. (b) Alfonzo, E.; Alfonso, F. S.; Beeler, A. B. Redesign of a Pyrylium Photoredox Catalyst and Its Application to the Generation of Carbonyl Ylides. Org. Lett. 2017, 19, 2989-2992. (c) White, A. R.; Wang, L.; Nicewicz, D. A. Synthesis and Characterization of Acridinium Dyes for Photoredox Catalysis. Synlett 2019, 30, 827-832

(11) (a) Lu, Z.; Yoon, T. P. Visible Light Photocatalysis of [2+2] Styrene Cycloadditions by Energy Transfer. Angew. Chem. Int. Ed. 2012, 51, 10329-10332. (b) Zou, Y-Q.; Duan, S-W.; Meng, X-G.; Hu, X-Q.; Gao, S.; Chen, J-R.; Xiao, W-J. Visible light induced intermolecular [2+2]-cycloaddition reactions of 3-ylideneoxindoles through energy transfer pathway. Tetrahedron, 2012, 68, 6914-6919. (c) Skubi, K. L.; Kidd, J. B.; Jung, H.; Guzei, I. A.; Baik, M-H.; Yoon, T. P. Enantioselective Excited-State Photoreactions Controlled by a Chiral Hydrogen-Bonding Iridium Sensitizer. J. Am. Chem. Soc. 2017, 139, 17186-17192. (d) Hörmann, F. M.; Chung, T. S.; Rodriguez, E.; Jakob, M.; Bach, T. Evidence for Triplet Sensitization in the VisibleLight-Induced [2+2] Photocycloaddition of Eniminium Ions. Angew. Chem. Int. Ed. 2018, 57, 827 -831 (e) James, M. J.; Schwarz, J. L.; Strieth-Kalthoff, F.; Wibbeling, B.; Glorius, F. Dearomative Cascade Photocatalysis: Divergent Synthesis through Catalyst Selective Energy Transfer. J. Am. Chem. Soc. 2018, 140, 8624-8628. (f) Zhu, M.; Zheng, C.; Zhang, X.; You, S-L. Synthesis of Cyclobutane-Fused Angular Tetracyclic Spiroindolines via Visible-Light-Promoted Intramolecular Dearomatization of Indole Derivatives. J. Am. Chem. Soc. 2019, 141, 2636-2644. (g) Becker, M. R.; Richardson, A. D.; Schindler, C. S. Functionalized azetidines via visible light-enabled aza Paternò-Büchi reactions. Nat. Commun, 2019, 10, 5095

(12) Hörmann, F. M.; Kerzig, C.; Chung, T. S.; Bauer, A.; Wenger, O. S.; Bach, T. Triplet Energy Transfer from Ruthenium Complexes to Chiral Eniminium Ions: Enantioselective Synthesis of Cyclobutanecarbaldehydes by [2+2] Photocycloaddition. Angew. Chem. Int. Ed. 2020, 59, 9659-9668

(13) Triplet sensitizers are more commonly designed for optoelectronic processes for triplet-triplet annihilation, optical sensors or ${ }^{1} \mathrm{O}_{2}$ generation for photodynamic therapy. See Zhao, J.; Wu, W.; Sun, J.; Guo, S. Triplet photosensitizers: from molecular design to applications. Chem. Soc. Rev. 2013, 42, 5323-5351

(14) Elliott, L. D.; Berry, M.; Harji, B.; Klauber, D.; Leonard, J.; Booker-Milburn. K. I. A Small-Footprint, High-Capacity Flow Reactor for UV Photochemical Synthesis on the Kilogram Scale. Org. Process Res. Dev. 2016, 20, 1806-1811

(15) Williams, J. D.; Nakano, M.; Gerardy, R.; Rincon, J. A.; de Frutos, O.; Mateos, C.; Monbaliu, J-C. M.; Kappe, C. O. Finding the Perfect Match: A Combined Computational and Experimental Study toward Efficient and Scalable Photosensitized [2 +2] Cycloadditions in Flow Org. Process Res. Dev. 2019, 23, 78-87

(16) (a) Alonso, R.; Bach, T. A Chiral Thioxanthone as an Organocatalyst for Enantioselective [2+2] Photocycloaddition Reactions Induced by Visible Light. Angew. Chem. Int. Ed. 2014, 53, 4368-4371. (b) Kumarasamy, E.; Raghunathan, R.; Jockusch, S.; Ugrinov, A.; Sivaguru, J. Tailoring Atropisomeric Maleimides for Stereospecific [2+ 2] Photocycloaddition-Photochemical and Photophysical Investigations Leading to Visible-Light Photocatalysis. J. Am. Chem. Soc. 2014, 136, 8729-8737. (c) Tröster, A.; Alonso, R.; Bauer, A.; Bach, T. Enantioselective Intermolecular [2 +2$]$ Photocycloaddition Reactions of 2(1H)-Quinolones Induced by Visible Light Irradiation. J. Am. Chem. Soc. 2016, 138, 7808-7811. (d) Hölzl-Hobmeier, A.; Bauer, A.; Silva, A. V.; Huber, S. M.; Bannwarth, C.; Bach, T. Catalytic deracemization of chiral allenes by sensitized excitation with visible light. Nature, 2018, 564, 240-243. (e) Tröster, A.; Bach, T. Triplet-sensitized di- $\pi$ methane rearrangement of $N$-substituted 2-azabarrelenones. Chem. Commun., 2019, 55, 302-305

(17) Iyer, A.; Clay, A.; Jockusch, S.; Sivaguru, J.; J. Evaluating brominated thioxanthones as organo-photocatalysts. Phys. Org. Chem. 2017, 30, e3738

(18) Qiu, G.; Li, Y.; Wu, J. Recent developments for the photoinduced $\mathrm{Ar}-\mathrm{X}$ bond dissociation reaction. Org. Chem. Front., 2016, 3, 1011-1027

(19) (a) Pitts, J. N., Jr; Letsinger, R. L.; Taylor, R. P.; Patterson, J. M.; Recktenwald, G.; Martin, R. B. Photochemical Reactions of Benzophenone in Alcohols. J. Am. Chem. Soc. 1959, 81, 1068-1077. (b) Lathioor, E. C.; Leigh, W. J. Bimolecular hydrogen abstraction from phenols by aromatic ketone triplets Photochem Photobiol. 2006, 82 , 291-300. (c) Kamijo, S.; Hoshikawa, T.; Inoue, M. Photochemically Induced Radical Transformation of $\mathrm{C}\left(\mathrm{sp}^{3}\right)-\mathrm{H}$ Bonds to $\mathrm{C}\left(\mathrm{sp}^{3}\right)-\mathrm{CN}$ Bonds. Org. Lett. 2011, 13, 5928-5931. (d) Gérardy, R.; Winter, M.; Horn, C. R.; Vizza, A.; Van Hecke, K.; Monbaliu, J-C. M. ContinuousFlow Preparation of $\gamma$-Butyrolactone Scaffolds from Renewable Fumaric and Itaconic Acids under Photosensitized Conditions. Org. Process Res. Dev. 2017, 21, 2012-2017 
(20) Ley, C.; Morlet-Savary, F.; Jacques, P.; Fouassier, J. P. Solvent dependence of the intersystem crossing kinetics of thioxanthone. Chem. Phys. 2000, 255, 335-346

(21) Montalti, M.; Credi, A.; Prodi, L.; Gandolfi, M. T. Handbook of Photochemistry, $3^{\text {rd }}$ ed.; CRC Press, 2006

(22) Herkstroeter, W. G.; Lamola, A. A.; Hammond, G. S. Mechanisms of Photochemical Reactions in Solution. XXVIII. Values of Triplet Excitation energies of Selected Sensitizers. J. Am. Chem. Soc. 1964, 86, 4537-4540

(23) Lowry, M. S.; Goldsmith, J. I.; Slinker, J. D.; Rohl, R.; Pascal, Jr., R. A.; Malliaras, G. G.; Bernhard, S. Single-Layer Electroluminescent Devices and Photoinduced Hydrogen Production from an Ionic Iridium(III) Complex. Chem. Mater. 2005, 17, 5712-5719

24) Mundt, R.; Villnow, T.; Ziegenbein, C. T.; Gilch, P.; Marian, C.; Rai-Constapel, V. Thioxanthone in apolar solvents: ultrafast internal conversion precedes fast intersystem crossing. Phys. Chem. Chem. Phys. 2016, 18, 6637-6647

(25) (a) Dalton, J. C.; Montgomery, F. C. Solvent effects on Thioxanthone Fluorescence. J. Am. Chem. Soc, 1974, 96, 6230-6232. (b) Lai, T. I.; Lim, E. C. Photophysical Behavior of Aromatic Carbonyl Compounds Related to Proximity Effect: Thioxanthone. Chem. Phys. Lett. 1980, 73, 244-248.

(26) Junker, A. K. R.; Sørensen, T. J. Rationalizing substituent effects in 1-azathioxanthone photophysics. Methods Appl. Fluoresc. 2018, 6,014002

(27) (a) Saltiel, J.; Hammond, G. S. Mechanisms of Photochemical Reactions in Solution. XVII. cis-trans Isomerization of the Stilbenes by Excitation Transfer from Low Energy Sensitizers. J. Am. Chem. Soc. 1963, 85, 2515-2516. (b) Arai, T.; Sakuragi, H.; Tokumaru, K. Photosensitized cis-trans Isomerization of $\beta$-Alkylstyrenes. Bull. Chem. Soc. Jpn. 1982, 55, 2204-2207

(28) Hammond, G. S.; Saltiel, J. Mechanisms of Photoreactions in Solution. XVIII. Energy Transfer with Nonvertical Transitions. J. Am. Chem. Soc. 1963, 85, 2516-2517.

(29) (a) Singh, K.; Staig, S. J.; Weaver, J. D. Facile Synthesis of Z Alkenes via Uphill Catalysis. J. Am. Chem. Soc. 2014, 136, 5275-5278. (b) Metternich, J. B.; Gilmour, R. A Bio-Inspired, Catalytic $E \rightarrow Z$ Isomerization of Activated Olefins. J. Am. Chem. Soc. 2015, 137, 11254-11257. (c) Hou, J.; Ee, A.; Feng, W.; Xu, J-H.; Zhao, Y.; Wu, J. Visible-Light-Driven Alkyne Hydro-/Carbocarboxylation Using $\mathrm{CO}_{2}$ via Iridium/Cobalt Dual Catalysis for Divergent Heterocycle Synthesis. J. Am. Chem. Soc. 2018, 140, 5257-5263. (d) Molloy, J. J.; Metternich, J. B.; Daniliuc, C. G.; Watson, A. J. B.; Gilmour, R. Contra-Thermodynamic, Photocatalytic $E \rightarrow Z$ Isomerization of Styrenyl Boron Species: Vectors to Facilitate Exploration of Two-Dimensional Chemical Space. Angew. Chem. Int. Ed. 2018, 57, 31683172. (e) Faßbender, S. I.; Molloy, J. J.; Mück-Lichtenfeld, C.; Gilmour, R. Geometric $E \rightarrow Z$ Isomerisation of Alkenyl Silanes by Selective Energy Transfer Catalysis: Stereodivergent Synthesis of Triarylethylenes via a Formal anti-Metallometallation. Angew. Chem. Int. Ed. 2019, 58, 18619 - 18626

(30) Booker-Milburn, K. I.; Cowell, J. K.; Jiménez, D.; Sharpe, A.; White, A. J. Stereoselective Intermolecular [2+2] photocycloaddition reactions of tetrahydrophthalic anhydride and derivatives with alkenols and alkynols. Tetrahedron, 1999, 55, 5875-5888
(31) For a similar sequence with a $\beta$-amino enone see (a) Kwak, YS.; Winkler, J. D. Synthesis of 6-Aza-bicyclo[3,2,1]octan-3-ones via Vinylogous Imide Photochemistry: An Approach to the Synthesis of the Hetisine Alkaloids. J. Am. Chem. Soc. 2001, 123, 7429-7430. The corresponding $\beta$-amino acrylate failed to react under direct irradiation and instead was prepared via oxidation of the ketone, see (b) Krow, $G$. R.; Lin, G.; Herzon, S. B.; Thomas, A. M.; Moore, K. P.; Huang, Q.; Carroll, P. J. Convenient Preparations of 2,4-Methanopyrrolidine and 5-Carboxy-2,4-methanopyrrolidines J. Org. Chem. 2003, 68, 75627564

(32) Allushi, A.; Kutahya, C.; Aydongan, C.; Kreutzer, J.; Yilmaz, G.; Yagci, Y. Conventional Type II photoinitiators as activators for photoinduced metal-free atom transfer radical polymerization. Polym. Chem., 2017, 8, 1972-1977

(33) (a) Pirrung, M. C. Total Synthesis of 2,4-Methanoproline. Tetrahedron Lett. 1980, 21, 4577-4578. (b) Varnes, J. G.; Lehr, G. S. Moore, G. L.; Hulsizer, J. M.; Albert, J. S. Efficient preparation of 2,4methanoproline. Tetrahedron Lett. 2010, 51, 3756-3758 (c) Levterov, V. V.; Michurin, O.; Borysko, P. O.; Zozulya, S.; Sadkova, I. V.; Tolmachev, A. A.; Mykhailiuk, P. K. Photochemical In-Flow Synthesis of 2,4-Methanopyrrolidines: Pyrrolidine Analogues with Improved Water Solubility and Reduced Lipophilicity. J. Org. Chem. 2018, 83, 1435014361

(34) Le, C.; Wismer, M. K.; Shi, Z-C.; Zhang, R.; Conway, D. V.; Li, G.; Vachal, P.; Davies, I. W.; MacMillan, D. W. C. A General Small-Scale Reactor To Enable Standardization and Acceleration of Photocatalytic Reactions. ACS Cent. Sci. 2017, 3, 647-653

(35) Elliott, L. D.; Knowles, J. P.; Stacey, C. S.; Klauber, D. J.; Booker-Milburn, K. I. Using batch reactor results to calculate optimal flow rates for the scale-up of UV photochemical reactions. React. Chem. Eng. 2018, 3, 86-93

(36) (a) Hook, B. D. A.; Dohle, W.; Hirst, P. R.; Pickworth, M.; Berry, M. B.; Booker-Milburn, K. I. J. Org. Chem. 2005, 70, 7558-7564. (b) Elliott, L. D.; Knowles, J. P.; Koovits, P. J.; Maskill, K. G.; Ralph, M. J.; Lejeune, G.; Edwards, L. J.; Robinson, R. I.; Clemens, I. R.; Cox, B.; Pascoe, D. D.; Koch, G.; Eberle, M.; Berry, M. B.; Booker-Milburn, K. I. Chem.- Eur. J. 2014, 20, 15226-15232.

(37) (a) Bach, T.; Krüger, C.; Harms, K. The Stereoselective Synthesis of 2-Substituted 3-Azabicyclo[3.2.0]heptanes by Intramolecular [2+2]-Photocycloaddition Reactions. Synthesis, 2000, 2, 305-320. (b) Oderinde, M. S.; Kempson, J.; Smith, D.; Meanwell, N. A.; Mao, E.; Pawluczyk, J.; Vetrichelvan, M.; Pitchai, M.; Karmakar, A.; Rampulla, R.; Li, J.; Dhar, T. G. M.; Mathur, A. Intramolecular [2+2] Cycloaddition of $N$-Allylcinnamamines and $N$-Allylcinnamamides by VisibleLight Photocatalysis. Eur. J. Org. Chem. 2020, 41-46

(38) Cookson, R. C.; Crundwell, E.; Hill, R.R.; Hudec, J. Photochemical Cyclisation of Diels-Alder Adducts. J. Chem. Soc. 1964, O, $3062-3075$

(39) (a) Kenwright, A. M.; Sellars, J. D. Preparation and complete ${ }^{1} \mathrm{H}$ and ${ }^{13} \mathrm{C}$ assignment of some pentacyclo $\left[5.4 .0 .0^{2,6} \cdot 0^{3,10} .0^{5,9}\right]$ undecane-8,11-dione (PCUD) derivatives. Magn. Reson. Chem. 2012, 50, 803-808. (b) Kotha, S.; Rao, S.; Cheekatla, S. R.; Meshram, M.; Bandi, V.; Seema, V. Realization of Photo-Thermal Metathesis Under Microwave Irradiation Conditions: An Entry to Triquinane Frameworks. Asian J. Org. Chem. 2019, 8, 2097-2104 


\title{
Supporting Information
}

\section{Rational Design of Triplet Sensitizers for the Transfer of Excited State Photochemistry from UV to Visible}

\author{
Luke D. Elliott, ${ }^{*[a]}$ Surajit Kayal, ${ }^{[\mathrm{b}]}$ Michael W. George ${ }^{[\mathrm{b}]}$ \\ and Kevin Booker-Milburn*[a]
}

\begin{abstract}
[a] School of Chemistry, University of Bristol, Cantock's Close, Bristol, BS8 1TS, UK
[b] School of Chemistry, University of Nottingham, University Park, NG7 2RD, UK
\end{abstract}




\section{Table of Contents}

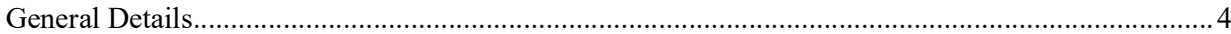

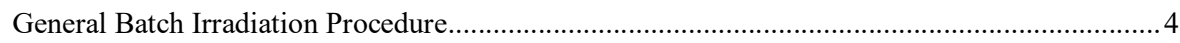

Synthesis of Thioxanthone Derivatives ................................................................................... 4

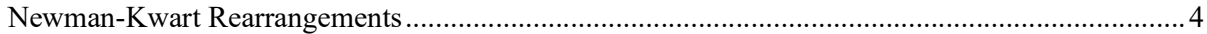

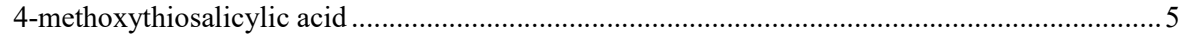

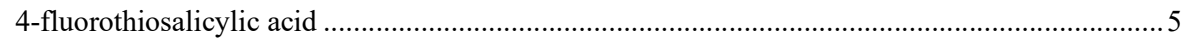

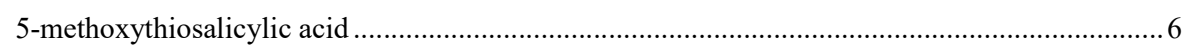

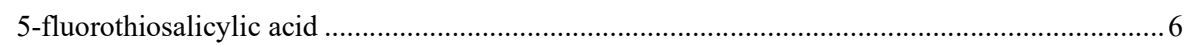

Ullmann-Coupling / Friedel-Crafts Cyclization to Thioxanthones.................................................... 7

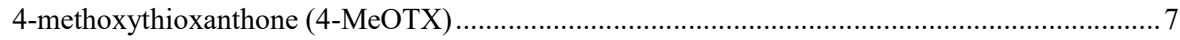

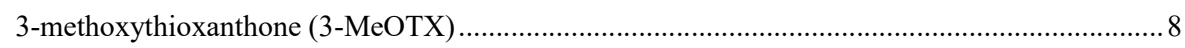

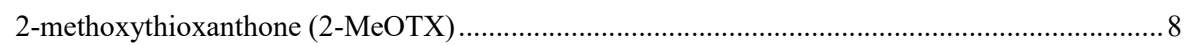

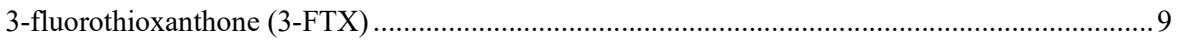

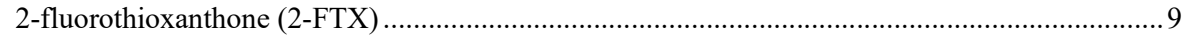

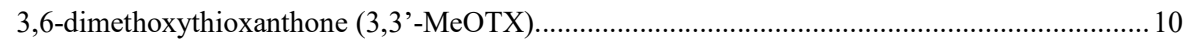

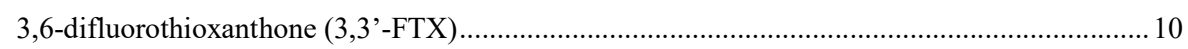

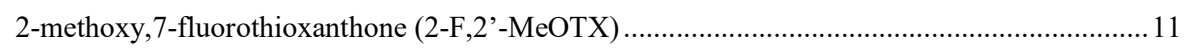

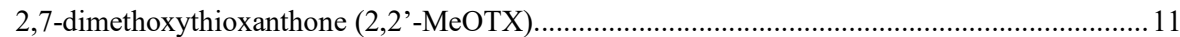

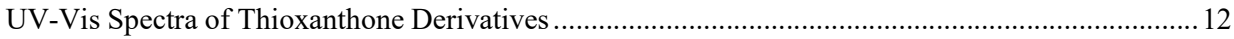

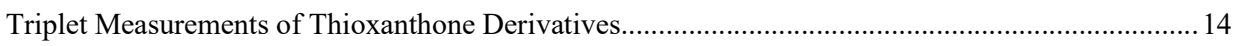

Low temperature $(77 \mathrm{~K})$ emission measurement: ........................................................................... 14

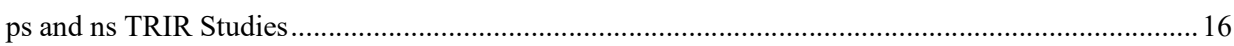

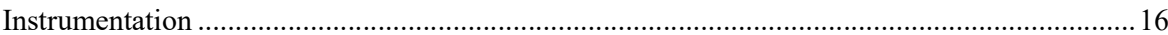

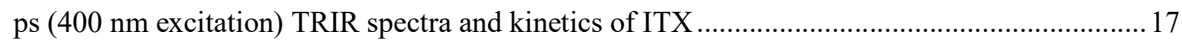

Estimation of triplet quantum yield for ITX from the parent bleach recovery kinetics................. 18

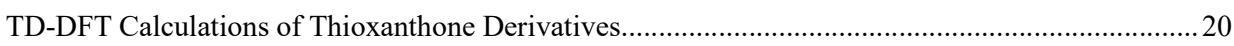

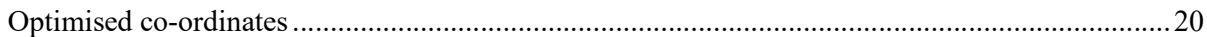

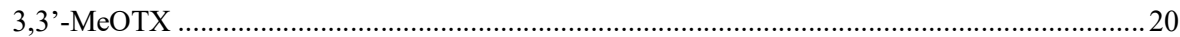

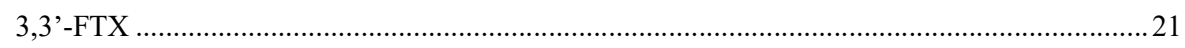

3-MeOTX

3-FTX

TX

ITX

2-FTX

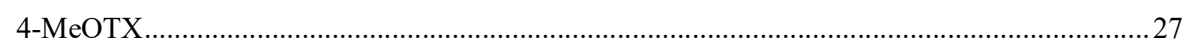

2-MeOTX 


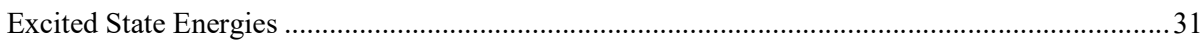

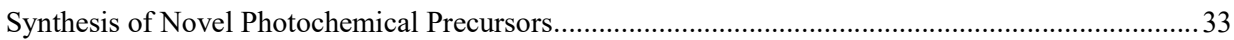

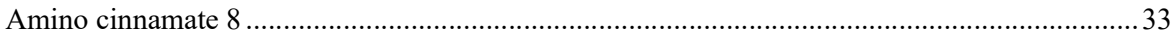

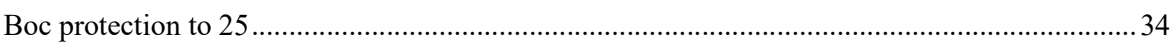

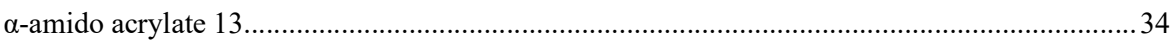

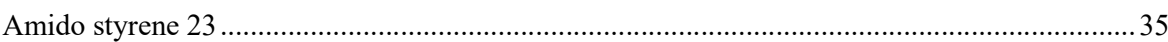

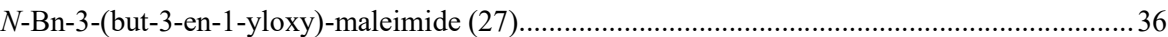

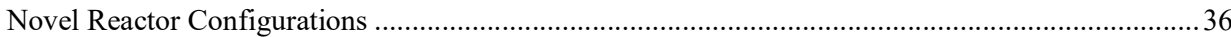

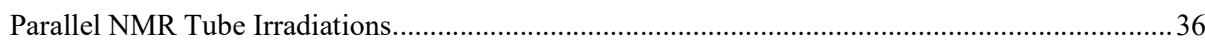

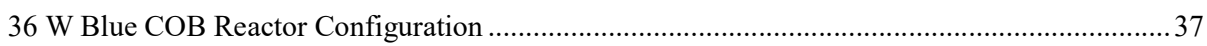

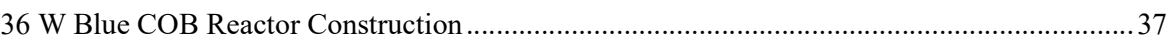

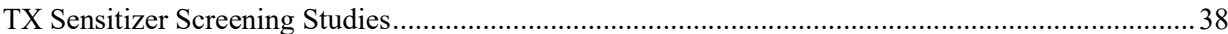

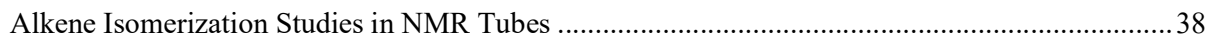

Sensitizer Screen with 125 W, 150 ml Immersion Well Reactor ...............................................40

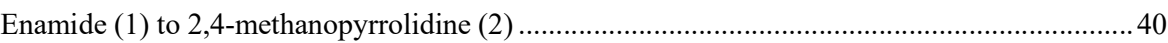

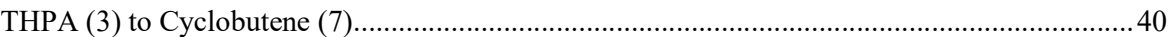

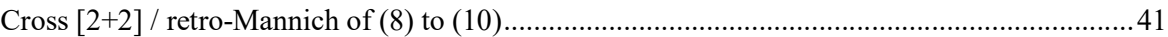

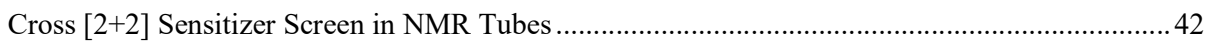

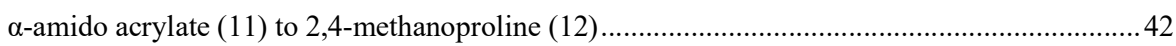

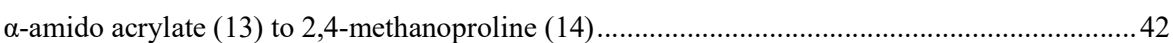

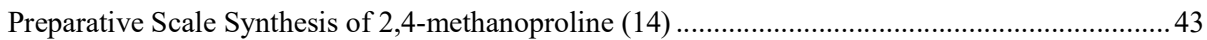

Blue Light Mediated Reactions with 36 W, 455 nm COB Reactor ..................................................44

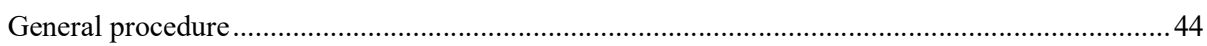

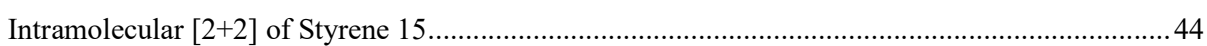

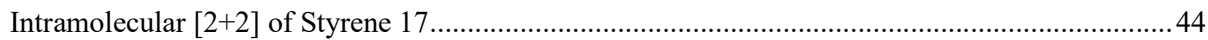

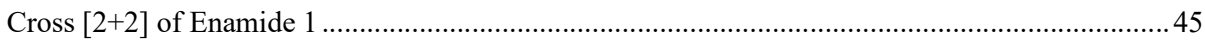

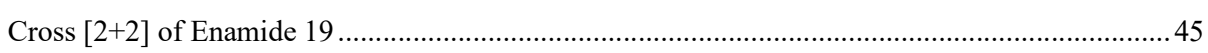

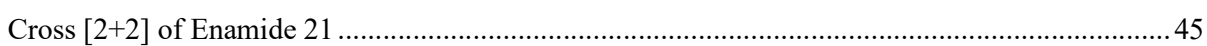

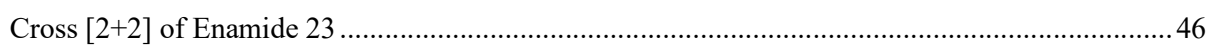

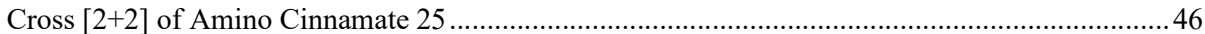

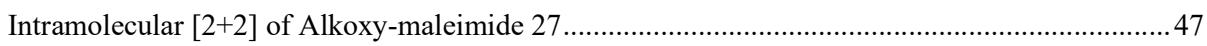

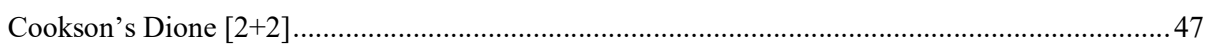

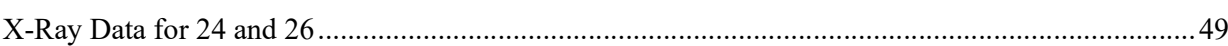

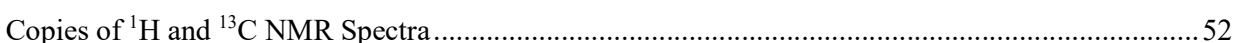




\section{General Details}

All reagents and solvents were used as purchased and no special precautions were taken to dry or otherwise further purify. For the purposes of thin layer chromatography (tlc), Merck silica-aluminium plates were used, visualising with UV light $(254 \mathrm{~nm})$ and/or dipping in potassium permanganate followed by heating. For column chromatography, Sigma Aldrich technical grade $60 \AA$ silica gel was used. All NMR data was collected using either a Jeol Eclipse $400 \mathrm{MHz}$, Varian $400 \mathrm{MHz}$ or Varian 500 $\mathrm{MHz}$ instruments. Data was processed directly using MestReNova (version 11.0.2). Chemical shifts $(\delta)$ are given in parts per million (ppm). Reference values for residual solvents were taken as $\delta=7.27$ $\left(\mathrm{CDCl}_{3}\right), 2.50$ (DMSO-d $\left.\mathrm{d}_{6}\right)$ and 2.05 (acetone- $\left.\mathrm{d}_{6}\right)$ for ${ }^{1} \mathrm{H}$ NMR and $\delta=77.16 \mathrm{ppm}\left(\mathrm{CDCl}_{3}\right), 39.52$ $\left(\right.$ DMSO- $\mathrm{d}_{6}$ ) and 206.26 (acetone- $\mathrm{d}_{6}$ ) for ${ }^{13} \mathrm{C}$ NMR. Multiplicities for coupled signals were denoted as: $\mathrm{s}=$ singlet, $\mathrm{d}=$ doublet, $\mathrm{t}=$ triplet, $\mathrm{q}=$ quartet, $\mathrm{m}=$ multiplet, br. = broad, app. $=$ apparent and $\mathrm{dd}=$ double doublet etc. Coupling constants $(\mathrm{J})$ are given in $\mathrm{Hz}$ and are quoted to the nearest $0.1 \mathrm{~Hz}$. Where appropriate, COSY, DEPT, HMQC and NOE NMR experiments were carried out to aid assignment. Mass spectrometry data was collected was carried out by the University of Bristol mass spectrometry service using Fisons Autospec or Bruker Daltonics MicrOTOF II instruments. Infrared data was collected using a Perkin-Elmer Spectrum One FTIR machine as thin films or solids compressed on a diamond plate. Melting points are uncorrected and were recorded on Stuart Scientific apparatus.

\section{General Batch Irradiation Procedure}

For all photochemical reactions, solvents were "degassed" by evacuating a stirred vessel under vacuum and re-filling with $\mathrm{N}_{2}$. For the duration of the reaction, $\mathrm{N}_{2}$ was bubbled through the solution. When photochemical reactions were followed for their duration by NMR, 1,3,5-trimethoxybenzene was used as an internal standard. In all cases, a stock solution $(0.05 \mathrm{M})$ of this was added to aliquots of the reaction mixture prior to NMR sample preparation. Batch reactors, $125 \mathrm{~W}$ and $400 \mathrm{~W}$ medium pressure mercury lamps were purchased from Photochemical Reactors Ltd. Reading. In all cases, Pyrex immersion wells were used for irradiations.

\section{Synthesis of Thioxanthone Derivatives}

\section{Newman-Kwart Rearrangements}

Substituted thiosalicylic acids were prepared from the corresponding methyl thiosalicylic acids via a Newman-Kwart rearrangement as shown (Scheme S1). The thermal Newman-Kwart rearrangement was successfully carried out as a melt for 4-substituted derivatives but the 5-substituted derivatives resulted in extensive degradation.
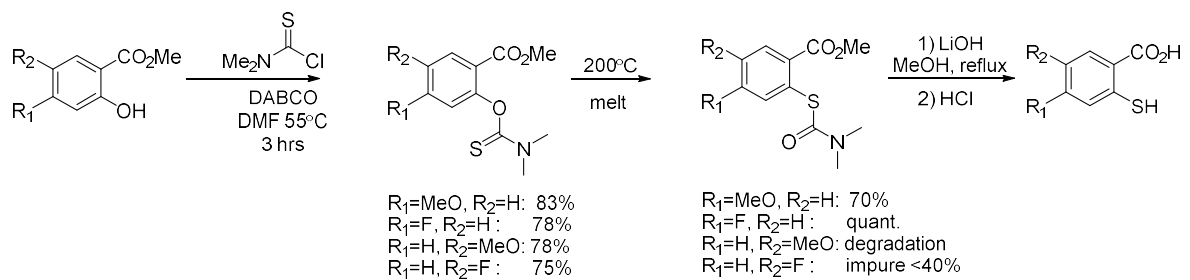

Scheme S1: Synthesis of thiosalicylic acids

A modification of the photoredox mediated Newman-Kwart rearrangement developed by Nicewicz ${ }^{1}$ gave the 5-methoxysalicylate derivative in excellent yield (Scheme S2). Unfortunately, the 5-fluoro derivative failed to react under the photoredox conditions. 


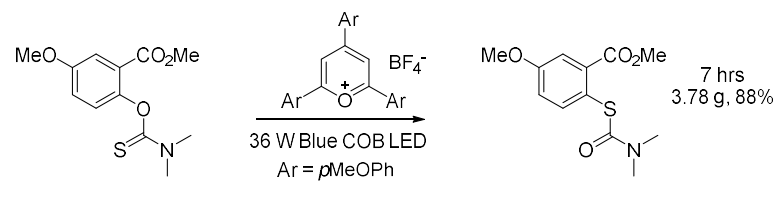

Scheme S2: Photoredox mediated Newman-Kwart

\section{Synthesis of $\boldsymbol{O}$-aryl thiocarbamates}

To a solution of the relevant methyl salicylate derivative $(200 \mathrm{mmol})$ and dimethylthiocarbamoyl chloride $(37.1 \mathrm{~g}, 300 \mathrm{mmol})$ in DMF $(100 \mathrm{ml})$ was added DABCO $(33.7 \mathrm{~g}, 300 \mathrm{mmol})$ before heating at $55^{\circ} \mathrm{C}$ for $3 \mathrm{hrs}$. The mixture was poured over water $(500 \mathrm{ml})$ and extracted with EtOAc $(3 \times 300 \mathrm{ml})$. The combined extracts were dried $\left(\mathrm{MgSO}_{4}\right)$, filtered and evaporated to a yellow solid which was washed with $\mathrm{Et}_{2} \mathrm{O}$ and dried to give the thiocarbamate as a colourless powder.

\section{4-methoxythiosalicylic acid}

$$
\text { 4-methoxythiosalicylic acid }
$$

The general procedure for $O$-aryl thiocarbamate synthesis was first followed using methyl 4methoxysalicylate (45 g, $247 \mathrm{mmol})$, dimethylthiocarbamoyl chloride $(42.7 \mathrm{~g}, 346 \mathrm{mmol})$ and DABCO $(38.8 \mathrm{~g}, 346 \mathrm{mmol})$. After heating at $55^{\circ} \mathrm{C}$ for $3 \mathrm{hrs}$ the work-up procedure was followed to give methyl 2-((dimethylcarbamothioyl)oxy)-4-methoxybenzoate as a colourless powder (55.2 g, 83\%): m.p. 128$129^{\circ} \mathrm{C}\left(\text { lit. } 122-124^{\circ} \mathrm{C}\right)^{2}$

The $O$-aryl thiocarbamate $(57.8 \mathrm{~g}, 215 \mathrm{mmol})$ was then heated as a melt at $200^{\circ} \mathrm{C}$ under $\mathrm{N}_{2}$ for $5.5 \mathrm{hrs}$. The cooled mixture was purified by chromatography on silica $(40-50 \%$ EtOAc in petrol) and the concentrated fractions were triturated with $\mathrm{Et}_{2} \mathrm{O}$ and filtered to give methyl 2((dimethylcarbamoyl)thio)-4-methoxybenzoate as a pale orange solid $(40.4 \mathrm{~g}, 70 \%)$. To a solution of the $S$-aryl thiocarbamate $(40.0 \mathrm{~g}, 149 \mathrm{mmol})$ in $\mathrm{MeOH}(110 \mathrm{ml})$ was added $\mathrm{LiOH}(8.91 \mathrm{~g}, 372 \mathrm{mmol})$ and the mixture heated at reflux for $2.5 \mathrm{hrs}$. The cooled solution was quenched with $3 \mathrm{M} \mathrm{HCl}(130 \mathrm{ml})$, diluted with water $(100 \mathrm{ml})$ and the resulting slurry extracted with EtOAc $(500 \mathrm{ml}$ and $2 \times 250 \mathrm{ml})$. The combined extracts were dried $\left(\mathrm{MgSO}_{4}\right)$, filtered and evaporated to give 4-methoxythiosalicylic acid as a white solid $(28.0 \mathrm{~g})$ of sufficient purity for further use: $\delta_{\mathrm{H}}\left(400 \mathrm{MHz}, \mathrm{DMSO}-\mathrm{d}_{6}\right) 7.88(1 \mathrm{H}, \mathrm{d}, J=8.8$ $\mathrm{Hz}, \operatorname{Ar} . \mathbf{H}), 7.11(1 \mathrm{H}, \mathrm{d}, J=2.6 \mathrm{~Hz}, \mathrm{Ar} . \mathbf{H}), 6.75(1 \mathrm{H}, \mathrm{dd}, J=8.8,2.6 \mathrm{~Hz}, \mathrm{Ar} . \mathbf{H}), 3.79\left(3 \mathrm{H}, \mathrm{s}, \mathrm{OCH}_{3}\right) ; \delta_{\mathrm{C}}$ (101 MHz, DMSO-d $\left.{ }_{6}\right)$ 167.3 (C), $161.7(\mathrm{C}), 140.8(\mathrm{C}), 133.3(\mathrm{CH}), 118.8(\mathrm{C}), 115.0(\mathrm{CH}), 110.9(\mathrm{CH})$, $55.5\left(\mathrm{CH}_{3}\right)$

\section{4-fluorothiosalicylic acid}

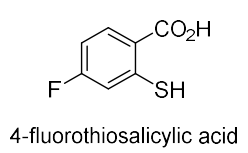

The general procedure for $O$-aryl thiocarbamate synthesis was first followed using methyl 4fluorosalicylate $(29.8 \mathrm{ml}, 200 \mathrm{mmol})$, dimethylthiocarbamoyl chloride $(37.1 \mathrm{~g}, 300 \mathrm{mmol})$ and DABCO $(33.7 \mathrm{~g}, 300 \mathrm{mmol})$. After heating at $55^{\circ} \mathrm{C}$ for $3 \mathrm{hrs}$ the work-up procedure was followed to give methyl 2-((dimethylcarbamothioyl)oxy)-4-fluorobenzoate as a colourless powder $(42.3 \mathrm{~g}, 78 \%)$ : m.p. 106$107^{\circ} \mathrm{C}$ (lit. $\left.106.8-107.2^{\circ} \mathrm{C}\right)^{3}$

The $O$-aryl thiocarbamate $(41.0 \mathrm{~g}, 159 \mathrm{mmol})$ was heated as a melt at $200^{\circ} \mathrm{C}$ under $\mathrm{N}_{2}$ for $2.5 \mathrm{hrs}$ to give methyl 2-((dimethylcarbamoyl)thio)-4-fluorobenzoate. The resulting material was of sufficient 
purity for subsequent hydrolysis. To a solution of the $S$-aryl thiocarbamate $(41.0 \mathrm{~g}, 159 \mathrm{mmol})$ in $\mathrm{MeOH}$ $(110 \mathrm{ml})$ was added $\mathrm{LiOH}(9.53 \mathrm{~g}, 398 \mathrm{mmol})$ and the mixture heated at reflux for $2.5 \mathrm{hrs}$. The cooled solution was quenched with $3 \mathrm{M} \mathrm{HCl}(140 \mathrm{ml})$, diluted with water $(100 \mathrm{ml})$ and the resulting slurry extracted with EtOAc $(3 \times 250 \mathrm{ml})$. The combined extracts were washed $(1 \mathrm{M} \mathrm{HCl}$, brine $)$, dried $\left(\mathrm{MgSO}_{4}\right)$, filtered and evaporated to give 4-fluorothiosalicylic acid as a white solid $(27.6 \mathrm{~g})$ of sufficient purity for further use: $\delta_{\mathrm{H}}\left(500 \mathrm{MHz}, \mathrm{DMSO}-\mathrm{d}_{6}\right) 8.11(1 \mathrm{H}, \mathrm{dd}, J=8.7,6.0 \mathrm{~Hz}, \mathrm{Ar} . \mathbf{H}), 7.33(1 \mathrm{H}, \mathrm{dd}, J=$ 10.2, $2.5 \mathrm{~Hz}, \mathrm{Ar} . \mathbf{H}), 7.20(1 \mathrm{H}$, app. td, $J=8.2,2.5 \mathrm{~Hz}, \mathrm{Ar} . \mathbf{H}) ; \delta_{\mathrm{C}}\left(126 \mathrm{MHz}, \mathrm{DMSO}-\mathrm{d}_{6}\right) 166.8$ (C), $164.8(\mathrm{~d}, J=253.1 \mathrm{~Hz}, \mathrm{C}), 142.4(\mathrm{~d}, J=7.7 \mathrm{~Hz}, \mathrm{C}), 134.7$ (d, $J=9.8 \mathrm{~Hz}, \mathrm{CH}), 124.8(\mathrm{~d}, J=2.8 \mathrm{~Hz}, \mathrm{C})$, $113.5(\mathrm{~d}, J=21.9 \mathrm{~Hz}, \mathrm{CH}), 111.7(\mathrm{~d}, J=26.8 \mathrm{~Hz}, \mathrm{CH}) ; \delta_{\mathrm{F}}\left(377 \mathrm{MHz}, \mathrm{CDCl}_{3}\right)-105.1$

5-methoxythiosalicylic acid

$$
\text { 5-methoxythiosalicylic acid }
$$

The general procedure for $O$-aryl thiocarbamate synthesis was first followed using methyl 5methoxysalicylate $(29.8 \mathrm{ml}, 200 \mathrm{mmol})$, dimethylthiocarbamoyl chloride $(37.1 \mathrm{~g}, 300 \mathrm{mmol})$ and $\operatorname{DABCO}(33.7 \mathrm{~g}, 300 \mathrm{mmol})$. After heating at $55^{\circ} \mathrm{C}$ for $3 \mathrm{hrs}$ the work-up procedure was followed to give methyl 2-((dimethylcarbamothioyl)oxy)-5-methoxybenzoate as a colourless powder $(42.3 \mathrm{~g}, 78 \%)$ : m.p. $103-104^{\circ} \mathrm{C}\left(\text { lit. } 99.5-100.5^{\circ} \mathrm{C}\right)^{4}$

A solution of the $O$-aryl thiocarbamate $(4.31 \mathrm{~g}, 16 \mathrm{mmol})$ and 2, 4, 6-tris(4-methoxyphenyl)pyrylium tetrafluoroborate $(0.08 \mathrm{mmol}, 39 \mathrm{mg})$ in $\mathrm{MeCN}(80 \mathrm{ml})$ was irradiated with a $36 \mathrm{~W}$ blue COB LED for $7 \mathrm{hrs}$. The solvent was removed in vacuo and chromatography on silica $\left(10 \% \mathrm{Et}_{2} \mathrm{O}\right.$ in $\left.\mathrm{DCM}\right)$ yielded methyl 2-((dimethylcarbamoyl)thio)-5-methoxybenzoate as a pale yellow solid (3.78 g, 88\%). To a solution of the $S$-aryl thiocarbamate $(23.0 \mathrm{~g}, 85.5 \mathrm{mmol})$ in $\mathrm{MeOH}(60 \mathrm{ml})$ was added LiOH $(5.13 \mathrm{~g}$, $214 \mathrm{mmol}$ ) and the mixture heated at reflux for $2.5 \mathrm{hrs}$. The cooled solution was quenched with $3 \mathrm{M}$ $\mathrm{HCl}(80 \mathrm{ml})$ and the resulting slurry extracted with EtOAc $(250 \mathrm{ml}$ and $3 \times 100 \mathrm{ml})$. The combined extracts were washed $\left(1 \mathrm{M} \mathrm{HCl}\right.$, brine), dried $\left(\mathrm{MgSO}_{4}\right)$, filtered and evaporated to give 5methoxythiosalicylic acid $(15.7 \mathrm{~g})$ as a pale yellow solid of sufficient purity for further use: $\delta_{\mathrm{H}}(400$ MHz, DMSO-d 6 ) $7.42(1 \mathrm{H}, \mathrm{d}, J=3.0 \mathrm{~Hz}, \mathrm{Ar} . \mathbf{H}), 7.41(1 \mathrm{H}, \mathrm{d}, J=8.7 \mathrm{~Hz}, \mathrm{Ar} . \mathbf{H}), 7.04$ (dd, $J=8.7,3.0$ $\mathrm{Hz}, \mathrm{Ar} . \mathrm{H}), 3.75$ (3H, s, OCH $)$; $\delta_{\mathrm{C}}\left(101 \mathrm{MHz}, \mathrm{DMSO}_{\mathrm{d}}\right.$ ) 167.4 (C), $156.4(\mathrm{C}), 131.9(\mathrm{CH}), 128.4(\mathrm{C})$, $127.5(\mathrm{C}), 119.6(\mathrm{CH}), 115.4(\mathrm{CH}), 55.3\left(\mathrm{CH}_{3}\right)$

\section{5-fluorothiosalicylic acid}

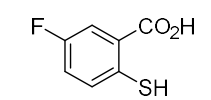

5-fluorothiosalicylic acid

The general procedure for $O$-aryl thiocarbamate synthesis was first followed using methyl 5fluorosalicylate $(40 \mathrm{~g}, 235 \mathrm{mmol})$, dimethylthiocarbamoyl chloride $(34.9 \mathrm{~g}, 282 \mathrm{mmol})$ and DABCO $(31.6 \mathrm{~g}, 282 \mathrm{mmol})$. After heating at $55^{\circ} \mathrm{C}$ for $3 \mathrm{hrs}$ the work-up procedure was followed to give methyl 2-((dimethylcarbamothioyl)oxy)-5-fluorobenzoate as a colourless powder (45.3 g, 75\%): m.p. 120$121^{\circ} \mathrm{C}$

The $O$-aryl thiocarbamate $(43.1 \mathrm{~g}, 168 \mathrm{mmol})$ was then heated as a melt at $215^{\circ} \mathrm{C}$ under $\mathrm{N}_{2}$ for $5.5 \mathrm{hrs}$. The cooled mixture was purified by chromatography on silica (30\% EtOAc in petrol) to give a dark oil ( $25.8 \mathrm{~g}$ ) which contained the $S$-aryl thiocarbamate in approximately $60 \%$ purity due to a significant unknown by-product. To the crude mixture in $\mathrm{MeOH}(100 \mathrm{ml})$ was added $\mathrm{LiOH}(6.36 \mathrm{~g}, 265 \mathrm{mmol})$ and the solution heated at reflux for $3 \mathrm{hrs}$. The cooled solution was quenched with $3 \mathrm{M} \mathrm{HCl}(100 \mathrm{ml})$, extracted with DCM $(3 \times 150 \mathrm{ml})$, the organic extracts concentrated in vacuo and re-dissolved in water $(150 \mathrm{ml})$ with $\mathrm{K}_{2} \mathrm{CO}_{3}(25 \mathrm{~g}, 181 \mathrm{mmol})$. The aqueous solution was washed with $\mathrm{DCM}(2 \times 50 \mathrm{ml})$ and 
acidified with $\mathrm{HCl}(12 \mathrm{M}, 30 \mathrm{ml})$ to give a pale yellow suspension which was extracted with DCM $(3 \times 50 \mathrm{ml})$. The combined extracts were dried $\left(\mathrm{MgSO}_{4}\right)$, filtered and evaporated to give 5fluorothiosalicylic acid $(9.3 \mathrm{~g})$ containing significant impurities, but of sufficient purity for further use

\section{Ullmann-Coupling / Friedel-Crafts Cyclization to Thioxanthones}

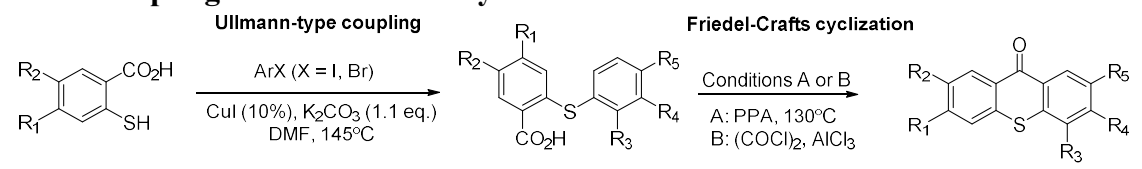

\begin{tabular}{|c|c|c|c|c|c|c|c|}
\cline { 2 - 7 } \multicolumn{1}{c|}{} & \multicolumn{6}{c|}{ Thiosalicylic acid } & \multicolumn{5}{c|}{ ArX } & Product \\
\hline Entry & $\mathbf{R}_{\mathbf{1}}$ & $\mathbf{R}_{\mathbf{2}}$ & $\mathbf{X}$ & $\mathbf{R}_{\mathbf{3}}$ & $\mathbf{R}_{\mathbf{4}}$ & $\mathbf{R}_{\mathbf{5}}$ & Prod \\
\hline 1 & $\mathrm{H}$ & $\mathrm{H}$ & $\mathrm{I}$ & $\mathrm{MeO}$ & $\mathrm{H}$ & $\mathrm{H}$ & $93 \%$ \\
\hline 2 & $\mathrm{H}$ & $\mathrm{H}$ & $\mathrm{Br}$ & $\mathrm{H}$ & $\mathrm{MeO}$ & $\mathrm{H}$ & $85 \%$ \\
\hline 3 & $\mathrm{H}$ & $\mathrm{H}$ & $\mathrm{Br}$ & $\mathrm{H}$ & $\mathrm{H}$ & $\mathrm{MeO}$ & $92 \%$ \\
\hline 4 & $\mathrm{H}$ & $\mathrm{H}$ & $\mathrm{I}$ & $\mathrm{H}$ & $\mathrm{F}$ & $\mathrm{H}$ & $95 \%$ \\
\hline 5 & $\mathrm{H}$ & $\mathrm{H}$ & $\mathrm{I}$ & $\mathrm{H}$ & $\mathrm{H}$ & $\mathrm{F}$ & $84 \%$ \\
\hline 6 & $\mathrm{MeO}$ & $\mathrm{H}$ & $\mathrm{I}$ & $\mathrm{H}$ & $\mathrm{MeO}$ & $\mathrm{H}$ & $87 \%$ \\
\hline 7 & $\mathrm{~F}$ & $\mathrm{H}$ & $\mathrm{I}$ & $\mathrm{H}$ & $\mathrm{F}$ & $\mathrm{H}$ & $78 \%$ \\
\hline 8 & $\mathrm{H}$ & $\mathrm{F}$ & $\mathrm{Br}$ & $\mathrm{H}$ & $\mathrm{H}$ & $\mathrm{MeO}$ & $55 \%$ \\
\hline 9 & $\mathrm{H}$ & $\mathrm{MeO}$ & $\mathrm{Br}$ & $\mathrm{H}$ & $\mathrm{H}$ & $\mathrm{MeO}$ & $62 \%$ \\
\hline
\end{tabular}

Table S1: Ullmann-type coupling of thiosalicylic acids with aryl bromides and iodides

\begin{tabular}{|c|c|c|c|c|c|c|c|}
\hline Entry & Conditions & $\mathbf{R}_{\mathbf{1}}$ & $\mathbf{R}_{\mathbf{2}}$ & $\mathbf{R}_{\mathbf{3}}$ & $\mathbf{R}_{\mathbf{4}}$ & $\mathbf{R}_{\mathbf{5}}$ & Product \\
\hline 1 & $\mathrm{~A}$ & $\mathrm{H}$ & $\mathrm{H}$ & $\mathrm{MeO}$ & $\mathrm{H}$ & $\mathrm{H}$ & $81 \%$ \\
\hline 2 & $\mathrm{~B}$ & $\mathrm{H}$ & $\mathrm{H}$ & $\mathrm{H}$ & $\mathrm{MeO}$ & $\mathrm{H}$ & $76 \%$ \\
\hline 3 & $\mathrm{~A}$ & $\mathrm{H}$ & $\mathrm{H}$ & $\mathrm{H}$ & $\mathrm{H}$ & $\mathrm{MeO}$ & $49 \%$ \\
\hline 4 & $\mathrm{~B}$ & $\mathrm{H}$ & $\mathrm{H}$ & $\mathrm{H}$ & $\mathrm{F}$ & $\mathrm{H}$ & $83 \%$ \\
\hline 5 & $\mathrm{~A}$ & $\mathrm{H}$ & $\mathrm{H}$ & $\mathrm{H}$ & $\mathrm{H}$ & $\mathrm{F}$ & $94 \%$ \\
\hline 6 & $\mathrm{~B}$ & $\mathrm{MeO}$ & $\mathrm{H}$ & $\mathrm{H}$ & $\mathrm{MeO}$ & $\mathrm{H}$ & $69 \%$ \\
\hline 7 & $\mathrm{~B}$ & $\mathrm{~F}$ & $\mathrm{H}$ & $\mathrm{H}$ & $\mathrm{F}$ & $\mathrm{H}$ & $84 \%$ \\
\hline 8 & $\mathrm{~A}$ & $\mathrm{H}$ & $\mathrm{F}$ & $\mathrm{H}$ & $\mathrm{H}$ & $\mathrm{MeO}$ & $62 \%$ \\
\hline 9 & $\mathrm{~A}$ & $\mathrm{H}$ & MeO & $\mathrm{H}$ & $\mathrm{H}$ & $\mathrm{MeO}$ & $80 \%$ \\
\hline
\end{tabular}

Table S2: Intramolecular Friedel-Crafts cyclization to thioxanthones

\section{4-methoxythioxanthone (4-MeOTX)}

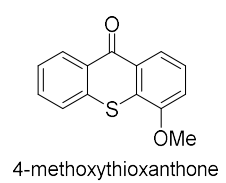

(4-MeOTX)

Thiosalicylic acid $(30.8 \mathrm{~g}, 200 \mathrm{mmol})$ and $\mathrm{K}_{2} \mathrm{CO}_{3}(30.4 \mathrm{~g}, 220 \mathrm{mmol})$ were added to DMF (300 $\left.\mathrm{ml}\right)$ in a $1 \mathrm{~L}$ flask. CuI $(3.8 \mathrm{~g}, 20 \mathrm{mmol})$ and 2-iodoanisole $(28.6 \mathrm{ml}, 220 \mathrm{mmol})$ were then added and the mixture heated at $145^{\circ} \mathrm{C}$ for $19 \mathrm{hrs}$ before cooling and pouring over water $(500 \mathrm{ml})$. The aqueous mixture was filtered before acidifying with $3 \mathrm{M} \mathrm{HCl}(80 \mathrm{ml})$. The resulting slurry was filtered and the residue washed with water, stirred in EtOH, filtered again and dried to give 2-((2methoxyphenyl)thio)benzoic acid as a grey power (48.3 g, 93\%).

A mixture of the thioether $(52 \mathrm{~g}, 200 \mathrm{mmol})$ and polyphosphoric acid $(100 \mathrm{~g})$ was heated at $130^{\circ} \mathrm{C}$ for $1 \mathrm{hr}$ before allowing to cool and quenching with water $(150 \mathrm{ml})$. The mixture was mechanically broken up to a suspension which was extracted with DCM $(500 \mathrm{ml})$. The aqueous solution was further extracted 
with $\mathrm{DCM}(2 \times 250 \mathrm{ml})$ and the combined extracts washed with sat. aq. $\mathrm{NaHCO}_{3}(2 \times 100 \mathrm{ml})$, dried $\left(\mathrm{MgSO}_{4}\right)$, filtered and evaporated to a beige solid $(41.5 \mathrm{~g})$ which was recrystallized from $\mathrm{MeCN}(600$ $\mathrm{ml}$ ) to give 4-methoxythioxanthone as a fluffy solid $(39.3 \mathrm{~g}, 81 \%)$ : m.p. $168-169{ }^{\circ} \mathrm{C}\left(\text { lit. } 165{ }^{\circ} \mathrm{C}\right)^{5}$; $\lambda_{\max }(\mathrm{MeCN}) / \mathrm{nm} 385\left(\varepsilon / \mathrm{M}^{-1} \mathrm{~cm}^{-1} 5,940\right) ; \delta_{\mathrm{H}}\left(400 \mathrm{MHz}, \mathrm{CDCl}_{3}\right) 8.60(1 \mathrm{H}$, app. d, $J=8.1 \mathrm{~Hz}), 8.25(1 \mathrm{H}$, app. d, $J=8.4 \mathrm{~Hz}), 7.66-7.58(2 \mathrm{H}, \mathrm{m}), 7.50-7.41(2 \mathrm{H}, \mathrm{m}), 7.13(1 \mathrm{H}$, app. d, $J=7.9 \mathrm{~Hz}), 4.03(3 \mathrm{H}$, s, $\left.\mathrm{OCH}_{3}\right) ; \delta_{\mathrm{C}}\left(101 \mathrm{MHz}, \mathrm{CDCl}_{3}\right) 180.2(\mathrm{C}), 154.5(\mathrm{C}), 137.5(\mathrm{C}), 132.3(\mathrm{CH}), 130.4(\mathrm{C}), 129.8(\mathrm{CH})$, $129.1(\mathrm{C}), 127.7(\mathrm{C}), 126.8(\mathrm{CH}), 126.4(\mathrm{CH}), 126.1(\mathrm{CH}), 121.8(\mathrm{CH}), 112.33(\mathrm{CH}) 56.6\left(\mathrm{CH}_{3}\right)$; ESIHRMS m/z $243.0474\left(\mathrm{MH}^{+} \mathrm{C}_{14} \mathrm{H}_{11} \mathrm{O}_{2} \mathrm{~S}\right.$ requires 243.0474)

\section{3-methoxythioxanthone (3-MeOTX)}

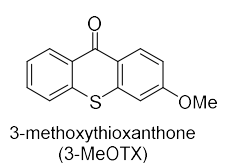

Thiosalicylic acid (30.8 g, $200 \mathrm{mmol})$ and $\mathrm{K}_{2} \mathrm{CO}_{3}(30.4 \mathrm{~g}, 220 \mathrm{mmol})$ were added to DMF (400 $\left.\mathrm{ml}\right)$ in a $1 \mathrm{~L}$ flask. CuI $(3.8 \mathrm{~g}, 20 \mathrm{mmol})$ and 3-bromoanisole $(27.9 \mathrm{ml}, 220 \mathrm{mmol})$ were then added and the mixture heated at $145^{\circ} \mathrm{C}$ for $20 \mathrm{hrs}$ before cooling and pouring over water $(600 \mathrm{ml})$. The aqueous mixture was filtered before acidifying with $3 \mathrm{M} \mathrm{HCl}(90 \mathrm{ml})$. The resulting slurry was filtered and the residue washed with water, stirred in $\mathrm{EtOH}$, filtered again and dried to give 2-((3methoxyphenyl)thio)benzoic acid as a grey power (44.2 $\mathrm{g}, 85 \%)$.

A mixture of the thioether $(10 \mathrm{~g}, 38.4 \mathrm{mmol})$ in anhydrous DCM $(70 \mathrm{ml})$ with a few drops of DMF was cooled in an ice bath before the addition of $(\mathrm{COCl})_{2}(3.9 \mathrm{ml}, 46 \mathrm{mmol})$. The stirred mixture was removed from the ice bath until the reaction had reached completion before removing the solvent in vacuo. The residue was re-dissolved in anhydrous DCM $(100 \mathrm{ml})$ and the solution cooled in an ice bath before the addition of $\mathrm{AlCl}_{3}(6.13 \mathrm{~g}, 46 \mathrm{mmol})$. After stirring overnight the mixture was quenched with water, extracted with DCM $(3 \times 150 \mathrm{ml})$, washed with sat. aq. $\mathrm{NaHCO}_{3}$, dried $\left(\mathrm{MgSO}_{4}\right)$, filtered and evaporated to a beige solid $(9 \mathrm{~g})$ which was recrystallized from $\mathrm{MeCN}(50 \mathrm{ml})$ to give 3-methoxythioxanthone as an off-white powder $(7.1 \mathrm{~g}, 76 \%)$ : m.p. $133-134^{\circ} \mathrm{C}\left(\text { lit. } 129^{\circ} \mathrm{C}\right)^{4} ; \lambda_{\max }(\mathrm{MeCN}) / \mathrm{nm} 367\left(\varepsilon / \mathrm{M}^{-1} \mathrm{~cm}^{-1}\right.$ 5,550); $\delta_{\mathrm{H}}\left(400 \mathrm{MHz}, \mathrm{CDCl}_{3}\right) 8.62-8.58(1 \mathrm{H}, \mathrm{m}), 8.55(1 \mathrm{H}, \mathrm{d}, J=9.0 \mathrm{~Hz}), 7.62-7.51(2 \mathrm{H}, \mathrm{m}), 7.49$ $-7.44(1 \mathrm{H}, \mathrm{m}), 7.03(1 \mathrm{H}, \mathrm{dd}, J=9.0,2.5 \mathrm{~Hz}), 6.96(1 \mathrm{H}, \mathrm{d}, J=2.4 \mathrm{~Hz}), 3.92\left(3 \mathrm{H}, \mathrm{s}, \mathrm{OCH}_{3}\right) ; \delta_{\mathrm{C}}(101$ $\left.\mathrm{MHz}, \mathrm{CDCl}_{3}\right)$ 179.2 (C), $162.7(\mathrm{C}), 139.7(\mathrm{C}), 137.1(\mathrm{C}), 132.1(\mathrm{CH}), 132.1(\mathrm{CH}), 129.9(\mathrm{CH}), 129.5$ (C), $126.4(\mathrm{CH}), 125.9(\mathrm{CH}), 123.2(\mathrm{C}), 115.3(\mathrm{CH}), 108.2(\mathrm{CH}), 55.8\left(\mathrm{CH}_{3}\right)$; ESI-HRMS m/z 243.0475 $\left(\mathrm{MH}^{+} \mathrm{C}_{14} \mathrm{H}_{11} \mathrm{O}_{2} \mathrm{~S}\right.$ requires 243.0474)

\section{2-methoxythioxanthone (2-MeOTX)}

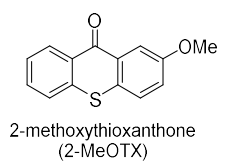

Thiosalicylic acid $(30.8 \mathrm{~g}, 200 \mathrm{mmol})$ and $\mathrm{K}_{2} \mathrm{CO}_{3}(30.4 \mathrm{~g}, 220 \mathrm{mmol})$ were added to DMF $(300 \mathrm{ml})$ in a $1 \mathrm{~L}$ flask. $\mathrm{CuI}(3.8 \mathrm{~g}, 20 \mathrm{mmol})$ and 4-bromoanisole $(27.9 \mathrm{ml}, 220 \mathrm{mmol})$ were then added and the mixture heated at $145^{\circ} \mathrm{C}$ for $20 \mathrm{hrs}$ before cooling and pouring over water $(600 \mathrm{ml})$. The aqueous mixture was filtered before acidifying with $3 \mathrm{M} \mathrm{HCl}(90 \mathrm{ml})$. The resulting slurry was filtered and the residue washed with water, stirred in $\mathrm{MeOH}$, filtered again and dried to give 2-((4methoxyphenyl)thio)benzoic acid as a grey power (47.8 g, 92\%).

A mixture of the thioether $(46 \mathrm{~g}, 177 \mathrm{mmol})$ and polyphosphoric acid $(180 \mathrm{~g})$ was heated at $130^{\circ} \mathrm{C}$ for $4.5 \mathrm{hrs}$ before allowing to cool and quenching with water $(150 \mathrm{ml})$. The mixture was mechanically broken up to a suspension which was extracted with DCM, washed with sat. aq. $\mathrm{NaHCO}_{3}$, dried $\left(\mathrm{MgSO}_{4}\right)$, filtered and evaporated to a yellow solid (25) which was recrystallized from MeCN (200 ml) 
to give 2-methoxythioxanthone as a fluffy yellow solid (20.8 g, 49\%): m.p. $128-129^{\circ} \mathrm{C}$ (lit. $\left.129{ }^{\circ} \mathrm{C}\right)^{6}$; $\lambda_{\max }(\mathrm{MeCN}) / \mathrm{nm} 399\left(\varepsilon / \mathrm{M}^{-1} \mathrm{~cm}^{-1} 6,050\right) ; \delta_{\mathrm{H}}\left(400 \mathrm{MHz}, \mathrm{CDCl}_{3}\right) 8.65-8.61(1 \mathrm{H}, \mathrm{m}), 8.08(1 \mathrm{H}, \mathrm{d}, J=2.9$ $\mathrm{Hz}), 7.64-7.56(2 \mathrm{H}, \mathrm{m}), 7.51-7.45(2 \mathrm{H}, \mathrm{m}), 7.26(1 \mathrm{~h}, \mathrm{dd}, J=8.8,3.0 \mathrm{~Hz}), 3.94\left(3 \mathrm{H}, \mathrm{s}, \mathrm{OCH}_{3}\right) ; \delta_{\mathrm{C}}$ (101 MHz, $\left.\mathrm{CDCl}_{3}\right) 179.8(\mathrm{C}), 158.6(\mathrm{C}), 137.7(\mathrm{C}), 132.2(\mathrm{CH}), 130.4(\mathrm{C}), 130.0(\mathrm{CH}), 129.3(\mathrm{C})$, $128.8(\mathrm{C}), 127.4(\mathrm{CH}), 126.2(\mathrm{CH}), 126.1(\mathrm{CH}), 122.9(\mathrm{CH}), 110.5(\mathrm{CH}), 55.9\left(\mathrm{CH}_{3}\right) ;$ ESI-HRMS m/z $243.0476\left(\mathrm{MH}^{+} \mathrm{C}_{14} \mathrm{H}_{11} \mathrm{O}_{2} \mathrm{~S}\right.$ requires 243.0474)

\section{3-fluorothioxanthone (3-FTX)}

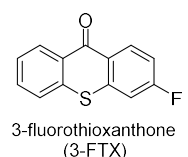

Thiosalicylic acid $(30.8 \mathrm{~g}, 200 \mathrm{mmol})$ and $\mathrm{K}_{2} \mathrm{CO}_{3}(30.4 \mathrm{~g}, 220 \mathrm{mmol})$ were added to DMF (300 $\left.\mathrm{ml}\right)$ in a $1 \mathrm{~L}$ flask. CuI (3.8 g, $20 \mathrm{mmol})$ and 3-fluoroiodobenzene $(25.8 \mathrm{ml}, 220 \mathrm{mmol})$ were then added and the mixture heated at $145^{\circ} \mathrm{C}$ for $19 \mathrm{hrs}$ before cooling and pouring over water $(500 \mathrm{ml})$. The aqueous mixture was filtered before acidifying with $3 \mathrm{M} \mathrm{HCl}(90 \mathrm{ml})$. The resulting slurry was filtered and the residue washed with water, stirred in hot $\mathrm{MeOH}(70 \mathrm{ml})$, filtered again and dried to give 2-((3fluorophenyl)thio)benzoic acid as a grey power $(47.1 \mathrm{~g}, 95 \%)$.

To a stirred mixture of the thioether $(10 \mathrm{~g}, 40.3 \mathrm{mmol})$ in anhydrous DCM $(90 \mathrm{ml})$ with a few drops of DMF was added $(\mathrm{COCl})_{2}(4.1 \mathrm{ml}, 48.5 \mathrm{mmol})$. When the reaction had reached full conversion after 3 hrs the solvent was removed in vacuo, the residue was re-dissolved in anhydrous DCM (130 ml) and the solution cooled in an ice bath before the addition of $\mathrm{AlCl}_{3}(6.5 \mathrm{~g}, 48.7 \mathrm{mmol})$. After stirring for $1 \mathrm{hr}$ the mixture was quenched with water $(80 \mathrm{ml})$ and extracted with DCM $(3 \times 150 \mathrm{ml})$. The combined organic extracts were washed with sat. aq. $\mathrm{NaHCO}_{3}$, dried $\left(\mathrm{MgSO}_{4}\right)$, filtered and evaporated to a beige solid which was recrystallized from $\mathrm{MeCN}(90 \mathrm{ml})$ to give 3-fluorothioxanthone as a colourless powder (7.7 g, 83\%): m.p. $166-167{ }^{\circ} \mathrm{C} ; \lambda_{\max }(\mathrm{MeCN}) / \mathrm{nm} 370\left(\varepsilon / \mathrm{M}^{-1} \mathrm{~cm}^{-1} 5,710\right) ; \delta_{\mathrm{H}}\left(400 \mathrm{MHz}, \mathrm{CDCl}_{3}\right) 8.63$ $(1 \mathrm{H}, \mathrm{dd}, J=9.0,6.0 \mathrm{~Hz}), 8.61-8.57(1 \mathrm{H}, \mathrm{m}), 7.62(1 \mathrm{H}, \mathrm{ddd}, J=8.4,7.0,1.5 \mathrm{~Hz}), 7.56-7.52(1 \mathrm{H}, \mathrm{m})$, 7.49 (1H, ddd, $J=8.2,7.0,1.3 \mathrm{~Hz}), 7.24(1 \mathrm{H}, \mathrm{dd}, J=8.8,2.5 \mathrm{~Hz}), 7.17(1 \mathrm{H}, \mathrm{ddd}, J=9.0,8.0,2.5 \mathrm{~Hz})$; $\delta_{\mathrm{C}}\left(101 \mathrm{MHz}, \mathrm{CDCl}_{3}\right) 179.1(\mathrm{C}), 164.8(\mathrm{~d}, J=256.8 \mathrm{~Hz}, \mathrm{C}), 139.8(\mathrm{~d}, J=10.2 \mathrm{~Hz}, \mathrm{C}), 136.9(\mathrm{C}), 133.2$ $(\mathrm{d}, J=9.9 \mathrm{~Hz}, \mathrm{CH}), 132.5(\mathrm{CH}), 130.0(\mathrm{CH}), 129.2(\mathrm{C}), 126.8(\mathrm{CH}), 126.1(\mathrm{~d}, J=2.1 \mathrm{~Hz}, \mathrm{C}), 126.0$ $(\mathrm{CH}), 115.1(\mathrm{~d}, J=22.5 \mathrm{~Hz}, \mathrm{CH}), 112.0(\mathrm{~d}, J=24.6 \mathrm{~Hz}, \mathrm{CH}) ; \delta_{\mathrm{F}}\left(376 \mathrm{MHz}, \mathrm{CDCl}_{3}\right)-104.8$; ESI-HRMS $\mathrm{m} / \mathrm{z} 231.0271\left(\mathrm{MH}^{+} \mathrm{C}_{13} \mathrm{H}_{8} \mathrm{OFS}\right.$ requires 231.0274)

2-fluorothioxanthone (2-FTX)

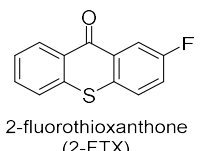

$(2-\mathrm{FTX})$
$(2-5)$

Thiosalicylic acid $(30.8 \mathrm{~g}, 200 \mathrm{mmol})$ and $\mathrm{K}_{2} \mathrm{CO}_{3}(30.4 \mathrm{~g}, 220 \mathrm{mmol})$ were added to DMF $(400 \mathrm{ml})$ in a $1 \mathrm{~L}$ flask. CuI ( $3.8 \mathrm{~g}, 20 \mathrm{mmol})$ and 4-fluoroiodobenzene $(24.2 \mathrm{ml}, 220 \mathrm{mmol})$ were then added and the mixture heated at $145^{\circ} \mathrm{C}$ for $12 \mathrm{hrs}$ before cooling and pouring over water $(500 \mathrm{ml})$. The aqueous mixture was filtered before acidifying with $3 \mathrm{M} \mathrm{HCl}(90 \mathrm{ml})$. The resulting slurry was filtered and the residue washed with water, stirred in hot $\mathrm{MeOH}(70 \mathrm{ml})$, filtered again and dried to give 2-((4fluorophenyl)thio)benzoic acid as a grey power $(41.9 \mathrm{~g}, 84 \%)$.

A mixture of the thioether $(40.5 \mathrm{~g}, 163 \mathrm{mmol})$ and polyphosphoric acid $(150 \mathrm{~g})$ was heated at $130^{\circ} \mathrm{C}$ for $11 \mathrm{hrs}$ before allowing to cool and quenching with water $(150 \mathrm{ml})$. The mixture was mechanically broken up to a suspension which was extracted with DCM $(500 \mathrm{ml})$. The aqueous solution was further extracted with DCM $(2 \times 250 \mathrm{ml})$ and the combined extracts washed with sat. aq. $\mathrm{NaHCO}_{3}(2 \times 100 \mathrm{ml})$, dried $\left(\mathrm{MgSO}_{4}\right)$, filtered and evaporated to give 2-fluorothioxanthone as an off white solid (35.4 g, 94\%): 
m.p. $170-171{ }^{\circ} \mathrm{C}\left(\text { lit. } 171{ }^{\circ} \mathrm{C}\right)^{7} ; \lambda_{\max }(\mathrm{MeCN}) / \mathrm{nm} 388\left(\varepsilon / \mathrm{M}^{-1} \mathrm{~cm}^{-1} 6,310\right) ; \delta_{\mathrm{H}}\left(400 \mathrm{MHz}, \mathrm{CDCl}_{3}\right) 8.63-$ $8.58(1 \mathrm{H}, \mathrm{m}), 8.29(1 \mathrm{H}, \mathrm{dd}, J=9.6,2.9 \mathrm{~Hz}), 7.66-7.54(3 \mathrm{H}, \mathrm{m}), 7.49(1 \mathrm{H}, \mathrm{ddd}, J=8.2,6.9,1.4 \mathrm{~Hz})$, $7.38(1 \mathrm{H}$, ddd, $J=8.8,7.5,2.9 \mathrm{~Hz}) ; \delta_{\mathrm{C}}\left(101 \mathrm{MHz}, \mathrm{CDCl}_{3}\right) 179.3(\mathrm{~d}, J=2.4 \mathrm{~Hz}, \mathrm{C}), 161.3(\mathrm{~d}, J=247.6$ $\mathrm{Hz}, \mathrm{C}), 137.3$ (C), 132.7 (d, $J=2.4 \mathrm{~Hz}, \mathrm{C}), 132.6(\mathrm{CH}), 131.0$ (d, $J=6.5 \mathrm{~Hz}, \mathrm{C}), 130.1(\mathrm{CH}), 128.43$ (C), $128.1(\mathrm{~d}, J=7.4 \mathrm{~Hz}, \mathrm{CH}), 126.7(\mathrm{CH}), 126.1(\mathrm{CH}), 121.2$ (d, $J=24.2 \mathrm{~Hz}, \mathrm{CH}), 115.5(\mathrm{~d}, J=22.9$ $\mathrm{Hz}, \mathrm{CH}) ; \delta_{\mathrm{F}}\left(376 \mathrm{MHz}, \mathrm{CDCl}_{3}\right)$-113.6; ESI-HRMS m/z $231.0270\left(\mathrm{MH}^{+} \mathrm{C}_{13} \mathrm{H}_{8} \mathrm{OFS}\right.$ requires 231.0274)

\section{3,6-dimethoxythioxanthone (3,3'-MeOTX)}

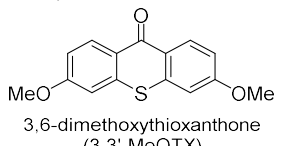

$\left(3,3^{\prime}-\mathrm{MeOTX}\right)$

4-Methoxythiosalicylic acid $(17.6 \mathrm{~g}, 96 \mathrm{mmol})$ and $\mathrm{K}_{2} \mathrm{CO}_{3}(14.6 \mathrm{~g}, 106 \mathrm{mmol})$ were added to DMF $(200 \mathrm{ml})$ in a $1 \mathrm{~L}$ flask. CuI $(1.83 \mathrm{~g}, 9.6 \mathrm{mmol})$ and 3-bromoanisole $(13.4 \mathrm{ml}, 106 \mathrm{mmol})$ were then added and the mixture heated at $145^{\circ} \mathrm{C}$ for $2.5 \mathrm{hrs}$ before cooling and pouring over water $(300 \mathrm{ml})$. The aqueous mixture was filtered before acidifying with $3 \mathrm{M} \mathrm{HCl}(40 \mathrm{ml})$. The resulting slurry was filtered and the residue washed with water, dissolved in EtOAc $(300 \mathrm{ml})$, washed with brine, dried $\left(\mathrm{MgSO}_{4}\right)$ and filtered. The solution was evaporated in vacuo to give 4-methoxy-2-((3methoxyphenyl)thio)benzoic acid as a white power (24.2 g, 87\%).

To a stirred mixture of the thioether $(10 \mathrm{~g}, 34.4 \mathrm{mmol})$ in anhydrous DCM $(70 \mathrm{ml})$ with a few drops of DMF was added $(\mathrm{COCl})_{2}(3.5 \mathrm{ml}, 41.3 \mathrm{mmol})$. When the reaction had reached full conversion after 1 $\mathrm{hr}$ the solvent was removed in vacuo, the residue was re-dissolved in anhydrous DCM $(130 \mathrm{ml})$ and the solution cooled in an ice bath before the addition of $\mathrm{AlCl}_{3}(5.51 \mathrm{~g}, 41.3 \mathrm{mmol})$. After stirring for $1 \mathrm{hr}$ the mixture was quenched with water $(50 \mathrm{ml})$ and extracted with DCM $(3 \times 150 \mathrm{ml})$. The combined organic extracts were washed with sat. aq. $\mathrm{NaHCO}_{3}$, dried $\left(\mathrm{MgSO}_{4}\right)$, filtered and evaporated to a beige solid $(9.2 \mathrm{~g})$ which was recrystallized from $\mathrm{MeCN}(90 \mathrm{ml})$ to give 3,6-dimethoxythioxanthone as a colourless powder $(6.5 \mathrm{~g}, 69 \%)$ : m.p. $175^{\circ} \mathrm{C} ; \lambda_{\max }(\mathrm{MeCN}) / \mathrm{nm} 354\left(\varepsilon / \mathrm{M}^{-1} \mathrm{~cm}^{-1} 5,850\right) ; \delta_{\mathrm{H}}(400 \mathrm{MHz}$, $\left.\mathrm{CDCl}_{3}\right) 8.52(2 \mathrm{H}, \mathrm{d}, J=9.0 \mathrm{~Hz}), 7.00(2 \mathrm{H}, \mathrm{dd}, J=9.0,2.5 \mathrm{~Hz}), 6.92(2 \mathrm{H}, \mathrm{d}, J=2.5 \mathrm{~Hz}), 3.91(6 \mathrm{H}, \mathrm{s}$, $\left.\mathrm{OCH}_{3}\right) ; \delta_{\mathrm{C}}\left(101 \mathrm{MHz}, \mathrm{CDCl}_{3}\right) 178.5(\mathrm{C}), 162.4(\mathrm{C}), 139.3(\mathrm{C}), 132.0(\mathrm{CH}), 123.3(\mathrm{C}), 114.9(\mathrm{CH})$, 108.2 $(\mathrm{CH}), 55.8\left(\mathrm{CH}_{3}\right)$; ESI-HRMS m/z $273.0572\left(\mathrm{MH}^{+} \mathrm{C}_{15} \mathrm{H}_{13} \mathrm{O}_{3} \mathrm{~S}\right.$ requires 273.0580)

\section{3,6-difluorothioxanthone (3,3'-FTX)}

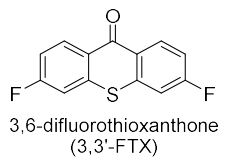

4-Fluorothiosalicylic acid ( $27 \mathrm{~g}, 157 \mathrm{mmol})$ and $\mathrm{K}_{2} \mathrm{CO}_{3}(24.2 \mathrm{~g}, 175 \mathrm{mmol})$ were added to DMF (250 $\mathrm{ml})$ in a $1 \mathrm{~L}$ flask. CuI $(3.1 \mathrm{~g}, 16 \mathrm{mmol})$ and 3-fluoroiodobenzene $(20.6 \mathrm{ml}, 175 \mathrm{mmol})$ were then added and the mixture heated at $145^{\circ} \mathrm{C}$ for $3 \mathrm{hrs}$ before cooling and pouring over water $(400 \mathrm{ml})$. The aqueous mixture was filtered before acidifying with $3 \mathrm{M} \mathrm{HCl}(70 \mathrm{ml})$. The resulting slurry was filtered and the residue washed with water, stirred in hot $\mathrm{MeOH}(80 \mathrm{ml})$, filtered again and dried to give 4-fluoro-2-((3fluorophenyl)thio)benzoic acid as a white power (32.5 g, 78\%).

To a stirred mixture of the thioether $(10 \mathrm{~g}, 37.6 \mathrm{mmol})$ in anhydrous DCM $(90 \mathrm{ml})$ with a few drops of DMF was added $(\mathrm{COCl})_{2}(3.8 \mathrm{ml}, 45 \mathrm{mmol})$. When the reaction had reached full conversion after $2 \mathrm{hrs}$ the solvent was removed in vacuo, the residue was re-dissolved in anhydrous DCM (130 ml) and the solution cooled in an ice bath before the addition of $\mathrm{AlCl}_{3}(6.0 \mathrm{~g}, 45 \mathrm{mmol})$. After stirring for $1 \mathrm{hr}$ the mixture was quenched with water $(80 \mathrm{ml})$ and extracted with DCM $(3 \times 150 \mathrm{ml})$. The combined organic extracts were washed with sat. aq. $\mathrm{NaHCO}_{3}$, dried $\left(\mathrm{MgSO}_{4}\right)$, filtered and evaporated to a pale orange solid $(9.0 \mathrm{~g})$ which was recrystallized from $\mathrm{MeCN}(100 \mathrm{ml})$ to give 3,6-difluorothioxanthone as a 
colourless powder (7.8 g, 84\%): m.p. $207-208{ }^{\circ} \mathrm{C} ; \lambda_{\max }(\mathrm{MeCN}) / \mathrm{nm} 361\left(\varepsilon / \mathrm{M}^{-1} \mathrm{~cm}^{-1} 5,290\right) ; \delta_{\mathrm{H}}(400$ $\left.\mathrm{MHz}, \mathrm{CDCl}_{3}\right) 8.62(2 \mathrm{H}, \mathrm{dd}, J=9.0,5.8 \mathrm{~Hz}), 7.25-7.16(4 \mathrm{H}, \mathrm{m}) ; \delta_{\mathrm{C}}\left(101 \mathrm{MHz}, \mathrm{CDCl}_{3}\right) 178.0(\mathrm{C})$, 164.8 (d, $J=257.2 \mathrm{~Hz}, \mathrm{C}), 139.2$ (d, $J=10.0 \mathrm{~Hz}, \mathrm{C}), 133.3$ (d, $J=10.0 \mathrm{~Hz}, \mathrm{CH}), 125.9$ (d, $J=2.5 \mathrm{~Hz}$, C), $115.4(\mathrm{~d}, J=22.3 \mathrm{~Hz}, \mathrm{CH}), 112.0(\mathrm{~d}, J=24.8 \mathrm{~Hz}, \mathrm{CH}) ; \delta_{\mathrm{F}}\left(376 \mathrm{MHz}, \mathrm{CDCl}_{3}\right)-104.5$; ESI-HRMS $\mathrm{m} / \mathrm{z} 249.0174\left(\mathrm{MH}^{+} \mathrm{C}_{13} \mathrm{H}_{7} \mathrm{OF}_{2} \mathrm{~S}\right.$ requires 249.0180)

\section{2-methoxy,7-fluorothioxanthone (2-F,2'-MeOTX)}

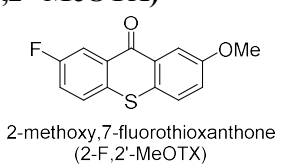

5-Fluorothiosalicylic acid $(9.3 \mathrm{~g}, 54 \mathrm{mmol})$ and $\mathrm{K}_{2} \mathrm{CO}_{3}(7.5 \mathrm{~g}, 54 \mathrm{mmol})$ were added to DMF (100 ml) in a $250 \mathrm{ml}$ flask. $\mathrm{CuI}(0.95 \mathrm{~g}, 5.0 \mathrm{mmol})$ and 4-bromoanisole $(6.8 \mathrm{ml}, 54 \mathrm{mmol})$ were then added and the mixture heated at $145^{\circ} \mathrm{C}$ for $23 \mathrm{hrs}$ before cooling and pouring over water $(200 \mathrm{ml})$. The aqueous mixture was filtered through celite before acidifying with $3 \mathrm{M} \mathrm{HCl}(25 \mathrm{ml})$. The resulting slurry was filtered and the residue dissolved in EtOAc $(200 \mathrm{ml})$, dried $\left(\mathrm{MgSO}_{4}\right)$ and filtered. The solution was evaporated in vacuo to a slurry which was washed with $\mathrm{Et}_{2} \mathrm{O}$ and dried to give 5-fluoro-2-((4methoxyphenyl)thio)benzoic acid as a white powder ( $8.2 \mathrm{~g}, 55 \%)$.

A mixture of the thioether $(1.0 \mathrm{~g}, 3.6 \mathrm{mmol})$ and polyphosphoric acid $(5 \mathrm{ml})$ was heated at $120^{\circ} \mathrm{C}$ for 1 $\mathrm{hr}$ before allowing to cool and quenching with water $(10 \mathrm{ml})$. The mixture was mechanically broken up to a suspension which was extracted with DCM and $\mathrm{Et}_{2} \mathrm{O}$. The combined extracts were dried $\left(\mathrm{MgSO}_{4}\right)$, filtered and evaporated to a yellow solid $(0.68 \mathrm{~g})$ which was recrystallized from $\mathrm{MeCN}(12 \mathrm{ml})$ to give 2-methoxy,7-fluorothioxanthone was a fluffy yellow powder $(858 \mathrm{mg}, 62 \%)$; m.p. $160-161^{\circ} \mathrm{C}$; $\lambda_{\max }(\mathrm{MeCN}) / \mathrm{nm} 408\left(\varepsilon / \mathrm{M}^{-1} \mathrm{~cm}^{-1} 6,220\right) ; \delta_{\mathrm{H}}\left(400 \mathrm{MHz}, \mathrm{CDCl}_{3}\right) 8.29(1 \mathrm{H}, \mathrm{dd}, J=9.7,2.9 \mathrm{~Hz}), 8.04(1 \mathrm{H}$, $\mathrm{d}, J=2.9 \mathrm{~Hz}), 7.57(1 \mathrm{H}, \mathrm{dd}, J=8.8,4.8 \mathrm{~Hz}), 7.49(1 \mathrm{H}, \mathrm{d}, J=8.8 \mathrm{~Hz}), 7.41-7.33(1 \mathrm{H}, \mathrm{m}), 7.30-7.24$ $(1 \mathrm{H}, \mathrm{m}), 3.94(3 \mathrm{H}, \mathrm{s}) ; \delta_{\mathrm{C}}\left(101 \mathrm{MHz}, \mathrm{CDCl}_{3}\right) 179.0(\mathrm{~d}, J=2.3 \mathrm{~Hz}, \mathrm{C}), 161.2(\mathrm{~d}, J=247.3 \mathrm{~Hz}, \mathrm{C}), 158.7$ (C), 132.94 (d, $J=2.4 \mathrm{~Hz}, \mathrm{C}), 130.3$ (d, $J=6.5 \mathrm{~Hz}, \mathrm{C}), 129.5$ (C), 129.2 (C), 128.1 (d, $J=7.5 \mathrm{~Hz}, \mathrm{CH}$ ), $127.4(\mathrm{CH}), 123.2(\mathrm{CH}), 121.0(\mathrm{~d}, J=24.2 \mathrm{~Hz}, \mathrm{CH}), 115.4(\mathrm{~d}, J=22.8 \mathrm{~Hz}, \mathrm{CH}), 110.4(\mathrm{~d}, J=1.5 \mathrm{~Hz}$, $\mathrm{CH}), 55.8\left(\mathrm{CH}_{3}\right) ; \delta_{\mathrm{F}}\left(376 \mathrm{MHz}, \mathrm{CDCl}_{3}\right)$-113.9; ESI-HRMS m/z $261.0376\left(\mathrm{MH}^{+} \mathrm{C}_{14} \mathrm{H}_{10} \mathrm{O}_{2} \mathrm{FS}\right.$ requires 261.0380)

\section{2,7-dimethoxythioxanthone (2,2'-MeOTX)}

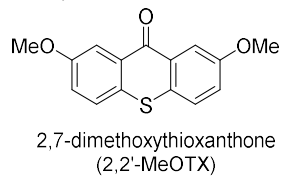

5-Methoxythiosalicylic acid $(15.5 \mathrm{~g}, 84 \mathrm{mmol})$ and $\mathrm{K}_{2} \mathrm{CO}_{3}(12.8 \mathrm{~g}, 93 \mathrm{mmol})$ were added to DMF (200 $\mathrm{ml})$ in a $1 \mathrm{~L}$ flask. CuI $(1.6 \mathrm{~g}, 8.4 \mathrm{mmol})$ and 4-bromoanisole $(13.4 \mathrm{ml}, 93 \mathrm{mmol})$ were then added and the mixture heated at $145^{\circ} \mathrm{C}$ for $23 \mathrm{hrs}$ before cooling and pouring over water $(300 \mathrm{ml})$. The aqueous mixture was filtered before acidifying with $3 \mathrm{M} \mathrm{HCl}(40 \mathrm{ml})$. The resulting slurry was filtered and the residue, dissolved in EtOAc $(200 \mathrm{ml})$, washed with brine, dried $\left(\mathrm{MgSO}_{4}\right)$ and filtered. The solution was evaporated in vacuo to a slurry which was washed with $\mathrm{Et}_{2} \mathrm{O}$ and dried to give 5-methoxy-2-((4methoxyphenyl)thio)benzoic acid as an off white solid (15.1 g, 62\%).

A mixture of the thioether $(13.9 \mathrm{~g}, 48 \mathrm{mmol})$ and polyphosphoric acid $(130 \mathrm{~g})$ was heated at $120^{\circ} \mathrm{C}$ for $1 \mathrm{hr}$ before allowing to cool and quenching with water $(100 \mathrm{ml})$. The mixture was mechanically broken up to a suspension which was extracted with $\mathrm{DCM}$, washed with sat. aq. $\mathrm{NaHCO}_{3}$, dried $\left(\mathrm{MgSO}_{4}\right)$, filtered and evaporated to a yellow solid (11.8 g) which was recrystallized from $\mathrm{MeCN}$ (155 ml) to give 2,7-dimethoxythioxanthone as a fluffy yellow solid $(10.5 \mathrm{~g}, 80 \%)$ : m.p. $155-157^{\circ} \mathrm{C} ; \lambda_{\max }(\mathrm{MeCN}) / \mathrm{nm}$ 
$415\left(\varepsilon / \mathrm{M}^{-1} \mathrm{~cm}^{-1} 6,270\right) ; \delta_{\mathrm{H}}\left(400 \mathrm{MHz}, \mathrm{CDCl}_{3}\right) 8.08(2 \mathrm{H}, \mathrm{d}, J=2.9 \mathrm{~Hz}), 7.49(2 \mathrm{H}, \mathrm{d}, J=8.9 \mathrm{~Hz}), 7.25$ $(2 \mathrm{H}, \mathrm{dd}, J=8.9,2.9 \mathrm{~Hz}), 3.94(6 \mathrm{H}, \mathrm{s}) ; \delta_{\mathrm{C}}\left(101 \mathrm{MHz}, \mathrm{CDCl}_{3}\right) 179.5(\mathrm{C}), 158.4(\mathrm{C}), 129.7(\mathrm{C}), 129.6$ $(\mathrm{C}), 127.5(\mathrm{CH}), 122.8(\mathrm{CH}), 110.4(\mathrm{CH}), 55.8\left(\mathrm{CH}_{3}\right)$; ESI-HRMS m/z $273.0573\left(\mathrm{MH}^{+} \mathrm{C}_{15} \mathrm{H}_{13} \mathrm{O}_{3} \mathrm{~S}\right.$ requires 273.0580 )

\section{UV-Vis Spectra of Thioxanthone Derivatives}

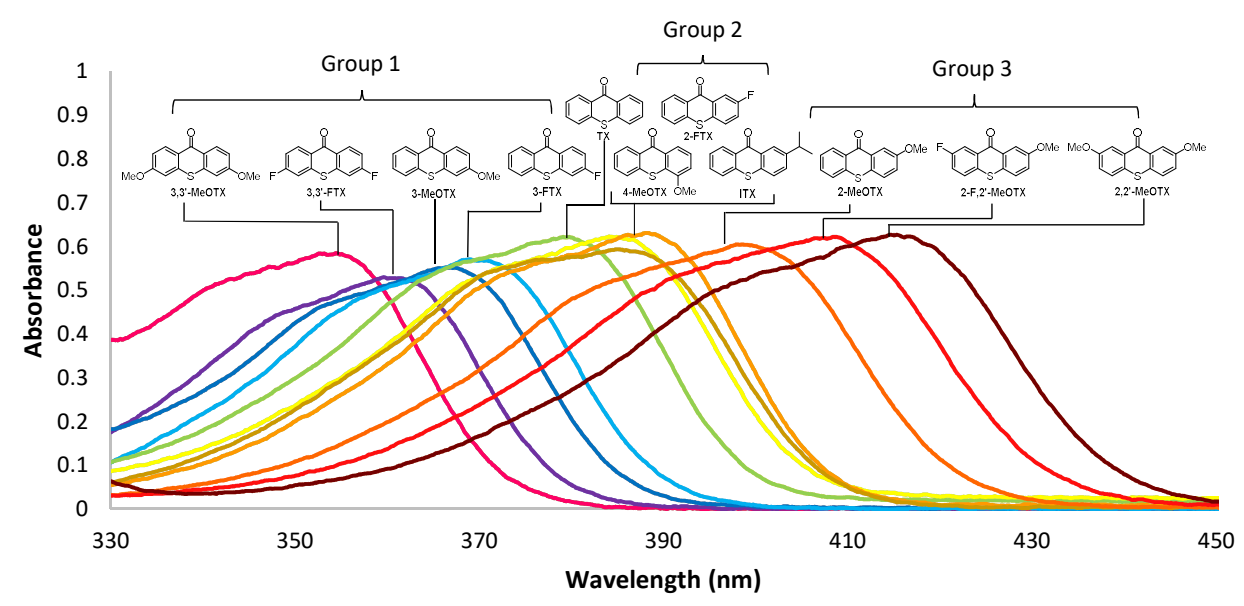

Figure S1: Composite UV-vis spectra of TX derivatives $\left(\mathrm{MeCN}, 1 \times 10^{-4} \mathrm{M}\right)$
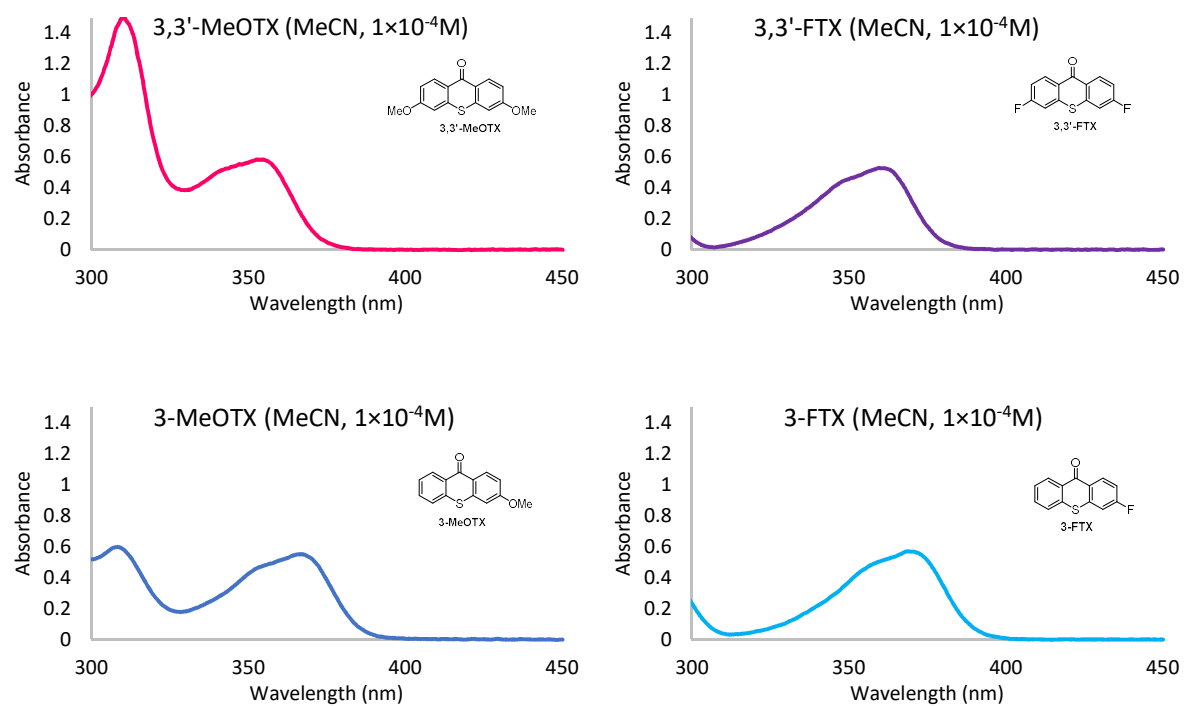

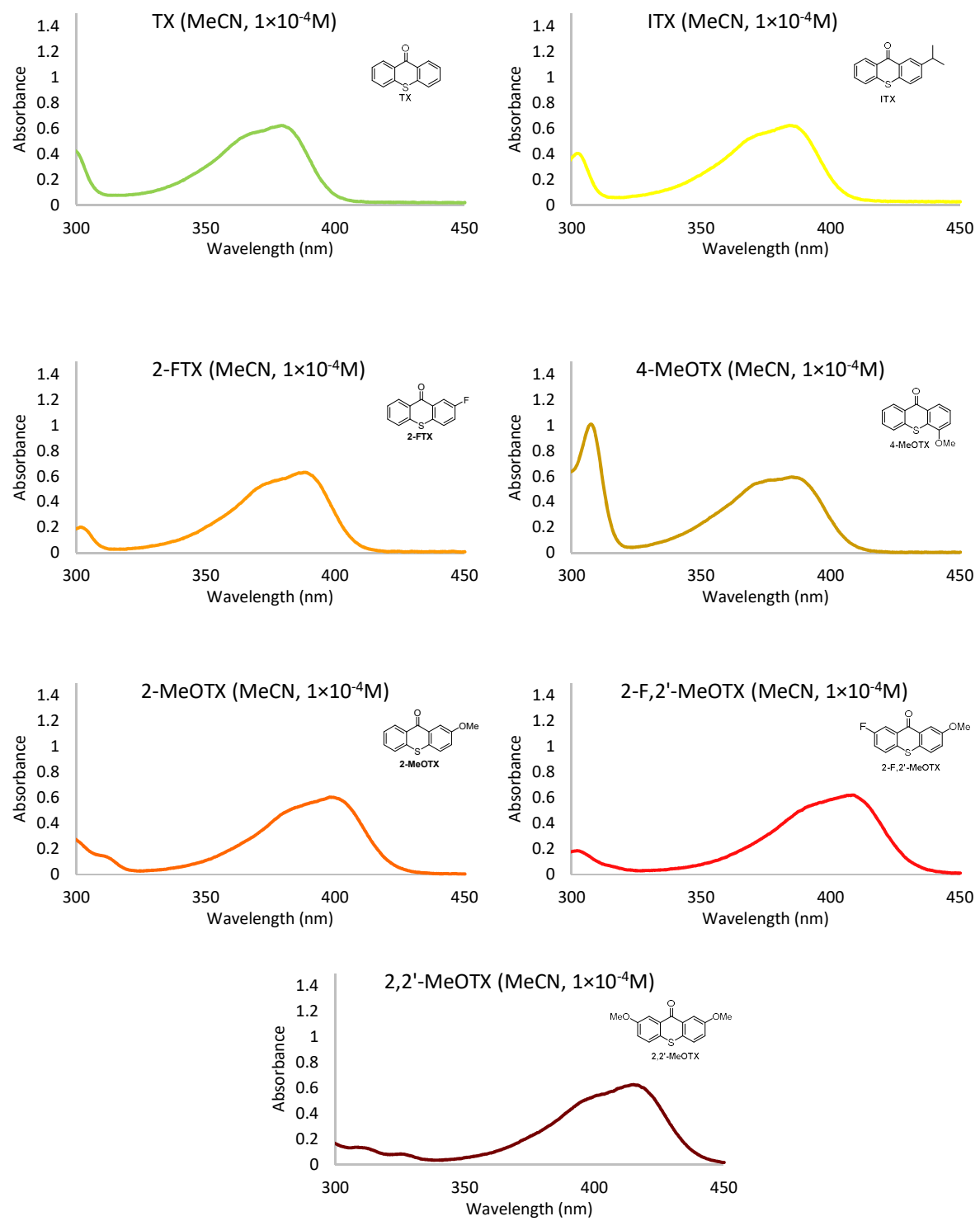

Figure S2: Individual UV-vis absorption spectra of TX derivatives 


\section{Triplet Measurements of Thioxanthone Derivatives}

\section{Low temperature ( $77 \mathrm{~K})$ emission measurement:}

The low temperature emission spectra were measured in FLS900 Fluorescence spectrometer (Edinburgh Instrument). The room temperature absorption spectra were measured in UV-Vis spectrometer (Agilent Cary 60). For all the measurements $10 \mu \mathrm{M}$ concentration was used. Methylcyclohexane (Alfa Aesar), 2-methyl tetrahydrofuran (Alfa Aesar) were used as received.

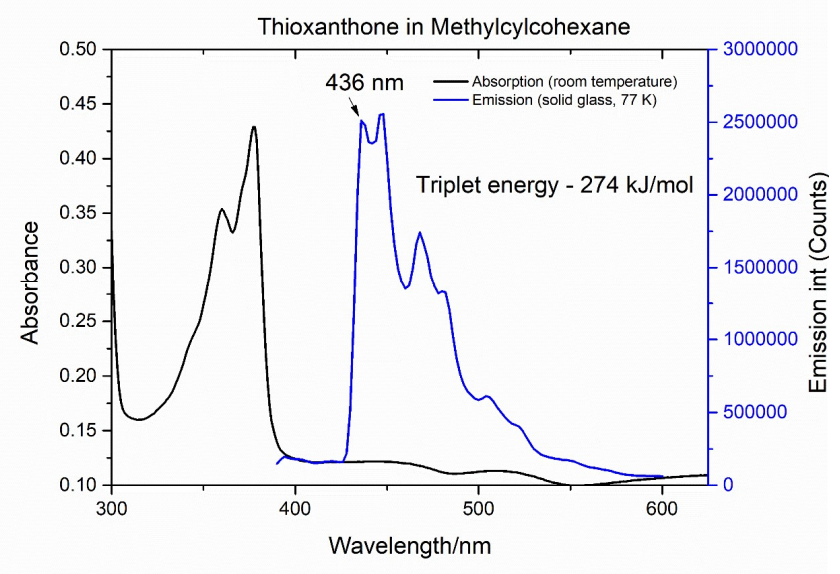

Figure S3: Room temperature absorption and glass temperature emission spectra of thioxathone in methylcyclohexane. The excitation wavelength was $380 \mathrm{~nm}$.

In Figure S3, the room temperature absorption and glass temperature emission spectra are presented for the thioxanthone. It is well known that the thioxanthone is nonemissive in nonpolar solvents at room temperature. Therefore, the strong red-shifted emission observed in nonpolar solvent (Methylcyclohexane) at glass temperature is safely assigned to the emission from the triplet state. The highest energy emission band $(436 \mathrm{~nm})$ is used as the lowest triplet energy and it matches well with the reported triplet energy of thioxanthone. The emission and absorption spectra of other molecules are presented in Figure S4 

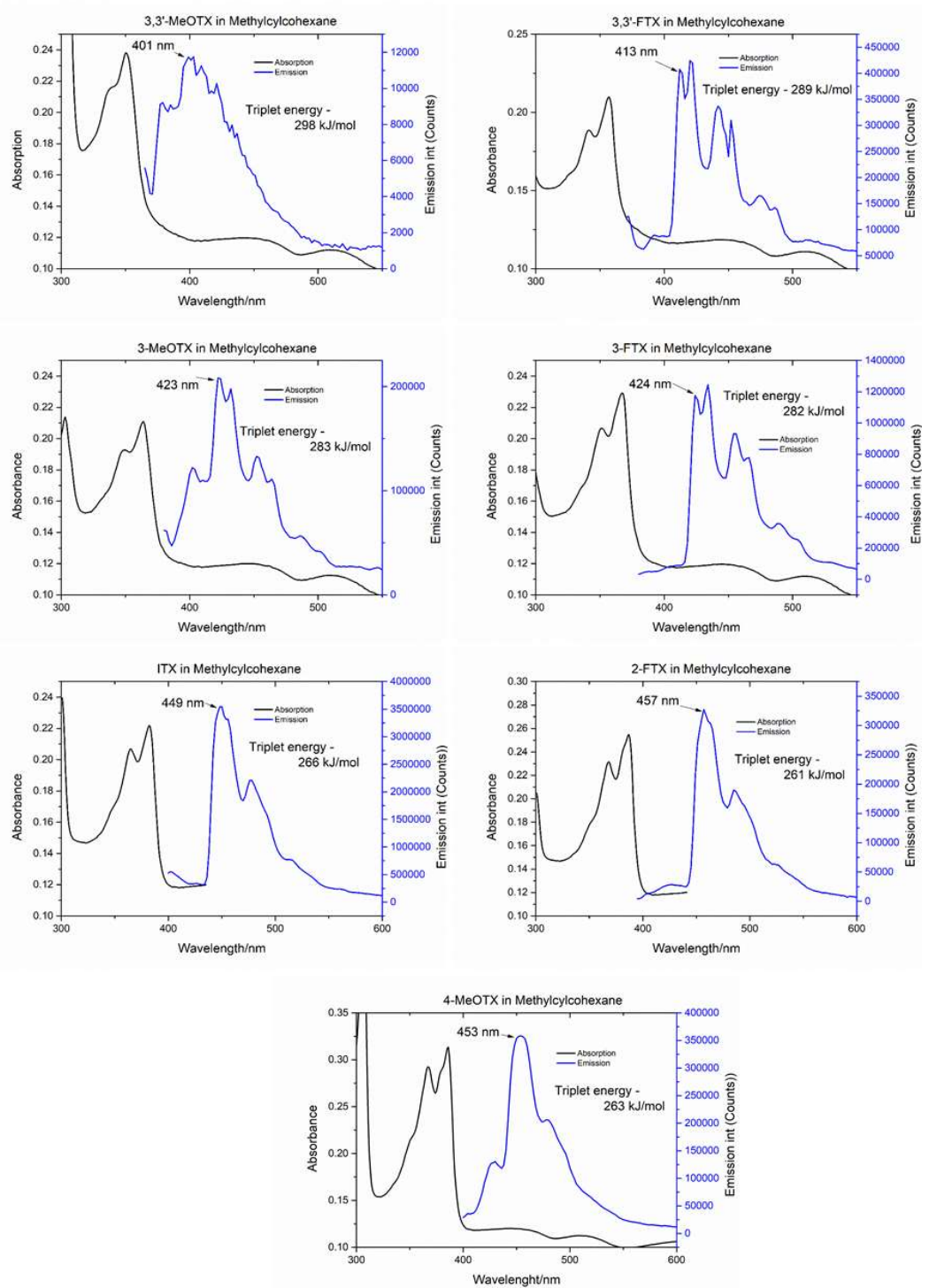

Figure S4. Room temperature absorption and glass temperature emission spectra of different thioxathone derivatives in methylcyclohexane. The lowest energy bands are mentioned and the calculated triplet energies are reported. The excitation wavelengths are: $350 \mathrm{~nm}$ (3,3'- MeOTX), $360 \mathrm{~nm}$ (3,3'-FTX), $370 \mathrm{~nm}$ (3-MeOTX), $375 \mathrm{~nm}$ (3-FTX), 380 $\mathrm{nm}$ (ITX), $385 \mathrm{~nm}(2-\mathrm{FTX}), 390 \mathrm{~nm}$ (4-MeOTX) respectively.

The emission results at 77K in 2-MeTHF for the last three derivatives, 2-MeOTX, 2-F, 2'-MeOTX, 2,2'MeOTX are shown in Figure S5 


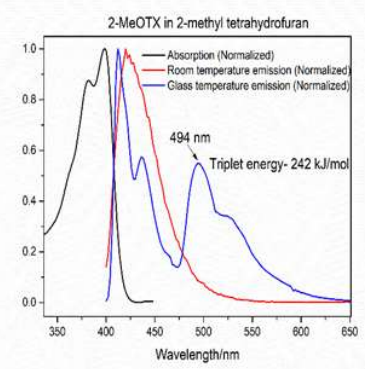

2-F 2 -MeOTX in 2-methyl tetrahydrofuran
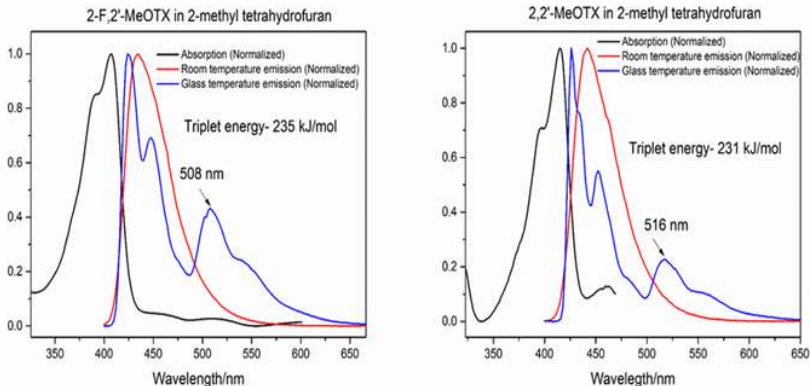

Figure S5. Room temperature absorption, room temperature emission and 77K emission of the thioxanthone derivatives in 2methyl tetrahydrofuran. For all the measurements $390 \mathrm{~nm}$ excitation wavelength was used. Here we have plotted all the spectra with $\mathrm{x}$-axis normalized.

\section{ps and ns TRIR Studies}

\section{Instrumentation}

We performed ps and ns time-resolved infrared (TRIR) measurements in order to measure the singlet and triplet lifetimes. All the measurements were performed in $\mathrm{CD}_{3} \mathrm{CN}(1 \mathrm{mM})$. Each solution was degassed using three freeze pump thaw cycles before time-resolved measurements. The sample Harrick cell (path length $400 \mu \mathrm{m}$ ) with $\mathrm{CaF}_{2}$ windows was continuously raster scan in order to avoid photodamage. The detailed description of the TRIR measurements at the Nottingham has been discussed in detail elsewhere. ${ }^{8}$ Breifly, $800 \mathrm{~nm}, 100 \mathrm{fs}, 80 \mathrm{MHz}$ fundamental pulses are generated with a commercial Ti:Sapphire oscillator (MaiTai). The input pulses are amplified in a Ti:Sapphire amplifier (Spitfire Pro/Spectra Physics) to produce $800 \mathrm{~nm}, 100 \mathrm{fs}, 1 \mathrm{kHz}, 2 \mathrm{~mJ}$ pulses. Half of the output is used to pump a TOPAS-C (Light Conversion) that produces tunable IR pulses using a difference frequency generator. The other part of the amplifier output is used to pump a harmonic generator (Timeplate tripler, Minioptic Technology) to produce $400 \mathrm{~nm}, 100 \mathrm{fs}$ pump pulses. For $355 \mathrm{~nm}$ picosecond experiments, we have used a second TOPAS output pumped by the $800 \mathrm{~nm}$ fundamental. The IR beam passes through a Ge beam splitter and half of the IR beam is reflected onto a single element MCT detector (Kolmar Technology) to serve as a reference and the other half is focused and overlaps with the pump beam at the sample position. The pump pulse was delayed relative to the probe pulse by using a translation stage (LMA Actuator, Aerotech, USA. The polarization of the pump pulse was set at the magic angle $\left(54.7^{\circ}\right)$ relative to the probe pulse to avoid rotational diffusion. For a measurement with a longer time delays a Q-switched Nd:YVO ns-laser (ACE- 25QSPXHP/MOPA, Advanced Optical Technology, UK) was employed as a pump source and this was synchronized relative to the Spitfire Pro amplifier output. The IR probe beam was dispersed with a spectrograph and detected with a 128 element $\mathrm{HgCdTe}$ linear array detector (Infrared Associates, USA). 


\section{ps (400 nm excitation) TRIR spectra and kinetics of ITX}

The ps and ns TRIR spectra of ITX in $\mathrm{CD}_{3} \mathrm{CN}$ as the photophysical properties (singlet lifetime, triplet quantum yield) are well known. The ps TRIR spectra of ITX in the $1650-1450 \mathrm{~cm}^{-1}$ region for selected time delays after $400 \mathrm{~nm}$ excitation were presented in Figure S6. The negative peaks at 1637 and 1592 $\mathrm{cm}^{-1}$ are associated with the ground state bleach and are assigned to $v(\mathrm{C}=\mathrm{O})$ and $v(\mathrm{C}=\mathrm{C})$ bands respectively. The transient peak at $1477 \mathrm{~cm}^{-1}$ appears immediately after the flash and is assigned to the singlet excited state. The $1477 \mathrm{~cm}^{-1}$ band decays at the same rate $(240 \pm 10 \mathrm{ps})$ as a new band at 1518 $\mathrm{cm}^{-1}$ grows in and this peak is assigned to the triplet state.
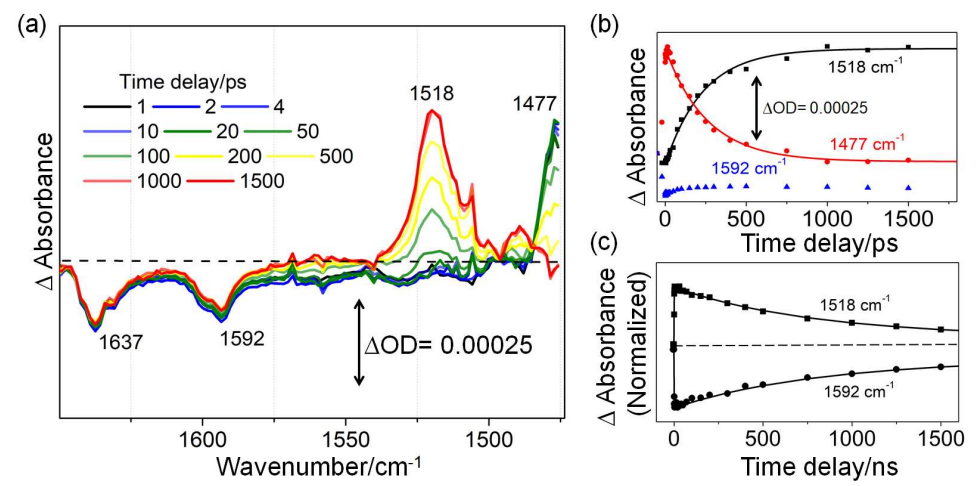

Figure S6. (a) ps-TRIR spectra of ITX for selected time delays in $\mathrm{CD}_{3} \mathrm{CN}$ following photoexcitation (400 nm). (b) and (c) show selected TRIR kinetic traces associated with the formation and decay of the parent $\left(1592 \mathrm{~cm}^{-1}\right)$, singlet $\left(1477 \mathrm{~cm}^{-1}\right)$ and triplet $(1518$ $\mathrm{cm}^{-1}$ ) excited state bands obtained from TRIR spectra. 


\section{Estimation of triplet quantum yield for ITX from the parent bleach recovery kinetics}

The triplet quantum yield ( $\left.\Phi_{\text {ISC }}\right)$ is estimated from the parent bleach recovery kinetics using the approximation that triplet quantum yield is given by the $\Delta \mathrm{A}^{\max } / \Delta \mathrm{A}^{\infty}$ ratio.

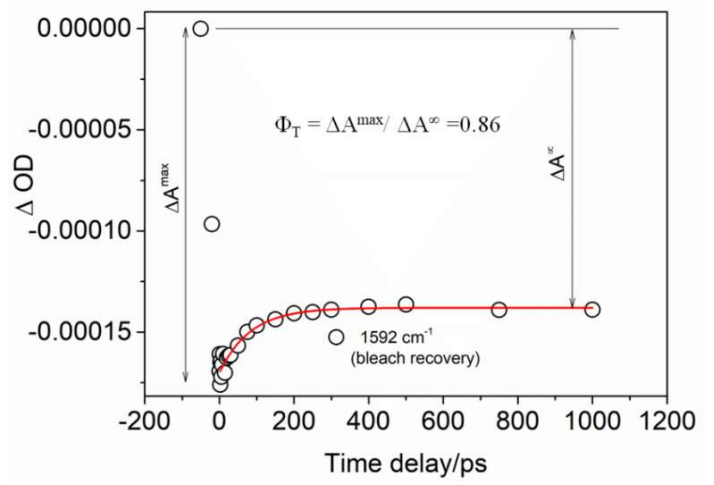

Figure S7. ps intensity kinetics of $1592 \mathrm{~cm}^{-1}$ band. The initial bleach recovery is associated with ground state recovery due to radiative (fluorescence) and nonradiative (internal conversion) decays. The bleach recovery at longer time is used to calculate the triplet quantum yield. 


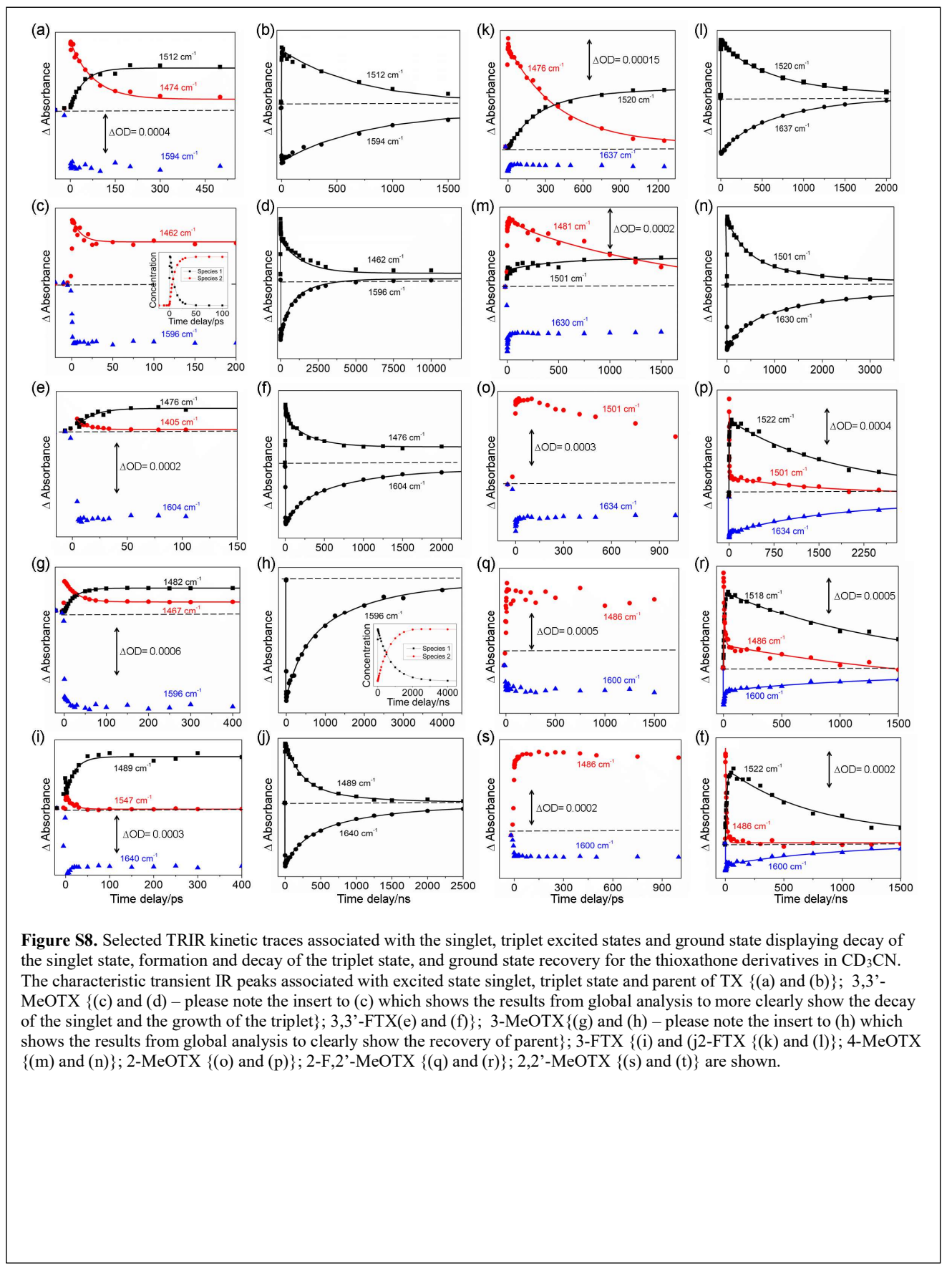


TD-DFT Calculations of Thioxanthone Derivatives

Calculations were carried out with Gaussian09W on a standard desktop PC (Octo-Core Intel i7-9700, 16 GB RAM) ${ }^{9}$

\section{Optimised co-ordinates}

\section{3,3'-MeOTX}

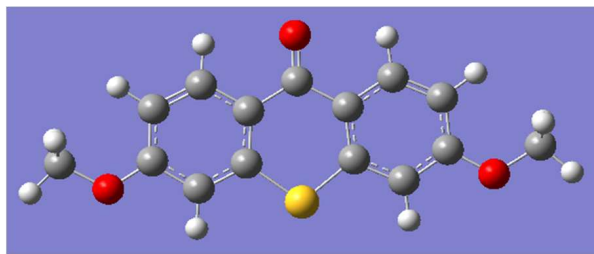

Charge $=0$ Multiplicity $=1$

\# opt b3lyp/6-31g(d,p)

scrf $=(\mathrm{cpcm}$, solvent=acetonitrile)

\# opt b3lyp/6-31g $(\mathrm{d}, \mathrm{p})$ geom=connectivity

\begin{tabular}{lrrr}
\hline C & 2.62616 & -1.20095 & -0.00017 \\
C & 1.39402 & -0.55507 & 0 \\
C & 1.28285 & 0.84041 & 0.00005 \\
C & 2.47053 & 1.60535 & 0.00005 \\
C & 3.72255 & 1.00171 & -0.00003 \\
C & 3.78835 & -0.40397 & -0.00007 \\
H & 2.72348 & -2.28645 & -0.00043 \\
H & 2.38366 & 2.69979 & 0.00015 \\
H & 4.62038 & 1.61058 & -0.0001 \\
$\mathrm{C}$ & 0 & 1.58152 & 0.00001 \\
O & 0 & 2.8042 & -0.0001 \\
$\mathrm{C}$ & -1.28284 & 0.84041 & 0.0001 \\
$\mathrm{C}$ & -1.39401 & -0.55506 & 0.00011 \\
$\mathrm{C}$ & -2.47052 & 1.60536 & 0.00015 \\
$\mathrm{C}$ & -2.62617 & -1.20095 & 0.00004 \\
$\mathrm{C}$ & -3.72255 & 1.00172 & 0.00011 \\
$\mathrm{H}$ & -2.38365 & 2.69979 & 0.00022 \\
$\mathrm{C}$ & -3.78835 & -0.40397 & -0.00004 \\
$\mathrm{H}$ & -2.72348 & -2.28644 & 0.00004 \\
$\mathrm{H}$ & -4.62037 & 1.61059 & 0.00022 \\
$\mathrm{~S}$ & 0 & -1.61602 & 0.00032 \\
$\mathrm{O}$ & 4.93884 & -1.14594 & 0.00012 \\
$\mathrm{O}$ & -4.93884 & -1.14593 & -0.00039 \\
$\mathrm{C}$ & 6.20772 & -0.44281 & -0.00029 \\
$\mathrm{H}$ & 6.30771 & 0.15996 & 0.90692 \\
$\mathrm{H}$ & 6.92256 & -1.27695 & 0.00003 \\
$\mathrm{H}$ & 6.30746 & 0.15922 & -0.90801 \\
$\mathrm{C}$ & -6.20774 & -0.44282 & -0.00018 \\
$\mathrm{H}$ & -6.30761 & 0.1599 & -0.90743 \\
$\mathrm{H}$ & -6.92257 & -1.27696 & -0.00055 \\
$\mathrm{H}$ & -6.30761 & 0.15926 & 0.90751 \\
\hline & & & \\
& & & \\
& & &
\end{tabular}

\begin{tabular}{lrrr} 
geom=connectivity & & \\
\hline $\mathrm{C}$ & 2.62328 & -1.20037 & -0.00502 \\
$\mathrm{C}$ & 1.39404 & -0.55274 & -0.01169 \\
$\mathrm{C}$ & 1.28096 & 0.84344 & -0.00732 \\
$\mathrm{C}$ & 2.47416 & 1.60622 & 0.0044 \\
$\mathrm{C}$ & 3.7217 & 1.00077 & 0.01178 \\
$\mathrm{C}$ & 3.79028 & -0.4068 & 0.00703 \\
$\mathrm{H}$ & 2.7164 & -2.2876 & -0.00855 \\
$\mathrm{H}$ & 2.39494 & 2.70044 & 0.00759 \\
$\mathrm{H}$ & 4.62526 & 1.60869 & 0.02098 \\
$\mathrm{C}$ & 0 & 1.57574 & -0.01455 \\
$\mathrm{O}$ & 0 & 2.80559 & -0.02539 \\
$\mathrm{C}$ & -1.28096 & 0.84344 & -0.00723 \\
$\mathrm{C}$ & -1.39404 & -0.55274 & -0.01175 \\
$\mathrm{C}$ & -2.47416 & 1.60621 & 0.00465 \\
$\mathrm{C}$ & -2.62328 & -1.20037 & -0.00519 \\
$\mathrm{C}$ & -3.7217 & 1.00076 & 0.01197 \\
$\mathrm{H}$ & -2.39494 & 2.70044 & 0.00801 \\
$\mathrm{C}$ & -3.79028 & -0.40681 & 0.00702 \\
$\mathrm{H}$ & -2.7164 & -2.2876 & -0.00895 \\
$\mathrm{H}$ & -4.62526 & 1.60869 & 0.02126 \\
$\mathrm{~S}$ & 0 & -1.61508 & -0.02879 \\
$\mathrm{O}$ & 4.93565 & -1.14493 & 0.01343 \\
$\mathrm{O}$ & -4.93564 & -1.14493 & 0.01336 \\
$\mathrm{C}$ & 6.21232 & -0.4448 & 0.02703 \\
$\mathrm{H}$ & 6.30693 & 0.15462 & 0.93764 \\
$\mathrm{H}$ & 6.92471 & -1.2814 & 0.03003 \\
$\mathrm{H}$ & 6.32249 & 0.16143 & -0.87729 \\
$\mathrm{C}$ & -6.21231 & -0.44479 & 0.02696 \\
$\mathrm{H}$ & -6.3225 & 0.16135 & -0.87741 \\
$\mathrm{H}$ & -6.9247 & -1.28139 & 0.0301 \\
$\mathrm{H}$ & -6.3069 & 0.1547 & 0.93752 \\
\hline & & & \\
\hline
\end{tabular}




\section{3,3'-FTX}

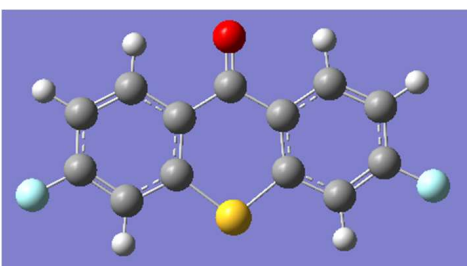

Charge $=0$ Multiplicity $=1$

\# opt b3lyp $/ 6-31 \mathrm{~g}(\mathrm{~d}, \mathrm{p})$ geom=connectivity

\begin{tabular}{lrrr}
\hline C & -1.26551 & -0.00002 & -2.63026 \\
C & -0.61501 & 0.00023 & -1.38956 \\
C & 0.77732 & 0.00019 & -1.28649 \\
C & 1.54813 & 0 & -2.47299 \\
C & 0.94041 & -0.00028 & -3.72298 \\
C & -0.46211 & -0.00035 & -3.77003 \\
H & -2.35447 & 0.00006 & -2.70765 \\
H & 2.64275 & 0.00013 & -2.38499 \\
H & 1.53502 & -0.00052 & -4.63664 \\
C & 1.52289 & 0.00026 & 0 \\
O & 2.74215 & 0.00029 & 0 \\
C & 0.77732 & 0.00019 & 1.28649 \\
C & -0.61501 & 0.00023 & 1.38956 \\
C & 1.54813 & 0 & 2.47299 \\
C & -1.26551 & -0.00002 & 2.63026 \\
C & 0.94041 & -0.00028 & 3.72298 \\
H & 2.64275 & 0.00013 & 2.38499 \\
C & -0.46211 & -0.00035 & 3.77003 \\
H & -2.35447 & 0.00006 & 2.70765 \\
H & 1.53502 & -0.00052 & 4.63664 \\
S & -1.6754 & 0.0007 & 0 \\
F & -1.0552 & -0.00064 & -4.96142 \\
F & -1.0552 & -0.00064 & 4.96142 \\
\hline & & &
\end{tabular}

\# opt b3lyp/6-31g(d,p)

$\mathrm{scrf}=(\mathrm{cpcm}$,solvent=acetonitrile)

geom=connectivity

\begin{tabular}{lrrr}
\hline C & -0.00061 & -1.26507 & -2.62752 \\
C & -0.00005 & -0.61344 & -1.38777 \\
C & 0.00053 & 0.78027 & -1.2855 \\
C & 0.00052 & 1.54896 & -2.47498 \\
C & -0.00005 & 0.93951 & -3.7233 \\
C & -0.0006 & -0.46314 & -3.76787 \\
H & -0.00104 & -2.35651 & -2.70291 \\
H & 0.00098 & 2.64344 & -2.39519 \\
H & -0.00007 & 1.53631 & -4.63782 \\
C & 0.00118 & 1.51891 & 0 \\
O & 0.00224 & 2.74415 & 0 \\
C & 0.00053 & 0.78027 & 1.2855 \\
C & -0.00005 & -0.61344 & 1.38777 \\
C & 0.00052 & 1.54896 & 2.47498 \\
C & -0.00061 & -1.26507 & 2.62752 \\
C & -0.00005 & 0.93951 & 3.7233 \\
H & 0.00098 & 2.64344 & 2.39519 \\
C & -0.0006 & -0.46314 & 3.76787 \\
H & -0.00104 & -2.35651 & 2.70291 \\
H & -0.00007 & 1.53631 & 4.63782 \\
S & -0.00005 & -1.67511 & 0 \\
F & -0.00115 & -1.05758 & -4.95934 \\
F & -0.00115 & -1.05758 & 4.95934 \\
\hline & & &
\end{tabular}




\section{3-MeOTX}

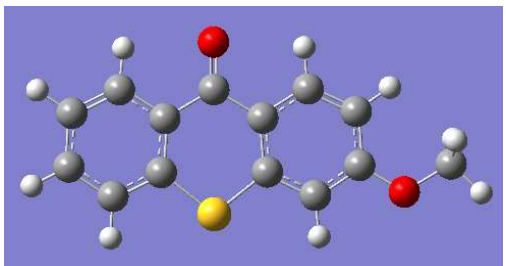

Charge $=0$ Multiplicity $=1$

\begin{tabular}{lrrr}
\multicolumn{5}{c}{ \# opt b3lyp/6-31g(d,p) geom=connectivity } \\
\hline C & 3.24792 & -1.5541 & -0.00014 \\
C & 2.05814 & -0.81243 & 0.00008 \\
C & 2.06601 & 0.582 & 0.00002 \\
C & 3.31133 & 1.24643 & -0.00026 \\
C & 4.50088 & 0.52347 & -0.00049 \\
C & 4.46827 & -0.87943 & -0.00044 \\
H & 3.22775 & -2.64447 & -0.0001 \\
H & 3.31948 & 2.34256 & -0.00027 \\
H & 5.45727 & 1.04449 & -0.00073 \\
H & 5.40137 & -1.44374 & -0.00063 \\
C & 0.8388 & 1.42904 & 0.00021 \\
O & 0.9423 & 2.64574 & 0.00033 \\
C & -0.49608 & 0.79217 & 0.00022 \\
C & -0.71805 & -0.5909 & 0.00025 \\
C & -1.61995 & 1.64938 & 0.00017 \\
C & -1.99818 & -1.13565 & 0.00013 \\
C & -2.91551 & 1.14761 & 0.00005 \\
H & -1.44646 & 2.73346 & 0.00022 \\
C & -3.09324 & -0.24887 & -0.0001 \\
H & -2.18157 & -2.21006 & 0.00022 \\
H & -3.76227 & 1.82586 & 0.00009 \\
S & 0.5868 & -1.75802 & 0.0005 \\
O & -4.29878 & -0.89621 & -0.00054 \\
C & -5.50802 & -0.09444 & -0.00037 \\
H & -5.5598 & 0.514 & -0.90783 \\
H & -6.28674 & -0.86938 & -0.00053 \\
H & -5.55979 & 0.51373 & 0.90726 \\
\hline & & & \\
& & &
\end{tabular}

\# opt b3lyp/6-31g(d,p)

$\mathrm{scrf}=(\mathrm{cpcm}$,solvent=acetonitrile $)$

geom=connectivity

\begin{tabular}{lrrr} 
geom=connectivity & & \\
\hline C & 3.24499 & -1.55372 & 0.02514 \\
C & 2.05806 & -0.81065 & -0.0122 \\
C & 2.06497 & 0.58505 & -0.00471 \\
C & 3.31209 & 1.24684 & 0.04361 \\
C & 4.49912 & 0.52204 & 0.08203 \\
C & 4.46598 & -0.88101 & 0.07231 \\
H & 3.22702 & -2.64668 & 0.01852 \\
H & 3.32918 & 2.34163 & 0.04977 \\
H & 5.45822 & 1.04176 & 0.11952 \\
H & 5.39999 & -1.44787 & 0.10233 \\
C & 0.83809 & 1.42323 & -0.04614 \\
O & 0.94303 & 2.64581 & -0.09475 \\
C & -0.49369 & 0.79517 & -0.02423 \\
C & -0.71684 & -0.5888 & -0.0329 \\
C & -1.62312 & 1.65052 & 0.00432 \\
C & -1.9945 & -1.13542 & -0.0152 \\
C & -2.91401 & 1.14628 & 0.02423 \\
H & -1.45745 & 2.735 & 0.01046 \\
C & -3.0942 & -0.25196 & 0.01417 \\
H & -2.17371 & -2.21179 & -0.0226 \\
H & -3.76642 & 1.82359 & 0.04673 \\
S & 0.58746 & -1.75608 & -0.07694 \\
O & -4.29463 & -0.89578 & 0.03144 \\
C & -5.51113 & -0.09611 & 0.06727 \\
H & -5.58576 & 0.52173 & -0.83281 \\
H & -6.28803 & -0.87308 & 0.07763 \\
H & -5.5443 & 0.50399 & 0.98176 \\
\hline & & &
\end{tabular}




\section{3-FTX}

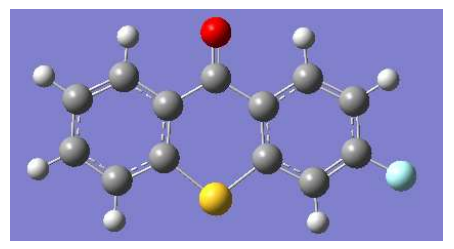

Charge $=0$ Multiplicity $=1$

\# opt b3lyp/6-31g $(\mathrm{d}, \mathrm{p})$ geom=connectivity

\begin{tabular}{lrrr}
\hline C & -2.86991 & -1.53686 & -0.00021 \\
C & -1.67411 & -0.80513 & 0.00014 \\
C & -1.67041 & 0.58961 & 0.00013 \\
C & -2.91065 & 1.26464 & -0.00011 \\
C & -4.10568 & 0.55125 & -0.00055 \\
C & -4.08461 & -0.852 & -0.00066 \\
H & -2.85925 & -2.62765 & -0.0001 \\
H & -2.91039 & 2.36092 & 0.00012 \\
H & -5.05828 & 1.07997 & -0.00097 \\
H & -5.02275 & -1.40858 & -0.00105 \\
C & -0.43878 & 1.42617 & 0.00025 \\
O & -0.52455 & 2.6425 & 0.0003 \\
C & 0.89759 & 0.77425 & 0.00025 \\
C & 1.09923 & -0.60766 & 0.00022 \\
C & 2.02619 & 1.62759 & 0.00019 \\
C & 2.38416 & -1.16727 & -0.00009 \\
C & 3.31644 & 1.11109 & -0.00014 \\
H & 1.86006 & 2.71291 & 0.00047 \\
C & 3.46303 & -0.28469 & -0.00038 \\
H & 2.53818 & -2.24783 & -0.00004 \\
H & 4.18511 & 1.76908 & -0.00031 \\
S & -0.2112 & -1.76292 & 0.00073 \\
F & 4.69422 & -0.79091 & -0.00074 \\
\hline & & &
\end{tabular}

\# opt b3lyp/6-31g(d,p)

$\mathrm{scrf}=(\mathrm{cpcm}$,solvent=acetonitrile)

geom=connectivity

\begin{tabular}{lrrr}
\hline C & -2.86544 & -1.53659 & -0.02403 \\
C & -1.6725 & -0.8033 & 0.01751 \\
C & -1.66888 & 0.59281 & 0.00869 \\
C & -2.91098 & 1.26483 & -0.04561 \\
C & -4.10302 & 0.54922 & -0.08867 \\
C & -4.08074 & -0.85427 & -0.07726 \\
H & -2.85644 & -2.62987 & -0.01613 \\
H & -2.91949 & 2.35985 & -0.05244 \\
H & -5.05817 & 1.07618 & -0.13098 \\
H & -5.01927 & -1.41379 & -0.11078 \\
C & -0.43875 & 1.42123 & 0.05625 \\
O & -0.52457 & 2.64199 & 0.12211 \\
C & 0.89627 & 0.77738 & 0.01898 \\
C & 1.09749 & -0.60588 & 0.02967 \\
C & 2.02721 & 1.62867 & -0.02528 \\
C & 2.38107 & -1.16681 & 0.00034 \\
C & 3.31542 & 1.11016 & -0.05696 \\
H & 1.86937 & 2.71441 & -0.03347 \\
C & 3.46 & -0.28584 & -0.04238 \\
H & 2.53377 & -2.24981 & 0.00965 \\
H & 4.1845 & 1.7701 & -0.09151 \\
S & -0.21112 & -1.76066 & 0.09169 \\
F & 4.69081 & -0.79357 & -0.07176 \\
\hline
\end{tabular}


TX

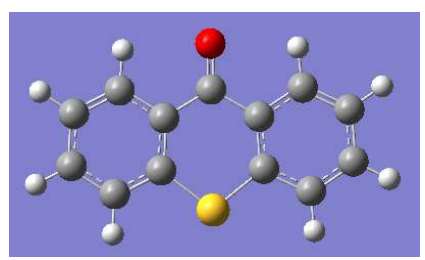

Charge $=0$ Multiplicity $=1$

\# opt b3lyp/6-31g(d,p) geom=connectivity

\begin{tabular}{lrrr}
\hline C & 1.40696 & -0.00037 & 2.63682 \\
C & 0.76295 & 0.00015 & 1.39092 \\
C & -0.62817 & 0.00023 & 1.28808 \\
C & -1.38992 & 0.00003 & 2.47735 \\
C & -0.76414 & -0.00058 & 3.72009 \\
C & 0.63742 & -0.00089 & 3.7991 \\
H & 2.4956 & -0.00032 & 2.70314 \\
H & -2.48318 & 0.00046 & 2.39839 \\
H & -1.3591 & -0.00103 & 4.63242 \\
H & 1.12515 & -0.00145 & 4.77459 \\
C & -1.3748 & 0.00037 & 0 \\
O & -2.59423 & 0.00055 & 0 \\
C & -0.62817 & 0.00023 & -1.28808 \\
C & 0.76295 & 0.00015 & -1.39092 \\
C & -1.38992 & 0.00003 & -2.47735 \\
C & 1.40696 & -0.00037 & -2.63682 \\
C & -0.76414 & -0.00058 & -3.72009 \\
H & -2.48318 & 0.00046 & -2.39839 \\
C & 0.63742 & -0.00089 & -3.7991 \\
H & 2.4956 & -0.00032 & -2.70314 \\
H & -1.3591 & -0.00103 & -4.63242 \\
H & 1.12515 & -0.00145 & -4.77459 \\
S & 1.82154 & 0.00095 & 0 \\
\hline
\end{tabular}

\# opt b3lyp/6-31g(d,p)

$\mathrm{scrf}=(\mathrm{cpcm}$, solvent=acetonitrile $)$ geom=connectivity

\begin{tabular}{lrrr}
\hline C & 1.4066 & -0.04575 & 2.62959 \\
C & 0.76095 & 0.03354 & 1.38872 \\
C & -0.63164 & 0.02252 & 1.28548 \\
C & -1.39091 & -0.07579 & 2.4732 \\
C & -0.76236 & -0.15809 & 3.71129 \\
C & 0.63923 & -0.14175 & 3.79008 \\
H & 2.49737 & -0.03504 & 2.69853 \\
H & -2.48344 & -0.08476 & 2.40279 \\
H & -1.35592 & -0.23467 & 4.62405 \\
H & 1.12987 & -0.20574 & 4.76472 \\
C & -1.36714 & 0.11568 & 0 \\
O & -2.58404 & 0.26102 & 0 \\
C & -0.63164 & 0.02252 & -1.28548 \\
C & 0.76095 & 0.03354 & -1.38872 \\
C & -1.39091 & -0.07579 & -2.4732 \\
C & 1.4066 & -0.04575 & -2.62959 \\
C & -0.76236 & -0.15809 & -3.71129 \\
H & -2.48344 & -0.08476 & -2.40279 \\
C & 0.63923 & -0.14175 & -3.79008 \\
H & 2.49737 & -0.03504 & -2.69853 \\
H & -1.35592 & -0.23467 & -4.62405 \\
H & 1.12987 & -0.20574 & -4.76472 \\
S & 1.81481 & 0.17012 & 0 \\
\hline
\end{tabular}


ITX

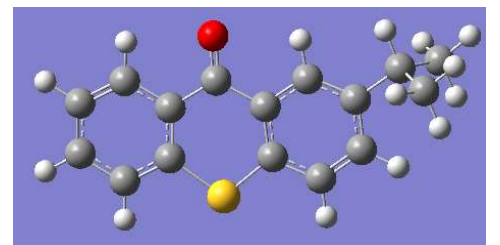

Charge $=0$ Multiplicity $=1$

\begin{tabular}{|c|c|c|c|}
\hline \multicolumn{4}{|c|}{ \# opt b3lyp $/ 6-31 \mathrm{~g}(\mathrm{~d}, \mathrm{p})$ geom=connectivity } \\
\hline C & -3.86202 & -1.09679 & -0.00092 \\
\hline $\mathrm{C}$ & -2.5326 & -0.64939 & 0.00003 \\
\hline $\mathrm{C}$ & -2.22007 & 0.71015 & 0.00029 \\
\hline C & -3.28036 & 1.64321 & -0.00047 \\
\hline $\mathrm{C}$ & -4.60361 & 1.21337 & -0.00142 \\
\hline $\mathrm{C}$ & -4.89413 & -0.16011 & -0.00163 \\
\hline $\mathrm{H}$ & -4.0924 & -2.16274 & -0.00114 \\
\hline $\mathrm{H}$ & -3.03659 & 2.71181 & -0.00026 \\
\hline $\mathrm{H}$ & -5.41494 & 1.93979 & -0.00199 \\
\hline $\mathrm{H}$ & -5.93216 & -0.49441 & -0.00235 \\
\hline C & -0.83396 & 1.25346 & 0.00144 \\
\hline $\mathrm{O}$ & -0.65069 & 2.45916 & 0.00282 \\
\hline $\mathrm{C}$ & 0.32743 & 0.31998 & 0.00075 \\
\hline C & 0.21571 & -1.06966 & 0.00052 \\
\hline C & 1.61587 & 0.89362 & 0.00041 \\
\hline C & 1.35208 & -1.89101 & 0.00001 \\
\hline C & 2.76016 & 0.09366 & -0.00007 \\
\hline $\mathrm{H}$ & 1.69462 & 1.9871 & 0.00058 \\
\hline C & 2.61642 & -1.30745 & -0.00027 \\
\hline $\mathrm{H}$ & 1.25493 & -2.97748 & -0.00019 \\
\hline $\mathrm{H}$ & 3.50455 & -1.94049 & -0.00065 \\
\hline S & -1.31843 & -1.90637 & 0.001 \\
\hline C & 4.13389 & 0.73704 & -0.0004 \\
\hline $\mathrm{H}$ & 4.00983 & 1.85258 & 0.00059 \\
\hline C & 4.90791 & 0.35186 & 1.26616 \\
\hline $\mathrm{H}$ & 5.86527 & 0.88214 & 1.31935 \\
\hline $\mathrm{H}$ & 4.33999 & 0.6033 & 2.16976 \\
\hline $\mathrm{H}$ & 5.12718 & -0.72033 & 1.30552 \\
\hline C & 4.90628 & 0.35387 & -1.26855 \\
\hline $\mathrm{H}$ & 4.33779 & 0.60804 & -2.17103 \\
\hline $\mathrm{H}$ & 5.86423 & 0.88312 & -1.32142 \\
\hline $\mathrm{H}$ & 5.12424 & -0.71849 & -1.31061 \\
\hline
\end{tabular}

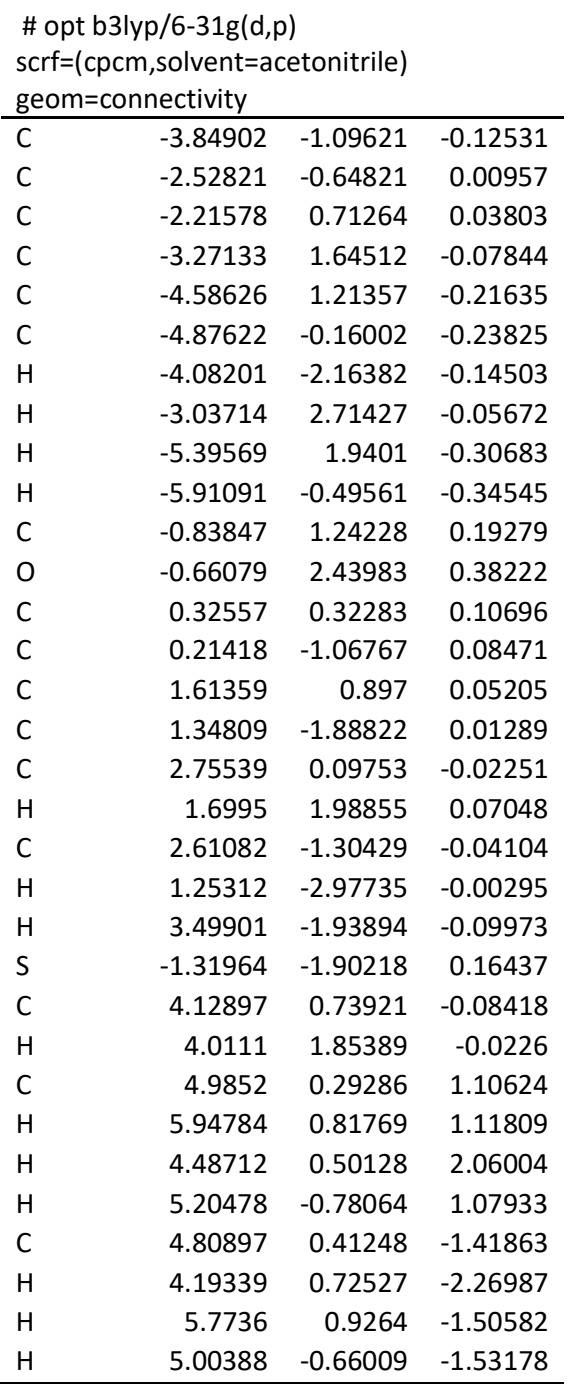




\section{2-FTX}

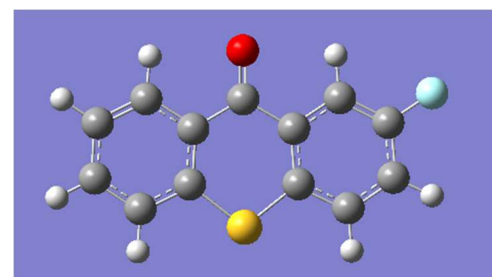

Charge $=0$ Multiplicity $=1$

\begin{tabular}{lrrr} 
\# opt b3lyp/6-31g(d,p) geom=connectivity \\
\hline C & -3.08091 & -1.24277 & -0.00041 \\
C & -1.7846 & -0.70758 & -0.00006 \\
C & -1.56353 & 0.66987 & 0.00018 \\
C & -2.68384 & 1.53054 & 0.00038 \\
C & -3.97517 & 1.01293 & 0.00011 \\
C & -4.1733 & -0.37686 & -0.00032 \\
H & -3.24037 & -2.32191 & -0.00076 \\
H & -2.51239 & 2.6133 & 0.00076 \\
H & -4.83368 & 1.68364 & 0.00033 \\
H & -5.18705 & -0.77983 & -0.00075 \\
C & -0.21906 & 1.30439 & -0.0001 \\
O & -0.10883 & 2.51738 & -0.00052 \\
C & 1.00592 & 0.4461 & 0.0001 \\
C & 0.98425 & -0.94877 & -0.00004 \\
C & 2.24925 & 1.11072 & 0.00017 \\
C & 2.16926 & -1.7056 & -0.00036 \\
C & 3.41112 & 0.34554 & -0.00002 \\
H & 2.27317 & 2.20757 & 0.00038 \\
C & 3.40132 & -1.0592 & -0.00036 \\
H & 2.13159 & -2.79755 & -0.00065 \\
H & 4.3327 & -1.62712 & -0.0007 \\
S & -0.49077 & -1.88201 & 0.00052 \\
F & 4.59052 & 0.9688 & 0.0002 \\
\hline & & &
\end{tabular}

\# opt b3lyp/6-31g(d,p)

$\mathrm{scrf}=(\mathrm{cpcm}$, solvent=acetonitrile) geom=connectivity

\begin{tabular}{lrrr} 
geom=connectivity & & \\
\hline C & -3.06901 & -1.24197 & -0.08992 \\
C & -1.78015 & -0.70545 & 0.02753 \\
C & -1.55921 & 0.67385 & 0.03305 \\
C & -2.67528 & 1.53284 & -0.08703 \\
C & -3.95936 & 1.0124 & -0.20742 \\
C & -4.1571 & -0.37762 & -0.20767 \\
H & -3.23094 & -2.32309 & -0.09247 \\
H & -2.51271 & 2.6155 & -0.08222 \\
H & -4.8164 & 1.68199 & -0.30094 \\
H & -5.16794 & -0.7831 & -0.30179 \\
C & -0.22099 & 1.29491 & 0.16717 \\
O & -0.11086 & 2.49963 & 0.35134 \\
C & 1.0032 & 0.44832 & 0.06471 \\
C & 0.98112 & -0.94695 & 0.06601 \\
C & 2.24426 & 1.11272 & -0.03002 \\
C & 2.16281 & -1.70509 & -0.01961 \\
C & 3.40036 & 0.34546 & -0.11682 \\
H & 2.27354 & 2.20738 & -0.03058 \\
C & 3.39112 & -1.05992 & -0.11246 \\
H & 2.12674 & -2.79999 & -0.01592 \\
H & 4.3198 & -1.63261 & -0.18156 \\
S & -0.49179 & -1.87473 & 0.19617 \\
F & 4.57699 & 0.97018 & -0.20767 \\
\hline & & & \\
\hline & & & \\
& &
\end{tabular}




\section{4-MeOTX}

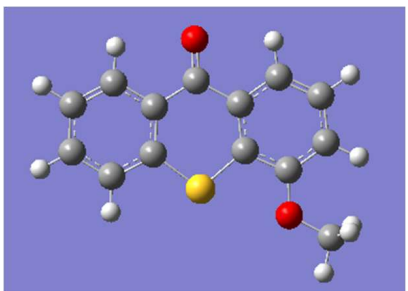

Charge $=0$ Multiplicity $=1$

\# opt b3lyp $/ 6-31 \mathrm{~g}(\mathrm{~d}, \mathrm{p})$ geom=connectivity

\begin{tabular}{lrrr}
\hline C & -2.60603 & -1.85527 & 0.00018 \\
C & -1.60776 & -0.86795 & -0.00003 \\
C & -1.92972 & 0.49051 & -0.00004 \\
C & -3.29452 & 0.85874 & 0.00007 \\
C & -4.29152 & -0.11016 & 0.0002 \\
C & -3.94477 & -1.47141 & 0.00029 \\
H & -2.34187 & -2.91343 & 0.00028 \\
H & -3.54782 & 1.925 & 0.00005 \\
H & -5.34022 & 0.18248 & 0.00023 \\
H & -4.72876 & -2.22942 & 0.00046 \\
C & -0.93247 & 1.5929 & -0.00013 \\
O & -1.29479 & 2.75645 & -0.00021 \\
C & 0.52766 & 1.26635 & -0.00007 \\
C & 1.00919 & -0.03601 & -0.00012 \\
C & 1.44515 & 2.33899 & 0.00007 \\
C & 2.40661 & -0.27098 & 0 \\
C & 2.81541 & 2.09764 & 0.0002 \\
H & 1.05408 & 3.36104 & 0.00008 \\
C & 3.31614 & 0.78584 & 0.00021 \\
H & 3.5152 & 2.93417 & 0.00028 \\
H & 4.38801 & 0.61371 & 0.00043 \\
S & 0.03342 & -1.47152 & -0.00039 \\
O & 2.69715 & -1.61553 & -0.00016 \\
C & 4.09499 & -1.99939 & 0.00025 \\
H & 4.02185 & -3.09565 & -0.00003 \\
H & 4.58823 & -1.63963 & -0.90703 \\
H & 4.58757 & -1.64002 & 0.90804 \\
\hline & & &
\end{tabular}

\# opt b3lyp/6-31g(d,p)

$\mathrm{scrf}=(\mathrm{cpcm}$, solvent=acetonitrile $)$

geom=connectivity

\begin{tabular}{lrrr}
\hline $\mathrm{C}$ & -2.57423 & -1.86103 & -0.07486 \\
$\mathrm{C}$ & -1.59993 & -0.86837 & 0.08282 \\
$\mathrm{C}$ & -1.9252 & 0.49054 & 0.03345 \\
$\mathrm{C}$ & -3.27223 & 0.85165 & -0.18823 \\
$\mathrm{C}$ & -4.24862 & -0.1262 & -0.35237 \\
$\mathrm{C}$ & -3.8998 & -1.48434 & -0.29345 \\
$\mathrm{H}$ & -2.31035 & -2.92077 & -0.03224 \\
$\mathrm{H}$ & -3.53705 & 1.91297 & -0.22716 \\
$\mathrm{H}$ & -5.28753 & 0.16009 & -0.52565 \\
$\mathrm{H}$ & -4.66961 & -2.24969 & -0.42163 \\
$\mathrm{C}$ & -0.93536 & 1.5808 & 0.2141 \\
$\mathrm{O}$ & -1.29926 & 2.71921 & 0.47094 \\
$\mathrm{C}$ & 0.5186 & 1.27555 & 0.06017 \\
$\mathrm{C}$ & 1.00701 & -0.02706 & 0.11686 \\
$\mathrm{C}$ & 1.41659 & 2.33818 & -0.14709 \\
$\mathrm{C}$ & 2.39059 & -0.26996 & -0.03354 \\
$\mathrm{C}$ & 2.78247 & 2.08898 & -0.29642 \\
$\mathrm{H}$ & 1.03481 & 3.36092 & -0.18881 \\
$\mathrm{C}$ & 3.28576 & 0.78451 & -0.2419 \\
$\mathrm{H}$ & 3.47141 & 2.92258 & -0.45741 \\
$\mathrm{H}$ & 4.35402 & 0.60526 & -0.36206 \\
$\mathrm{~S}$ & 0.0296 & -1.43686 & 0.39568 \\
$\mathrm{O}$ & 2.69578 & -1.60522 & 0.05453 \\
$\mathrm{C}$ & 4.07968 & -1.99726 & -0.16293 \\
$\mathrm{H}$ & 4.02166 & -3.08965 & -0.06086 \\
$\mathrm{H}$ & 4.40306 & -1.71393 & -1.16907 \\
$\mathrm{H}$ & 4.72194 & -1.56581 & 0.6106 \\
\hline
\end{tabular}




\section{2-MeOTX}

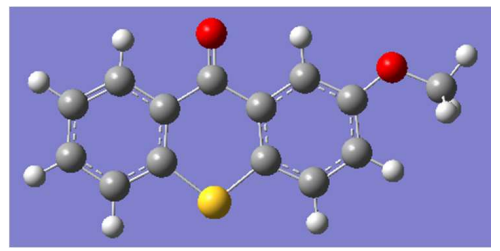

Charge $=0$ Multiplicity $=1$

\# opt b3lyp/6-31g(d,p) geom=connectivity

\begin{tabular}{lrrr}
\hline C & -3.50144 & -1.18383 & -0.00018 \\
C & -2.19039 & -0.68401 & 0.00001 \\
C & -1.93311 & 0.68723 & 0.00007 \\
C & -3.03054 & 1.5772 & -0.00005 \\
C & -4.33516 & 1.0948 & -0.00028 \\
C & -4.57008 & -0.28953 & -0.00035 \\
H & -3.68865 & -2.25826 & -0.0002 \\
H & -2.83012 & 2.65478 & 0.00006 \\
H & -5.17514 & 1.78787 & -0.0004 \\
H & -5.59398 & -0.66512 & -0.00055 \\
C & -0.57273 & 1.28704 & 0.00023 \\
O & -0.43445 & 2.49723 & 0.00047 \\
C & 0.63328 & 0.39803 & 0.00008 \\
C & 0.571 & -1.00042 & 0.00014 \\
C & 1.88423 & 1.02421 & -0.00005 \\
C & 1.73405 & -1.78002 & 0.00008 \\
C & 3.04999 & 0.23546 & -0.00012 \\
H & 1.9586 & 2.11728 & -0.00009 \\
C & 2.98724 & -1.1672 & -0.00011 \\
H & 1.67292 & -2.87084 & 0.00022 \\
H & 3.88781 & -1.77444 & -0.00025 \\
S & -0.9292 & -1.89228 & 0.00025 \\
O & 4.20166 & 0.98774 & -0.00022 \\
C & 5.46883 & 0.28653 & -0.00019 \\
H & 5.57235 & -0.31474 & -0.90772 \\
H & 6.18253 & 1.12212 & -0.00017 \\
H & 5.57231 & -0.3147 & 0.90739 \\
\hline & & & \\
\hline
\end{tabular}

\# opt b3lyp/6-31g(d,p) $\mathrm{scrf}=(\mathrm{cpcm}$, solvent=acetonitrile $)$ geom=connectivity

\begin{tabular}{lrrr} 
geom=connectivity & & \\
\hline C & -3.45545 & -1.17913 & -0.24409 \\
C & -2.17633 & -0.68085 & 0.0274 \\
C & -1.91848 & 0.69274 & 0.05914 \\
C & -2.98146 & 1.58504 & -0.19642 \\
C & -4.25694 & 1.10086 & -0.47359 \\
C & -4.49473 & -0.28182 & -0.49522 \\
H & -3.64811 & -2.2545 & -0.26524 \\
H & -2.7899 & 2.66205 & -0.17133 \\
H & -5.07508 & 1.79541 & -0.67262 \\
H & -5.49806 & -0.6576 & -0.71179 \\
C & -0.58397 & 1.26067 & 0.36613 \\
O & -0.46493 & 2.41909 & 0.73578 \\
C & 0.62604 & 0.39789 & 0.19653 \\
C & 0.56207 & -0.99959 & 0.18341 \\
C & 1.86542 & 1.03002 & 0.05057 \\
C & 1.71676 & -1.77888 & 0.03362 \\
C & 3.02163 & 0.24216 & -0.10465 \\
H & 1.94201 & 2.11937 & 0.06004 \\
C & 2.95762 & -1.16229 & -0.11126 \\
H & 1.65694 & -2.87228 & 0.02629 \\
H & 3.85584 & -1.76898 & -0.22951 \\
S & -0.94074 & -1.86877 & 0.38675 \\
O & 4.16404 & 0.99116 & -0.23989 \\
C & 5.42337 & 0.28963 & -0.42325 \\
H & 5.40349 & -0.29435 & -1.34844 \\
H & 6.1343 & 1.1236 & -0.50136 \\
H & 5.64427 & -0.33302 & 0.44886 \\
\hline & & &
\end{tabular}




\section{2-F,2'-MeOTX}

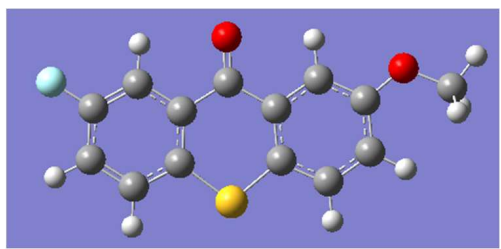

Charge $=0$ Multiplicity $=1$

\# opt b3lyp/6-31g(d,p) geom=connectivity

\begin{tabular}{lrrr} 
\# opt b3lyp $/ 6-31 \mathrm{~g}(\mathrm{~d}, \mathrm{p})$ & geom=connectivity \\
\hline $\mathrm{C}$ & 3.07115 & 1.524 & -0.09087 \\
$\mathrm{C}$ & 1.80549 & 0.92801 & 0.04938 \\
$\mathrm{C}$ & 1.64984 & -0.45835 & 0.08347 \\
$\mathrm{C}$ & 2.79029 & -1.27946 & -0.02751 \\
$\mathrm{C}$ & 4.03352 & -0.67114 & -0.16898 \\
$\mathrm{C}$ & 4.20333 & 0.72289 & -0.20218 \\
H & 3.17288 & 2.61146 & -0.11585 \\
H & 2.67577 & -2.36943 & 0.00659 \\
H & 5.19426 & 1.16503 & -0.3131 \\
$\mathrm{C}$ & 0.33341 & -1.14607 & 0.24519 \\
O & 0.28972 & -2.34254 & 0.45711 \\
$\mathrm{C}$ & -0.92881 & -0.35156 & 0.12152 \\
$\mathrm{C}$ & -0.96363 & 1.04778 & 0.08877 \\
$\mathrm{C}$ & -2.1276 & -1.06703 & 0.04126 \\
$\mathrm{C}$ & -2.17438 & 1.74152 & -0.02182 \\
$\mathrm{C}$ & -3.3423 & -0.36358 & -0.07142 \\
H & -2.1271 & -2.16186 & 0.07242 \\
$\mathrm{C}$ & -3.37754 & 1.03975 & -0.10244 \\
H & -2.18992 & 2.83374 & -0.04819 \\
H & -4.31576 & 1.58065 & -0.18861 \\
$\mathrm{~S}$ & 0.46843 & 2.03933 & 0.20395 \\
F & 5.11687 & -1.4423 & -0.27704 \\
O & -4.43388 & -1.19619 & -0.14374 \\
$\mathrm{C}$ & -5.74428 & -0.58858 & -0.25334 \\
H & -5.82137 & -0.01218 & -1.17942 \\
H & -6.39456 & -1.47394 & -0.28738 \\
H & -5.9586 & 0.01867 & 0.63053 \\
\hline & & & \\
& & &
\end{tabular}

\# opt b3lyp/6-31g(d,p)

$\mathrm{scrf}=(\mathrm{cpcm}$, solvent=acetonitrile $)$

geom=connectivity

\begin{tabular}{lrrr} 
geom=connectivity & & \\
\hline C & 3.04169 & 1.51588 & -0.1918 \\
C & 1.79663 & 0.92938 & 0.08902 \\
C & 1.64127 & -0.45671 & 0.1657 \\
C & 2.75755 & -1.28847 & -0.0508 \\
C & 3.9802 & -0.68679 & -0.3335 \\
H & 4.15238 & 0.70524 & -0.40755 \\
H & 3.14749 & 2.60445 & -0.24679 \\
H & 2.64779 & -2.37558 & 0.0105 \\
C & 5.12861 & 1.14368 & -0.63103 \\
O & 0.33967 & -1.10807 & 0.48679 \\
C & 0.30526 & -2.2469 & 0.92216 \\
C & -0.92107 & -0.34487 & 0.24461 \\
C & -0.95422 & 1.05222 & 0.17433 \\
C & -2.10712 & -1.0704 & 0.09018 \\
C & -2.15563 & 1.73971 & -0.043 \\
H & -3.31037 & -0.37395 & -0.13182 \\
C & -2.10762 & -2.16119 & 0.1437 \\
H & -3.34453 & 1.03022 & -0.19724 \\
H & -2.17249 & 2.83344 & -0.09637 \\
S & -4.279 & 1.5658 & -0.36822 \\
F & 0.47523 & 2.03342 & 0.39294 \\
O & 5.04258 & -1.46814 & -0.54258 \\
C & -4.39219 & -1.20745 & -0.267 \\
H & -5.69156 & -0.60639 & -0.51701 \\
H & -5.68397 & -0.06298 & -1.46678 \\
H & -6.33897 & -1.49206 & -0.57712 \\
\hline & -5.98276 & 0.03578 & 0.31957 \\
\hline & & &
\end{tabular}




\section{2,2'-MeOTX}

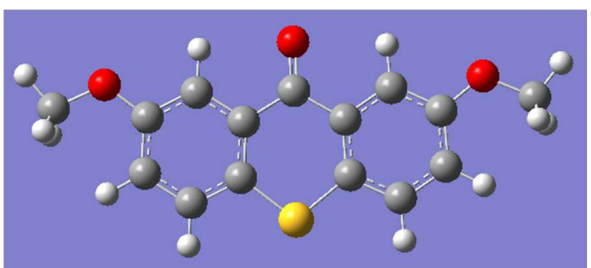

Charge $=0$ Multiplicity $=1$

\begin{tabular}{lrrr} 
\# opt b3lyp/6-31g(d,p) geom=connectivity \\
\hline C & -2.60279 & 1.6956 & 0.1087 \\
C & -1.37967 & 1.06855 & -0.14868 \\
C & -1.28633 & -0.32548 & -0.25178 \\
C & -2.43522 & -1.10423 & -0.09299 \\
C & -3.66339 & -0.46574 & 0.16932 \\
C & -3.75976 & 0.93066 & 0.26958 \\
H & -2.66408 & 2.78318 & 0.18941 \\
H & -2.39049 & -2.19378 & -0.18177 \\
H & -4.70839 & 1.41987 & 0.4702 \\
C & -0.00002 & -1.03663 & -0.53895 \\
O & 0 & -2.17301 & -0.96643 \\
C & 1.28631 & -0.32548 & -0.2518 \\
C & 1.37973 & 1.06858 & -0.14919 \\
C & 2.43515 & -1.10426 & -0.09277 \\
C & 2.60297 & 1.69567 & 0.10754 \\
C & 3.66339 & -0.46574 & 0.16917 \\
H & 2.39034 & -2.19383 & -0.18108 \\
C & 3.75992 & 0.93072 & 0.26857 \\
H & 2.66438 & 2.78328 & 0.18766 \\
H & 4.70866 & 1.41997 & 0.46857 \\
S & -0.00002 & 2.11726 & -0.37774 \\
O & -4.70436 & -1.35473 & 0.30762 \\
O & 4.70424 & -1.35479 & 0.30811 \\
C & -6.02452 & -0.81706 & 0.56332 \\
H & -6.34731 & -0.18572 & -0.26928 \\
H & -6.62872 & -1.73322 & 0.61737 \\
H & -6.04027 & -0.28217 & 1.51695 \\
C & 6.02441 & -0.81719 & 0.56398 \\
H & 6.03988 & -0.2817 & 1.51732 \\
H & 6.62843 & -1.73342 & 0.61884 \\
H & 6.34764 & -0.18643 & -0.26886 \\
\hline & & & \\
\hline
\end{tabular}

\# opt b3lyp/6-31g(d,p)

$\mathrm{scrf}=(\mathrm{cpcm}$,solvent=acetonitrile)

geom=connectivity

\begin{tabular}{lrrr} 
geom=connectivity & & \\
\hline C & 1.6896 & -0.1593 & 2.58229 \\
C & 1.07892 & 0.18936 & 1.37233 \\
C & -0.30958 & 0.34479 & 1.27956 \\
C & -1.10484 & 0.14191 & 2.41043 \\
C & -0.4838 & -0.21425 & 3.62393 \\
C & 0.91013 & -0.36353 & 3.7202 \\
H & 2.77595 & -0.27772 & 2.64689 \\
H & -2.18917 & 0.25873 & 2.36493 \\
H & 1.38576 & -0.63771 & 4.66227 \\
C & -0.97786 & 0.73148 & 0 \\
O & -2.04035 & 1.32729 & 0 \\
C & -0.30958 & 0.34479 & -1.27956 \\
C & 1.07892 & 0.18936 & -1.37233 \\
C & -1.10484 & 0.14191 & -2.41043 \\
C & 1.6896 & -0.1593 & -2.58229 \\
C & -0.4838 & -0.21425 & -3.62393 \\
H & -2.18917 & 0.25873 & -2.36493 \\
C & 0.91013 & -0.36353 & -3.7202 \\
H & 2.77595 & -0.27772 & -2.64689 \\
H & 1.38576 & -0.63771 & -4.66227 \\
S & 2.12649 & 0.47819 & 0 \\
O & -1.3799 & -0.3848 & 4.64982 \\
O & -1.3799 & -0.3848 & -4.64982 \\
C & -0.86366 & -0.77361 & 5.95137 \\
H & -1.78463 & -0.83412 & 6.54753 \\
H & -0.37277 & -1.74972 & 5.89116 \\
H & -0.19347 & -0.00235 & 6.34247 \\
C & -0.86366 & -0.77361 & -5.95137 \\
H & -0.37277 & -1.74972 & -5.89116 \\
H & -1.78463 & -0.83412 & -6.54753 \\
H & -0.19347 & -0.00235 & -6.34247 \\
\hline & & & \\
& & & \\
\hline
\end{tabular}




\section{Excited State Energies}

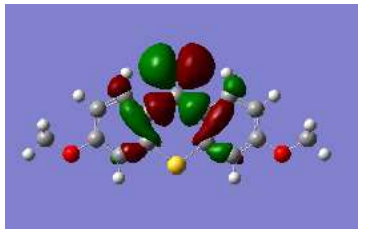

n-orbital

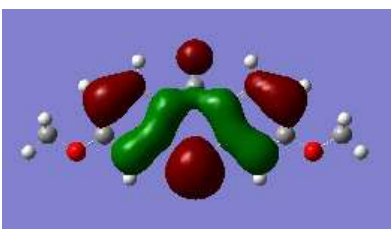

HOMO ( $\pi$-orbital)

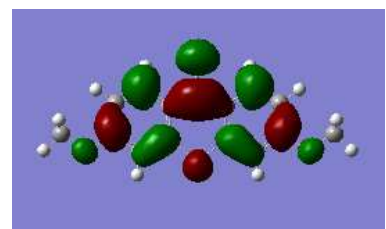

LUMO ( $\pi^{*}$-orbital)

Figure S9: Representetive MOs for the lowest energy transitions of interest, 3,3'-MeOTX shown

\begin{tabular}{|c|c|c|c|c|c|c|c|c|c|}
\hline Thioxanthone & & \multicolumn{4}{|c|}{ Gaseous } & \multicolumn{4}{|c|}{ CPCM } \\
\hline 3,3'-MeOTX & & $\mathrm{S}_{1}$ & $\mathrm{~S}_{2}$ & $\mathrm{~T}_{1}$ & $\mathrm{~T}_{2}$ & $\mathrm{~S}_{1}$ & $\mathrm{~S}_{2}$ & $\mathrm{~T}_{1}$ & $\mathrm{~T}_{2}$ \\
\hline \multirow{3}{*}{$\begin{array}{c}\text { 3,6-dimethoxythioxanthone } \\
\left(3,3^{\prime} \text {-MeOTX }\right)\end{array}$} & $\begin{array}{l}\text { Energy } \\
(\mathrm{kj} / \mathrm{mol})\end{array}$ & 355 & 363 & 292 & 313 & 356 & 364 & 291 & 308 \\
\hline & Character & $\mathrm{n} \pi^{*}$ & $\pi \pi^{*}$ & $\pi \pi^{*}$ & $\mathrm{n} \pi^{*}$ & $\pi \pi^{*}$ & $\mathrm{n} \pi^{*}$ & $\pi \pi^{*}$ & $\pi \pi^{*}$ \\
\hline & $\Delta \mathrm{n}-\mathrm{p}$ & & mol & & $/ \mathrm{mol}$ & & $/ \mathrm{mol}$ & & nol \\
\hline
\end{tabular}

Table S3

\begin{tabular}{|c|c|c|c|c|c|c|c|c|c|}
\hline Thioxanthone & & \multicolumn{4}{|c|}{ Gaseous } & \multicolumn{4}{|c|}{ CPCM } \\
\hline 3,3'-FTX & & $\mathrm{S}_{1}$ & $\mathrm{~S}_{2}$ & $\mathrm{~T}_{1}$ & $\mathrm{~T}_{2}$ & $\mathrm{~S}_{1}$ & $\mathrm{~S}_{2}$ & $\mathrm{~T}_{1}$ & $\mathrm{~T}_{2}$ \\
\hline & $\begin{array}{l}\text { Energy } \\
(\mathrm{kj} / \mathrm{mol})\end{array}$ & 353 & 365 & 290 & 310 & 355 & 360 & 286 & 319 \\
\hline $\begin{array}{c}\text { 3,6-difluorothioxanthone } \\
\left(3,3^{\prime}-F T X\right)\end{array}$ & Character & $\mathrm{n} \pi^{*}$ & $\pi \pi^{*}$ & $\pi \pi^{*}$ & $\mathrm{n} \pi^{*}$ & $\pi \pi^{*}$ & $\mathrm{n} \pi *$ & $\pi \pi^{*}$ & $\mathrm{n} \pi^{*}$ \\
\hline & $\Delta \mathrm{n}-\mathrm{p}$ & \multicolumn{2}{|c|}{$-12 \mathrm{kj} / \mathrm{mol}$} & \multicolumn{2}{|c|}{$21 \mathrm{kj} / \mathrm{mol}$} & \multicolumn{2}{|c|}{$5 \mathrm{kj} / \mathrm{mol}$} & \multicolumn{2}{|c|}{$33 \mathrm{kj} / \mathrm{mol}$} \\
\hline
\end{tabular}

\begin{tabular}{|l|l|l|l|l|l|l|l|l|l|}
\hline Thioxanthone & & \multicolumn{4}{|c|}{ Gaseous } & \multicolumn{4}{c|}{ CPCM } \\
\hline 3-MeOTX & & $\mathrm{S}_{1}$ & $\mathrm{~S}_{2}$ & $\mathrm{~T}_{1}$ & $\mathrm{~T}_{2}$ & $\mathrm{~S}_{1}$ & $\mathrm{~S}_{2}$ & $\mathrm{~T}_{1}$ & $\mathrm{~T}_{2}$ \\
\hline \multirow{2}{*}{$\begin{array}{c}\text { 3-methoxythioxanthone } \\
\text { (3-MeOTX) }\end{array}$} & $\begin{array}{l}\text { Energy } \\
(\mathrm{kj} / \mathrm{mol})\end{array}$ & 349 & 354 & 284 & 307 & 346 & 358 & 280 & 306 \\
\cline { 2 - 10 } & Character & $\mathrm{n} \pi^{*}$ & $\pi \pi^{*}$ & $\pi \pi^{*}$ & $\mathrm{n} \pi^{*}$ & $\pi \pi^{*}$ & $\mathrm{n} \pi^{*}$ & $\pi \pi^{*}$ & $\pi \pi^{*}$ \\
\hline & $\Delta \mathrm{n}-\mathrm{p}$ & \multicolumn{2}{|c|}{$-5 \mathrm{kj} / \mathrm{mol}$} & \multicolumn{2}{|c|}{$23 \mathrm{kj} / \mathrm{mol}$} & $12 \mathrm{kj} / \mathrm{mol}$ & $38 \mathrm{kj} / \mathrm{mol}$ \\
\hline
\end{tabular}

Table S5

\begin{tabular}{|c|c|c|c|c|c|c|c|c|c|}
\hline Thioxanthone & & \multicolumn{4}{|c|}{ Gaseous } & \multicolumn{4}{|c|}{ СРСМ } \\
\hline 3-FTX & & $\mathrm{S}_{1}$ & $\mathrm{~S}_{2}$ & $\mathrm{~T}_{1}$ & $\mathrm{~T}_{2}$ & $\mathrm{~S}_{1}$ & $\mathrm{~S}_{2}$ & $\mathrm{~T}_{1}$ & $\mathrm{~T}_{2}$ \\
\hline \multirow{3}{*}{$\begin{array}{c}\text { 3-fluorothioxanthone } \\
(3-\mathrm{FTX})\end{array}$} & $\begin{array}{l}\text { Energy } \\
(\mathrm{kj} / \mathrm{mol})\end{array}$ & 349 & 356 & 282 & 306 & 346 & 357 & 278 & 316 \\
\hline & Character & $\mathrm{n} \pi^{*}$ & $\pi \pi^{*}$ & $\pi \pi^{*}$ & $\mathrm{n} \pi^{*}$ & $\pi \pi^{*}$ & $\mathrm{n} \pi^{*}$ & $\pi \pi^{*}$ & $\mathrm{n} \pi^{*}$ \\
\hline & $\Delta \mathrm{n}-\mathrm{p}$ & \multicolumn{2}{|c|}{$-7 \mathrm{kj} / \mathrm{mol}$} & \multicolumn{2}{|c|}{$23 \mathrm{kj} / \mathrm{mol}$} & \multicolumn{2}{|c|}{$11 \mathrm{kj} / \mathrm{mol}$} & \multicolumn{2}{|c|}{$38 \mathrm{kj} / \mathrm{mol}$} \\
\hline
\end{tabular}




\begin{tabular}{|c|c|c|c|c|c|c|c|c|c|}
\hline Thioxanthone & & \multicolumn{4}{|c|}{ Gaseous } & \multicolumn{4}{|c|}{ CPCM } \\
\hline TX & & $\mathrm{S}_{1}$ & $\mathrm{~S}_{2}$ & $\mathrm{~T}_{1}$ & $\mathrm{~T}_{2}$ & $\mathrm{~S}_{1}$ & $\mathrm{~S}_{2}$ & $\mathrm{~T}_{1}$ & $\mathrm{~T}_{2}$ \\
\hline \multirow{3}{*}{$\begin{array}{c}\text { Thioxanthone } \\
(\mathrm{TX})\end{array}$} & $\begin{array}{l}\text { Energy } \\
(\mathrm{kj} / \mathrm{mol})\end{array}$ & 345 & 347 & 274 & 302 & 338 & 353 & 269 & 312 \\
\hline & Character & $\mathrm{n} \pi^{*}$ & $\pi \pi^{*}$ & $\pi \pi^{*}$ & $\mathrm{n} \pi^{*}$ & $\pi \pi^{*}$ & $\mathrm{n} \pi^{*}$ & $\pi \pi^{*}$ & $\mathrm{n} \pi^{*}$ \\
\hline & $\Delta \mathrm{n}-\mathrm{p}$ & \multicolumn{2}{|c|}{$-2 \mathrm{kj} / \mathrm{mol}$} & \multicolumn{2}{|c|}{$28 \mathrm{kj} / \mathrm{mol}$} & \multicolumn{2}{|c|}{$15 \mathrm{kj} / \mathrm{mol}$} & \multicolumn{2}{|c|}{$43 \mathrm{kj} / \mathrm{mol}$} \\
\hline
\end{tabular}

\begin{tabular}{|c|c|c|c|c|c|c|c|c|c|}
\hline Thioxanthone & & \multicolumn{4}{|c|}{ Gaseous } & \multicolumn{4}{|c|}{ CPCM } \\
\hline ITX & & $\mathrm{S}_{1}$ & $\mathrm{~S}_{2}$ & $\mathrm{~T}_{1}$ & $\mathrm{~T}_{2}$ & $\mathrm{~S}_{1}$ & $\mathrm{~S}_{2}$ & $\mathrm{~T}_{1}$ & $\mathrm{~T}_{2}$ \\
\hline \multirow{3}{*}{$\begin{array}{l}\text { Isopropylthioxanthone } \\
(\mathrm{ITX})\end{array}$} & $\begin{array}{l}\text { Energy } \\
(\mathrm{kj} / \mathrm{mol})\end{array}$ & 343 & 345 & 270 & 302 & 333 & 353 & 264 & 312 \\
\hline & Character & $\pi \pi^{*}$ & $\mathrm{n} \pi^{*}$ & $\pi \pi^{*}$ & $\mathrm{n} \pi^{*}$ & $\pi \pi^{*}$ & $\mathrm{n} \pi^{*}$ & $\pi \pi^{*}$ & $\mathrm{n} \pi^{*}$ \\
\hline & $\Delta \mathrm{n}-\mathrm{p}$ & \multicolumn{2}{|c|}{$2 \mathrm{kj} / \mathrm{mol}$} & \multicolumn{2}{|c|}{$32 \mathrm{kj} / \mathrm{mol}$} & \multicolumn{2}{|c|}{$20 \mathrm{kj} / \mathrm{mol}$} & \multicolumn{2}{|c|}{$48 \mathrm{kj} / \mathrm{mol}$} \\
\hline
\end{tabular}

\begin{tabular}{|c|c|c|c|c|c|c|c|c|c|}
\hline Thioxanthone & & \multicolumn{4}{|c|}{ Gaseous } & \multicolumn{4}{|c|}{ CPCM } \\
\hline 2-FTX & & $\mathrm{S}_{1}$ & $\mathrm{~S}_{2}$ & $\mathrm{~T}_{1}$ & $\mathrm{~T}_{2}$ & $\mathrm{~S}_{1}$ & $\mathrm{~S}_{2}$ & $\mathrm{~T}_{1}$ & $\mathrm{~T}_{2}$ \\
\hline \multirow{3}{*}{$\begin{array}{l}\text { 2-fluorothioxanthone } \\
\text { (2-FTX) }\end{array}$} & $\begin{array}{l}\text { Energy } \\
(\mathrm{kj} / \mathrm{mol})\end{array}$ & 337 & 344 & 263 & 301 & 329 & 353 & 258 & 311 \\
\hline & Character & $\pi \pi^{*}$ & $\mathrm{n} \pi^{*}$ & $\pi \pi^{*}$ & $\mathrm{n} \pi^{*}$ & $\pi \pi^{*}$ & $\mathrm{n} \pi^{*}$ & $\pi \pi^{*}$ & $\mathrm{n} \pi^{*}$ \\
\hline & $\Delta \mathrm{n}-\mathrm{p}$ & \multicolumn{2}{|c|}{$7 \mathrm{kj} / \mathrm{mol}$} & \multicolumn{2}{|c|}{$38 \mathrm{kj} / \mathrm{mol}$} & \multicolumn{2}{|c|}{$24 \mathrm{kj} / \mathrm{mol}$} & \multicolumn{2}{|c|}{$53 \mathrm{kj} / \mathrm{mol}$} \\
\hline
\end{tabular}

\begin{tabular}{|c|c|c|c|c|c|c|c|c|c|}
\hline Thioxanthone & & \multicolumn{4}{|c|}{ Gaseous } & \multicolumn{4}{|c|}{ CPCM } \\
\hline 4-MeOTX & & $\mathrm{S}_{1}$ & $\mathrm{~S}_{2}$ & $\mathrm{~T}_{1}$ & $\mathrm{~T}_{2}$ & $\mathrm{~S}_{1}$ & $\mathrm{~S}_{2}$ & $\mathrm{~T}_{1}$ & $\mathrm{~T}_{2}$ \\
\hline \multirow{3}{*}{$\begin{array}{c}\text { OMe } \\
\text { 4-methoxythioxanthon } \\
\text { (4-MeOTX) }\end{array}$} & $\begin{array}{l}\text { Energy } \\
(\mathrm{kj} / \mathrm{mol})\end{array}$ & 336 & 346 & 267 & 302 & 325 & 354 & 261 & 303 \\
\hline & Character & $\pi \pi^{*}$ & $\mathrm{n} \pi^{*}$ & $\pi \pi^{*}$ & $\mathrm{n} \pi^{*}$ & $\pi \pi^{*}$ & $\mathrm{n} \pi^{*}$ & $\pi \pi^{*}$ & $\pi \pi^{*}$ \\
\hline & $\Delta \mathrm{n}-\mathrm{p}$ & \multicolumn{2}{|c|}{$10 \mathrm{kj} / \mathrm{mol}$} & \multicolumn{2}{|c|}{$35 \mathrm{kj} / \mathrm{mol}$} & \multicolumn{2}{|c|}{$29 \mathrm{kj} / \mathrm{mol}$} & \multicolumn{2}{|c|}{$52 \mathrm{kj} / \mathrm{mol}$} \\
\hline
\end{tabular}

\begin{tabular}{|c|c|c|c|c|c|c|c|c|c|}
\hline Thioxanthone & & \multicolumn{4}{|c|}{ Gaseous } & \multicolumn{4}{|c|}{ CPCM } \\
\hline 2-MeOTX & & $\mathrm{S}_{1}$ & $\mathrm{~S}_{2}$ & $\mathrm{~T}_{1}$ & $\mathrm{~T}_{2}$ & $\mathrm{~S}_{1}$ & $\mathrm{~S}_{2}$ & $\mathrm{~T}_{1}$ & $\mathrm{~T}_{2}$ \\
\hline \multirow{3}{*}{$\begin{array}{l}\text { 2-methoxythioxantho } \\
\text { (2-MeOTX) }\end{array}$} & $\begin{array}{l}\text { Energy } \\
(\mathrm{kj} / \mathrm{mol})\end{array}$ & 320 & 343 & 252 & 300 & 310 & 353 & 243 & 312 \\
\hline & Character & $\pi \pi^{*}$ & $\mathrm{n} \pi^{*}$ & $\pi \pi^{*}$ & $\mathrm{n} \pi^{*}$ & $\pi \pi^{*}$ & $\mathrm{n} \pi^{*}$ & $\pi \pi^{*}$ & $\mathrm{n} \pi^{*}$ \\
\hline & $\Delta \mathrm{n}-\mathrm{p}$ & \multicolumn{2}{|c|}{$23 \mathrm{kj} / \mathrm{mol}$} & \multicolumn{2}{|c|}{$48 \mathrm{kj} / \mathrm{mol}$} & \multicolumn{2}{|c|}{$43 \mathrm{kj} / \mathrm{mol}$} & \multicolumn{2}{|c|}{$69 \mathrm{kj} / \mathrm{mol}$} \\
\hline
\end{tabular}




\begin{tabular}{|c|c|c|c|c|c|c|c|c|c|}
\hline Thioxanthone & & \multicolumn{4}{|c|}{ Gaseous } & \multicolumn{4}{|c|}{ CPCM } \\
\hline 2-MeO,2'-FTX & & $\mathrm{S}_{1}$ & $\mathrm{~S}_{2}$ & $\mathrm{~T}_{1}$ & $\mathrm{~T}_{2}$ & $\mathrm{~S}_{1}$ & $\mathrm{~S}_{2}$ & $\mathrm{~T}_{1}$ & $\mathrm{~T}_{2}$ \\
\hline \multirow{3}{*}{$\begin{array}{l}\text { 2-methoxy, 7-fluorothioxanthone } \\
\left(2-\mathrm{MeO}, 2^{\prime}-\mathrm{FTX}\right)\end{array}$} & $\begin{array}{l}\text { Energy } \\
(\mathrm{kj} / \mathrm{mol})\end{array}$ & 311 & 342 & 242 & 299 & 301 & 352 & 234 & 311 \\
\hline & Character & $\pi \pi^{*}$ & $\mathrm{n} \pi^{*}$ & $\pi \pi^{*}$ & $\mathrm{n} \pi^{*}$ & $\pi \pi^{*}$ & $\mathrm{n} \pi^{*}$ & $\pi \pi^{*}$ & $\mathrm{n} \pi^{*}$ \\
\hline & $\Delta \mathrm{n}-\mathrm{p}$ & \multicolumn{2}{|c|}{$31 \mathrm{kj} / \mathrm{mol}$} & \multicolumn{2}{|c|}{$57 \mathrm{kj} / \mathrm{mol}$} & \multicolumn{2}{|c|}{$51 \mathrm{kj} / \mathrm{mol}$} & \multicolumn{2}{|c|}{$77 \mathrm{kj} / \mathrm{mol}$} \\
\hline
\end{tabular}

\begin{tabular}{|c|c|c|c|c|c|c|c|c|c|}
\hline Thioxanthone & & \multicolumn{4}{|c|}{ Gaseous } & \multicolumn{4}{|c|}{ CPCM } \\
\hline 2,2'-MeOTX & & $\mathrm{S}_{1}$ & $\mathrm{~S}_{2}$ & $\mathrm{~T}_{1}$ & $\mathrm{~T}_{2}$ & $\mathrm{~S}_{1}$ & $\mathrm{~S}_{2}$ & $\mathrm{~T}_{1}$ & $\mathrm{~T}_{2}$ \\
\hline \multirow{3}{*}{$\begin{array}{c}\text { 2,7-dimethoxythioxanthone } \\
\left(2,2^{\prime} \text {-MeOTX }\right)\end{array}$} & $\begin{array}{l}\text { Energy } \\
(\mathrm{kj} / \mathrm{mol})\end{array}$ & 302 & 342 & 235 & 299 & 291 & 352 & 225 & 310 \\
\hline & Character & $\pi \pi^{*}$ & $\mathrm{n} \pi^{*}$ & $\pi \pi^{*}$ & $\mathrm{n} \pi^{*}$ & $\pi \pi^{*}$ & $\mathrm{n} \pi^{*}$ & $\pi \pi^{*}$ & $\pi \pi^{*}$ \\
\hline & $\Delta \mathrm{n}-\mathrm{p}$ & \multicolumn{2}{|c|}{$40 \mathrm{kj} / \mathrm{mol}$} & \multicolumn{2}{|c|}{$64 \mathrm{kj} / \mathrm{mol}$} & \multicolumn{2}{|c|}{$61 \mathrm{kj} / \mathrm{mol}$} & \multicolumn{2}{|c|}{$86 \mathrm{kj} / \mathrm{mol}$} \\
\hline
\end{tabular}

\section{Synthesis of Novel Photochemical Precursors}

\section{Amino cinnamate 8}

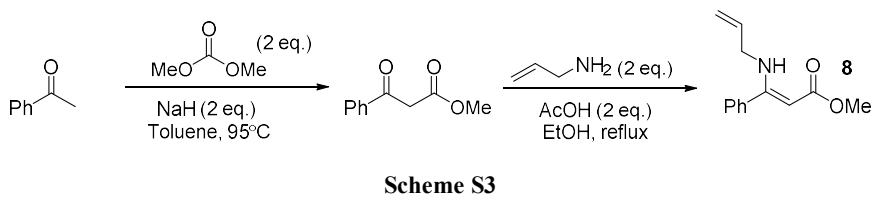

A stirred suspension of $\mathrm{NaH}(60 \%$ on oil, $32 \mathrm{~g}, 800 \mathrm{mmol})$ in toluene $(300 \mathrm{ml})$ with dimethyl carbonate $(68 \mathrm{ml}, 808 \mathrm{mmol})$ was heated to $95^{\circ} \mathrm{C}$ in a $1 \mathrm{~L}$ flask with an overhead stirrer and condenser. A solution of acetophenone $(46.6 \mathrm{ml}, 400 \mathrm{mmol})$ in toluene $(100 \mathrm{ml})$ was added dropwise to allow for a controlled exotherm and $\mathrm{H}_{2}$ evolution. After the addition was complete, heating was continued for 1 hour before the solution was cooled in an ice bath and quenched with acetic acid $(23 \mathrm{ml}, 400 \mathrm{mmol})$ and $1 \mathrm{M} \mathrm{HCl}$ $(400 \mathrm{ml})$. The biphasic mixture was separated and the aqueous layer further extracted with EtOAC $(2 \times 150 \mathrm{ml})$ before the pooled organic extracts were washed with brine, dried $\left(\mathrm{MgSO}_{4}\right)$, filtered and concentrated in vacuo. The resulting oil was filtered through silica with pet. ether 40/60, then $\mathrm{Et}_{2} \mathrm{O}$ and the solution evaporated under reduced pressure to give the 1,3-keto ester as an oil ( $71.5 \mathrm{~g}, 100 \%) .53 .5$ $\mathrm{g}(300 \mathrm{mmol})$ of this oil, along with allylamine $(45 \mathrm{ml}, 600 \mathrm{mmol})$ and acetic acid $(34 \mathrm{ml}, 600 \mathrm{mmol})$ was added to $\mathrm{EtOH}(300 \mathrm{ml})$ in a $1 \mathrm{~L}$ flask and the solution refluxed for 3 hours until all keto-ester had been consumed. The cooled solution was concentrated, purified by chromatography on silica $(10-20 \%$ $\mathrm{Et}_{2} \mathrm{O}$ in petrol) and concentrated to an oil $(52 \mathrm{~g})$ with was re-dissolved in petrol $(50 \mathrm{ml})$, cooled in a freezer at $-20^{\circ} \mathrm{C}$ and the resulting suspension rapidly filtered to give 8 as a white solid $(47.5 \mathrm{~g}, 73 \%)$ : m.p. $35-36{ }^{\circ} \mathrm{C} ; \delta_{\mathrm{H}}\left(400 \mathrm{MHz}, \mathrm{CDCl}_{3}\right) 8.61(1 \mathrm{H}, \mathrm{s}, \mathrm{NH}), 7.43-7.32(5 \mathrm{H}, \mathrm{m}, \mathrm{Ar} . \mathbf{H}), 5.78(1 \mathrm{H}, \mathrm{ddt}, J=$ $17.1,10.1,4.9 \mathrm{~Hz}, \mathrm{CH}=\mathrm{CHH}), 5.21(1 \mathrm{H}$, app. dq, $J=17.1,1.7 \mathrm{~Hz}, \mathrm{CH}=\mathrm{CHH}), 5.11(1 \mathrm{H}$, app. dq, $J=$ $10.3,1.6 \mathrm{~Hz}, \mathrm{CH}=\mathrm{CHH}), 4.64(1 \mathrm{H}, \mathrm{s}, \mathrm{CH}=\mathrm{C}), 3.72-3.64\left(5 \mathrm{H}, \mathrm{m}, \mathrm{NCH}_{2}, \mathrm{OCH}_{3}\right) ; \delta_{\mathrm{C}}\left(101 \mathrm{MHz}, \mathrm{CDCl}_{3}\right)$ $170.9(\mathrm{C}), 165.1(\mathrm{C}), 136.0(\mathrm{C}), 135.5(\mathrm{CH}), 129.5(\mathrm{CH}), 128.5(2 \times \mathrm{CH}), 127.9(2 \times \mathrm{CH}), 116.0\left(\mathrm{CH}_{2}\right)$, $85.5(\mathrm{CH}), 50.4\left(\mathrm{CH}_{2}\right), 46.9\left(\mathrm{CH}_{3}\right)$; ESI-HRMS m/z $218.1180\left(\mathrm{MH}^{+} \mathrm{C}_{13} \mathrm{H}_{16} \mathrm{NO}_{2}\right.$ requires 218.1176) 


\section{Boc protection to 25}

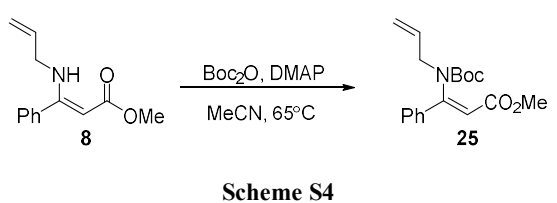

To a solution of amino cinnamate $8(21.7 \mathrm{~g}, 100 \mathrm{~mol})$ in $\mathrm{MeCN}(100 \mathrm{ml})$ was added $\mathrm{Boc}_{2} \mathrm{O}(28.3 \mathrm{~g}, 130$ $\mathrm{mmol})$ and DMAP $(0.61 \mathrm{~g}, 5 \mathrm{mmol})$ and the mixture heated to $65^{\circ} \mathrm{C}$. After gas evolution had ceased, additional $\mathrm{Boc}_{2} \mathrm{O}(16.7 \mathrm{~g}, 77 \mathrm{mmol})$ was added portionwise. The solution was concentrated and purified by chromatography on silica (10-20\% $\mathrm{Et}_{2} \mathrm{O}$ in petrol) to give 25 as a solid $(19.0 \mathrm{~g}, 60 \%)$ : m.p. $60-61$ ${ }^{\circ} \mathrm{C} ; \delta_{\mathrm{H}}\left(400 \mathrm{MHz}, \mathrm{CDCl}_{3}\right) 7.40-7.29(5 \mathrm{H}, \mathrm{m}, \mathrm{Ar} . \mathbf{H}), 5.92(1 \mathrm{H}, \mathrm{ddt}, J=17.0,10.6,5.4 \mathrm{~Hz}, \mathrm{CH}=\mathrm{CHH})$, $5.86(1 \mathrm{H}, \mathrm{s}, \mathrm{CH}=\mathrm{C}), 5.25-5.16(2 \mathrm{H}, \mathrm{m}, \mathrm{CH}=\mathrm{CHH}), 4.24(2 \mathrm{H}$, app. dt, $J=5.4,1.6 \mathrm{~Hz}, \mathrm{NCH} 2), 3.56$ $\left(3 \mathrm{H}, \mathrm{s}, \mathrm{OCH}_{3}\right), 1.15\left(9 \mathrm{H}, \mathrm{s}, 3 \times \mathrm{CH}_{3}\right) ; \delta_{\mathrm{C}}\left(101 \mathrm{MHz}, \mathrm{CDCl}_{3}\right) 167.0(\mathrm{C}), 156.1(\mathrm{C}), 153.7(\mathrm{C}), 136.9(\mathrm{C})$, 133.6 (CH), $129.4(\mathrm{CH}), 128.8(2 \times \mathrm{CH}), 127.8(2 \times \mathrm{CH}), 117.1\left(\mathrm{CH}_{2}\right), 109.7(\mathrm{CH}), 81.8(\mathrm{C}), 53.3\left(\mathrm{CH}_{2}\right)$, $51.3\left(\mathrm{CH}_{3}\right), 27.8\left(3 \times \mathrm{CH}_{3}\right)$; ESI-HRMS m/z $318.1699\left(\mathrm{MH}^{+} \mathrm{C}_{18} \mathrm{H}_{24} \mathrm{NO}_{4}\right.$ requires 318.1700)

a-amido acrylate 13

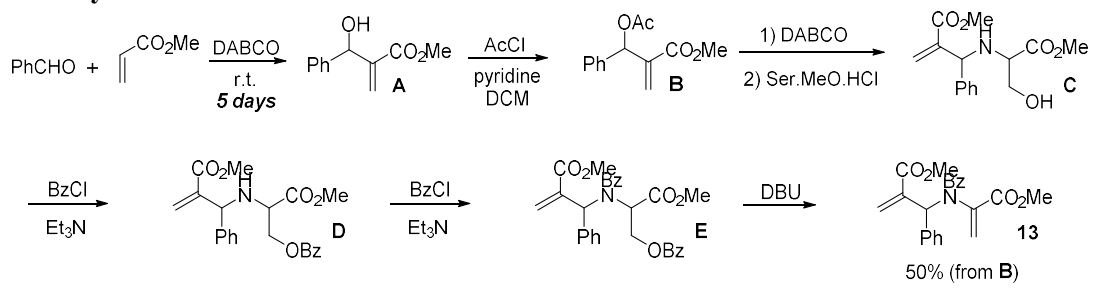

Scheme S5

Solvent-free Baylis-Hillman : A mixture of methyl acrylate (333 mmol, 1.0 eq.), benzaldehyde (333 mmol, 1.0 eq. ) and DABCO (20 mol \%) was stirred at room temp for 5 days before pouring over $1 \mathrm{M}$ $\mathrm{HCl}(250 \mathrm{ml})$ and extracting with EtOAc $(3 \times 200 \mathrm{ml})$. The organic extracts were dried $\left(\mathrm{MgSO}_{4}\right)$, filtered and evaporated to an oil (62.9 g) containing $\sim 15 \mathrm{~mol}$. \% benzaldehyde. The product $\mathbf{A}$ was of sufficient purity to use in next step.

Acylation: To an ice cooled solution of the above Baylis-Hillman adduct A in DCM ( $\sim 300 \mathrm{mmol}$; $2 \mathrm{M})$, and pyridine (1.15 eq), was added acetyl chloride (1.15 eq.) dropwise. The mixture was allowed to warm to room temperature and stirring continued until the alcohol was fully consumed (monitored by tlc). The concentration was halved by the addition of more DCM and the mixture washed with $1 \mathrm{M}$ $\mathrm{HCl}(\times 2)$ and water. The solution was dried $\left(\mathrm{MgSO}_{4}\right)$, filtered and evaporated to give $\mathbf{B}$ as an oil containing residual benzaldehyde as an impurity $(\sim 15 \%)$. Yield $\approx 83 \%$ (2-steps)

Ser-OMe.HCl: Acetyl chloride (2.5 eq) was added dropwise to $\mathrm{MeOH}(600 \mathrm{ml})$ before the portionwise addition of DL-serine ( $0.5 \mathrm{~mol}, 1.0$ eq.) and the mixture refluxed for $2 \mathrm{hrs}$. The solvent was evaporated, the product was triturated with $\mathrm{Et}_{2} \mathrm{O}$, filtered and washed $\left(\mathrm{Et}_{2} \mathrm{O}\right)$ before drying to a free-flowing powder $(76 \mathrm{~g}, 98 \%)$

Serine Adduct C: To a 1:1 THF/Water solution of crude allylic acetate B $(200 \mathrm{mmol}, 1 \mathrm{M})$ cooled in an ice bath was added DABCO (2.5 eq.) The ice bath was removed and the mixture stirred for $15 \mathrm{~min}$ before the portionwise addition of Ser-OMe. $\mathrm{HCl}$ (1.2 eq.). The mixture was stirred, until the reaction had gone to completion, before removal of THF under reduced pressure. The remaining mixture was extracted with EtOAc, dried $\left(\mathrm{MgSO}_{4}\right)$ and chromatography on silica (gradient elution 30\% -80\% EtOAc in hexane) yielded the product $\mathbf{C}$ as an oil $(49 \mathrm{~g})$, free from benzaldehyde and as a mix of diastereomers. 
Benzoylation to E: To a solution of $\mathbf{C}(\sim 167 \mathrm{mmol})$ in $\operatorname{DCM}(1 \mathrm{M})$ was added $\mathrm{Et}_{3} \mathrm{~N}(1.15$ eq. $)$ and the solution cooled in an ice bath after which was added $\mathrm{BzCl}$ (1.15 eq.) dropwise. The solution was stirred at room temperature for approx. $1 \mathrm{hr}$. before washing with $1 \mathrm{M} \mathrm{HCl}(\times 2)$ and brine. The solution was dried $\left(\mathrm{MgSO}_{4}\right)$, filtered and evaporated to $\mathbf{D}$ an oil which was used directly for the second benzoylation. To solution of $\mathbf{D}$ in $\mathrm{MeCN}(1 \mathrm{M})$ and $\mathrm{Et}_{3} \mathrm{~N}$ (1.2 eq.) was added $\mathrm{BzCl}(1.2 \mathrm{eq})$ and the mixture then heated at reflux with stirring until full consumption of the starting material (tlc monitoring). After cooling to room temperature the slurry was filtered and the solution concentrated in vacuo before redissolving in $\mathrm{DCM}$ and washing with $1 \mathrm{M} \mathrm{HCl}$ and brine. The solution was dried $\left(\mathrm{MgSO}_{4}\right)$, filtered and evaporated to an oil which was purified by chromatography on silica (20 - 30\% EtOAc in hexane) to give $\mathbf{E}$ as an oil ( $75 \mathrm{~g}$, mixture of diastereomers).

Benzoate Elimination to 13: To an ice cooled solution of $\mathbf{E}(\sim 150 \mathrm{mmol})$ in DCM $(0.6 \mathrm{M})$ was added neat DBU (1 eq.) dropwise. The ice bath was removed and stirring continued until the reaction had gone to completion (tlc monitoring). The solution was washed (sat. $\left.\mathrm{NaHCO}_{3}\right)$, brine and dried $\left(\mathrm{MgSO}_{4}\right)$. Chromatography on silica (30\% EtOAc in hexane) yielded product 13 as a white solid $(40.5 \mathrm{~g}, 50 \%$ from B): m.p. $110-112{ }^{\circ} \mathrm{C}$; $\delta_{\mathrm{H}}\left(400 \mathrm{MHz}, \mathrm{CDCl}_{3}\right) 7.55-7.50(2 \mathrm{H}, \mathrm{m}, \mathrm{Ar} . \mathbf{H}), 7.38-7.23(8 \mathrm{H}, \mathrm{m}$, Ar.H), 6.71 (1H, br. s, PhCH), $6.56(1 \mathrm{H}$, app. t, $J=1.0 \mathrm{~Hz}, \mathrm{CHH}=\mathrm{C}), 5.99-5.97(1 \mathrm{H}, \mathrm{m}, \mathrm{CHH}=\mathrm{C})$, $5.96(1 \mathrm{H}, \mathrm{d}, J=0.7 \mathrm{~Hz}, \mathrm{CHH}=\mathrm{C}), 5.45(1 \mathrm{H}, \mathrm{d}, J=0.7 \mathrm{~Hz}, \mathrm{CHH}=\mathrm{C}), 3.70\left(3 \mathrm{H}, \mathrm{s}, \mathrm{CH}_{3}\right), 3.43(3 \mathrm{H}, \mathrm{s}$, $\left.\mathrm{CH}_{3}\right) ; \delta_{\mathrm{C}}\left(101 \mathrm{MHz}, \mathrm{CDCl}_{3}\right) 171.1(\mathrm{C}), 166.6(\mathrm{C}), 164.8(\mathrm{C}), 139.5(\mathrm{C}), 139.4(\mathrm{C}), 136.5(\mathrm{C}), 136.3$ $(\mathrm{C}), 130.5(\mathrm{CH}), 129.7(2 \times \mathrm{CH}), 128.4(2 \times \mathrm{CH}), 128.3(2 \times \mathrm{CH}), 128.2(2 \times \mathrm{CH}), 128.1(\mathrm{CH}), 127.8\left(\mathrm{CH}_{2}\right)$, $124.8\left(\mathrm{CH}_{2}\right), 62.5(\mathrm{CH}), 52.3\left(\mathrm{CH}_{3}\right), 52.2\left(\mathrm{CH}_{3}\right)$; ESI-HRMS m/z $380.1496\left(\mathrm{MH}^{+} \mathrm{C}_{22} \mathrm{H}_{22} \mathrm{NO}_{5}\right.$ requires 380.1498)

Amido styrene 23

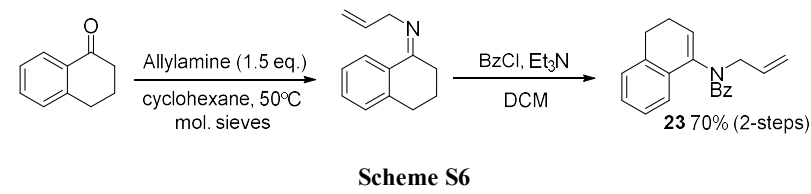

A solution of $\alpha$-tetralone $(100 \mathrm{~g}, 684 \mathrm{mmol})$ and allylamine $(77 \mathrm{ml}, 1.03 \mathrm{~mol})$ in cyclohexane $(250 \mathrm{ml})$ was stirred over $3 \AA$ molecular sieves, $3-5 \mathrm{~mm}$ beads, $(140 \mathrm{~g})$ in a $1 \mathrm{~L}$ flask, heated at $50^{\circ} \mathrm{C}$ for $90 \mathrm{hrs}$ ( $95 \%$ conversion). The mixture was filtered through celite, concentrated in vacuo and the resulting oil poured oved DCM $(500 \mathrm{ml})$, cooled in an ice bath, before the addition of benzoyl chloride $(79 \mathrm{ml}, 684$ $\mathrm{mmol})$ then triethylamine $(95 \mathrm{ml}, 684 \mathrm{mmol})$ over about 20 mins. The fully charged vessel was allowed to warm to room temperature and stirred for $17 \mathrm{hrs}$ before filtering and the filtrate washed $(1 \mathrm{M} \mathrm{HCl}$, sat. aq. $\mathrm{NaHCO}_{3}$ and brine), dried $\left(\mathrm{MgSO}_{4}\right)$ and filtered before concentrating under reduced pressure. To the resulting oil was added hexane to allow trituration of the product before filtering to give enamide 23 as an off-white solid $(139$ g, $70 \%)$ : m.p. $86-87^{\circ} \mathrm{C}$; $\delta_{\mathrm{H}}\left(400 \mathrm{MHz}, \mathrm{CDCl}_{3}\right) 7.49-7.11(9 \mathrm{H}, \mathrm{m}$, Ar.H), $5.99\left(1 \mathrm{H}\right.$, dddd, $\left.J=17.3,10.2,7.3,5.4 \mathrm{~Hz}, \mathrm{CH}_{2}=\mathrm{CH}\right), 5.52\left(1 \mathrm{H}, \mathrm{dd}, J=6.0,3.5 \mathrm{~Hz}, \mathrm{C}=\mathrm{CHCH}_{2}\right)$, $5.22-5.09\left(2 \mathrm{H}, \mathrm{m}, \mathrm{CH}_{2}=\mathrm{CH}\right), 4.83(1 \mathrm{H}, \mathrm{dd}, J=14.5,5.4 \mathrm{~Hz}, \mathrm{NCHHCH}), 3.68(1 \mathrm{H}, \mathrm{dd}, J=14.5,7.3$ $\mathrm{Hz}, \mathrm{NCHHCH}), 2.73\left(1 \mathrm{H}\right.$, app. td, $\left.J=14.3,6.7 \mathrm{~Hz}, \mathrm{CCHHCH}_{2}\right), 2.60(1 \mathrm{H}$, app. dt, $J=15.5,5.9 \mathrm{~Hz}$, $\left.\mathrm{CCHHCH}_{2}\right), 2.18\left(1 \mathrm{H}\right.$, app. dq, $\left.J=17.6,6.1 \mathrm{~Hz}, \mathrm{CH}_{2} \mathrm{CHHCH}\right), 2.00(1 \mathrm{H}$, dddd, $J=17.0,13.5,6.7,3.5$ $\left.\mathrm{Hz}, \mathrm{CH}_{2} \mathrm{CHHCH}\right) ; \delta_{\mathrm{C}}\left(101 \mathrm{MHz}, \mathrm{CDCl}_{3}\right) 171.2(\mathrm{C}), 138.8(\mathrm{C}), 137.3(\mathrm{C}), 136.2(\mathrm{C}), 133.1(\mathrm{CH}), 131.8$ $(\mathrm{C}), 130.0(\mathrm{CH}), 129.4(\mathrm{CH}), 128.1(\mathrm{CH}), 128.1(\mathrm{CH}), 127.8(2 \times \mathrm{CH}), 127.6(2 \times \mathrm{CH}), 127.0(\mathrm{CH}), 122.8$ $(\mathrm{CH}), 118.4\left(\mathrm{CH}_{2}\right), 50.2\left(\mathrm{CH}_{2}\right), 27.3\left(\mathrm{CH}_{2}\right), 22.9\left(\mathrm{CH}_{2}\right)$; ESI-HRMS m/z $290.1549\left(\mathrm{MH}^{+} \mathrm{C}_{20} \mathrm{H}_{20} \mathrm{NO}\right.$ requires 290.1539) 
$N$-Bn-3-(but-3-en-1-yloxy)-maleimide (27)

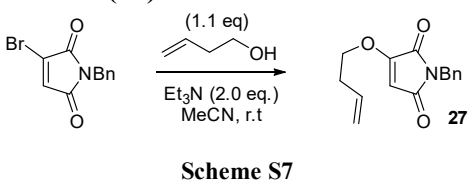

A mixture of $N$-benzyl-3-bromomaleimide $(16.9 \mathrm{~g}, 63.5 \mathrm{mmol}), 3$-buten-1-ol $(6 \mathrm{ml}, 70 \mathrm{mmol})$ and triethylamine $(17.6 \mathrm{ml}, 127 \mathrm{mmol})$ in $\mathrm{MeCN}(65 \mathrm{ml})$ was stirred at room temperature for 4 days. The mixture was concentrated, re-dissolved in DCM $(100 \mathrm{ml})$ and washed with water $(2 \times 50 \mathrm{ml})$, dried $\left(\mathrm{MgSO}_{4}\right)$, filtered and concentrated to an oil which was filtered through silica with $\mathrm{Et}_{2} \mathrm{O}$. The solvent was removed in vacuo, purified by chromatography on silica $(70-100 \%$ DCM in petrol) and concentrated to an oil which was triturated with petrol / $\mathrm{Et}_{2} \mathrm{O}$, filtered and dried to give $\mathbf{2 7}$ as a white solid (10.3 g, 63\%): m.p. $66-67^{\circ} \mathrm{C} ; \delta_{\mathrm{H}}\left(400 \mathrm{MHz}, \mathrm{CDCl}_{3}\right) 7.35-7.22(5 \mathrm{H}, \mathrm{m}, \mathrm{Ar} . \mathrm{H}), 5.80(1 \mathrm{H}, \mathrm{ddt}, J$ $=17.0,10.2,6.7 \mathrm{~Hz}, \mathrm{CH}=\mathrm{CHH}), 5.36(1 \mathrm{H}, \mathrm{s}, \mathrm{CH}=\mathrm{C}), 5.20-5.10\left(2 \mathrm{H}, \mathrm{m}, \mathrm{CH}=\mathrm{C} \mathbf{H}_{2}\right), 4.64(2 \mathrm{H}, \mathrm{s}$, $\left.\mathrm{NCH}_{2} \mathrm{Ph}\right), 4.05\left(2 \mathrm{H}, \mathrm{t}, J=6.8 \mathrm{~Hz}, \mathrm{OCH}_{2} \mathrm{CH}_{2}\right), 2.57\left(2 \mathrm{H}\right.$, app. qt, $\left.J=6.8,1.3 \mathrm{~Hz}, \mathrm{OCH}_{2} \mathrm{CH}_{2}\right) ; \delta_{\mathrm{C}}(101$ $\left.\mathrm{MHz}, \mathrm{CDCl}_{3}\right) 170.1(\mathrm{C}), 165.5(\mathrm{C}), 160.2(\mathrm{C}), 136.4(\mathrm{C}), 132.6(\mathrm{CH}), 128.8(2 \times \mathrm{CH}), 128.6(2 \times \mathrm{CH})$, $127.9(\mathrm{CH}), 118.6\left(\mathrm{CH}_{2}\right), 96.6(\mathrm{CH}), 71.7\left(\mathrm{CH}_{2}\right), 41.3\left(\mathrm{CH}_{2}\right), 32.7\left(\mathrm{CH}_{2}\right)$; ESI-HRMS m/z 280.0940 $\left(\mathrm{MNa}^{+} \mathrm{C}_{15} \mathrm{H}_{15} \mathrm{NO}_{3} \mathrm{Na}\right.$ requires 280.0944$)$

\section{Novel Reactor Configurations}

\section{Parallel NMR Tube Irradiations}

For rapid screening of the sensitizer series, a simple new method was devised to save time and material. Irradiations were carried out directly in standard NMR tubes using deuterated acetonitrile. Stock solutions of the substrate $(5 \mathrm{ml}, 0.1-0.2 \mathrm{M})$ were prepared in a $5 \mathrm{ml}$ volumetric flask, with adiponitrile $(0.5 \mathrm{eq})$ as an internal standard if necessary, before dispensing $0.4 \mathrm{ml}$ aliquots into individual NMR tubes containing the sensitizer of interest. The solutions were then irradiated in parallel with a $9 \mathrm{~W}$ PLS UVA lamp by holding the tubes equidistant from the lamp (1-2 $\mathrm{mm})$ using an improvised tube holder (Figure S10). The low power output of the lamp meant that external cooling was not required.

The reaction progress was monitored periodically by ${ }^{1} \mathrm{H}-\mathrm{NMR}$. By using this method, the entire sensitizer series could be screened within a working day, without the need for sample preparation, and using just $0.5-1.0 \mathrm{mmol}$ of the substrate.
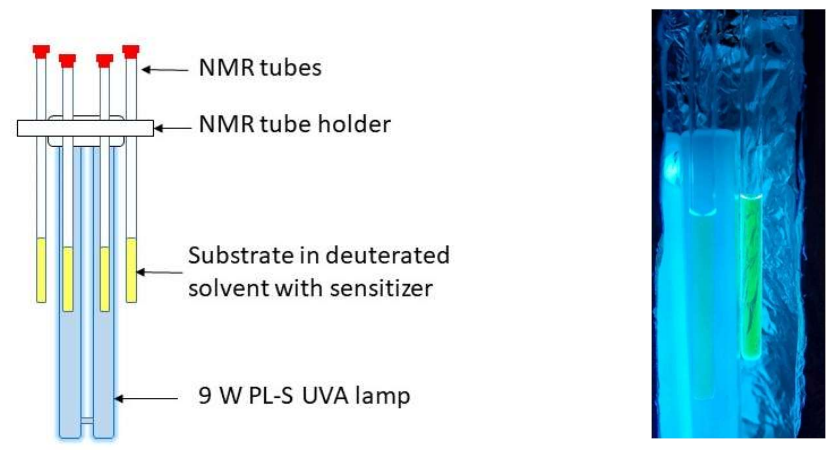

Figure S10: Parallel NMR tube irradiations with $9 \mathrm{~W}$ pl-s lamp 


\section{W Blue COB Reactor Configuration}

To investigate the efficacy of the visible light absorbing TX derivatives as 'energy transfer photocatalysts' it was necessary to construct a novel reactor based around a high-intensity blue light source. Reported reactors for visible light photocatalysis are usually based around SMD (Surface Mount Device) LED chips. Single colour, high power SMD LEDs typically operate at about $1-3 \mathrm{~W}$, have about 1- 3 individual diodes in a single housing and must be connected in arrays if more power / light intensity is required.

COB (Chip On board) LEDs have many more diodes ( $>9$ ) mounted on a single surface and can offer much higher power densities without having to connect multiple chips in an array. These devices can be commonly found in high power white LED spotlights. The white light is produced by a phosphor film over an LED chip which down-converts a higher energy light source to the full range of visible colours. . In the case of white COB LEDs the phosphor is driven by the much easier / cheaper to access emission from blue LEDs. As a result, all white COB chips have at their centre a powerful source of blue light which is ideal for many photoredox catalysts and lower energy triplet sensitizers which can excited by visible light. Interestingly, 'naked' blue $\mathrm{COB}$ chips have only relatively recently become commercially available. LED manufacturer Citizen produce such chips for aquariums, swimming pools and architectural use.

A tray of the $34.6 \mathrm{~V}, 22 \mathrm{~mm}$ COB chips was ordered for initial investigations based on the convenient chip size and availability of a compact $36 \mathrm{~W} 1.05 \mathrm{~A}$ constant current driver. The peak wavelength is $455 \mathrm{~nm}$ and the emission spans from approximately $430-480 \mathrm{~nm}$.

\section{W Blue COB Reactor Construction}

The key requirements of a photochemical batch reactor are:

1) light source in optimal position to ensure efficient light delivery to solution

2) a means of stirring solution and

3) effective heat management.

Reported visible light mediated photoredox reactions are often driven by a $40 \mathrm{~W}$ Kessil lamp or a flexible LED strip placed side-on and a few centimetres away from a vial containing the reaction solution (Figure S11, left). The overall light capture is poor and as a result the reactions are often left on overnight to drive a successful reaction to completion. The side-on method of irradiation is necessary since the vials are stirred over a magnetic stirrer and there is no room below for the bulky commercial light source.
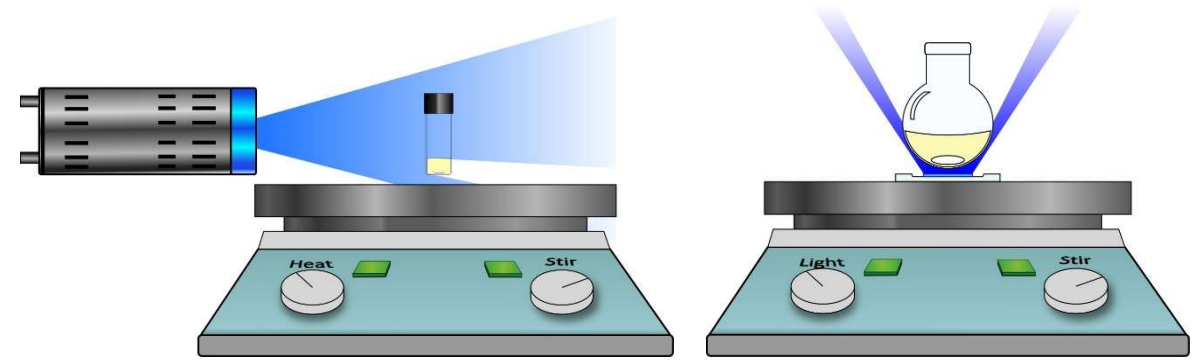

Figure S11 - Left: Inefficient side-on irradiation with external Kessil lamps over magnetic stirrer; Right: Novel integrated COB LED and magnetic stirrer for efficient light capture

The use of a COB LED allows for efficient stirring with simultaneous irradiation since the flat COB chip can be mounted directly onto the metal surface of a magnetic stirrer without affecting its ability to stir (Figure S11, right). In this way, a vessel can be magnetically stirred directly over the high intensity 
discharge of the COB. In the case of the $36 \mathrm{~W}$ COB used, it was assumed the metal body of the stirrer should allow for sufficient heat dissipation and so prevent the COB chip overheating.

The reactor was based around a Heidolph stirrer hotplate with broken heating controls (Figure S12). The heating circuitry could be removed and replaced with the LED driver which fortuitously fit neatly within the resulting cavity. As a result, the driver could be wired internally onto the original heating switch allowing for a compact and safe design with minimal effort. The LED COB was fixed to the plate with a commercially available mount and a couple of screws tapped into the metal surface. Thermal contact was made with some thermal paste.

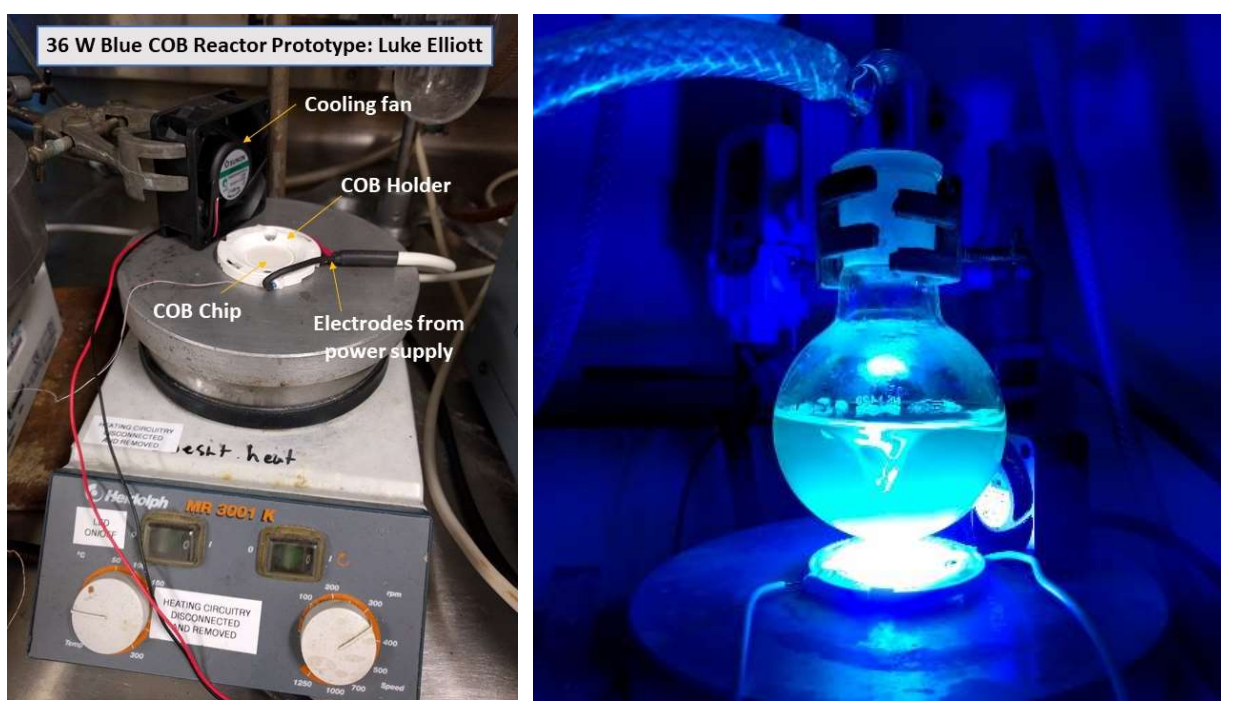

Figure S12: Working prototype of the $36 \mathrm{~W}$ blue $\mathrm{COB}$ reactor

Stirring acetonitrile in a $50 \mathrm{ml}$ rbf over the $36 \mathrm{~W}$ COB resulted in rapid heating of the solvent to near reflux and so a fan was introduced to the side of the vessel. This allowed the temperature to be maintained below $40^{\circ} \mathrm{C}$ and also assisted in cooling the surface of the stirrer. Additional control over the temperature could involve a small double jacketed vessel or cold-finger.

\section{TX Sensitizer Screening Studies}

\section{Alkene Isomerization Studies in NMR Tubes}

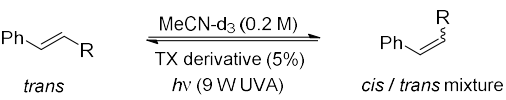

$$
\begin{aligned}
& \begin{array}{l}
\mathrm{R}=\mathrm{Me}: \beta-\mathrm{Me} \text { styrene } \\
\mathrm{R}=\mathrm{CO}_{2} \mathrm{Me} \text { : methyl cinnamate }
\end{array}
\end{aligned}
$$

A stock solution was prepared in a $5 \mathrm{ml}$ volumetric flask using $1 \mathrm{mmol}$ of the relevant trans-styrene derivative and deuterated acetonitrile $(0.2 \mathrm{M})$. For each irradiation, $0.5 \mathrm{ml}$ aliquots were added to an NMR tube containing the relevant thioxanthone derivative $(5 \mathrm{~mol} \%)$ before gently warming to ensure the sensitizer was fully dissolved. The NMR tube was placed against a low pressure $9 \mathrm{~W}$ PL-S UVA lamp and the isomeric ratio was monitored every 15 mins by ${ }^{1} \mathrm{H}-\mathrm{NMR}$. 


\begin{tabular}{|l|l|l|}
\hline & \multicolumn{2}{|c|}{ trans $:$ cis } \\
\hline Time / mins & $\beta$-Me styrene & Me-cinnamate \\
\hline 15 & $1: 1.09$ & $1: 0.87$ \\
\hline 30 & $1: 1.15$ & $1: 1.03$ \\
\hline 45 & $1: 1.15$ & $1: 1.04$ \\
\hline
\end{tabular}

Table S14: 3,3'-MeOTX

\begin{tabular}{|l|l|l|l|}
\hline & \multicolumn{2}{|c|}{ trans $:$ cis } \\
\hline Time / mins & $\beta$-Me styrene & Me-cinnamate \\
\hline 15 & $1: 0.97$ & $1: 0.76$ \\
\hline 30 & $1: 1.13$ & $1: 1.00$ \\
\hline 45 & $1: 1.14$ & $1: 1.03$ & \\
\hline
\end{tabular}

\begin{tabular}{|l|l|l|l|}
\hline & \multicolumn{2}{|c|}{ trans $:$ cis } \\
\hline Time / mins & $\beta$-Me styrene & Me-cinnamate \\
\hline 15 & $1: 1.03$ & $1: 1.02$ \\
\hline 60 & $1: 1.23$ & & $1: 1.05$ \\
\hline
\end{tabular}

Table S16: 3-MeOTX

\begin{tabular}{|l|l|l|}
\hline & \multicolumn{2}{|c|}{ trans $:$ cis } \\
\hline Time / mins & $\beta$-Me styrene & Me-cinnamate \\
\hline 15 & $1: 0.88$ & $1: 0.77$ \\
\hline 30 & $1: 1.19$ & $1: 1.00$ \\
\hline 65 & $1: 1.24$ & $1: 1.04$ \\
\hline
\end{tabular}

Table S17: 3-FTX

\begin{tabular}{|l|l|l|}
\hline & \multicolumn{2}{|c|}{ trans $:$ cis } \\
\hline Time / mins & $\beta$-Me styrene & Me-cinnamate \\
\hline 15 & $1: 1.22$ & \\
\hline 30 & $1: 1.57$ & $1: 1.10$ \\
\hline 45 & $1: 1.64$ & $1: 1.11$ \\
\hline 60 & $1: 1.63$ & \\
\hline
\end{tabular}

Table S18: ITX

\begin{tabular}{|l|l|l|}
\hline & \multicolumn{2}{|c|}{ trans $:$ cis } \\
\hline Time / mins & $\beta$-Me styrene & Me-cinnamate \\
\hline 15 & $1: 1.50$ & $1: 0.83$ \\
\hline 30 & $1: 1.83$ & $1: 1.12$ \\
\hline 60 & $1: 1.86$ & $1: 1.15$ \\
\hline
\end{tabular}

Table S19: 2-FTX

\begin{tabular}{|l|l|l|}
\hline & \multicolumn{2}{|c|}{ trans $:$ cis } \\
\hline Time / mins & $\beta$-Me styrene & Me-cinnamate \\
\hline 15 & $1: 1.05$ & $1: 0.78$ \\
\hline 30 & $1: 1.90$ & $1: 1.11$ \\
\hline 45 & $1: 2.09$ & $1: 1.18$ \\
\hline 60 & $1: 2.13$ & $1: 1.21$ \\
\hline
\end{tabular}

Table S20: 4-MeOTX 


\begin{tabular}{|l|l|l|}
\hline & \multicolumn{2}{|c|}{ trans $:$ cis } \\
\hline Time / mins & $\beta$-Me styrene & Me-cinnamate \\
\hline 15 & $1: 2.32$ & $1: 1.06$ \\
\hline 30 & $1: 4.91$ & $1: 1.47$ \\
\hline 45 & $1: 4.82$ & $1: 1.52$ \\
\hline 60 & $1: 4.82$ & \\
\hline
\end{tabular}

Table S21: 2-MeOTX

\begin{tabular}{|l|l|l|l|}
\hline & \multicolumn{2}{|c|}{ trans $:$ cis } & \\
\hline Time / mins & $\beta$-Me styrene & Me-cinnamate \\
\hline 15 & $1: 1.72$ & $1: 1.31$ & \\
\hline 30 & $1: 4.66$ & $1: 1.73$ & \\
\hline 45 & $1: 4.92$ & $1: 1.73$ & \\
\hline 60 & $1: 4.97$ & & \\
\hline
\end{tabular}

Table S22: 2-F,2'-MeOTX

\begin{tabular}{|l|l|l|}
\hline & \multicolumn{2}{|c|}{ trans $:$ cis } \\
\hline Time / mins & $\beta$-Me styrene & Me-cinnamate \\
\hline 15 & $1: 2.02$ & $1: 1.17$ \\
\hline 30 & $1: 3.70$ & $1: 1.48$ \\
\hline 45 & $1: 3.55$ & $1: 1.46$ \\
\hline
\end{tabular}

Table S23: 2,2'-MeOTX

Sensitizer Screen with $125 \mathrm{~W}, 150 \mathrm{ml}$ Immersion Well Reactor

Enamide (1) to 2,4-methanopyrrolidine (2)

(A)

Scheme S9

The general immersion well batch irradiation procedure was followed using a $125 \mathrm{~W} \mathrm{Hg}$ lamp and 150 $\mathrm{ml}$ Pyrex reactor. A solution of enamide $1(3.95 \mathrm{~g}, 15 \mathrm{mmol})$ in degassed $\mathrm{MeCN}(150 \mathrm{ml})$ was irradiated with the relevant thioxanthone derivative $(0.6 \mathrm{mmol})$ and the reaction monitored by quantitative ${ }^{1} \mathrm{H}$ NMR using 1,3,5-trimethoxybenzene as an internal standard.

\begin{tabular}{|c|c|c|c|c|c|c|c|c|c|}
\cline { 2 - 10 } \multicolumn{1}{c}{ Sensitizer (4 mol \%) } \\
\hline Time (min) & $3,3^{\prime}-\mathrm{MeO}$ & $3,3^{\prime}-\mathrm{F}$ & $3-\mathrm{MeO}$ & $3-\mathrm{F}$ & $\mathrm{ITX}$ & $2-\mathrm{F}$ & $4-\mathrm{MeO}$ & 2-MeO & $2,2^{\prime}-\mathrm{MeO}$ \\
\hline 30 & 20 & 21 & 21 & 23 & 23 & 26 & 28 & 28 & 24 \\
\hline 60 & 36 & 41 & 46 & 42 & 45 & 52 & 55 & 49 & \\
\hline 150 & 93 & 99 & 99 & 97 & 94 & 95 & 96 & 100 & 92 \\
\hline $\begin{array}{c}\text { Initial } \\
\text { productivity } \\
\text { mmol/h }\end{array}$ & 5.4 & 6.2 & 6.9 & 6.3 & 6.8 & 7.8 & 8.3 & 7.4 & 7.2 \\
\hline
\end{tabular}

Table S24

THPA (3) to Cyclobutene (7)

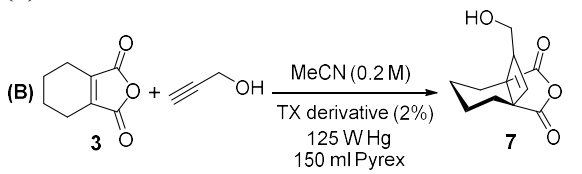

Scheme S10

The general immersion well batch irradiation procedure was followed using a $125 \mathrm{~W} \mathrm{Hg}$ lamp and 150 $\mathrm{ml}$ Pyrex reactor. A solution of THPA 3 (4.56 g, $30 \mathrm{mmol})$ and propargyl alcohol $(2.62 \mathrm{ml}, 45 \mathrm{mmol})$ 
in degassed $\mathrm{MeCN}(150 \mathrm{ml})$ was irradiated with the relevant thioxanthone derivative $(0.6 \mathrm{mmol})$ and the reaction monitored by quantitative ${ }^{1} \mathrm{H}$-NMR using $1,3,5$-trimethoxybenzene as an internal standard.

\begin{tabular}{|c|c|c|c|c|c|c|c|c|c|}
\cline { 2 - 11 } \multicolumn{1}{c|}{ Sensitizer (4 mol \%) } \\
\hline Time (min) & $3,3^{\prime}-\mathrm{MeO}$ & $3,3^{\prime}-\mathrm{F}$ & $3-\mathrm{MeO}$ & $3-\mathrm{F}$ & ITX & $2-\mathrm{F}$ & $4-\mathrm{MeO}$ & $2-\mathrm{MeO}$ & $2,2^{\prime}-\mathrm{MeO}$ \\
\hline 20 & 24 & 29 & 23 & 28 & 27 & 28 & 9 & & $/$ \\
\hline 40 & 48 & 58 & 47 & 55 & 58 & 59 & 17 & & $/$ \\
\hline 60 & 70 & 74 & 68 & 70 & 75 & 74 & 26 & 6 & $/$ \\
\hline $\begin{array}{c}\text { Initial } \\
\text { productivity } \\
\text { mmol/h }\end{array}$ & 22 & 26 & 21 & 25 & 24 & 8 & 1.8 & 0 \\
\hline
\end{tabular}

Table S25

Cross $[2+2]$ / retro-Mannich of $(8)$ to $(10)$

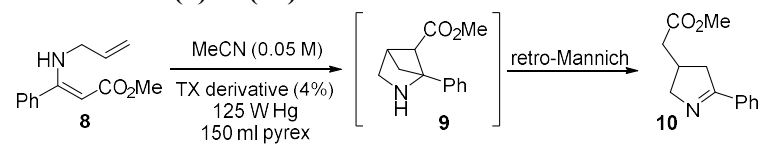

Scheme S11

A solution of enamine $8(1.63 \mathrm{~g}, 7.5 \mathrm{mmol})$ and the relevant TX derivative $(0.3 \mathrm{mmol})$ in degassed $\mathrm{MeCN}(150 \mathrm{ml})$ was irradiated in a $150 \mathrm{ml}$ Pyrex immersion well batch reactor with a $125 \mathrm{~W} \mathrm{Hg}$ lamp. The reaction was followed by quantitative ${ }^{1} \mathrm{H}-\mathrm{NMR}$ using 1,3,5-trimethoxybenzene as an internal standard. When at full conversion the concentrated reaction mixture was purified by chromatography on silica (30-40\% EtOAc in petrol) to yield cyclic imine $\mathbf{1 0}$ as a pale orange oil.

$\delta_{\mathrm{H}}\left(400 \mathrm{MHz}, \mathrm{CDCl}_{3}\right) 7.85-7.78(2 \mathrm{H}, \mathrm{m}, \mathrm{Ar} . \mathbf{H}), 7.45-7.36(3 \mathrm{H}, \mathrm{m}, \mathrm{Ar} . \mathbf{H}), 4.26(1 \mathrm{H}$, app. ddt, $J=$ 16.4, 8.0, $1.8 \mathrm{~Hz}, \mathrm{NCHH}), 3.74(1 \mathrm{H}, \mathrm{ddt}, J=16.4,5.4,1.9 \mathrm{~Hz}, \mathrm{NCHH}), 3.69\left(3 \mathrm{H}, \mathrm{s}, \mathrm{OCH}_{3}\right), 3.21(1 \mathrm{H}$, app. ddt, $J=17.0,9.0,1.8 \mathrm{~Hz}, \mathrm{CHH}), 2.94-2.82(1 \mathrm{H}, \mathrm{m}, \mathrm{CH}), 2.70$ (1H, app. ddt, $J=17.0,5.7,1.9$ $\mathrm{Hz}, \mathrm{CHH}), 2.53-2.40\left(2 \mathrm{H}, \mathrm{m}, \mathrm{CH}_{2}\right) ; \delta_{\mathrm{C}}\left(101 \mathrm{MHz}, \mathrm{CDCl}_{3}\right) 173.0(\mathrm{C}), 172.6(\mathrm{C}), 134.5(\mathrm{C}), 130.6$ $(\mathrm{CH}), 128.6(2 \times \mathrm{CH}), 127.6(2 \times \mathrm{CH}), 66.9\left(\mathrm{CH}_{2}\right), 51.8\left(\mathrm{CH}_{3}\right), 41.2\left(\mathrm{CH}_{2}\right), 39.3\left(\mathrm{CH}_{2}\right), 33.5(\mathrm{CH})$; ESIHRMS m/z $218.1175\left(\mathrm{MH}^{+} \mathrm{C}_{13} \mathrm{H}_{16} \mathrm{NO}_{2}\right.$ requires 218.1176)

\begin{tabular}{rrrrrrrrr} 
& \multicolumn{7}{c}{ Sensitizer (4 mol\%) } \\
\cline { 2 - 8 } time / $\min$ & 3,3'-MeOTX & 3,3'-FTX & 3-MeOTX & 3-FTX* & ITX* & 2-FTX* & 4-MeO* & 2-MeOTX* \\
\hline 0 & 0 & 0 & 0 & 0 & 0 & & 0 & 0 \\
30 & 22 & 25 & 24 & & 31 & 50 & 22 \\
60 & 38 & 43 & 41 & & 50 & & 53 & 30 \\
90 & 56 & 54 & 57 & 47 & 50 & 40 & 56 & 30 \\
120 & 72 & 63 & 64 & & & & 44 & 30 \\
150 & 78 & 62 & 62 & & & & & \\
\hline Isolated (g) & 1.08 & 0.76 & 0.76 & 0.78 & 0.68 & 0.64 & 0.51 & 0.48 \\
Isolated (\%) & $67 \%$ & $47 \%$ & $47 \%$ & $48 \%$ & $42 \%$ & $39 \%$ & $31 \%$ & $29 \%$ \\
\hline
\end{tabular}

* Full consumption of staring enamine observed but product integration inaccurate due to significant degradation by-products

Table S26 


\section{Cross [2+2] Sensitizer Screen in NMR Tubes}

A stock solution was prepared in a $5 \mathrm{ml}$ volumetric flask using $0.5 \mathrm{mmol}$ of the relevant $\alpha$-amido acrylate derivative and adiponitrile $(0.25 \mathrm{mmol})$ in deuterated acetonitrile $(0.1 \mathrm{M})$. For each irradiation, $0.4 \mathrm{ml}$ aliquots were added to an NMR tube containing the relevant thioxanthone derivative $(10 \mathrm{~mol} \%)$ before gently warming to ensure the sensitizer was fully dissolved. The NMR tube was placed against a low pressure $9 \mathrm{~W}$ PL-S UVA lamp and reaction was monitored every 15 mins by ${ }^{1} \mathrm{H}-\mathrm{NMR}$.

\section{$\alpha$-amido acrylate (11) to 2,4-methanoproline (12)}

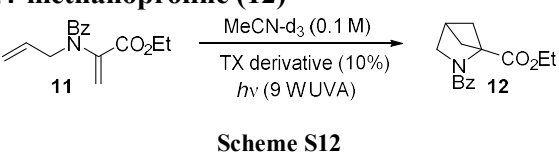

a-amido acrylate (13) to 2,4-methanoproline (14)

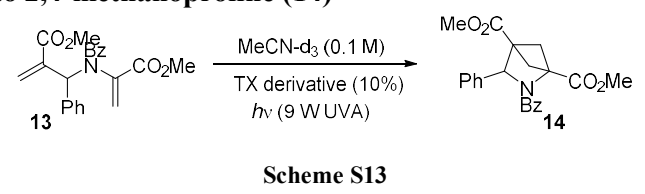

\begin{tabular}{|l|l|l|l|l|}
\cline { 2 - 5 } \multicolumn{1}{c|}{} & \multicolumn{2}{c|}{ Reaction D } & \multicolumn{2}{c|}{ Reaction E } \\
\hline Time / min & s.m. 11 (\%) & prod 12 (\%) & s.m. 13 (\%) & prod 14 (\%) \\
\hline 15 & 9 & 73 & 30 & 36 \\
\hline 30 & 0 & 80 & 7 & 52 \\
\hline
\end{tabular}

\begin{tabular}{|l|l|l|l|l|}
\cline { 2 - 5 } \multicolumn{1}{c|}{} & \multicolumn{2}{c|}{ Reaction D } & \multicolumn{2}{c|}{ Reaction E } \\
\hline Time / min & s.m. 11 (\%) & prod 12 (\%) & s.m. 13 (\%) & prod 14 (\%) \\
\hline 15 & 22 & 65 & 33 & 33 \\
\hline 30 & 0 & 84 & 9 & 46 \\
\hline
\end{tabular}

\begin{tabular}{|l|l|l|l|l|}
\cline { 2 - 5 } \multicolumn{1}{c|}{} & \multicolumn{2}{c|}{ Reaction D } & \multicolumn{2}{c|}{ Reaction E } \\
\hline Time / min & s.m. 11 (\%) & prod 12 (\%) & s.m. 13 (\%) & prod 14 (\%) \\
\hline 15 & 1 & 82 & 47 & 27 \\
\hline 30 & 0 & 83 & 17 & 42 \\
\hline
\end{tabular}

\begin{tabular}{|l|l|l|l|l|}
\cline { 2 - 5 } \multicolumn{1}{c|}{} & \multicolumn{2}{c|}{ Reaction D } & \multicolumn{2}{c|}{ Reaction E } \\
\hline Time / min & s.m. 11 (\%) & prod 12 (\%) & s.m. 13 (\%) & prod 14 (\%) \\
\hline 15 & 20 & 64 & 47 & 25 \\
\hline 30 & 3 & 78 & 17 & 40 \\
\hline
\end{tabular}

\begin{tabular}{|l|l|l|l|l|}
\cline { 2 - 5 } \multicolumn{1}{c|}{} & \multicolumn{2}{c|}{ Reaction D } & \multicolumn{2}{c|}{ Reaction E } \\
\hline Time / min & s.m. 11 (\%) & prod 12 (\%) & s.m. 13 (\%) & prod 14 (\%) \\
\hline 15 & 20 & 66 & 76 & 10 \\
\hline 30 & 2 & 80 & 56 & 18 \\
\hline
\end{tabular}




\begin{tabular}{|l|l|l|l|l|}
\cline { 2 - 5 } \multicolumn{1}{c|}{} & \multicolumn{2}{c|}{ Reaction D } & \multicolumn{2}{c|}{ Reaction E } \\
\hline Time / min & S.m. 11 (\%) & prod 12 (\%) & s.m. 13 (\%) & prod 14 (\%) \\
\hline 15 & 27 & 57 & 53 & 5 \\
\hline 30 & 2 & 76 & 73 & 9 \\
\hline
\end{tabular}

\begin{tabular}{|l|l|l|l|l|}
\cline { 2 - 5 } \multicolumn{1}{c|}{} & \multicolumn{2}{c|}{ Reaction D } & \multicolumn{2}{c|}{ Reaction E } \\
\hline Time / min & S.m. 11 (\%) & prod 12 (\%) & s.m. 13 (\%) & prod 14 (\%) \\
\hline 15 & 47 & 37 & & \\
\hline 30 & 27 & 57 & 75 & 8 \\
\hline
\end{tabular}

\begin{tabular}{|l|l|l|l|l|}
\cline { 2 - 5 } \multicolumn{1}{c|}{} & \multicolumn{2}{c|}{ Reaction D } & \multicolumn{2}{c|}{ Reaction E } \\
\hline Time / min & s.m. 11 (\%) & prod 12 (\%) & s.m. 13 (\%) & prod 14 (\%) \\
\hline 15 & 47 & 37 & & 8 \\
\hline 30 & 27 & 57 & 75 & Table S34 \\
\hline
\end{tabular}

\begin{tabular}{|l|l|l|l|l|}
\cline { 2 - 5 } \multicolumn{1}{c|}{} & \multicolumn{2}{c|}{ Reaction D } & \multicolumn{2}{c|}{ Reaction E } \\
\hline Time / min & s.m. 11 (\%) & prod 12 (\%) & s.m. 13 (\%) & prod 14 (\%) \\
\hline 15 & 79 & 4 & & 2 \\
\hline 60 & & \multicolumn{3}{c}{ Table S35 } \\
\hline
\end{tabular}

Preparative Scale Synthesis of 2,4-methanoproline (14)

\begin{tabular}{|c|c|c|c|c|c|}
\hline Entry & Sensitizer (mol \%) & Conc. (M) & Time (h) & Yield (\%) & Mass (g) \\
\hline 1 & $\mathrm{BP}(10)$ & 0.05 & 9 & 46 & 1.3 \\
\hline 2 & ITX (10) & 0.05 & 12 & 38 & 1.1 \\
\hline 3 & 3-FTX (10) & 0.05 & 5 & 51 & 1.45 \\
\hline 4 & 3,3'-MeOTX (5) & 0.1 & 3 & 56 & 3.2 \\
\hline 5 & 3,3'-MeOTX (2.5) & 0.2 & 7 & 51 & 5.8 \\
\hline
\end{tabular}

The general immersion well batch irradiation procedure was followed using a $125 \mathrm{~W} \mathrm{Hg}$ lamp and 150 $\mathrm{ml}$ Pyrex reactor. In all cases the sensitizer concentration was fixed at $0.005 \mathrm{M}$. When the reaction had reached full conversion, the solution was concentrated and triturated with $\mathrm{Et}_{2} \mathrm{O}$, filtered and the residue washed with $\mathrm{Et}_{2} \mathrm{O}$ to yield product 14 as a white solid: m.p. $170-171^{\circ} \mathrm{C} ; \delta_{\mathrm{H}}\left(400 \mathrm{MHz}, \mathrm{CDCl}_{3}\right) 7.43-$ 7.29 (8H, m, Ar.H), 7.15 - 7.09 (2H, m, Ar.H), 4.95 (1H, s, NCH), 3.85 (3H, s, OCH $), 3.61(3 \mathrm{H}, \mathrm{s}$, $\left.\mathrm{OCH}_{3}\right), 2.63(1 \mathrm{H}, \mathrm{d}, J=7.3 \mathrm{~Hz}, \mathrm{CHH}), 2.58(1 \mathrm{H}, \mathrm{dd}, J=10.0,8.3 \mathrm{~Hz}, \mathrm{CHH}), 2.26-2.20(2 \mathrm{H}, \mathrm{m}$, CHH, CHH); $\delta_{\mathrm{C}}\left(101 \mathrm{MHz}, \mathrm{CDCl}_{3}\right) 177.0(\mathrm{C}), 169.2(\mathrm{C}), 168.3(\mathrm{C}), 138.4(\mathrm{C}), 134.1(\mathrm{C}), 131.6(\mathrm{CH})$, $128.6(2 \times \mathrm{CH}), 128.4(\mathrm{CH}), 128.3(2 \times \mathrm{CH}), 128.0(2 \times \mathrm{CH}), 127.7(2 \times \mathrm{CH}), 67.6(\mathrm{CH}), 67.4(\mathrm{C}), 53.7(\mathrm{C})$, $52.5\left(\mathrm{CH}_{3}\right), 52.1\left(\mathrm{CH}_{3}\right), 48.3\left(\mathrm{CH}_{2}\right), 38.8\left(\mathrm{CH}_{2}\right)$; ESI-HRMS m/z $380.1489\left(\mathrm{MH}^{+} \mathrm{C}_{22} \mathrm{H}_{22} \mathrm{NO}_{5}\right.$ requires $380.1492)$ 


\section{Blue Light Mediated Reactions with 36 W, 455 nm COB Reactor}

\section{General procedure}

A solution of the relevant substrate in degassed solvent was added to a multi-necked round bottom flask connected to a nitrogen line. The headspace was purged with $\mathrm{N}_{2}$ several times before the addition of 2,2'-MeOTX. The solution was stirred over the modified hotplate COB reactor (see above) from a distance of approximately $15 \mathrm{~mm}$, with fan cooling. Sample were taken periodically for quantitative analysis by ${ }^{1} \mathrm{H}-\mathrm{NMR}$ using 1,3,6-trimethoxybenzene as an internal standard (see general batch irradiation procedure above) to determine the precise endpoint of the reaction for accurate reactor comparison.

\section{Intramolecular $[2+2]$ of Styrene 15}

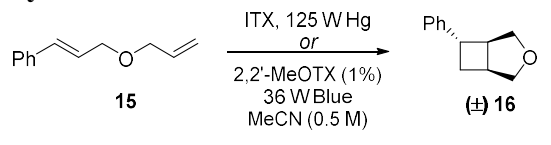

Scheme S14

$125 \mathrm{~W}$ Batch Irradiation: The general immersion well batch procedure was followed using a $125 \mathrm{~W}$ $\mathrm{Hg}$ lamp and $150 \mathrm{ml}$ Pyrex reactor to irradiate allylic ether $15(2.61 \mathrm{~g}, 15 \mathrm{mmol})$ in degassed $\mathrm{MeCN}$ $(0.1 \mathrm{M})$ with ITX $(191 \mathrm{mg}, 0.75 \mathrm{mmol})$. After $2.75 \mathrm{hrs}$ the reaction mixture was concentrated in vacuo and chromatography on silica $\left(10 \% \mathrm{Et}_{2} \mathrm{O}\right.$ in $\left.\mathrm{DCM}\right)$ yielded product 16 as a mixture of diastereomers (1 : 0.17), oil (2.34 g, 90\%)

$36 \mathrm{~W}$ Blue COB Irradiation: The general $36 \mathrm{~W}$ COB reactor procedure was followed by irradiating allylic ether $15(1.74 \mathrm{~g}, 10 \mathrm{mmol})$ in degassed $\mathrm{MeCN}(0.5 \mathrm{M})$ with 2,2'-MeOTX $(27 \mathrm{mg}, 0.1 \mathrm{mmol})$ in a $50 \mathrm{ml}$ flask for $3 \mathrm{hrs}$. The reaction mixture was concentrated in vacuo and chromatography on silica $\left(10 \% \mathrm{Et}_{2} \mathrm{O}\right.$ in DCM) yielded product 16 as a mixture of diastereomers (1:0.15), oil (1.54 g, 89\%)

\section{Intramolecular [2+2] of Styrene 17}

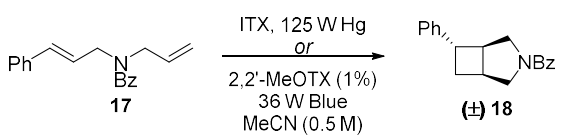

Scheme S15

$125 \mathrm{~W}$ Batch Irradiation: The general immersion well batch procedure was followed using a $125 \mathrm{~W}$ Hg lamp and $150 \mathrm{ml}$ Pyrex reactor to irradiate allylic amide 17 (4.16 g, $15 \mathrm{mmol})$ in degassed $\mathrm{MeCN}$ $(0.1 \mathrm{M})$ with ITX $(191 \mathrm{mg}, 0.75 \mathrm{mmol})$. After $3.5 \mathrm{hrs}$ the reaction mixture was concentrated in vacuo and chromatography on silica (30\% EtOAc in petrol) yielded product $\mathbf{1 8}$ as a rotameric mixture of diastereomers, oil $(4.02 \mathrm{~g}, 97 \%)$ Major diastereomer: $\delta_{\mathrm{H}}\left(500 \mathrm{MHz}, \mathrm{DMSO}-\mathrm{d}_{6}, 100^{\circ} \mathrm{C}\right) 7.57-7.44(5 \mathrm{H}$, $\mathrm{m}, \mathrm{Ar} . \mathbf{H}), 7.33-7.16(5 \mathrm{H}, \mathrm{m}, \mathrm{Ar} . \mathbf{H}), 3.90-3.70(2 \mathrm{H}, \mathrm{m}, 2 \times \mathrm{NCHH}), 3.56(1 \mathrm{H}, \mathrm{dd}, J=12.3,6.6 \mathrm{~Hz}$, $\mathrm{NCHH}), 3.45(1 \mathrm{H}, \mathrm{dd}, J=12.3,5.2 \mathrm{~Hz}, \mathrm{NCHH}), 3.26-3.20(1 \mathrm{H}, \mathrm{m}, \mathrm{CH}), 3.02-2.93(2 \mathrm{H}, \mathrm{m}, \mathrm{CH}$, CH), $2.33-2.25(1 \mathrm{H}, \mathrm{m}, \mathrm{CHH}), 2.17-2.09(1 \mathrm{H}, \mathrm{m}, \mathrm{CHH}) ; \delta_{\mathrm{C}}\left(126 \mathrm{MHz}, \mathrm{DMSO}-\mathrm{d}_{6}, 120^{\circ} \mathrm{C}\right) 168.6$ $(\mathrm{C}), 144.4(\mathrm{C}), 137.2(\mathrm{C}), 128.8(\mathrm{CH}), 127.7(2 \times \mathrm{CH}), 127.6(2 \times \mathrm{CH}), 126.4(2 \times \mathrm{CH}), 125.6(2 \times \mathrm{CH})$, $125.3(\mathrm{CH}), 52.7\left(\mathrm{CH}_{2}\right), 44.9(\mathrm{CH}), 41.5(\mathrm{CH}), 33.1(\mathrm{CH}), 31.0\left(\mathrm{CH}_{2}\right)$; ESI-HRMS m/z $278.1542\left(\mathrm{MH}^{+}\right.$ $\mathrm{C}_{19} \mathrm{H}_{20} \mathrm{NO}$ requires 278.1539)

$36 \mathrm{~W}$ Blue COB Irradiation: The general $36 \mathrm{~W}$ COB reactor procedure was followed by irradiating allylic amide 17 (8.32 g, $30 \mathrm{mmol})$ in degassed $\mathrm{MeCN}(0.5 \mathrm{M})$ with 2,2'-MeOTX (82 mg, $0.3 \mathrm{mmol}$ ) in a $100 \mathrm{ml}$ flask for $5 \mathrm{hrs}$. The reaction mixture was concentrated in vacuo and chromatography on 
silica (30\% EtOAc in petrol) yielded product 18 as a rotameric mixture of diastereomers, oil ( $7.13 \mathrm{~g}$, $86 \%)$

\section{Cross $[2+2]$ of Enamide 1}

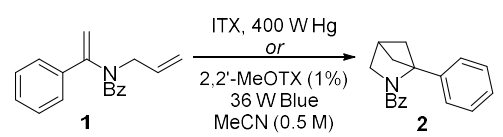

Scheme S16

400 W Batch Irradiation: Batch irradiation previously reported ${ }^{10}$ when enamide 1 (105 g, 400 mmol) was irradiated in $\mathrm{MeCN}(0.4 \mathrm{M})$ with ITX $(1.0 \mathrm{~g}, 4 \mathrm{mmol})$ with a $400 \mathrm{~W}$ Hg lamp in a $1 \mathrm{~L}$ Pyrex reactor for $24 \mathrm{hrs}$. The product 2 was isolated as a pale yellow solid $(93.4 \mathrm{~g}, 89 \%)$

36 W Blue COB Irradiation: The general $36 \mathrm{~W}$ COB reactor procedure was followed by irradiating enamide 1 (7.90 g, $30 \mathrm{mmol})$ in degassed $\mathrm{MeCN}(0.5 \mathrm{M})$ with 2,2'-MeOTX ( $82 \mathrm{mg}, 0.3 \mathrm{mmol})$ in a $100 \mathrm{ml}$ flask for $3 \mathrm{hrs}$. The reaction mixture was concentrated in vacuo and triturated with hexane and filtered, washing with cold $\mathrm{Et}_{2} \mathrm{O}$ to give 2 as a pale yellow solid (6.58 g, 83\%)

\section{Cross $[2+2]$ of Enamide 19}

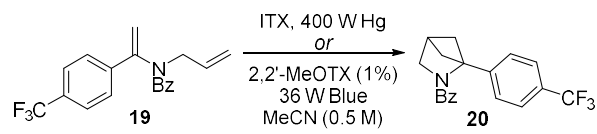

Scheme S17

400 W Batch Irradiation: Batch irradiation previously reported ${ }^{11}$ when enamide 19 (265 g, $\left.800 \mathrm{mmol}\right)$ was irradiated in $\mathrm{MeCN}(0.4 \mathrm{M})$ with ITX $(2.0 \mathrm{~g}, 8 \mathrm{mmol})$ with a $400 \mathrm{~W} \mathrm{Hg}$ lamp in a 2 L Pyrex reactor for $35 \mathrm{hrs}$. The product $\mathbf{2 0}$ was isolated as a pale yellow solid $(249 \mathrm{~g}, 94 \%)$

36 W Blue COB Irradiation: The general $36 \mathrm{~W}$ COB reactor procedure was followed by irradiating enamide 19 (9.94 g, $30 \mathrm{mmol})$ in degassed $\mathrm{MeCN}(0.5 \mathrm{M})$ with 2,2'-MeOTX ( $82 \mathrm{mg}, 0.3 \mathrm{mmol})$ in a $100 \mathrm{ml}$ flask for $1.5 \mathrm{hrs}$. The reaction mixture was concentrated in vacuo and triturated with hexane and filtered, washing with cold $\mathrm{Et}_{2} \mathrm{O}$ to give $\mathbf{2 0}$ as a pale yellow solid (9.05 g, 91\%)

\section{Cross [2+2] of Enamide 21}

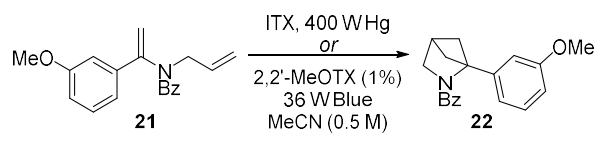

400 W Batch Irradiation: Batch irradiation previously reported ${ }^{11}$ when enamide 21 (117 g, $\left.400 \mathrm{mmol}\right)$ was irradiated in $\mathrm{MeCN}(0.2 \mathrm{M})$ with ITX $(1.0 \mathrm{~g}, 4 \mathrm{mmol})$ with a $400 \mathrm{~W}$ Hg lamp in a 2 L Pyrex reactor for $29 \mathrm{hrs}$. The product 22 was isolated as a pale yellow solid (102 g, 87\%)

$36 \mathrm{~W}$ Blue COB Irradiation: The general $36 \mathrm{~W}$ COB reactor procedure was followed by irradiating enamide $21(8.80 \mathrm{~g}, 30 \mathrm{mmol})$ in degassed $\mathrm{MeCN}(0.5 \mathrm{M})$ with 2,2'-MeOTX $(82 \mathrm{mg}, 0.3 \mathrm{mmol})$ in a $100 \mathrm{ml}$ flask for $3.5 \mathrm{hrs}$. The reaction mixture was concentrated in vacuo and triturated with hexane and filtered, washing with cold $\mathrm{Et}_{2} \mathrm{O}$ to give 22 as a pale yellow solid $(7.78 \mathrm{~g}, 88 \%)$ 


\section{Cross $[2+2]$ of Enamide 23}

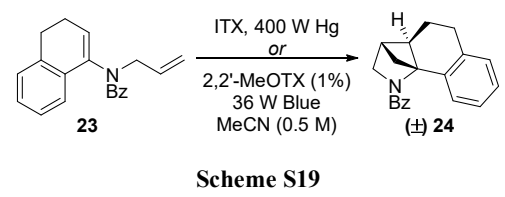

400 W Batch Irradiation: The general immersion well batch procedure was followed using a $400 \mathrm{~W}$ Hg lamp and $1 \mathrm{~L}$ Pyrex reactor to irradiate enamide 23 (57.9 g, $200 \mathrm{mmol})$ in degassed $\mathrm{MeCN}(0.2 \mathrm{M})$ with ITX (1.0 g, $4 \mathrm{mmol})$. After $20 \mathrm{hrs}$ the reaction mixture was concentrated in vacuo and triturated with hexane and filtered, washing with cold $\mathrm{Et}_{2} \mathrm{O}$ to give $\mathbf{2 4}$ as a beige powder $(39.5 \mathrm{~g}, 68 \%)$ : m.p. 138$139^{\circ} \mathrm{C} ; \delta_{\mathrm{H}}\left(500 \mathrm{MHz}, \mathrm{DMSO}_{-} \mathrm{d}_{6}, 80^{\circ} \mathrm{C}\right) 7.58-7.52(2 \mathrm{H}, \mathrm{m} \mathrm{Ar} . \mathbf{H}), 7.44-7.32(3 \mathrm{H}, \mathrm{m}, \mathrm{Ar} . \mathbf{H}), 7.12-$ $6.92(4 \mathrm{H}, \mathrm{m}, \mathrm{Ar} . \mathbf{H}), 3.90(1 \mathrm{H}, \mathrm{d}, J=8.0 \mathrm{~Hz}, \mathrm{NCHH}), 3.38(1 \mathrm{H}, \mathrm{d}, J=8.0 \mathrm{~Hz}, \mathrm{NCHH}), 2.85-2.73(2 \mathrm{H}$, $\left.\mathrm{m}, \mathbf{C H}_{2}\right), 2.70(1 \mathrm{H}, \mathrm{s}, \mathrm{CH}), 2.42-2.37(1 \mathrm{H}, \mathrm{m}, \mathrm{CHH}), 2.19-1.96\left(4 \mathrm{H}, \mathrm{m}, \mathrm{CH}_{2}, \mathrm{CH}, \mathrm{CHH}\right) ; \delta_{\mathrm{C}}(126$ MHz, DMSO-d $\left.6,80^{\circ} \mathrm{C}\right) 171.3(\mathrm{C}), 136.4(\mathrm{C}), 135.7(\mathrm{C}), 135.0(\mathrm{C}), 129.9(\mathrm{CH}), 128.0(\mathrm{CH}), 127.6$ $(2 \times \mathrm{CH}), 127.4(2 \times \mathrm{CH}), 125.6(\mathrm{CH}), 125.1(\mathrm{CH}), 125.0(\mathrm{CH}), 71.1(\mathrm{C}), 56.7\left(\mathrm{CH}_{2}\right), 49.8(\mathrm{CH}), 45.8$ $\left(\mathrm{CH}_{2}\right), 36.6(\mathrm{CH}), 28.7\left(\mathrm{CH}_{2}\right), 23.2\left(\mathrm{CH}_{2}\right)$; ESI-HRMS m/z $290.1544\left(\mathrm{MH}^{+} \mathrm{C}_{20} \mathrm{H}_{20} \mathrm{NO}\right.$ requires 290.1539)

$36 \mathrm{~W}$ Blue COB Irradiation: The general $36 \mathrm{~W}$ COB reactor procedure was followed by irradiating enamide $23(8.68 \mathrm{~g}, 30 \mathrm{mmol})$ in degassed $\mathrm{MeCN}(0.5 \mathrm{M})$ with 2,2'-MeOTX ( $82 \mathrm{mg}, 0.3 \mathrm{mmol})$ in a $100 \mathrm{ml}$ flask for 6 hrs. The reaction mixture was concentrated in vacuo and triturated with hexane and filtered, washing with cold $\mathrm{Et}_{2} \mathrm{O}$ to give $\mathbf{2 4}$ as a beige solid (5.87 g, 68\%)

Cross [2+2] of Amino Cinnamate 25

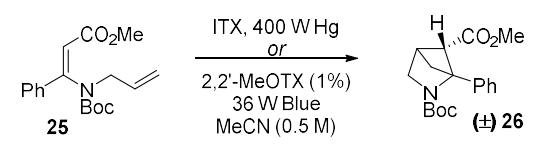

Scheme S20

$400 \mathrm{~W}$ Batch Irradiation: The general immersion well batch procedure was followed using a $400 \mathrm{~W}$ Hg lamp and $400 \mathrm{ml}$ Pyrex reactor to irradiate amino cinnamate $25(12.7 \mathrm{~g}, 40 \mathrm{mmol})$ in degassed $\operatorname{MeCN}(0.1 \mathrm{M})$ with ITX $(0.5 \mathrm{~g}, 2 \mathrm{mmol})$. After $3.5 \mathrm{hrs}$ the reaction mixture was concentrated in vacuo and triturated with hexane and filtered, washing with petrol to give $\mathbf{2 6}$ as a pale yellow solid $(9.2 \mathrm{~g}$, $72 \%)$

$36 \mathrm{~W}$ Blue COB Irradiation: The general $36 \mathrm{~W}$ COB reactor procedure was followed by irradiating amino cinnamate $25(9.52 \mathrm{~g}, 30 \mathrm{mmol})$ in degassed $\mathrm{MeCN}(0.5 \mathrm{M})$ with 2,2'-MeOTX $(82 \mathrm{mg}, 0.3$ $\mathrm{mmol}$ ) in a $100 \mathrm{ml}$ flask for $3.75 \mathrm{hrs}$. The reaction mixture was concentrated in vacuo and triturated with hexane and filtered, washing with petrol to give $\mathbf{2 6}$ as a white solid $(7.98 \mathrm{~g}, 84 \%)$ : m.p. $73-74^{\circ} \mathrm{C}$; $\delta_{\mathrm{H}}\left(400 \mathrm{MHz}, \mathrm{CDCl}_{3}\right) 7.45-7.21(5 \mathrm{H}, \mathrm{m}, \mathrm{Ar} . \mathbf{H}), 3.92(1 \mathrm{H}, \mathrm{d}, J=8.9 \mathrm{~Hz}, \mathrm{NCHH}), 3.70\left(3 \mathrm{H}, \mathrm{s}, \mathrm{OCH}_{3}\right)$, $3.56(1 \mathrm{H}, \mathrm{d}, J=8.9 \mathrm{~Hz}, \mathrm{NCHH}), 3.08-3.02(2 \mathrm{H}, \mathrm{m}, \mathrm{CH}, \mathrm{CH}), 1.92-1.84\left(2 \mathrm{H}, \mathrm{m}, \mathrm{CH}_{2}\right), 1.07(9 \mathrm{H}, \mathrm{s}$, $\left.3 \times \mathrm{CH}_{3}\right) ; \delta_{\mathrm{C}}\left(101 \mathrm{MHz}, \mathrm{CDCl}_{3}\right) 169.7(\mathrm{C}), 157.1(\mathrm{C}), 138.5(\mathrm{C}), 127.9(2 \times \mathrm{CH}), 127.3(\mathrm{CH}), 126.8$ $(2 \times \mathrm{CH}), 79.1(\mathrm{C}), 76.5(\mathrm{C}), 51.7\left(\mathrm{CH}_{3}\right), 51.0(\mathrm{CH}), 50.9\left(\mathrm{CH}_{2}\right), 45.3\left(\mathrm{CH}_{2}\right), 38.0(\mathrm{CH}), 28.0\left(3 \times \mathrm{CH}_{3}\right)$; ESI-HRMS m/z $318.1693\left(\mathrm{MH}^{+} \mathrm{C}_{18} \mathrm{H}_{24} \mathrm{NO}_{4}\right.$ requires 318.1700) 
Intramolecular [2+2] of Alkoxy-maleimide 27

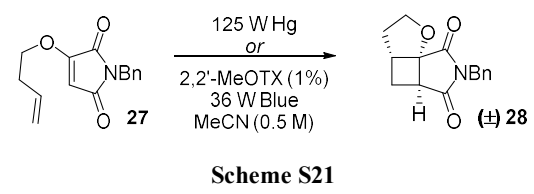

125 W Batch Irradiation: The general immersion well batch procedure was followed using a $125 \mathrm{~W}$ $\mathrm{Hg}$ lamp and $150 \mathrm{ml}$ Pyrex reactor to irradiate alkoxy-maleimide $27(3.86 \mathrm{~g}, 15 \mathrm{mmol})$ in degassed $\mathrm{MeCN}(0.1 \mathrm{M})$. After $1.5 \mathrm{hrs}$ the reaction mixture was concentrated in vacuo and chromatography on silica (5\% $\mathrm{Et}_{2} \mathrm{O}$ in DCM) yielded product 28 as a white solid (3.57 $\left.\mathrm{g}, 92 \%\right)$

$36 \mathrm{~W}$ Blue COB Irradiation: The general $36 \mathrm{~W}$ COB reactor procedure was followed by irradiating alkoxy-maleimide 27 (2.57 g, $10 \mathrm{mmol})$ in degassed $\mathrm{MeCN}(0.1 \mathrm{M})$ with 2,2'-MeOTX (136 mg, 0.5 $\mathrm{mmol}$ ) in a $250 \mathrm{ml}$ flask for $1.5 \mathrm{hrs}$. The reaction mixture was concentrated in vacuo and triturated with hexane and filtered, washing with cold $\mathrm{Et}_{2} \mathrm{O}$ to give $\mathbf{2 8}$ as a pale yellow solid $(2.38 \mathrm{~g}, 93 \%)$ : m.p. 127$129^{\circ} \mathrm{C} ; \delta_{\mathrm{H}}\left(400 \mathrm{MHz}, \mathrm{CDCl}_{3}\right) 7.40-7.25(5 \mathrm{H}, \mathrm{m}, \mathrm{Ar} . \mathbf{H}), 4.75(1 \mathrm{H}, \mathrm{d}, J=14.1 \mathrm{~Hz}, \mathrm{NCHHPh}), 4.71$ $(1 \mathrm{H}, \mathrm{d}, J=14.1 \mathrm{~Hz}, \mathrm{NCHHPh}), 4.45(1 \mathrm{H}$, ddd, $J=9.3,7.7,1.8 \mathrm{~Hz}, \mathrm{OCHH}), 4.09$ (1H, ddd, $J=10.7$, 9.3, $5.7 \mathrm{~Hz}, \mathrm{OCHH}), 3.15-3.08(1 \mathrm{H}, \mathrm{m}, \mathrm{CH}), 3.05(1 \mathrm{H}, \mathrm{ddd}, J=10.4,4.3,1.1 \mathrm{~Hz}, \mathrm{CH}), 2.20(1 \mathrm{H}$, ddd, $J=13.7,8.2,4.2 \mathrm{~Hz}, \mathrm{CHH}), 2.15-2.06(1 \mathrm{H}, \mathrm{m}, \mathrm{CHH}), 2.12(1 \mathrm{H}, \mathrm{dd}, J=10.4,5.7 \mathrm{~Hz}, \mathrm{CHH}), 1.87$ $(1 \mathrm{H}, \mathrm{ddt}, J=12.8,5.7,1.7 \mathrm{~Hz}, \mathrm{CHH}) ; \delta_{\mathrm{C}}\left(101 \mathrm{MHz}, \mathrm{CDCl}_{3}\right) 176.4(\mathrm{C}), 175.3(\mathrm{C}), 135.7(\mathrm{C}), 128.8$ $(2 \times \mathrm{CH}), 128.7(2 \times \mathrm{CH}), 128.1(\mathrm{CH}), 84.6(\mathrm{C}), 71.0\left(\mathrm{CH}_{2}\right), 42.6\left(\mathrm{CH}_{2}\right), 42.6(\mathrm{CH}), 41.9(\mathrm{CH}), 31.9$ $\left(\mathrm{CH}_{2}\right), 25.0\left(\mathrm{CH}_{2}\right)$

\section{Cookson's Dione [2+2]}

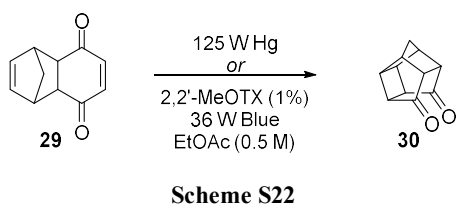

125 W Batch Irradiation: Batch irradiation previously reported when Diels Alder adduct 29 (2.61 g, $15 \mathrm{mmol}$ ) was irradiated in EtOAc $(0.1 \mathrm{M})$ with a $125 \mathrm{~W} \mathrm{Hg}$ lamp in a $150 \mathrm{ml}$ Pyrex reactor for 15 min. The product 30 was isolated as an off-white solid (2.38 g, 91\%)

$36 \mathrm{~W}$ Blue COB Irradiation: The general $36 \mathrm{~W}$ COB reactor procedure was followed by irradiating Diels Alder adduct 29 (2.61 g, $15 \mathrm{mmol})$ in degassed EtOAc $(0.5 \mathrm{M})$ with 2,2'-MeOTX (41 mg, 0.15 $\mathrm{mmol}$ ) in a $50 \mathrm{ml}$ flask for $25 \mathrm{~min}$. The reaction mixture was concentrated in vacuo and triturated with hexane and filtered, washing with cold $\mathrm{Et}_{2} \mathrm{O}$ to give 30 as a pale yellow solid (2.41 $\left.\mathrm{g}, 92 \%\right)$ 


\section{Comparison with non-Sensitized Reaction}
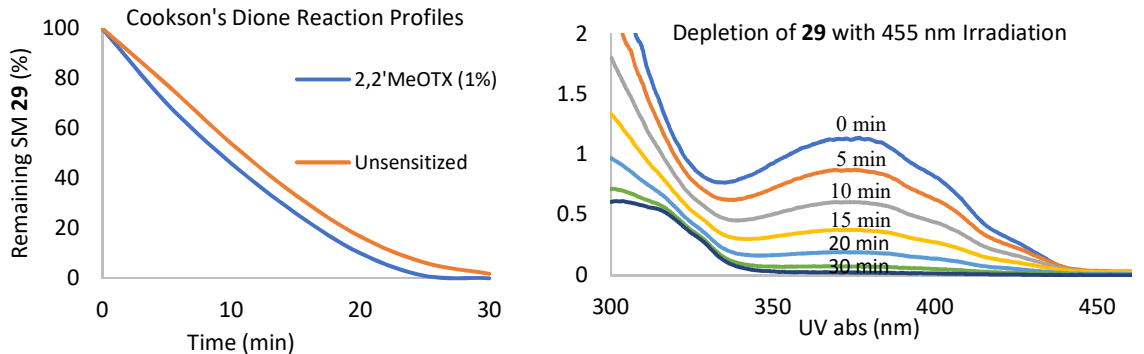

Figure S13: left- Depletion of $\mathbf{2 9}$ over time with, and without 2,2'MeOTX (36 W blue COB); Right- UV absorption of 29 over time with irradiation at $455 \mathrm{~nm}$ showing depletion of peak at $374 \mathrm{~nm}$

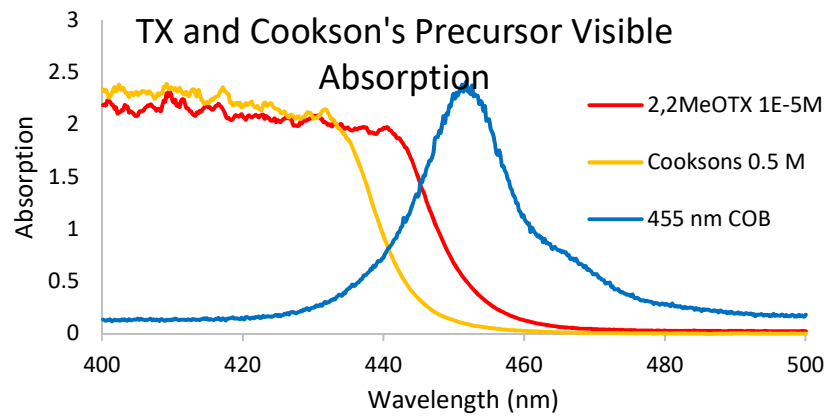

Figure S14: Comparison of vis light absorption of enedione 29 and 2,2'-MeOTX 
X-Ray Data for 24 and 26

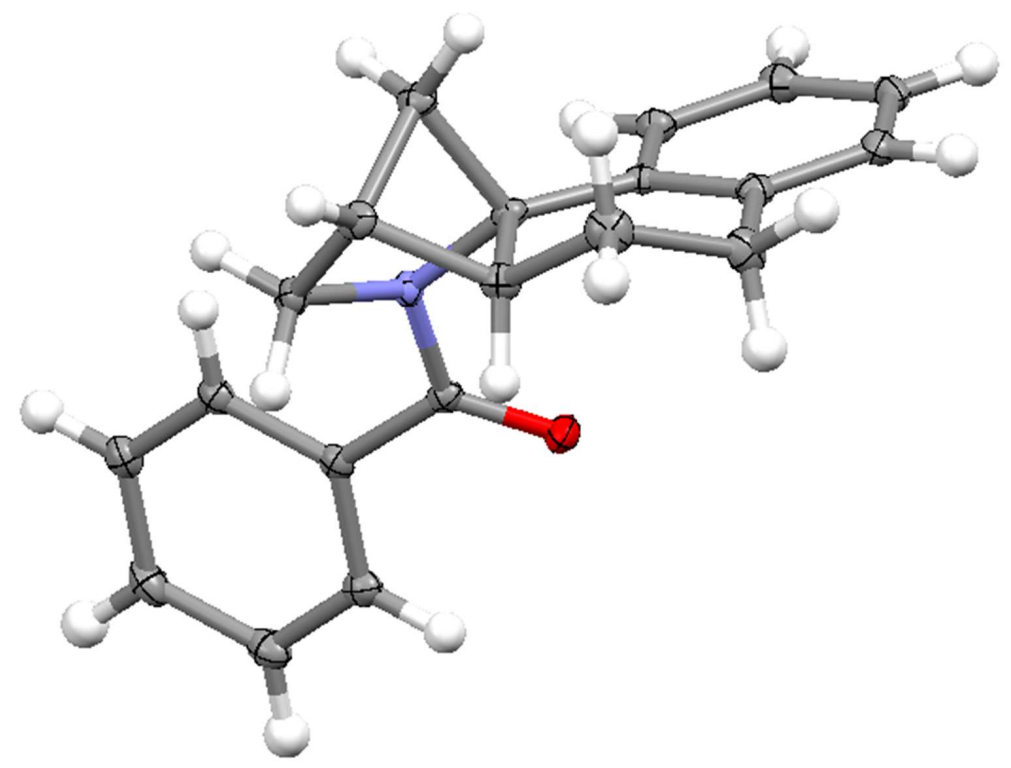

Figure S15: X-Ray structure of compound 24. Ellipsoids shown at 30\% probability

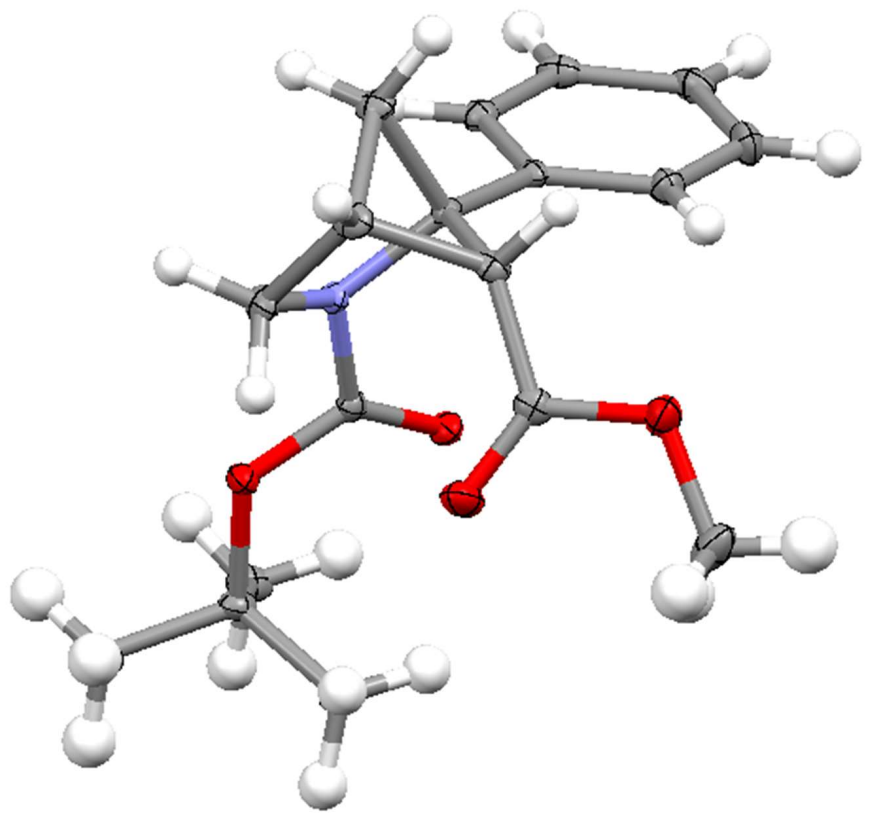

Figure S16: X-Ray structure of compound 26. Ellipsoids shown at 30\% probability 


\section{Crystallography}

X-ray diffraction experiments on $\mathbf{2 4}$ and $\mathbf{2 6}$ were carried out at 100(2) $\mathrm{K}$ on a Bruker APEX II diffractometer with CCD using Mo- $\mathrm{K}_{\alpha}$ radiation $(\lambda=0.71073 \AA)$. Intensities were integrated in SAINT $^{12}$ and absorption corrections based on equivalent reflections were applied using SADABS. ${ }^{13}$ Both structures were solved using ShelXT ${ }^{14}$ and refined by full matrix least squares against $F^{2}$ in ShelXL ${ }^{15,16}$ using Olex $2^{17}$. All of the non-hydrogen atoms were refined anisotropically. While all of the hydrogen atoms were located geometrically and refined using a riding model. Crystal structure and refinement data are given in Table S37. Crystallographic data for compounds $\mathbf{2 4}$ and $\mathbf{2 6}$ have been deposited with the Cambridge Crystallographic Data Centre as supplementary publication CCDC 1989743-1989744. Copies of the data can be obtained free of charge on application to CCDC, 12 Union Road, Cambridge CB2 1EZ, UK [fax(+44) 1223 336033, e-mail: deposit@ccdc.cam.ac.uk]. 


\begin{tabular}{|c|c|c|}
\hline Identification code & 24 & 26 \\
\hline Empirical formula & $\mathrm{C}_{20} \mathrm{H}_{19} \mathrm{NO}$ & $\mathrm{C}_{18} \mathrm{H}_{23} \mathrm{NO}_{4}$ \\
\hline Formula weight & 289.36 & 317.37 \\
\hline Temperature/K & $100(2)$ & $100(2)$ \\
\hline Crystal system & monoclinic & monoclinic \\
\hline Space group & $P 2_{1} / c$ & $P 2_{1} / n$ \\
\hline$a / \AA$ & $18.0122(7)$ & $12.9756(6)$ \\
\hline$b / \AA$ & $7.3245(2)$ & $7.5343(3)$ \\
\hline$c / \AA$ & $11.5355(4)$ & $17.9068(8)$ \\
\hline$\alpha /{ }^{\circ}$ & 90 & 90 \\
\hline$\beta /{ }^{\circ}$ & $97.158(2)$ & $100.916(3)$ \\
\hline$\gamma /{ }^{\circ}$ & 90 & 90 \\
\hline Volume $/ \AA^{3}$ & $1510.02(9)$ & $1718.93(13)$ \\
\hline Z & 4 & 4 \\
\hline$\rho_{\text {calc }} \mathrm{g} / \mathrm{cm}^{3}$ & 1.273 & 1.226 \\
\hline$\mu / \mathrm{mm}^{-1}$ & 0.078 & 0.086 \\
\hline $\mathrm{F}(000)$ & 616.0 & 680.0 \\
\hline Crystal size $/ \mathrm{mm}^{3}$ & $0.456 \times 0.198 \times 0.14$ & $0.495 \times 0.405 \times 0.373$ \\
\hline Radiation & $\operatorname{MoK} \alpha(\lambda=0.71073)$ & $\operatorname{MoK} \alpha(\lambda=0.71073)$ \\
\hline $2 \theta$ range for data collection $/{ }^{\circ}$ & 4.558 to 50.694 & 3.574 to 55.886 \\
\hline Index ranges & $\begin{array}{l}-21 \leq \mathrm{h} \leq 21 \\
-8 \leq \mathrm{k} \leq 8 \\
-13 \leq 1 \leq 13\end{array}$ & $\begin{array}{l}-16 \leq \mathrm{h} \leq 17 \\
-9 \leq \mathrm{k} \leq 9 \\
-23 \leq 1 \leq 23\end{array}$ \\
\hline Reflections collected & 21808 & 15326 \\
\hline $\mathrm{R}_{\text {int }} / \mathrm{R}_{\text {sigma }}$ & $0.0653 / 0.0358$ & $0.0340 / 0.0327$ \\
\hline Data/restraints/parameters & $2759 / 0 / 199$ & $4103 / 0 / 212$ \\
\hline Goodness-of-fit on $\mathrm{F}^{2}$ & 1.034 & 1.035 \\
\hline Final R indexes $[\mathrm{I}>=2 \sigma(\mathrm{I})]$ & $\begin{array}{l}\mathrm{R}_{1}=0.0400 \\
\mathrm{wR}_{2}=0.0933\end{array}$ & $\begin{array}{l}\mathrm{R}_{1}=0.0400 \\
\mathrm{wR}_{2}=0.0950\end{array}$ \\
\hline Final $\mathrm{R}$ indexes [all data] & $\begin{array}{l}\mathrm{R}_{1}=0.0590 \\
\mathrm{wR}_{2}=0.1040\end{array}$ & $\begin{array}{l}\mathrm{R}_{1}=0.0515 \\
\mathrm{wR}_{2}=0.1018\end{array}$ \\
\hline Largest diff. peak/hole / e $\AA^{-3}$ & $0.17 /-0.21$ & $0.24 /-0.24$ \\
\hline
\end{tabular}

Table S37: Crystal data and structure refinement for $\mathbf{2 4}$ and $\mathbf{2 6}$. 


\section{Copies of ${ }^{1} \mathrm{H}$ and ${ }^{13} \mathrm{C}$ NMR Spectra}

1H-NMR (400 MHz, $\mathrm{CDCl}_{3}$ )

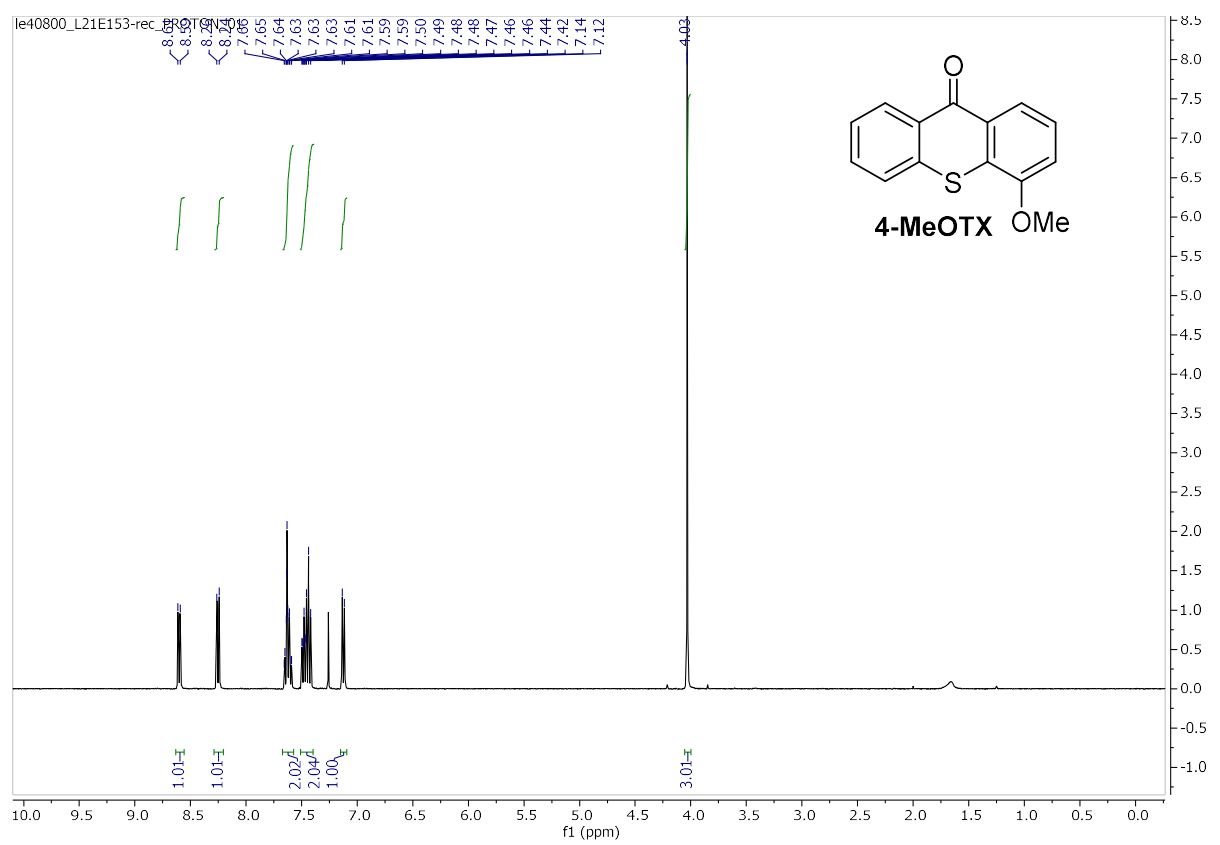

13C-NMR (101 MHz, $\mathrm{CDCl}_{3}$ )

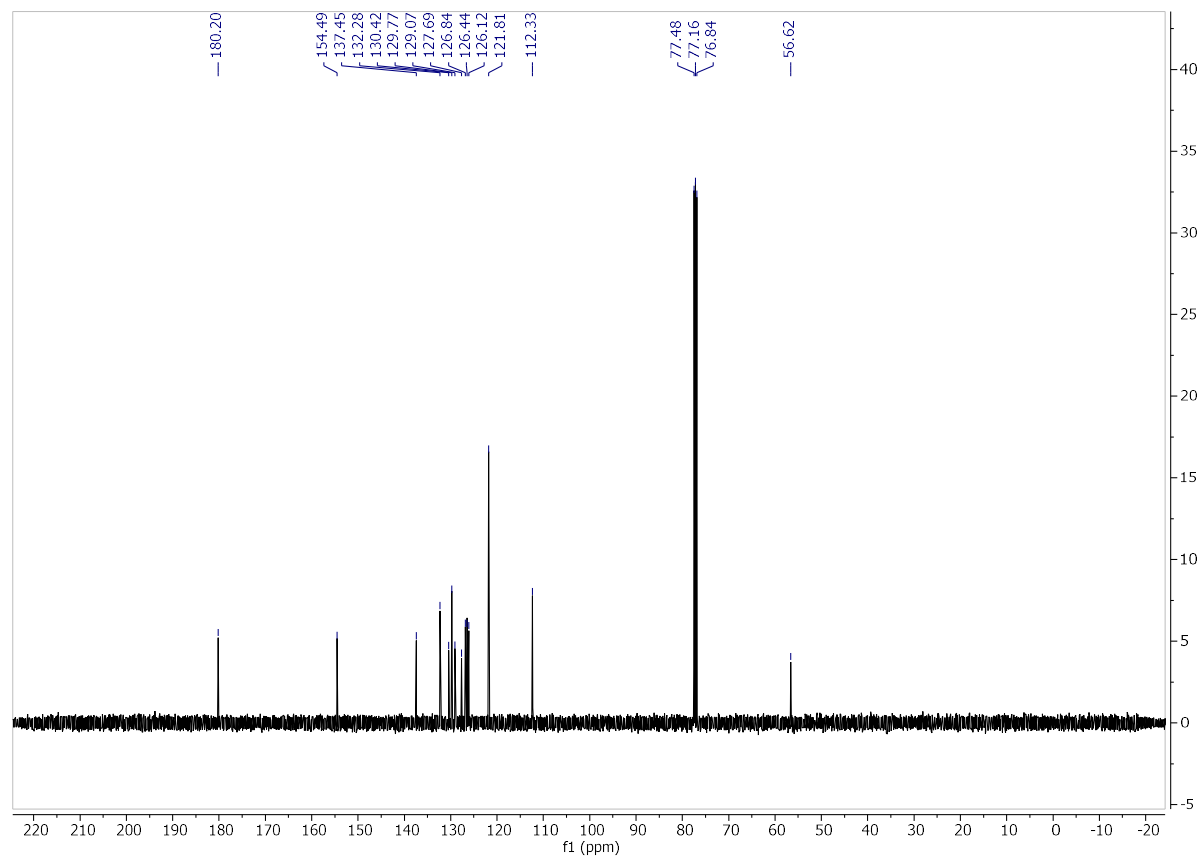


1H-NMR (400 MHz, $\mathrm{CDCl}_{3}$ )

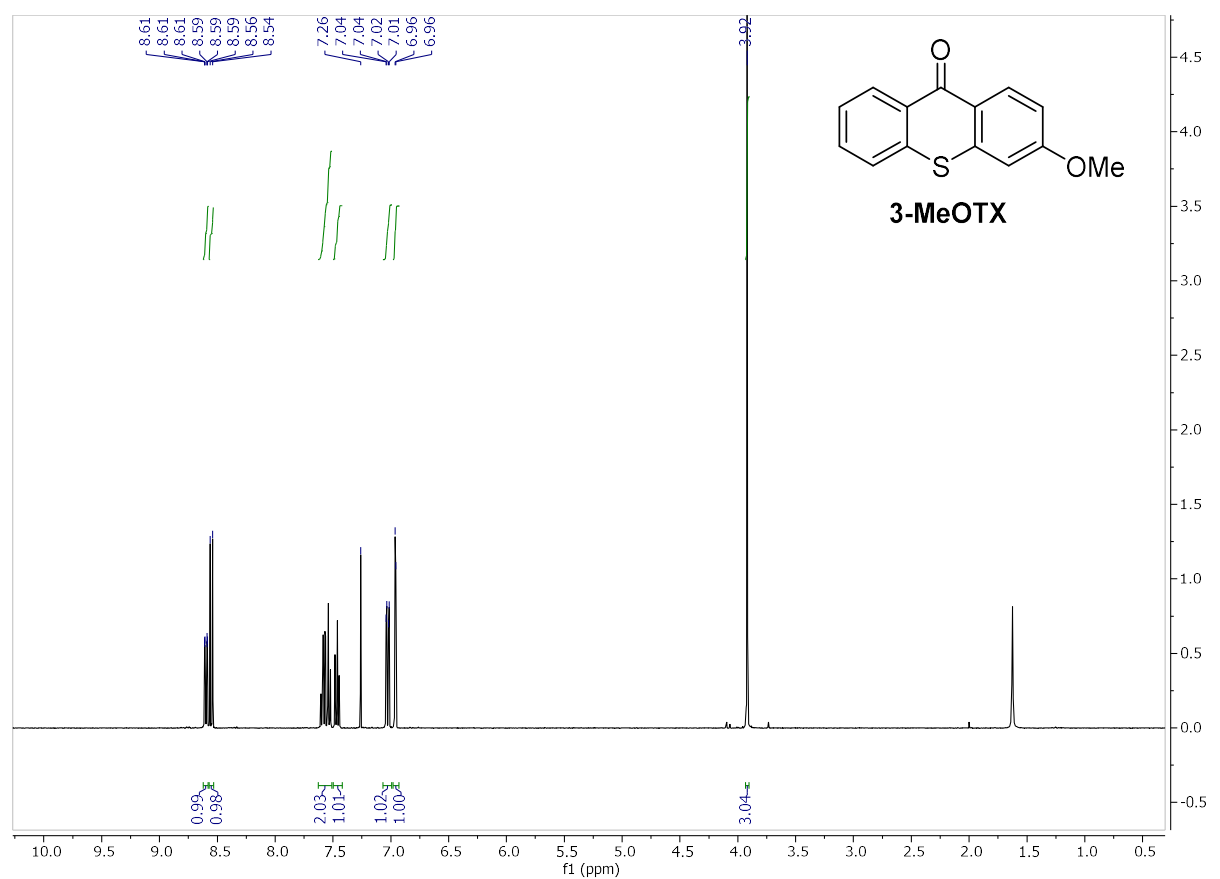

13C-NMR (101 MHz, $\mathrm{CDCl}_{3}$ )

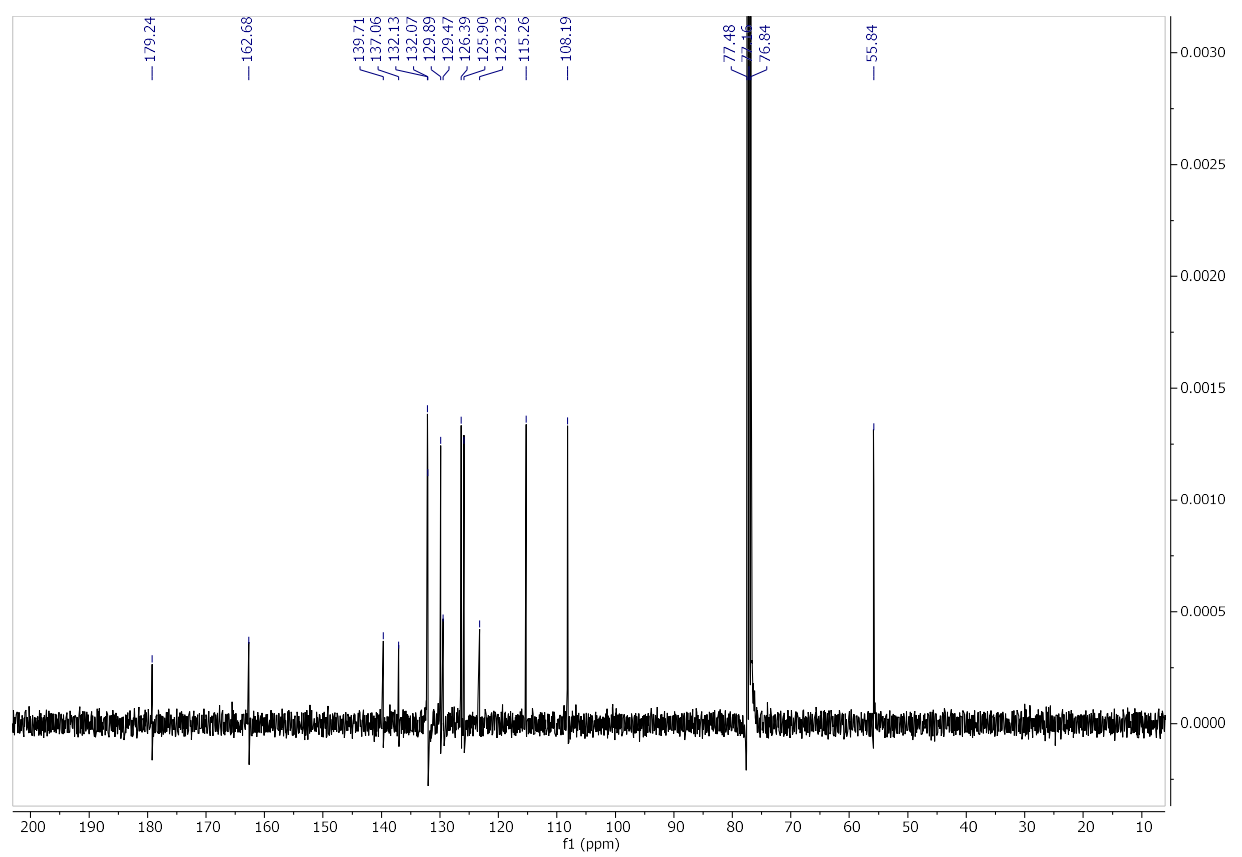




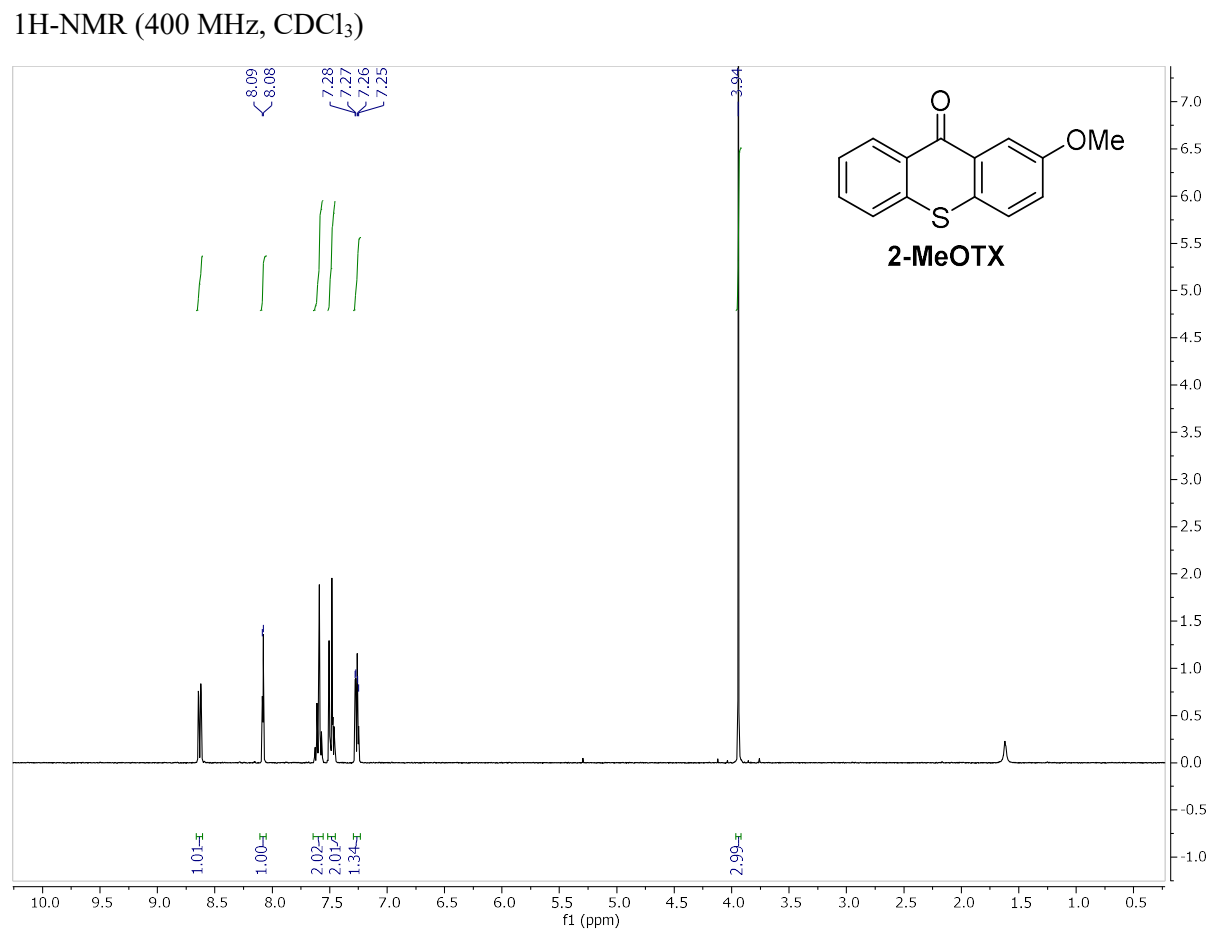

13C-NMR (101 MHz, $\mathrm{CDCl}_{3}$ )

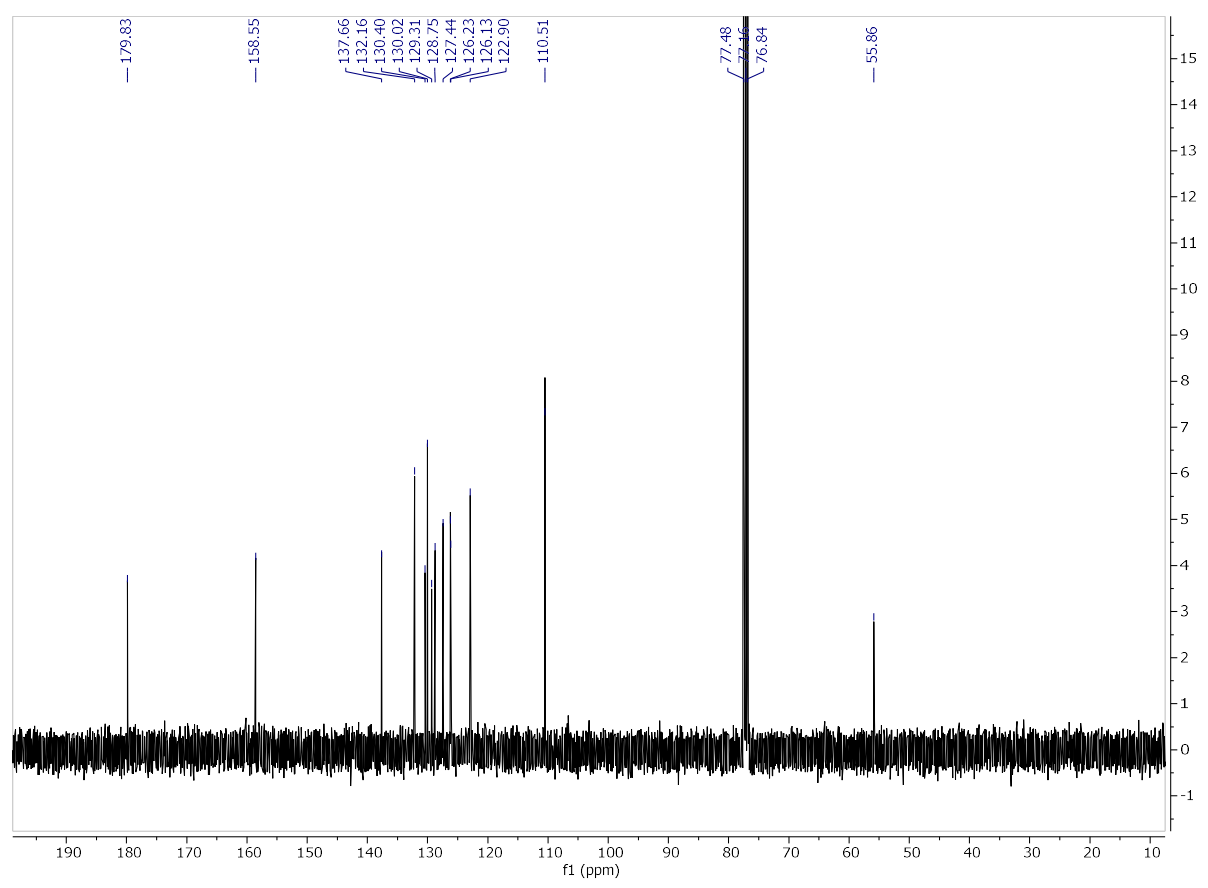

S54 
1H-NMR (400 MHz, $\mathrm{CDCl}_{3}$ )

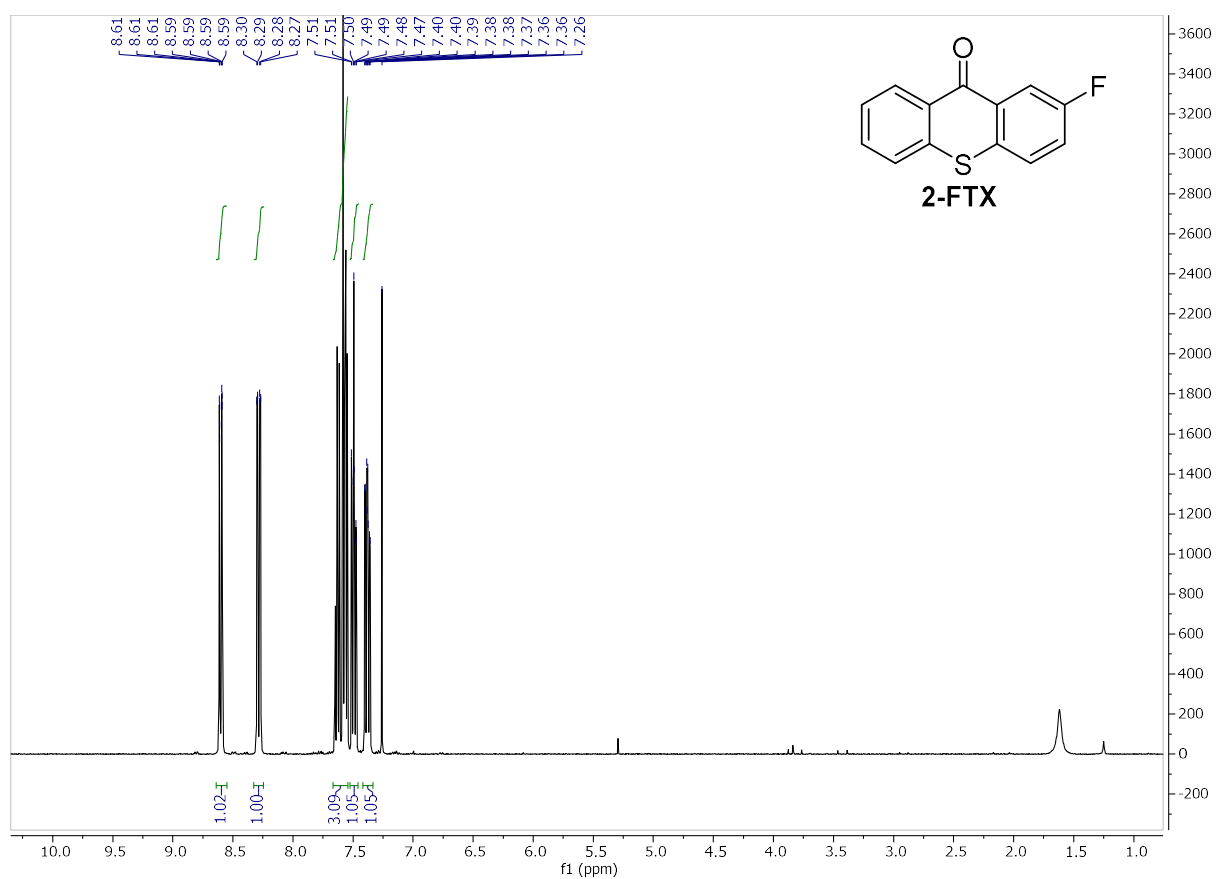

13C-NMR (101 MHz, $\left.\mathrm{CDCl}_{3}\right)$

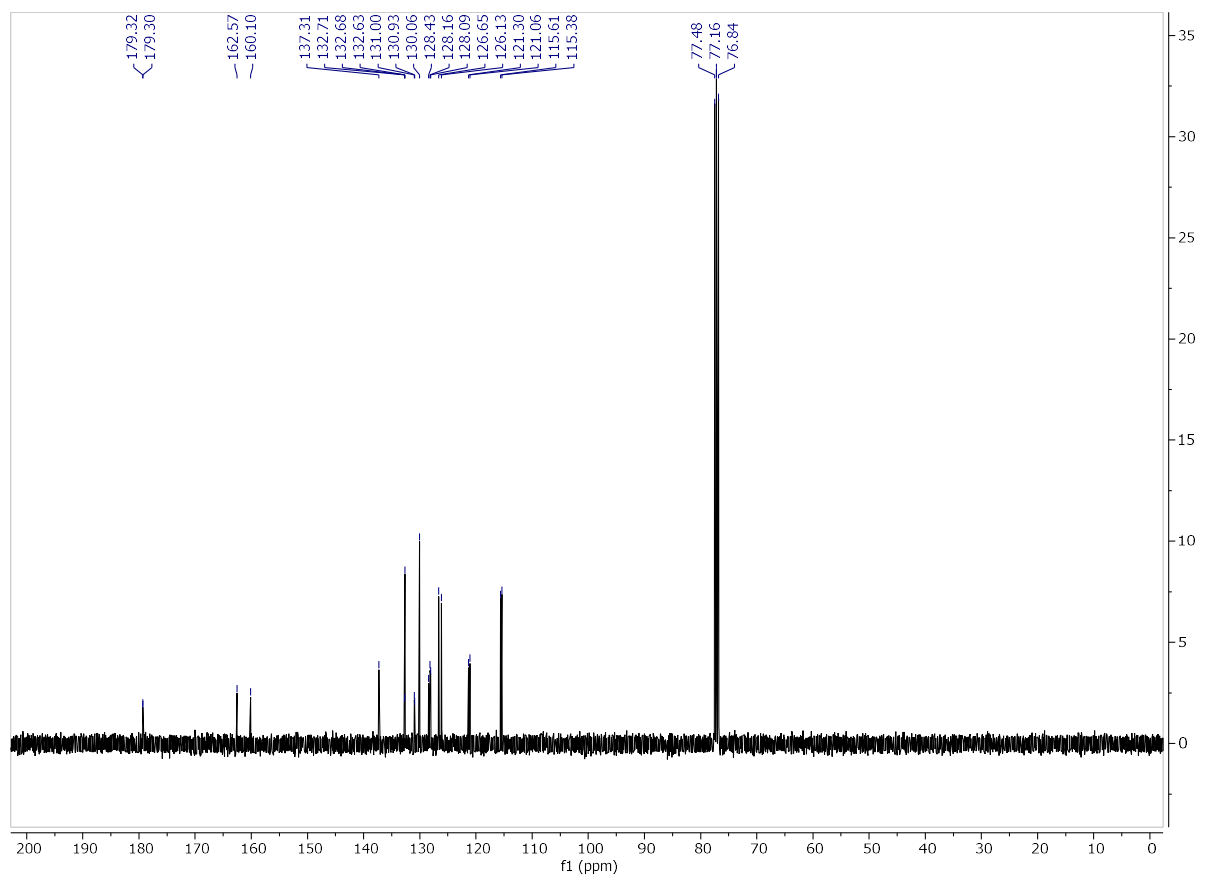


1H-NMR (400 MHz, $\left.\mathrm{CDCl}_{3}\right)$

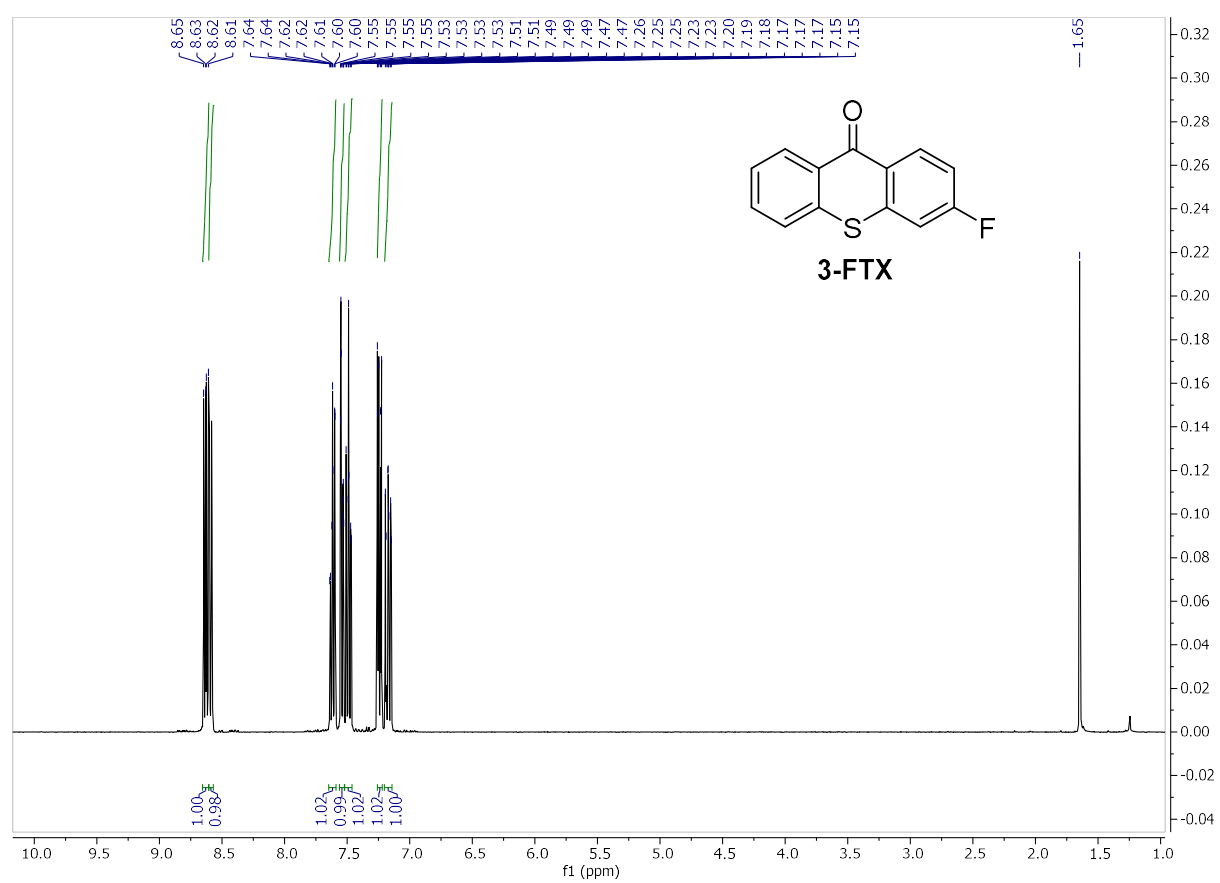

13C-NMR (101 MHz, $\left.\mathrm{CDCl}_{3}\right)$

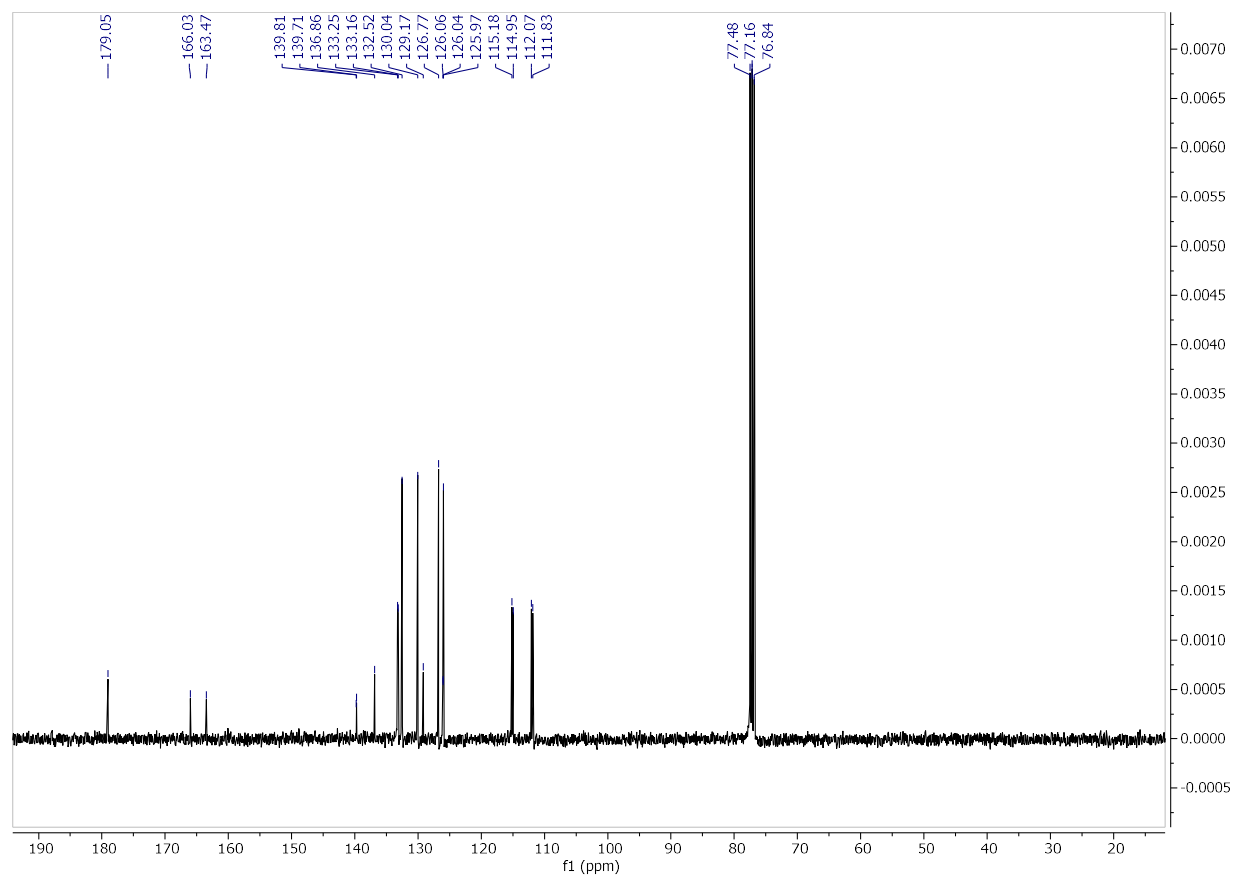


1H-NMR (400 MHz, $\mathrm{CDCl}_{3}$ )

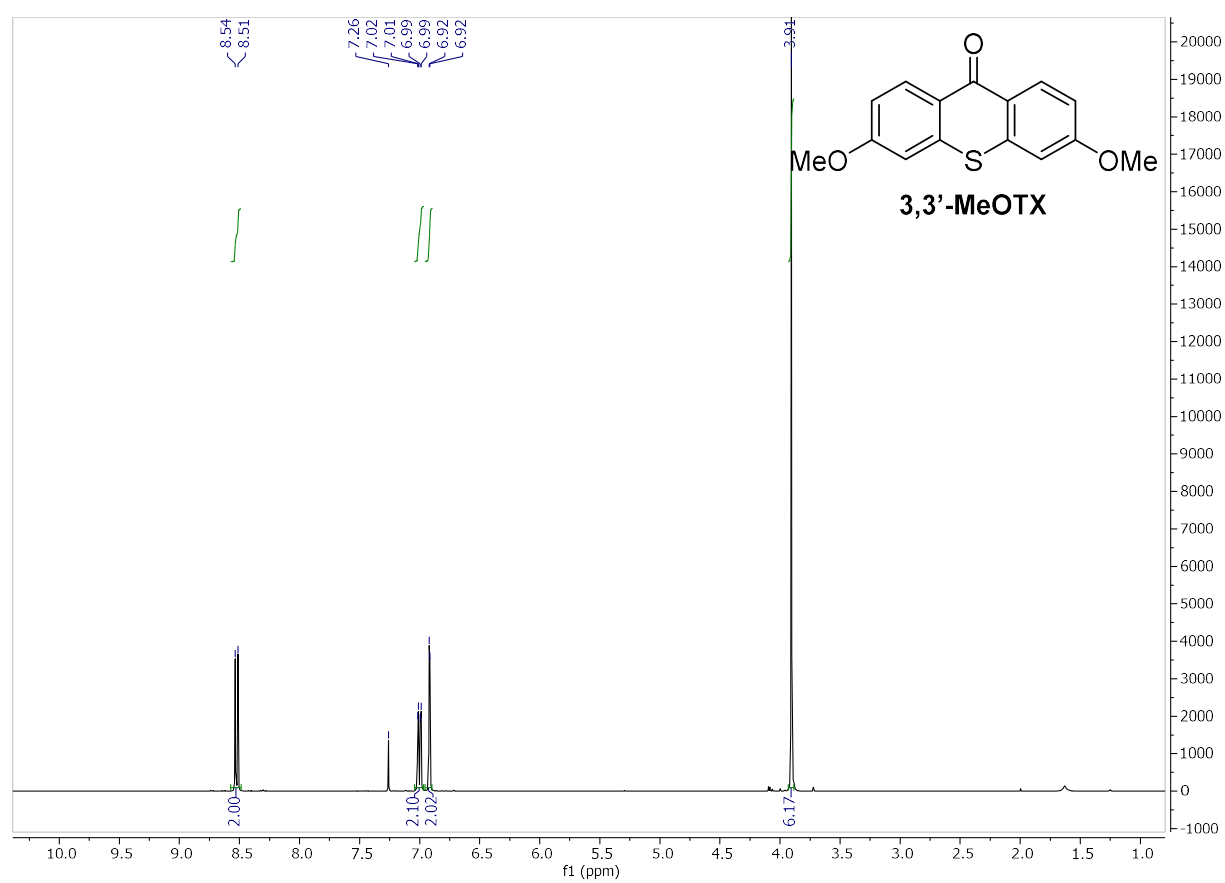

13C-NMR (101 MHz, $\left.\mathrm{CDCl}_{3}\right)$

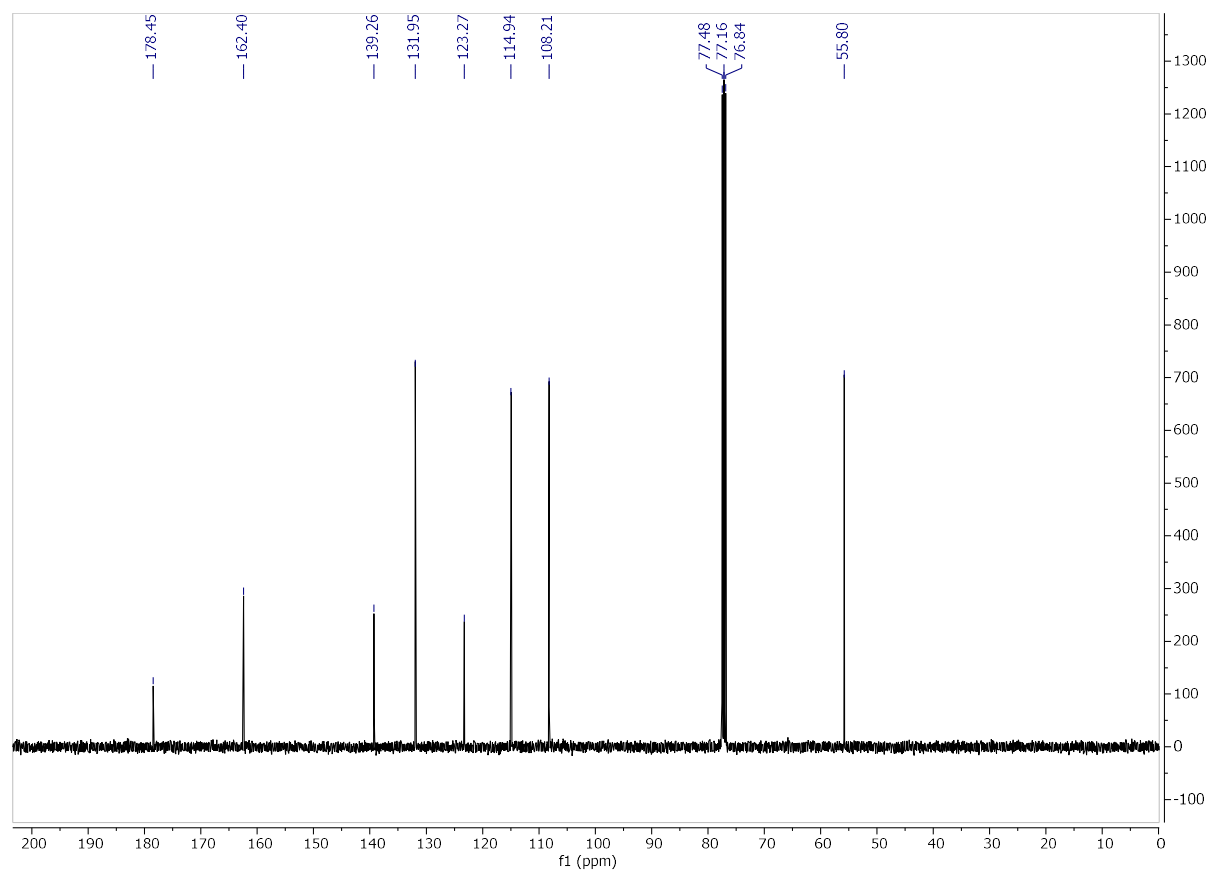



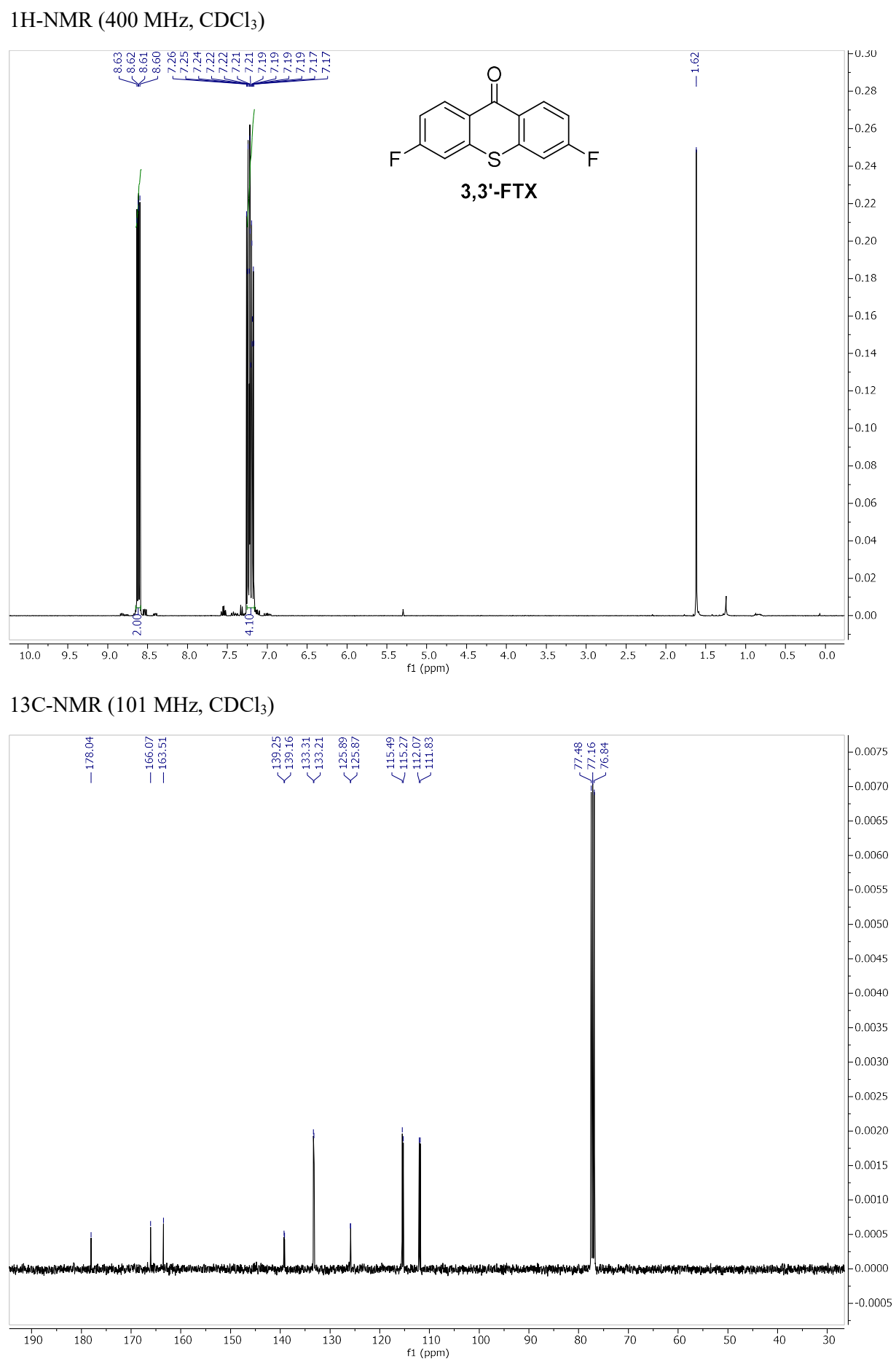

S58 
1H-NMR (400 MHz, $\mathrm{CDCl}_{3}$ )

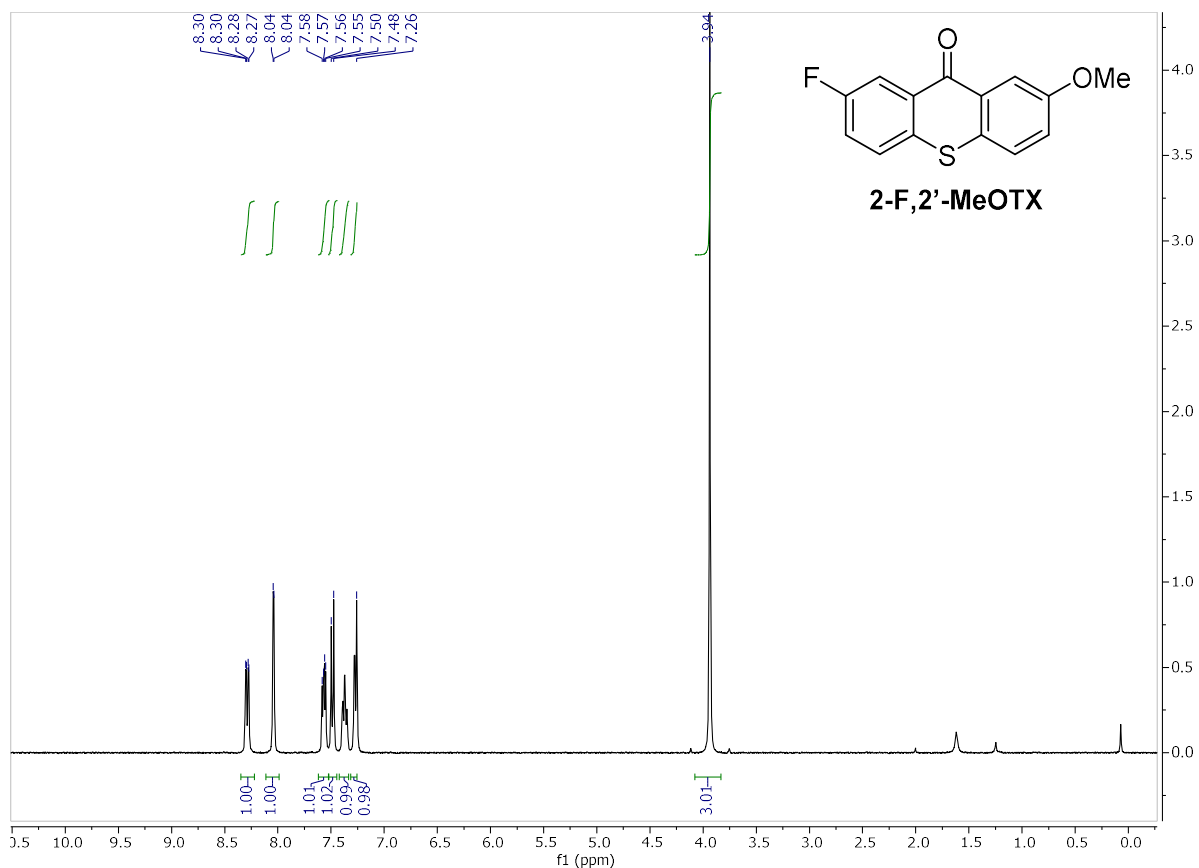

13C-NMR (101 MHz, $\left.\mathrm{CDCl}_{3}\right)$

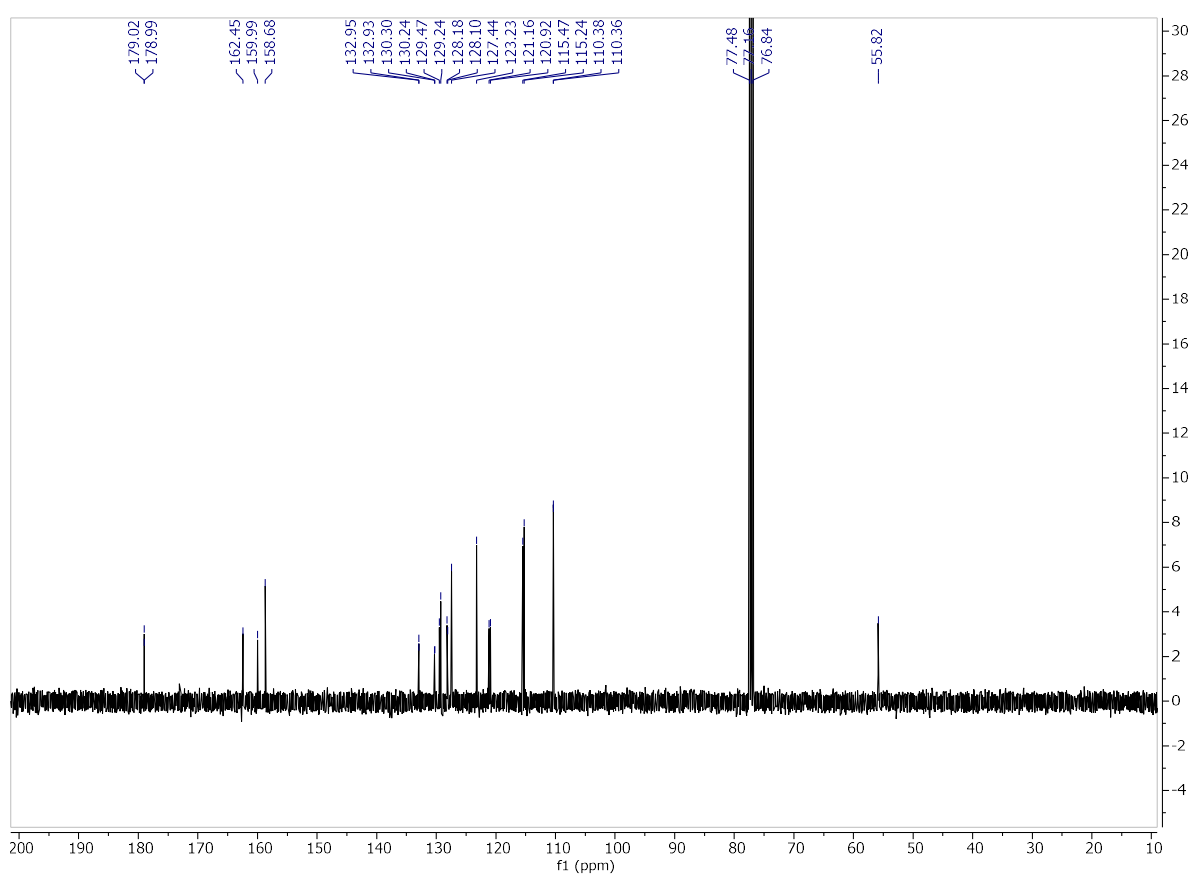


1H-NMR (400 MHz, $\mathrm{CDCl}_{3}$ )

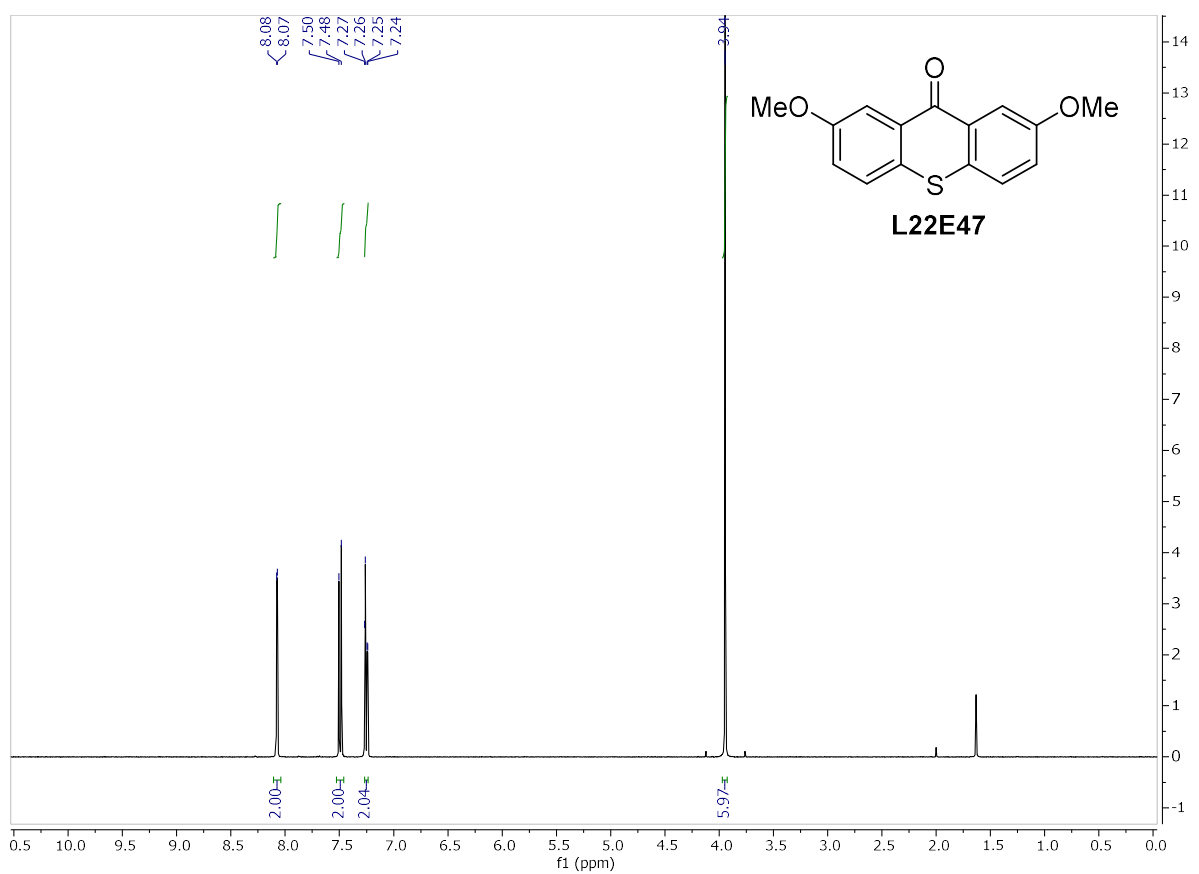

13C-NMR (101 MHz, $\mathrm{CDCl}_{3}$ )

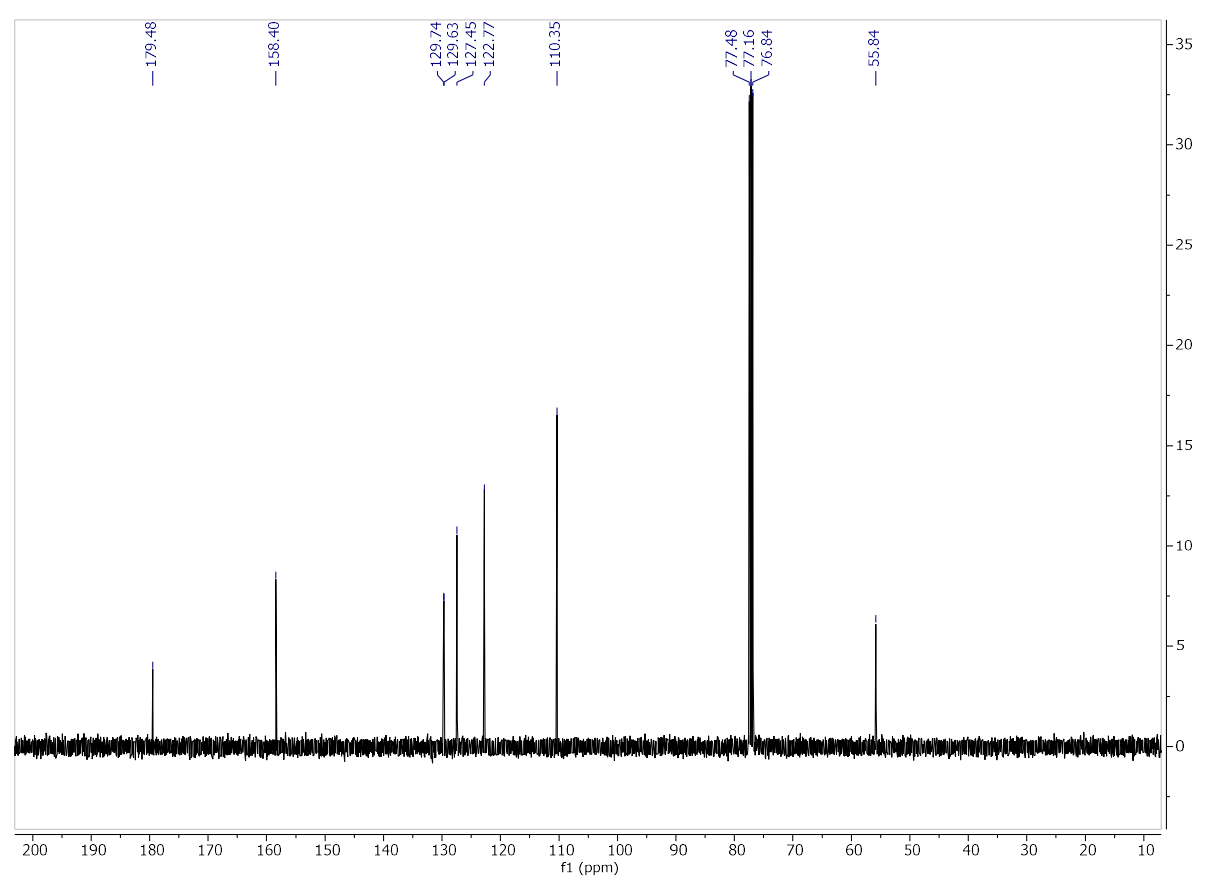


1H-NMR (400 MHz, $\left.\mathrm{CDCl}_{3}\right)$

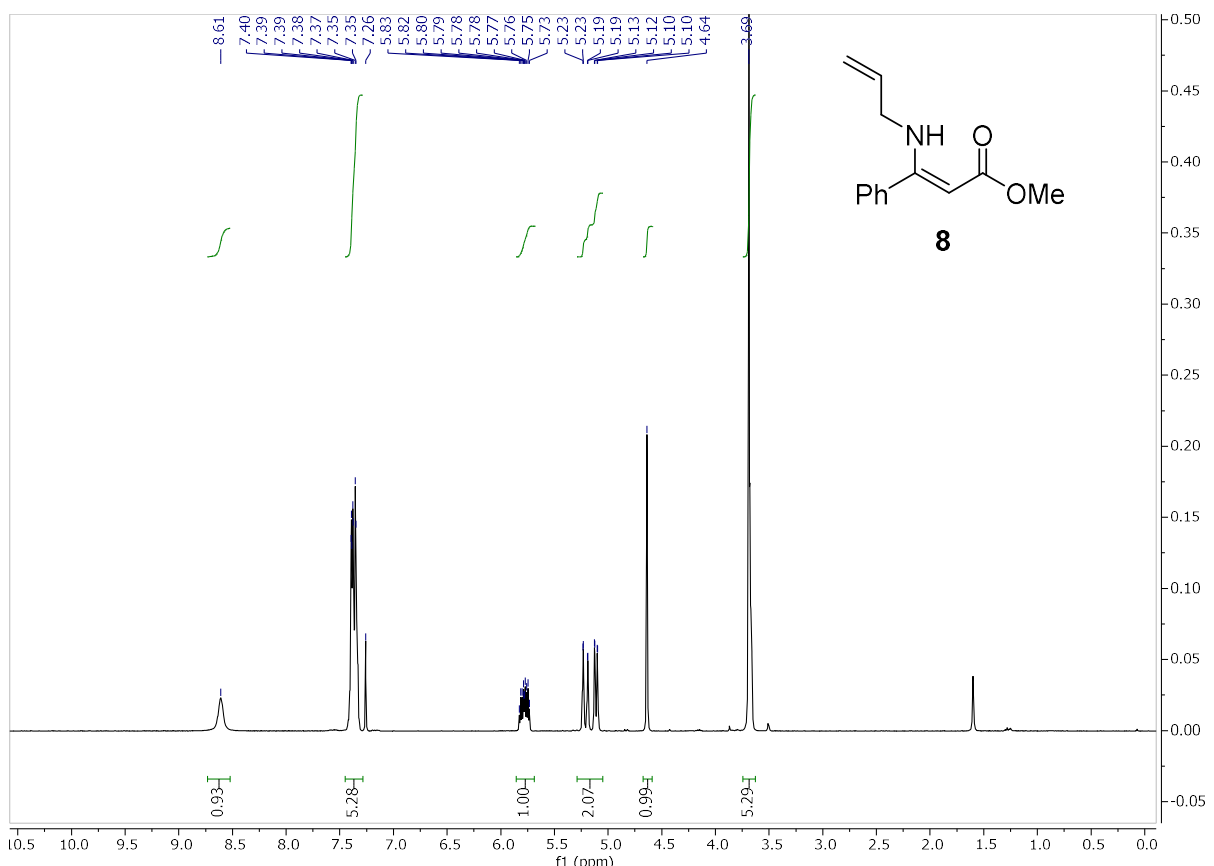

13C-NMR (101 MHz, $\left.\mathrm{CDCl}_{3}\right)$

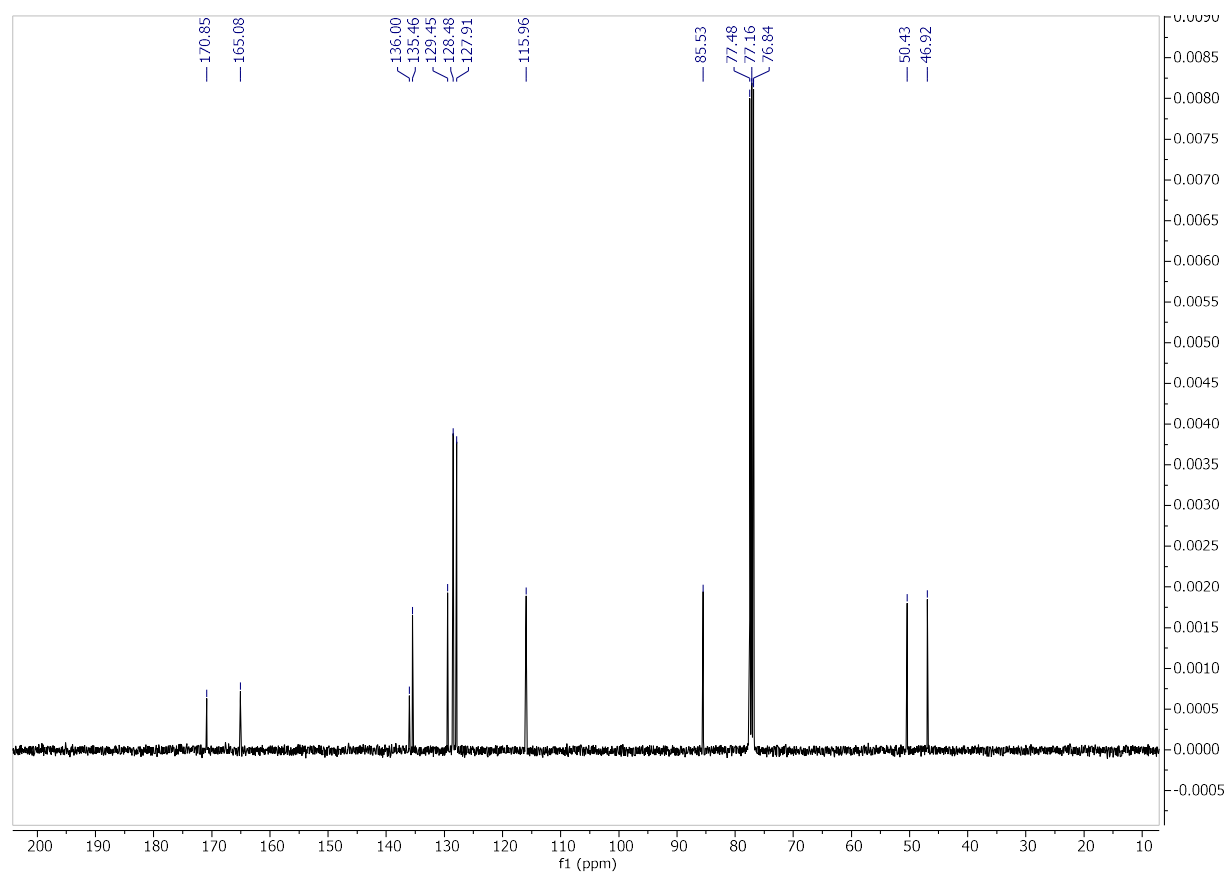


1H-NMR (400 MHz, $\left.\mathrm{CDCl}_{3}\right)$

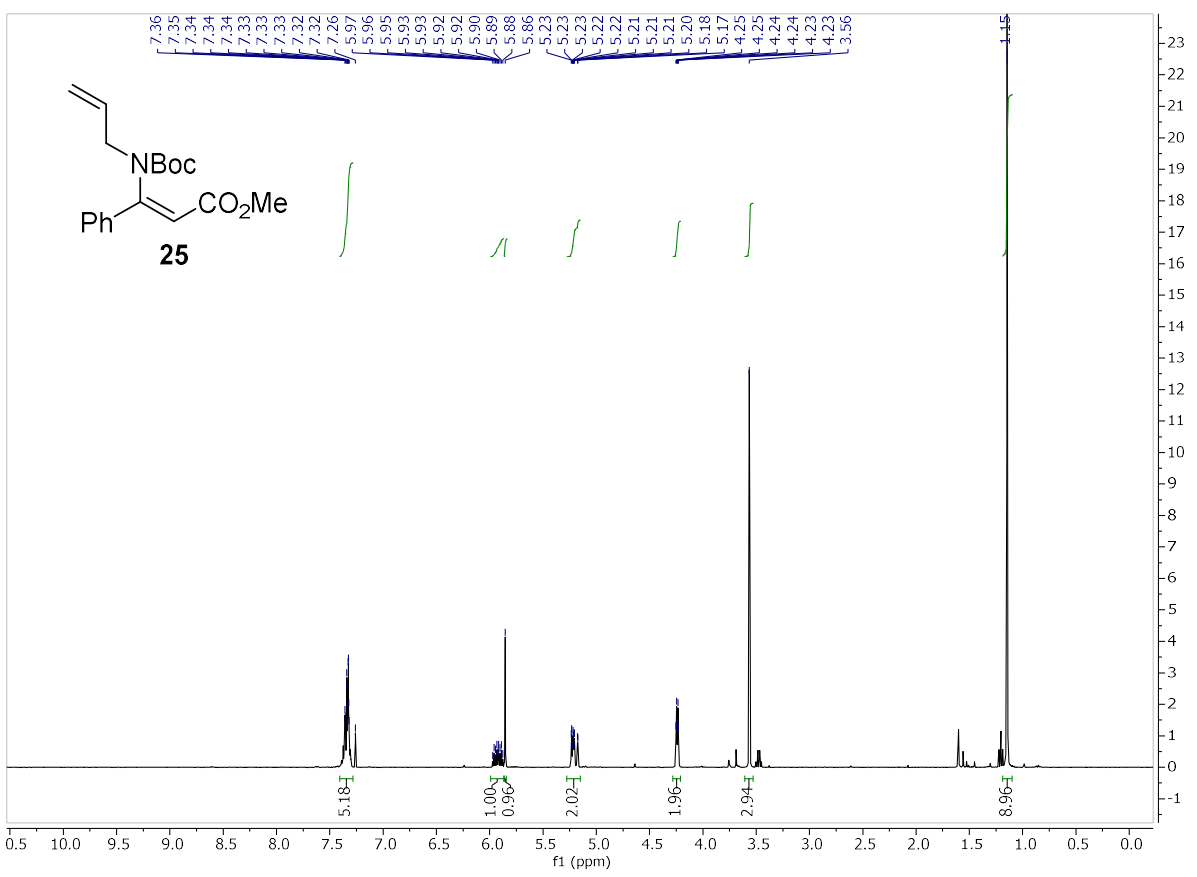

13C-NMR (101 MHz, $\left.\mathrm{CDCl}_{3}\right)$

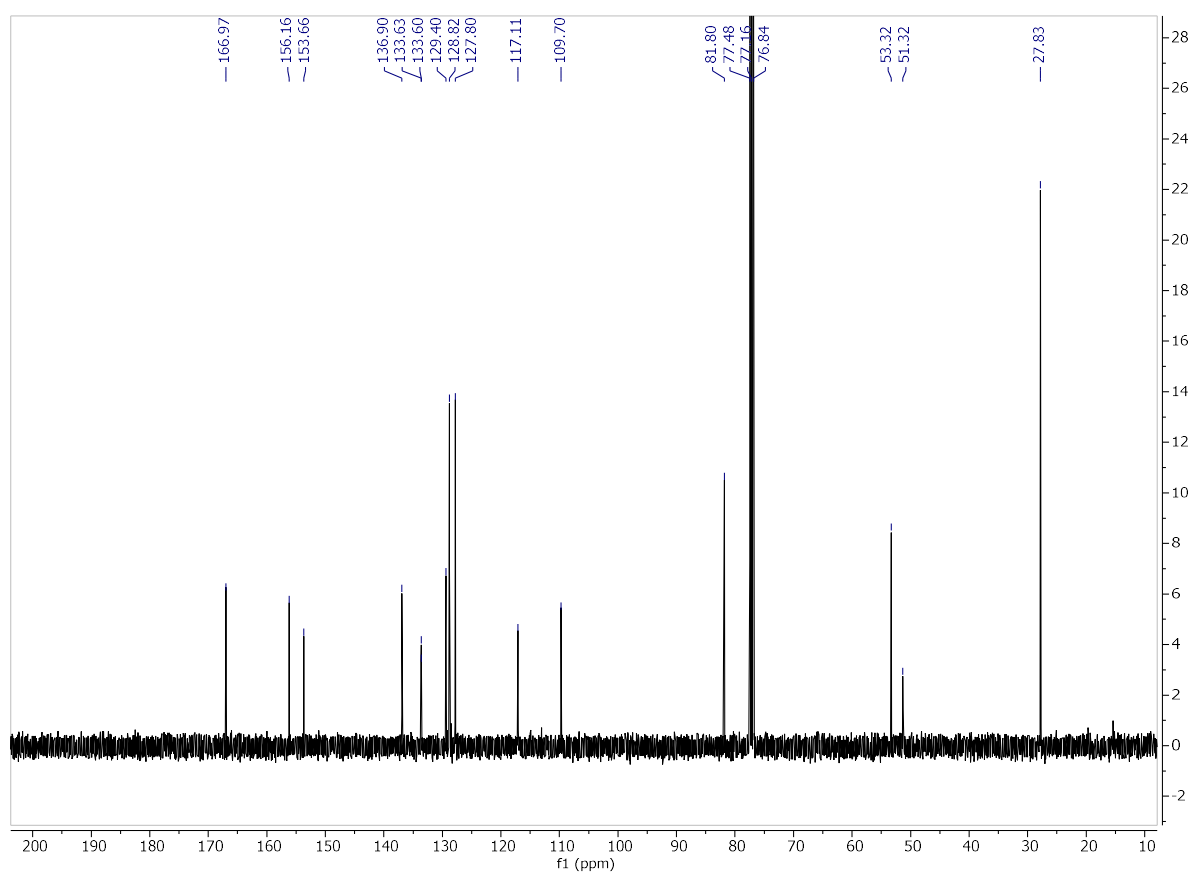


1H-NMR (400 MHz, $\mathrm{CDCl}_{3}$ )

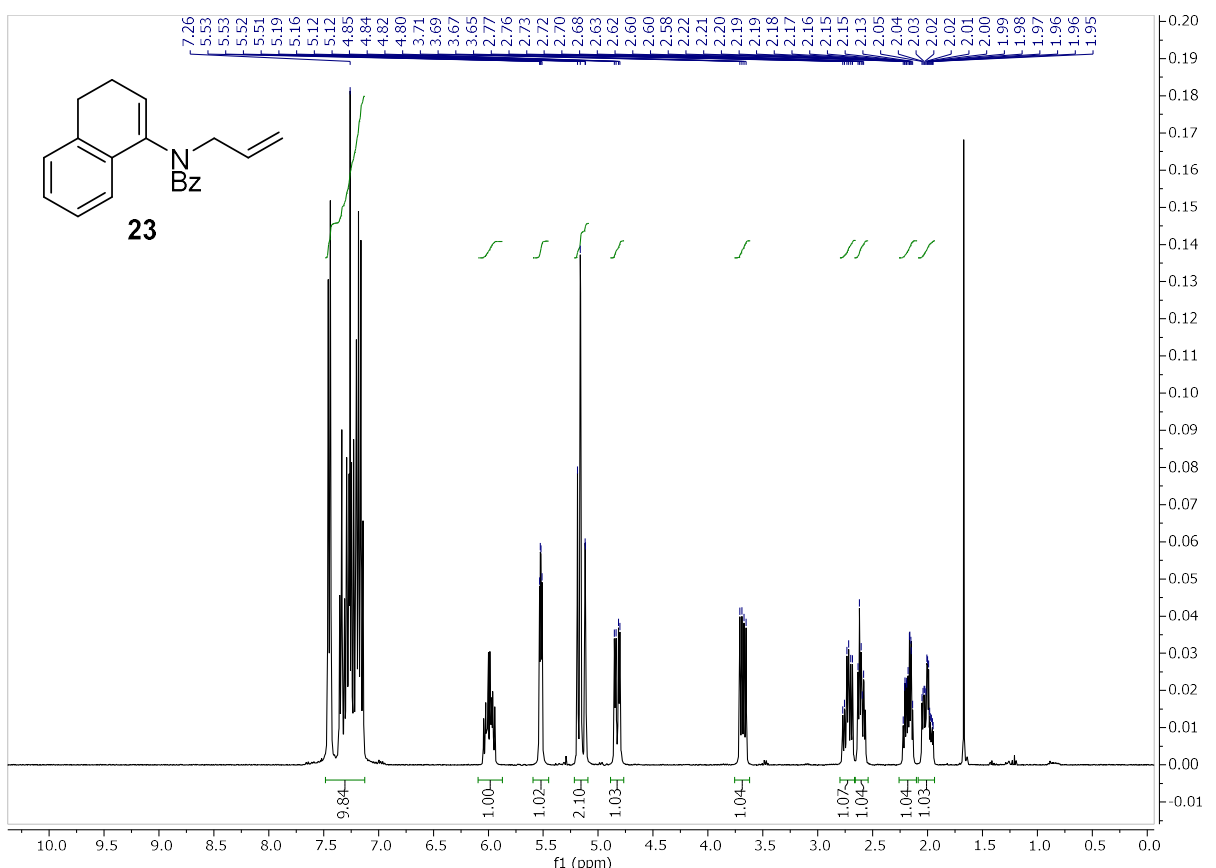

13C-NMR (101 MHz, $\mathrm{CDCl}_{3}$ )

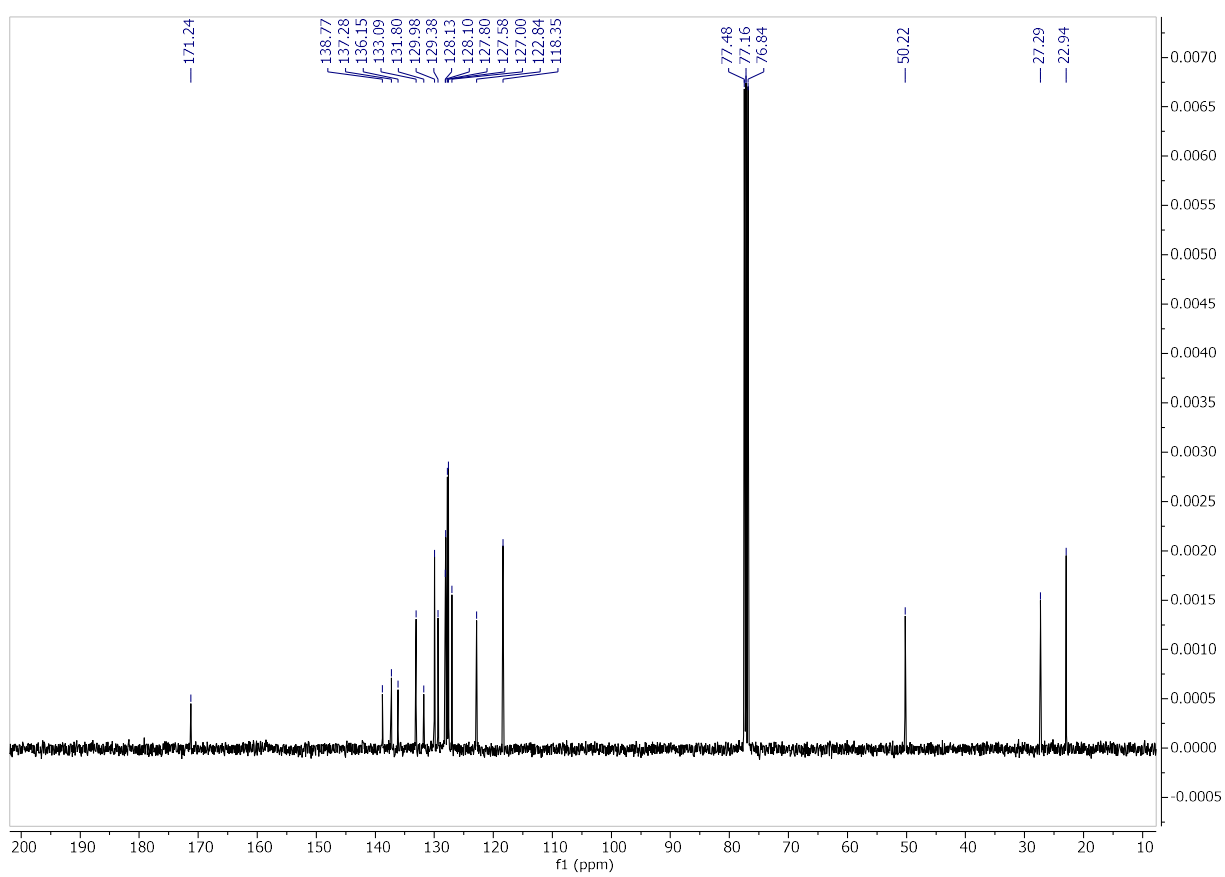


1H-NMR (400 MHz, $\mathrm{CDCl}_{3}$ )

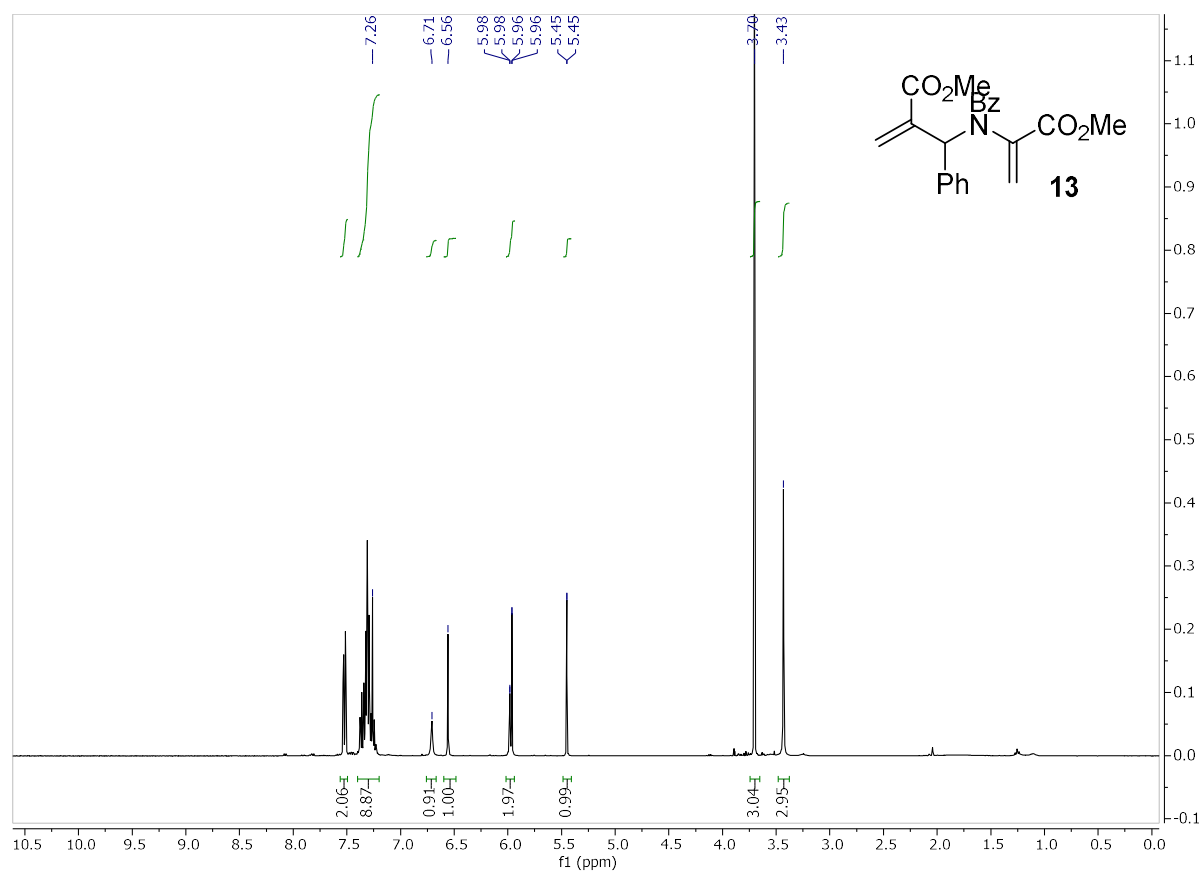

13C-NMR (101 MHz, $\mathrm{CDCl}_{3}$ )

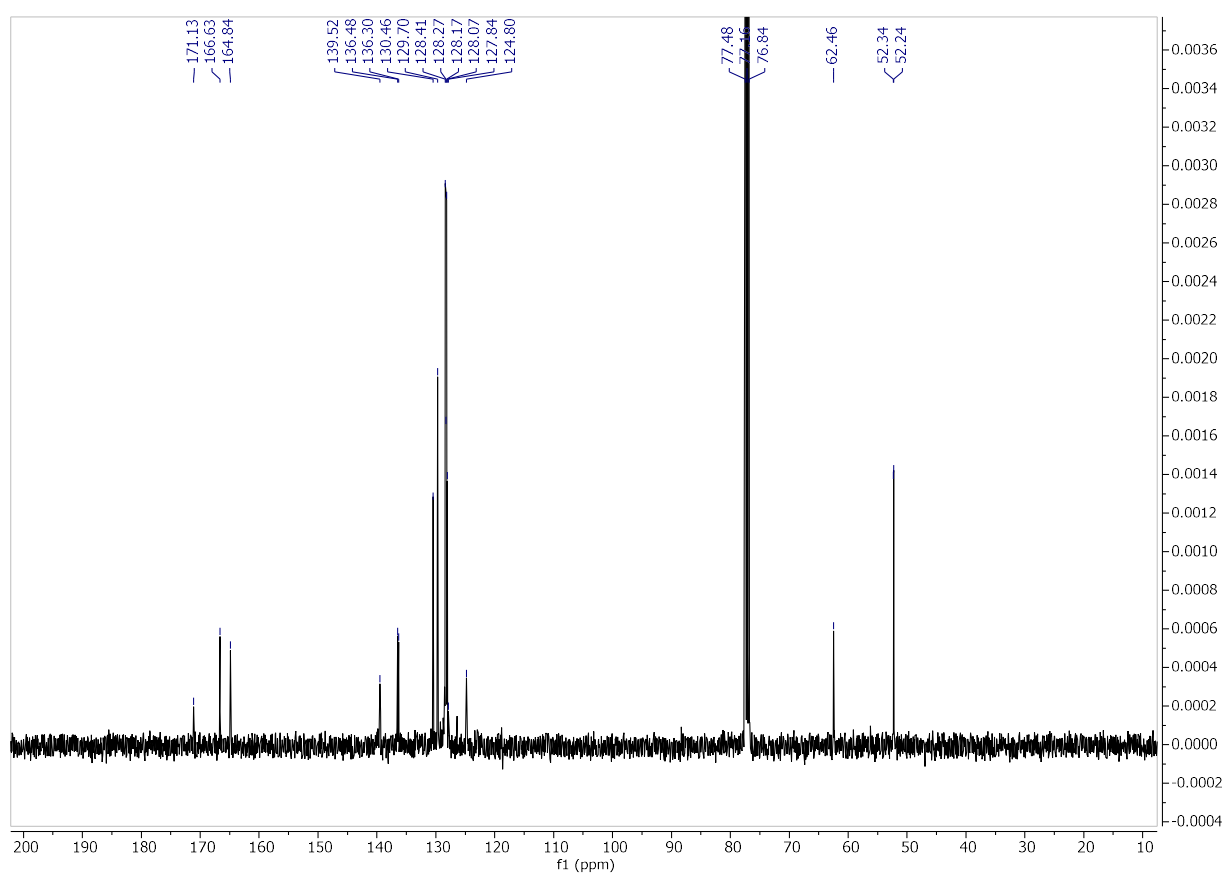




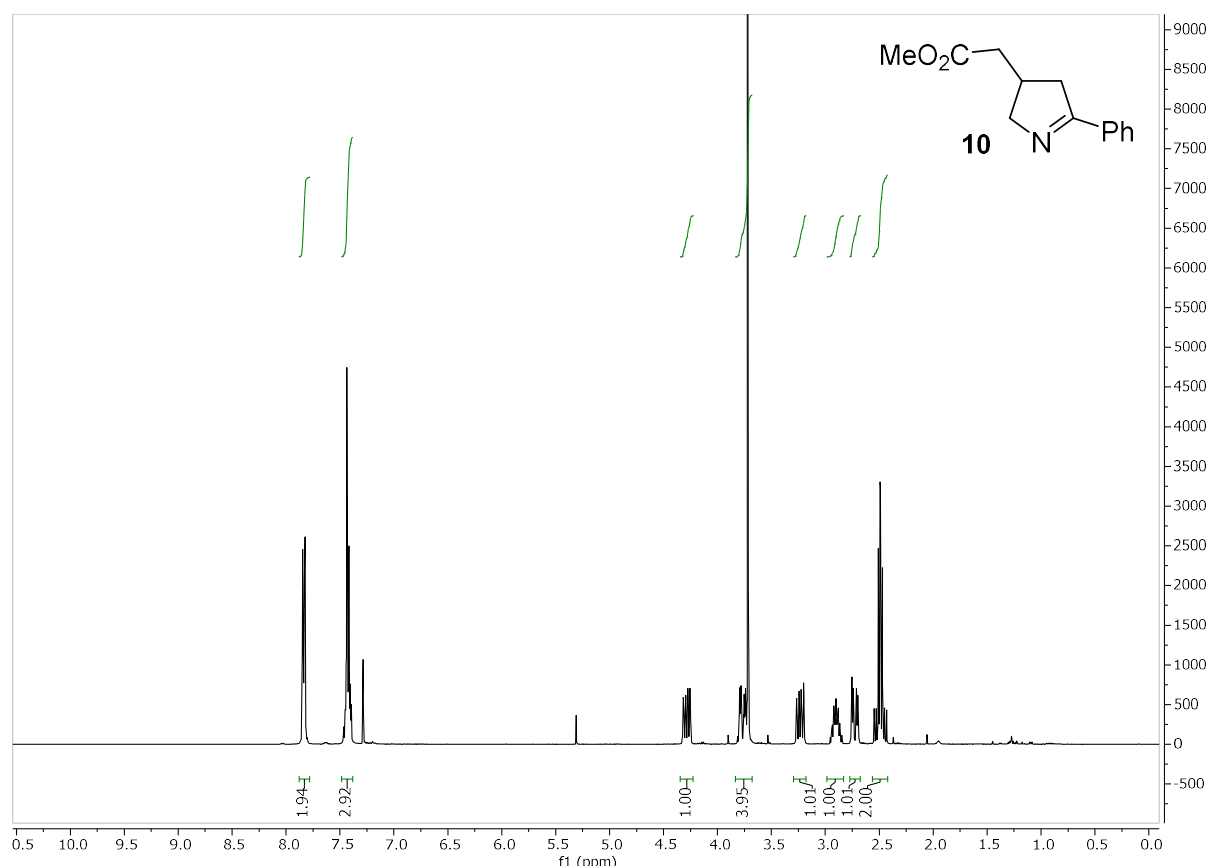

13C-NMR (101 MHz, $\mathrm{CDCl}_{3}$ )

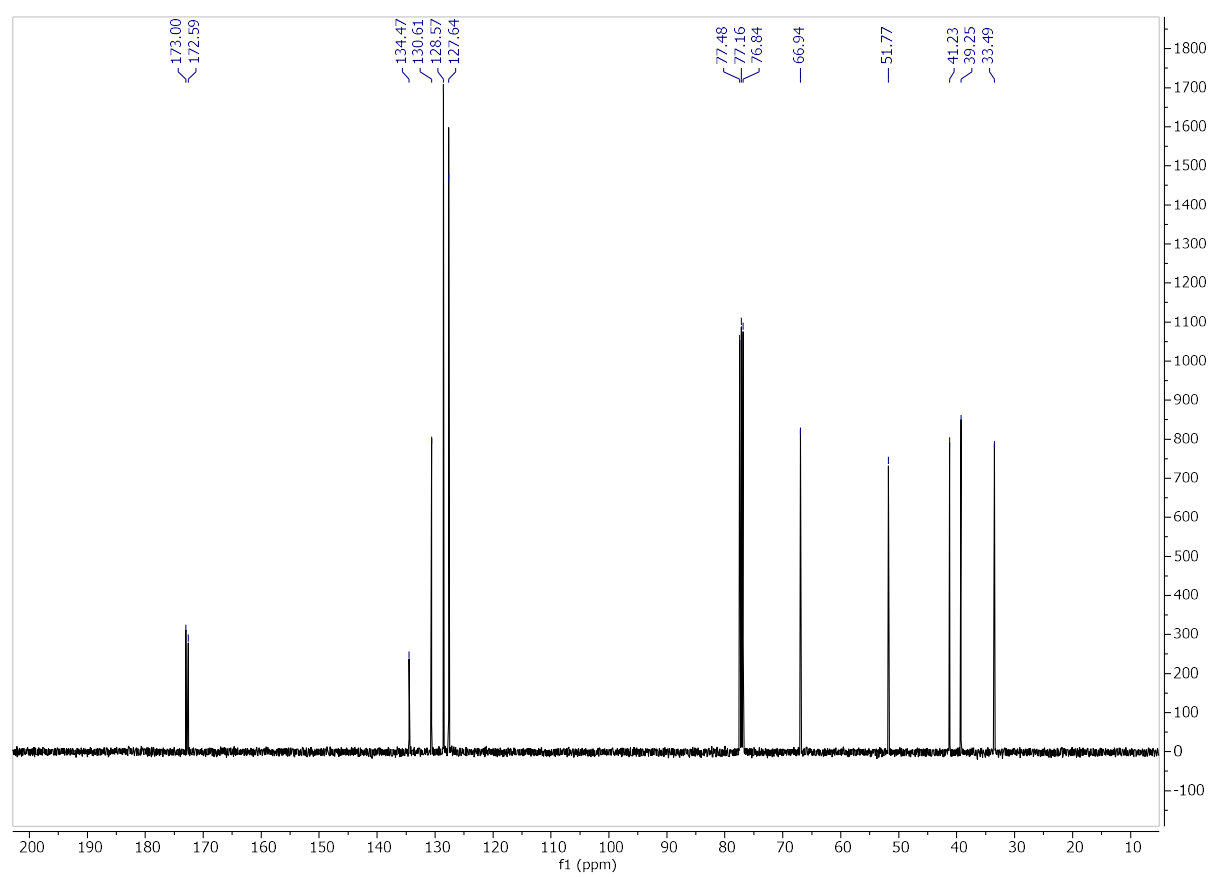


1H-NMR (400 MHz, $\mathrm{CDCl}_{3}$ )

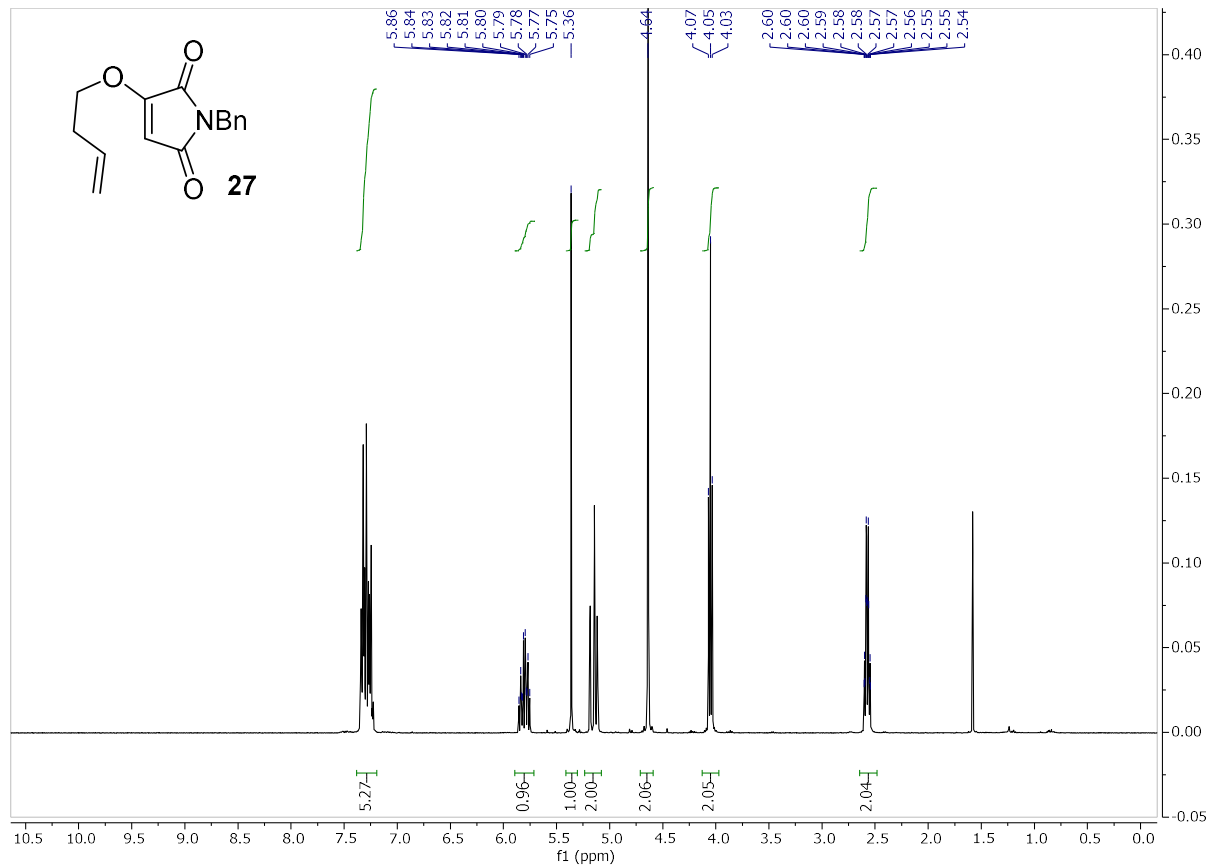

13C-NMR (101 MHz, $\left.\mathrm{CDCl}_{3}\right)$

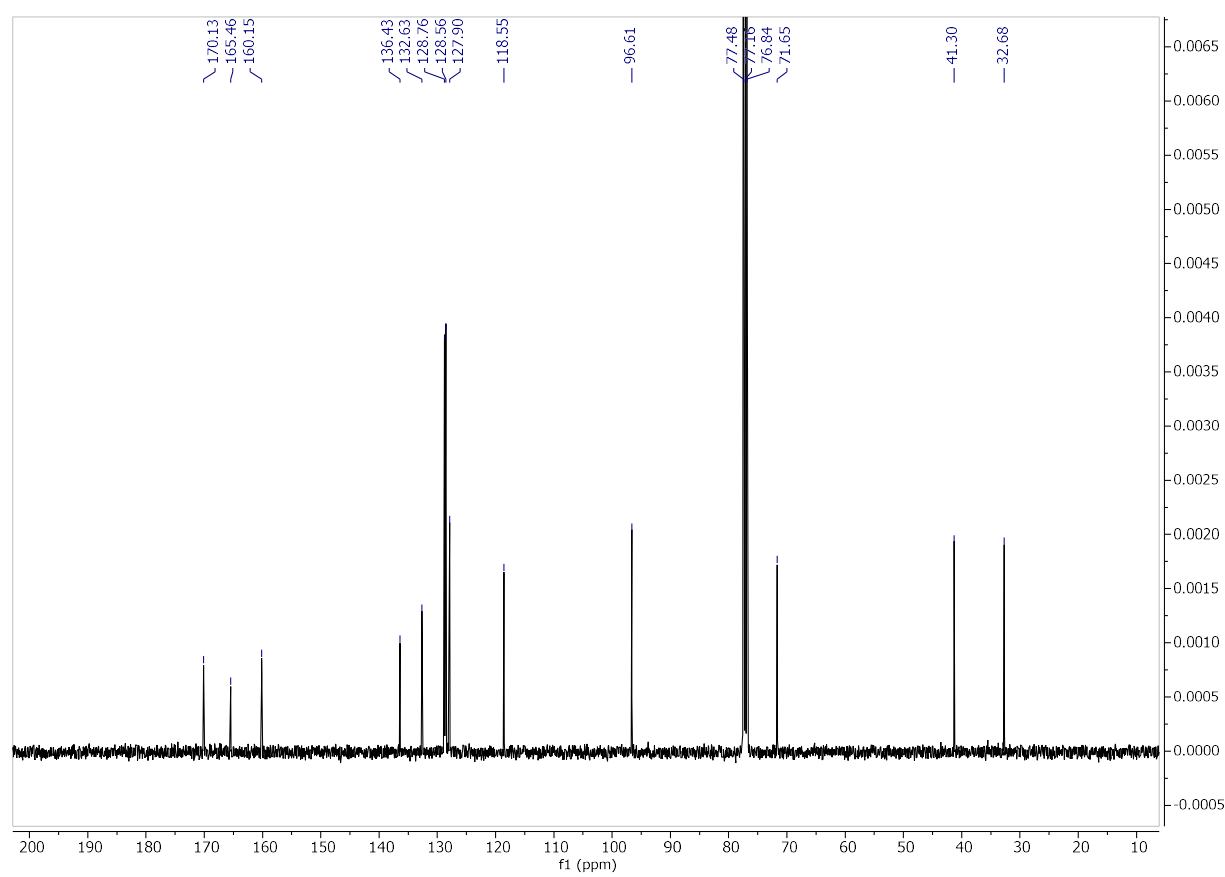


1H-NMR (400 MHz, $\mathrm{CDCl}_{3}$ )

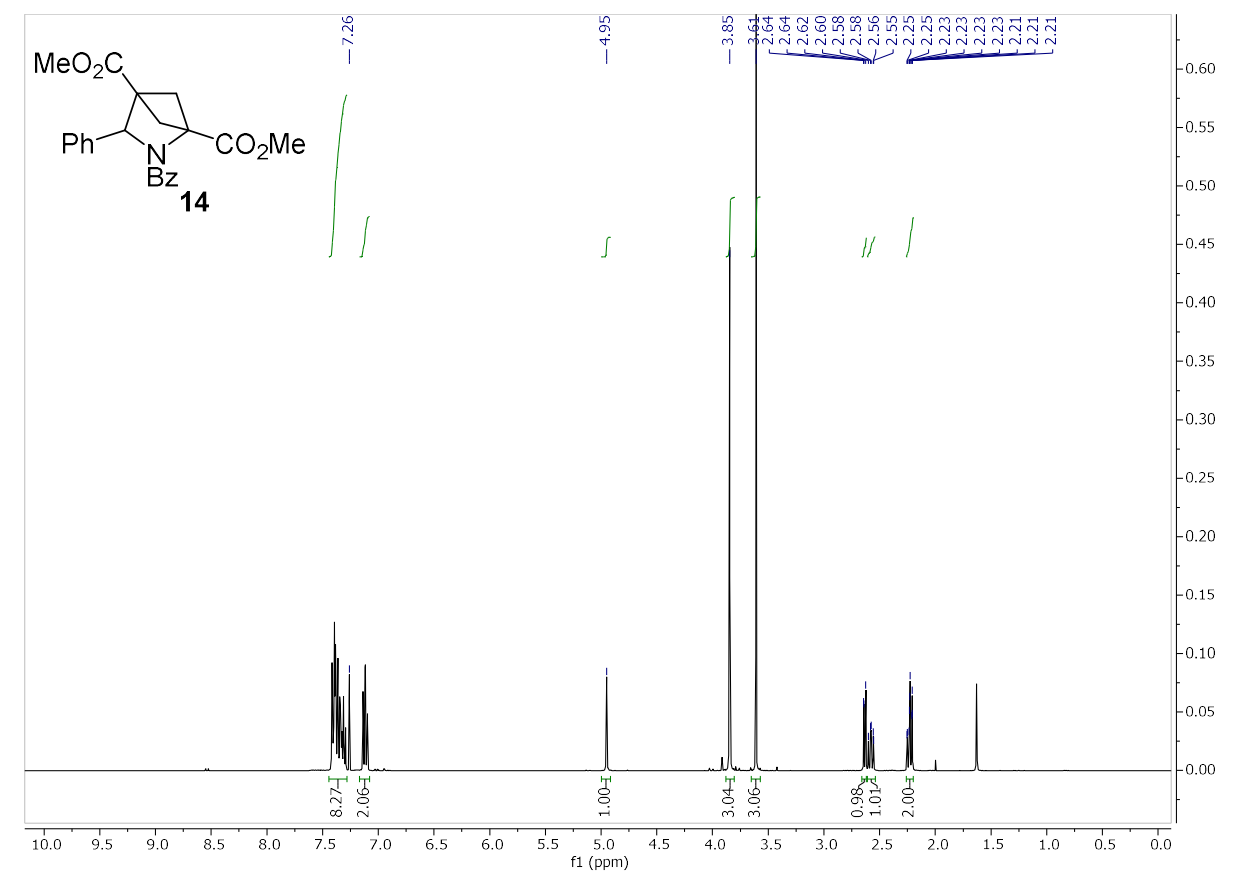

13C-NMR (101 MHz, $\mathrm{CDCl}_{3}$ )

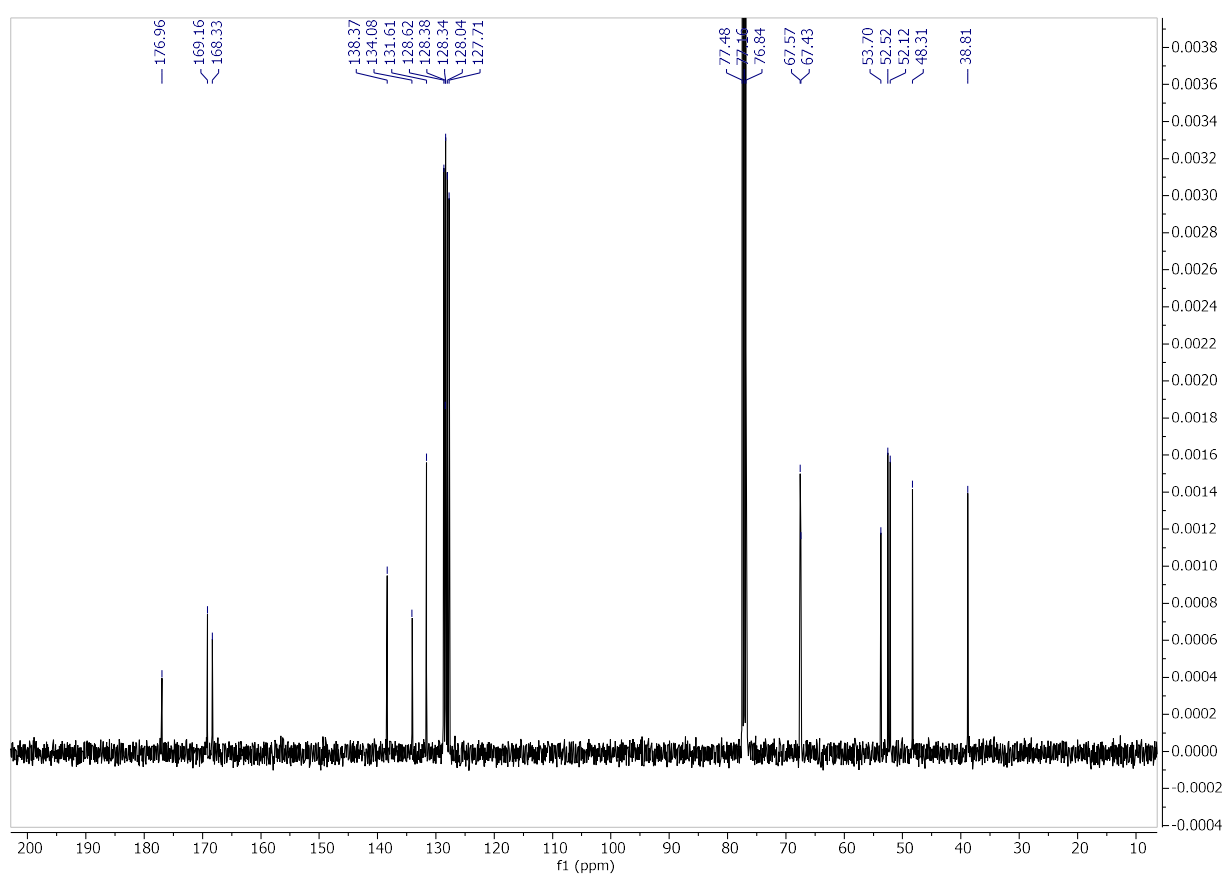




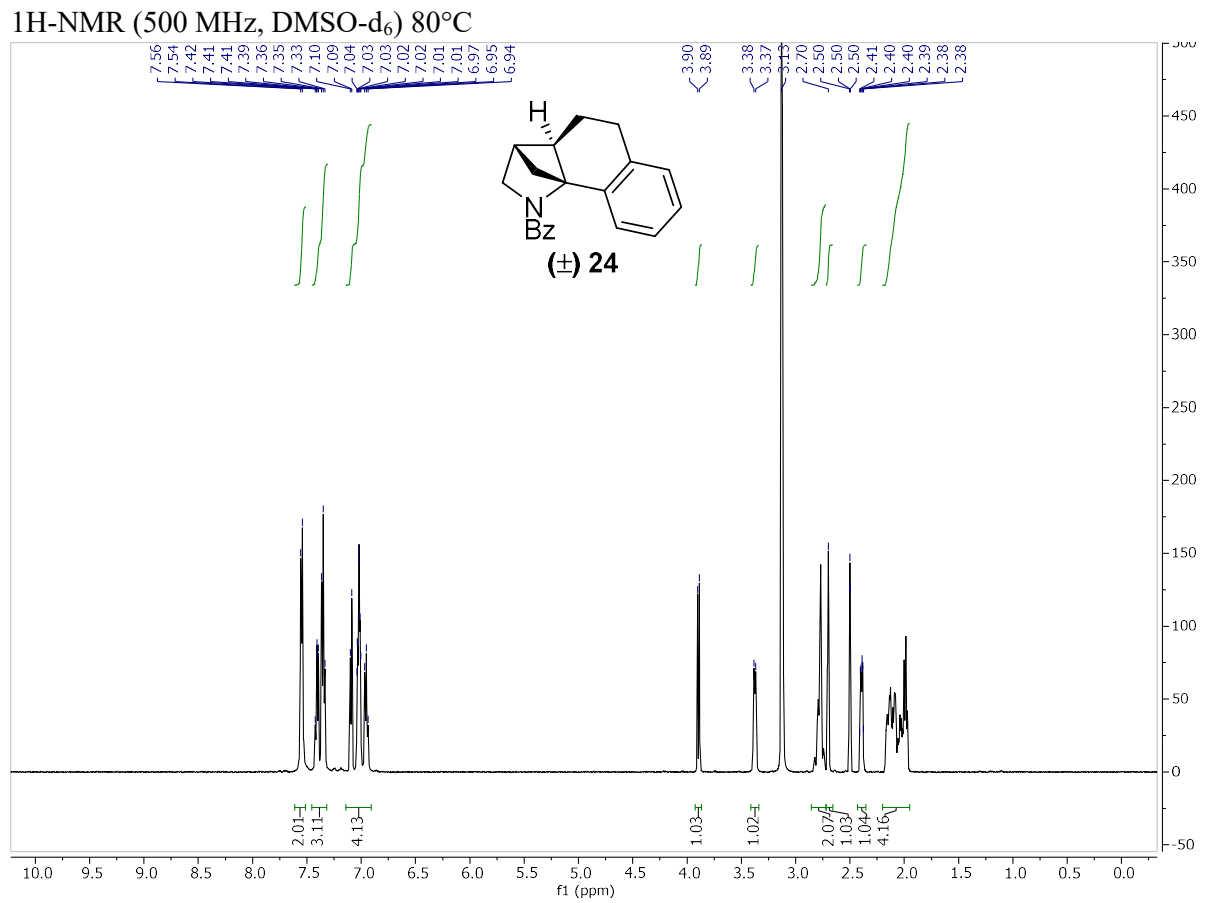

13C-NMR (126 MHz, DMSO-d 6 ) $80^{\circ} \mathrm{C}$

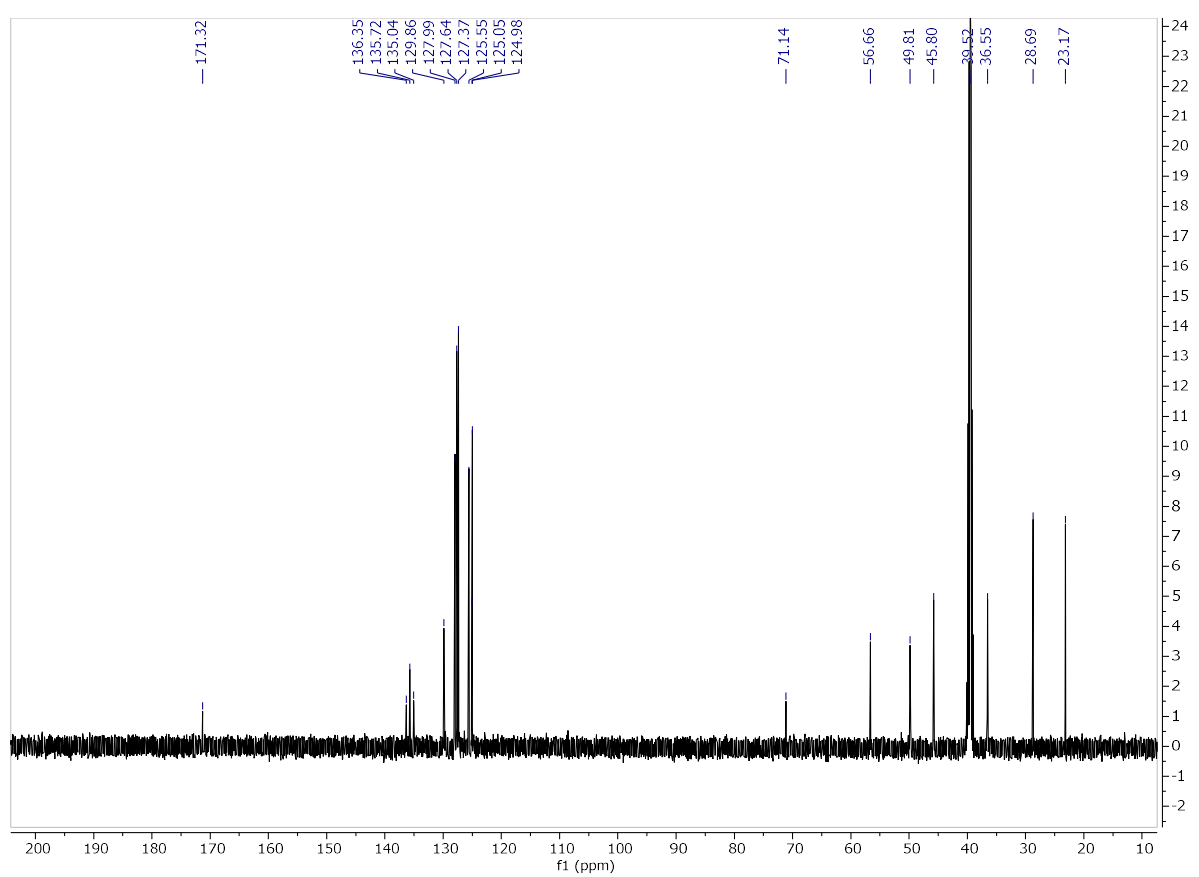


1H-NMR (400 MHz, $\mathrm{CDCl}_{3}$ )

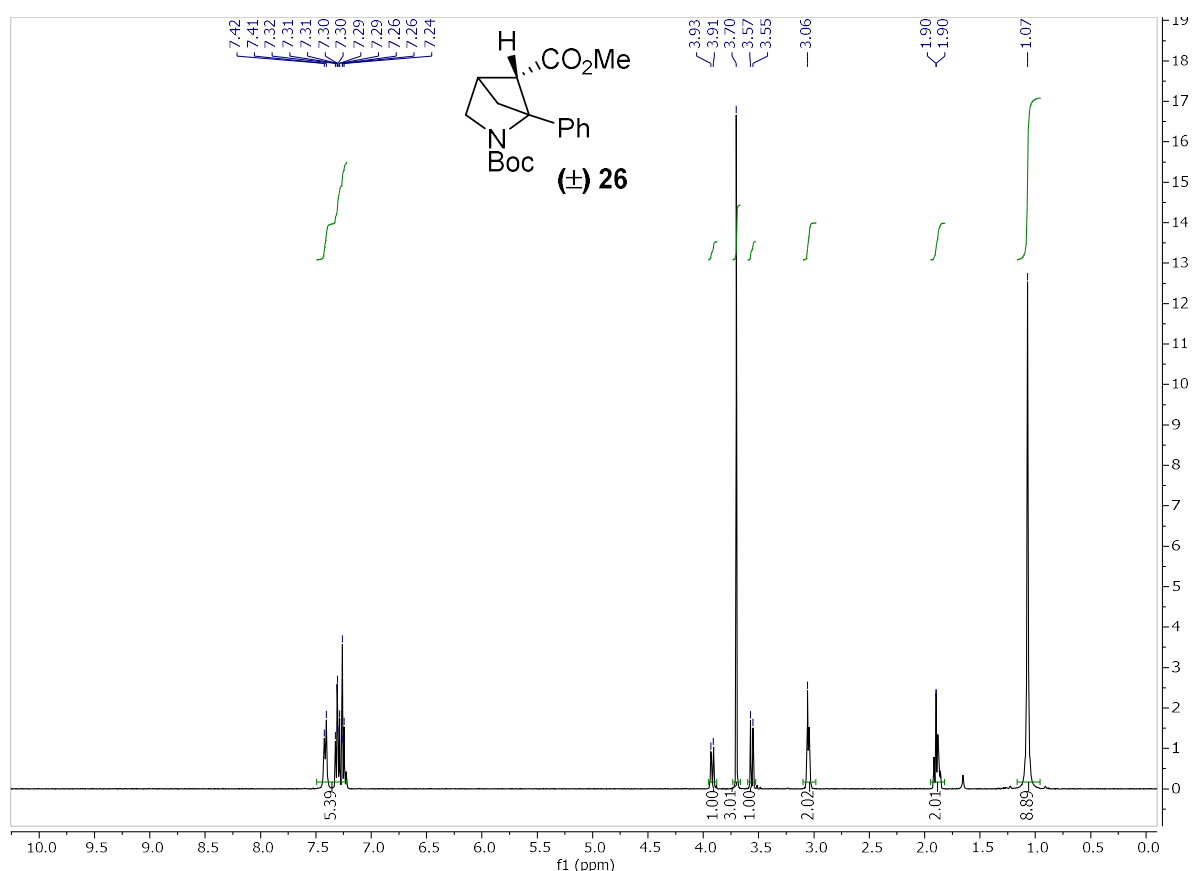

13C-NMR (101 MHz, $\left.\mathrm{CDCl}_{3}\right)$

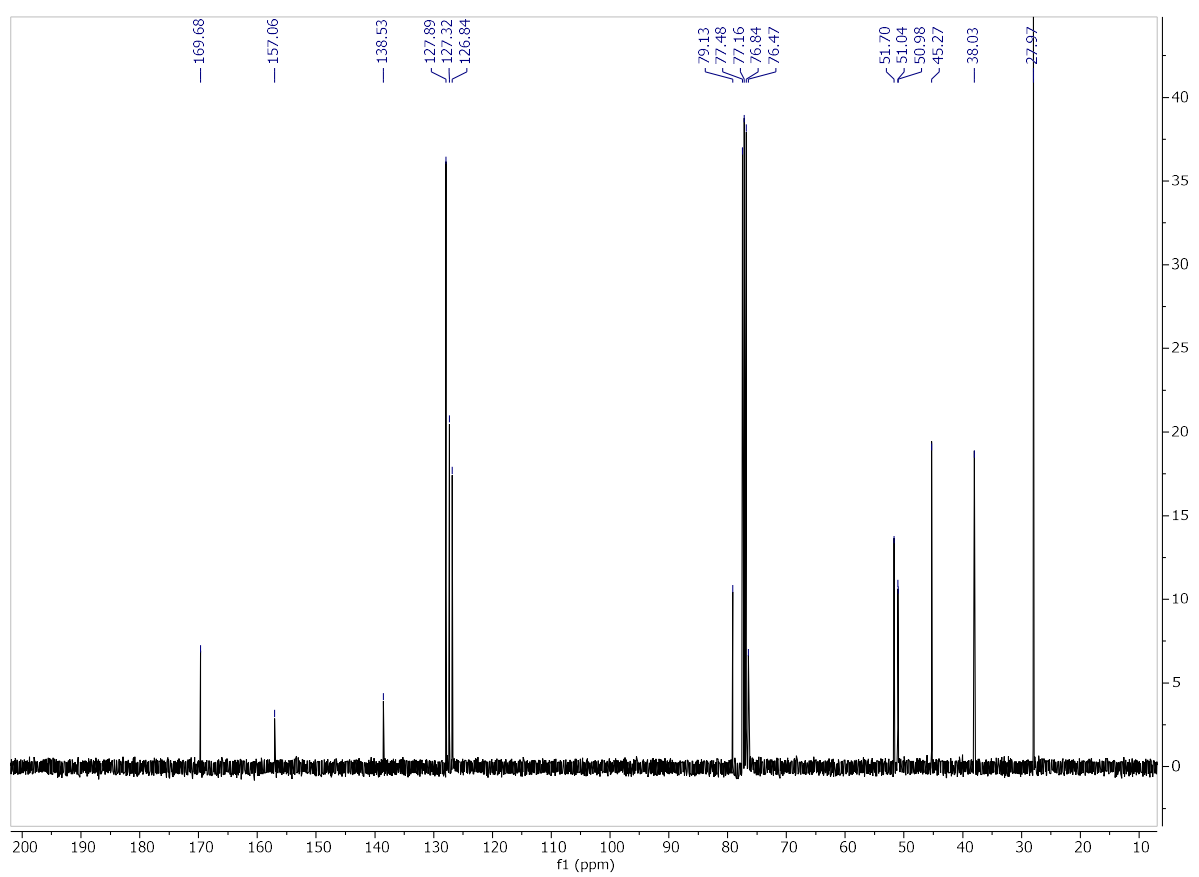


1H-NMR (400 MHz, $\mathrm{CDCl}_{3}$ )

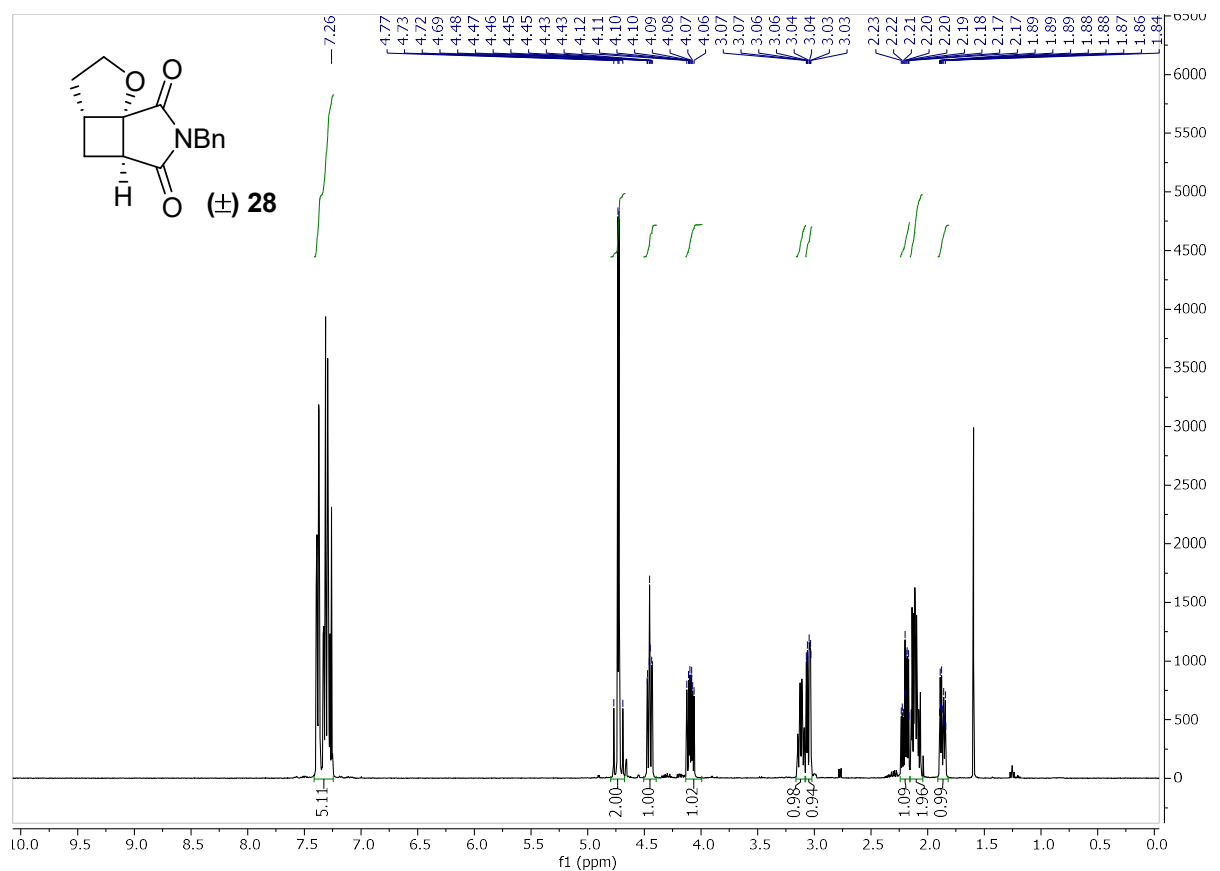

13C-NMR (101 MHz, $\left.\mathrm{CDCl}_{3}\right)$

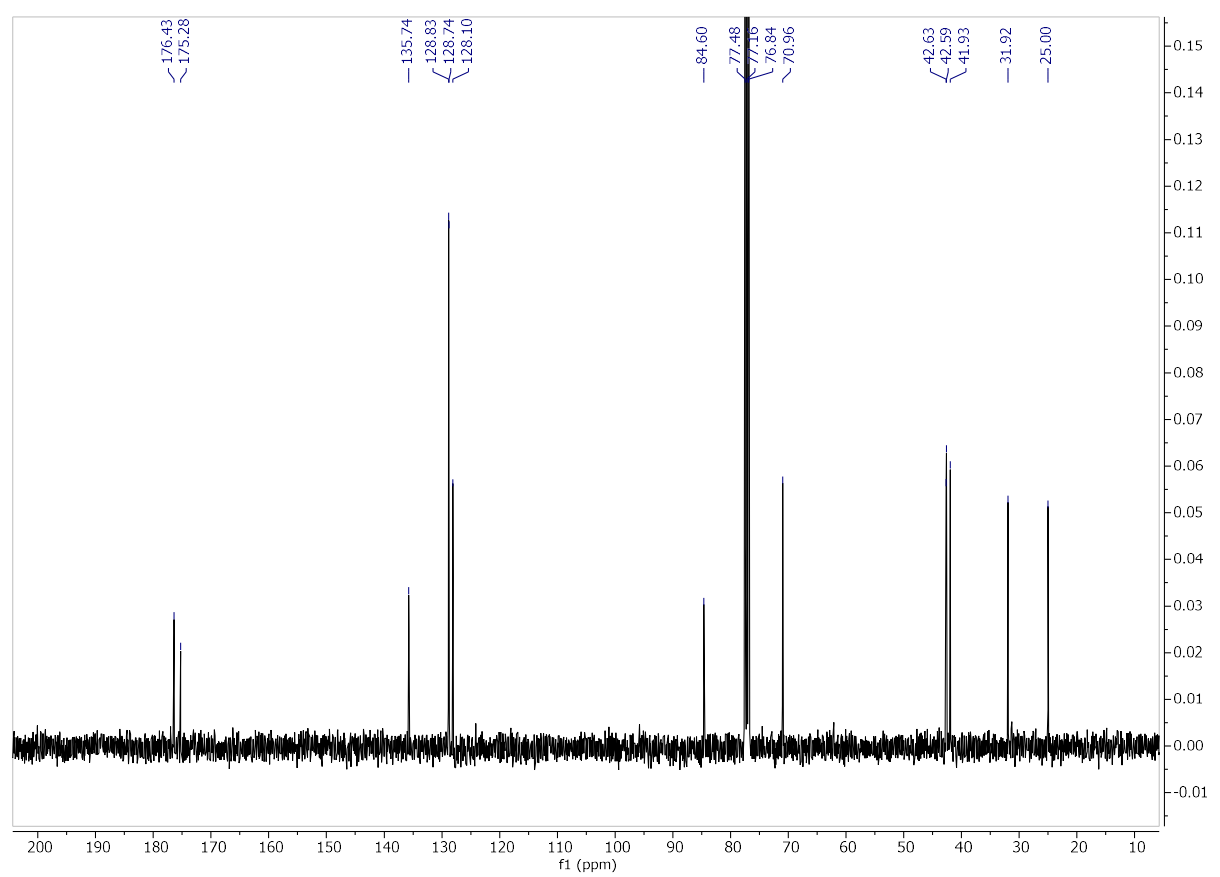




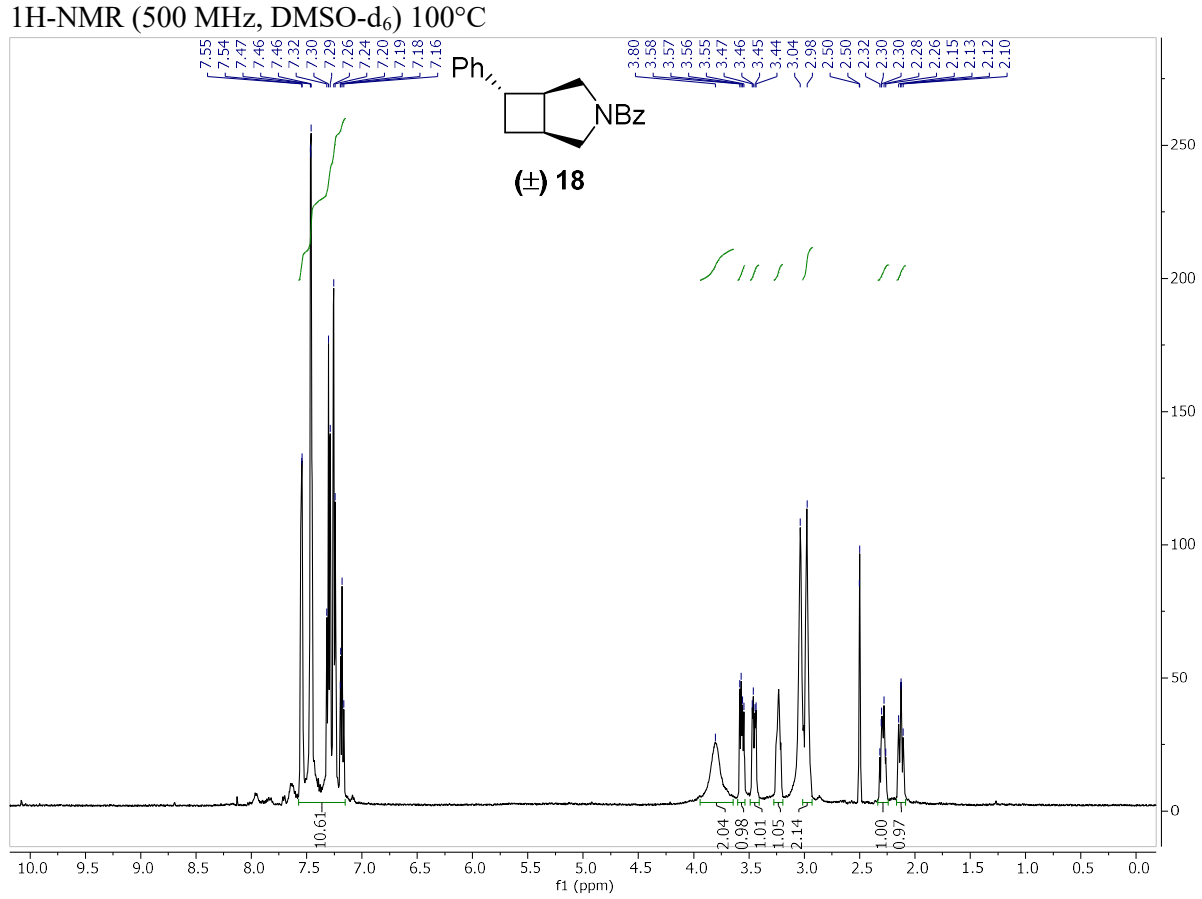

13C-NMR (126 MHz, DMSO-d 6 ) $120^{\circ} \mathrm{C}$

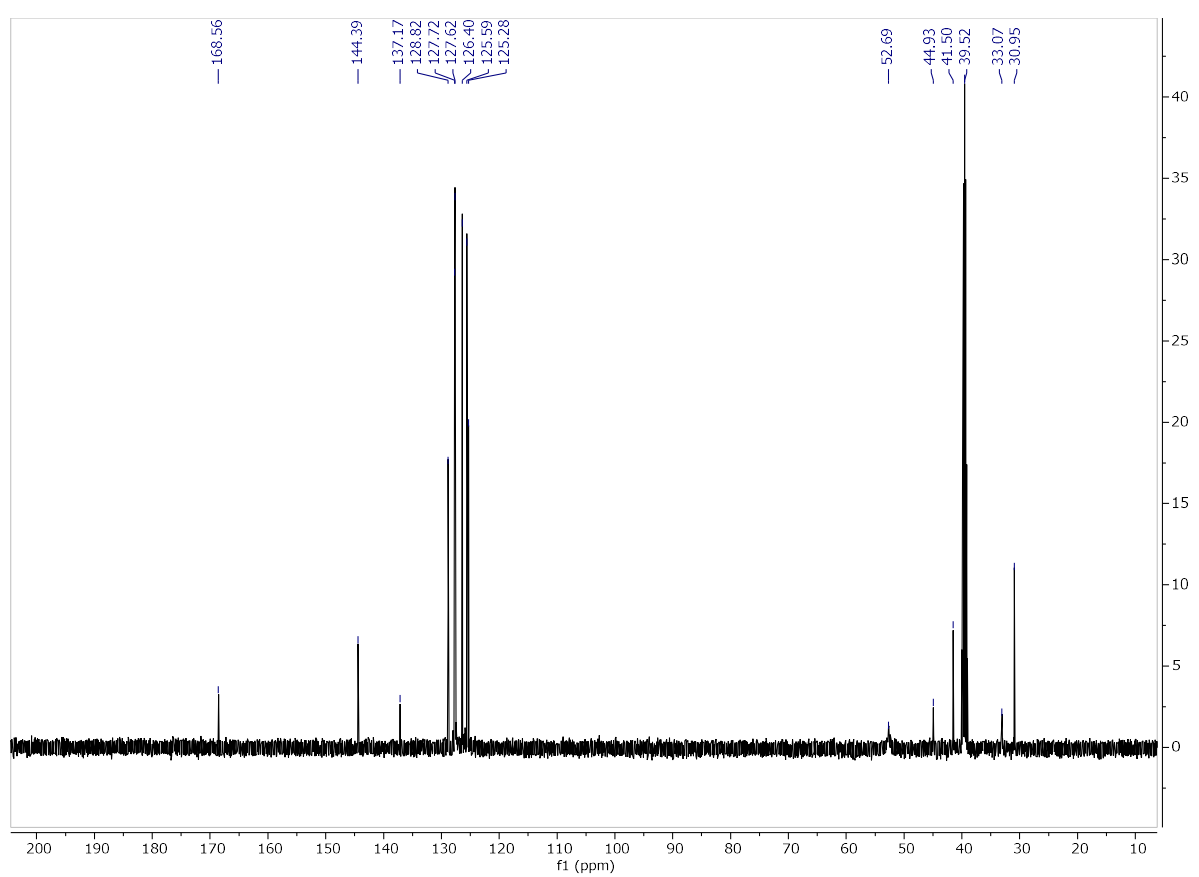


1H-NMR (400 MHz, DMSO-d6)

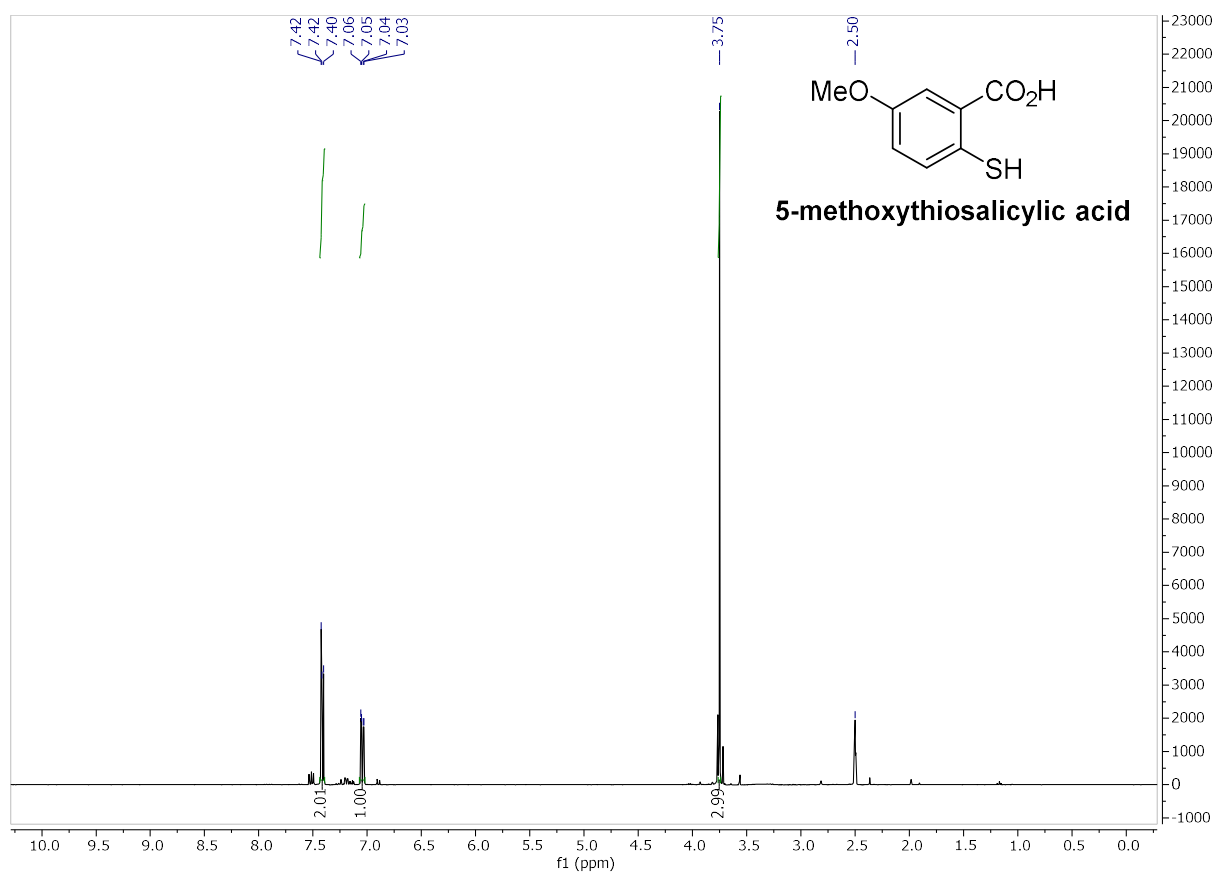

13C-NMR (101 MHz, DMSO-d 6 )

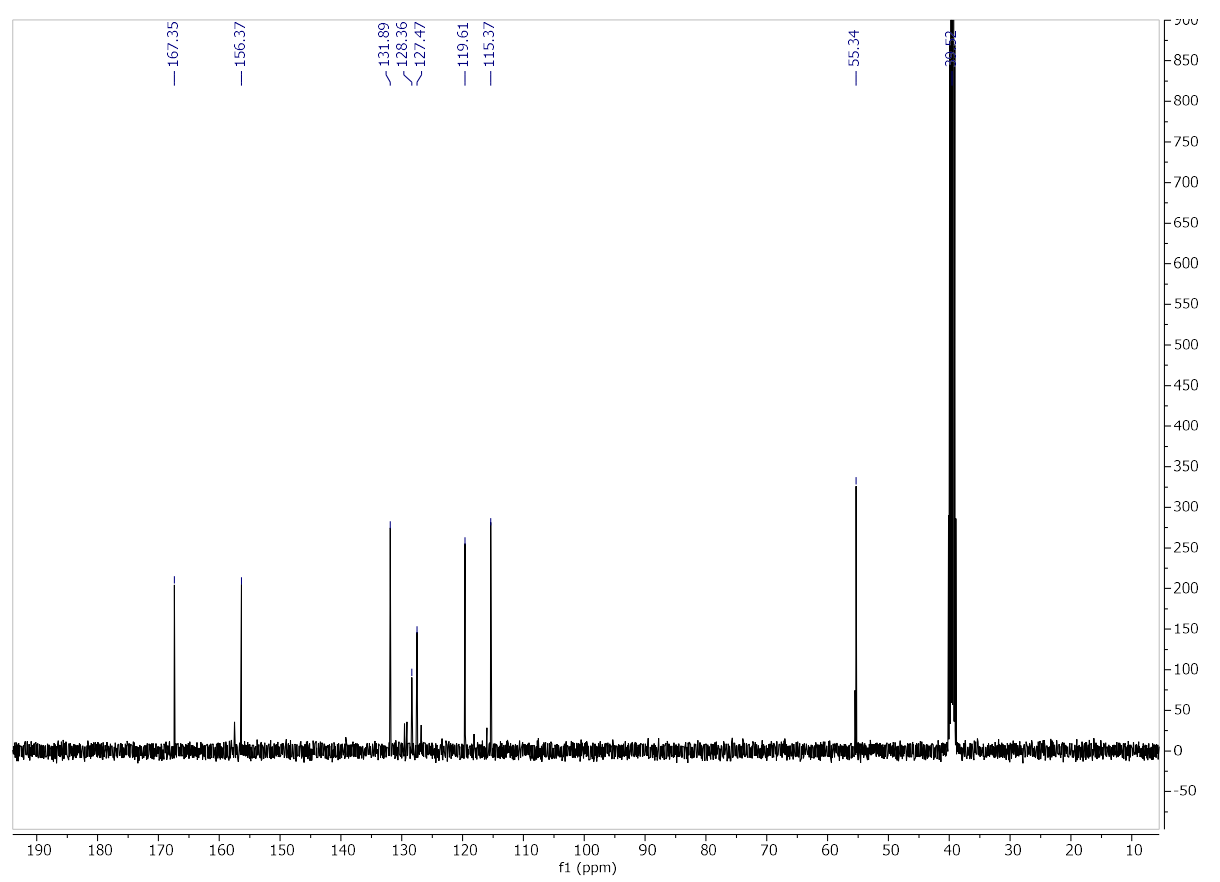


1H-NMR (400 MHz, DMSO-d 6 )

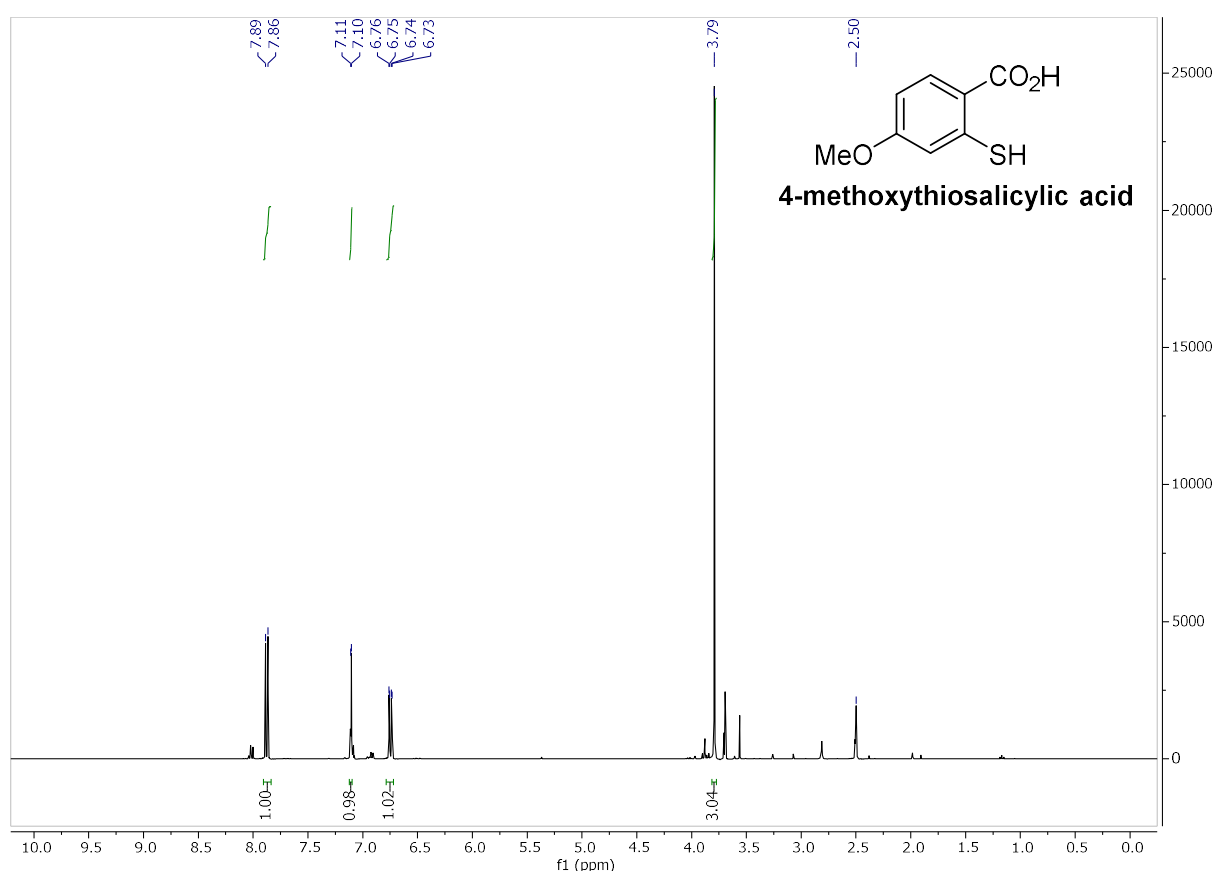

13C-NMR (101 MHz, DMSO-d 6 )

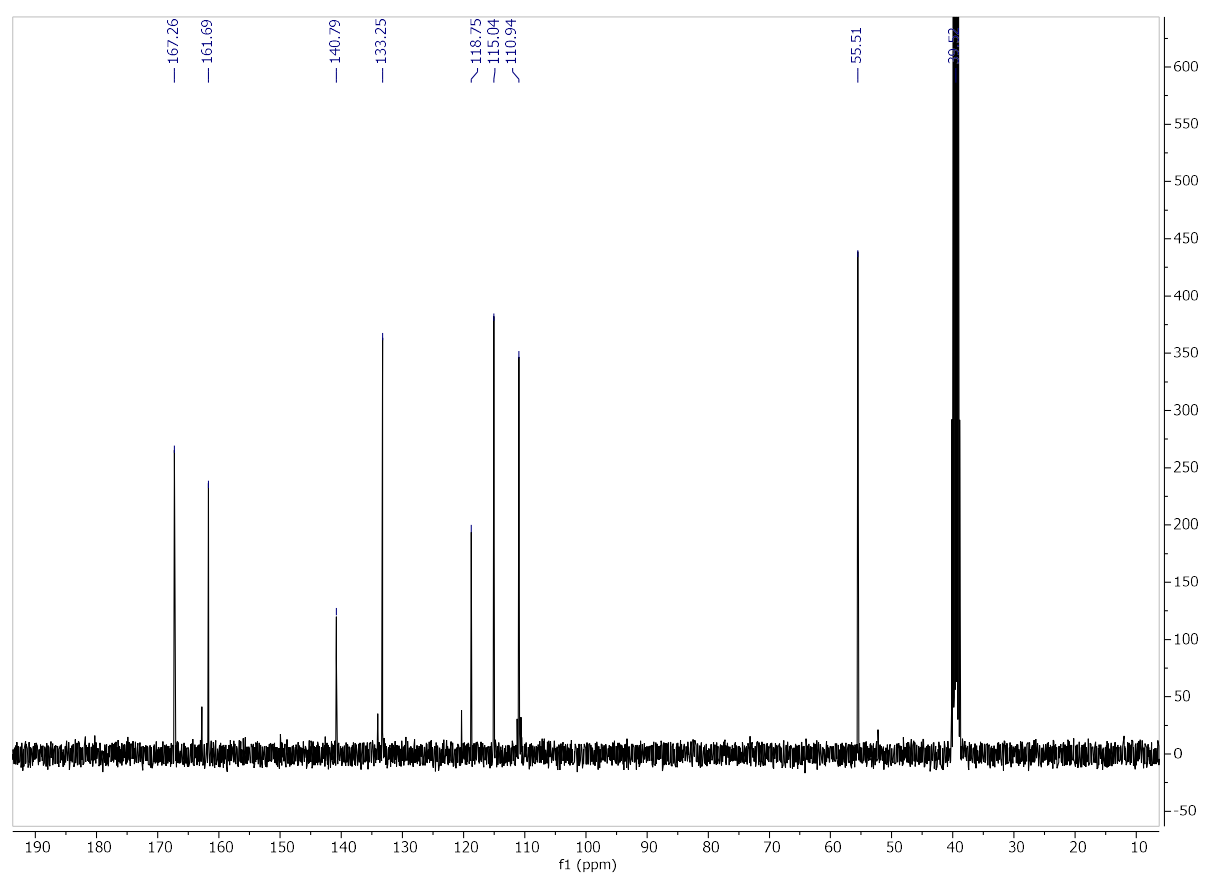


1H-NMR (500 MHz, DMSO-d 6 )

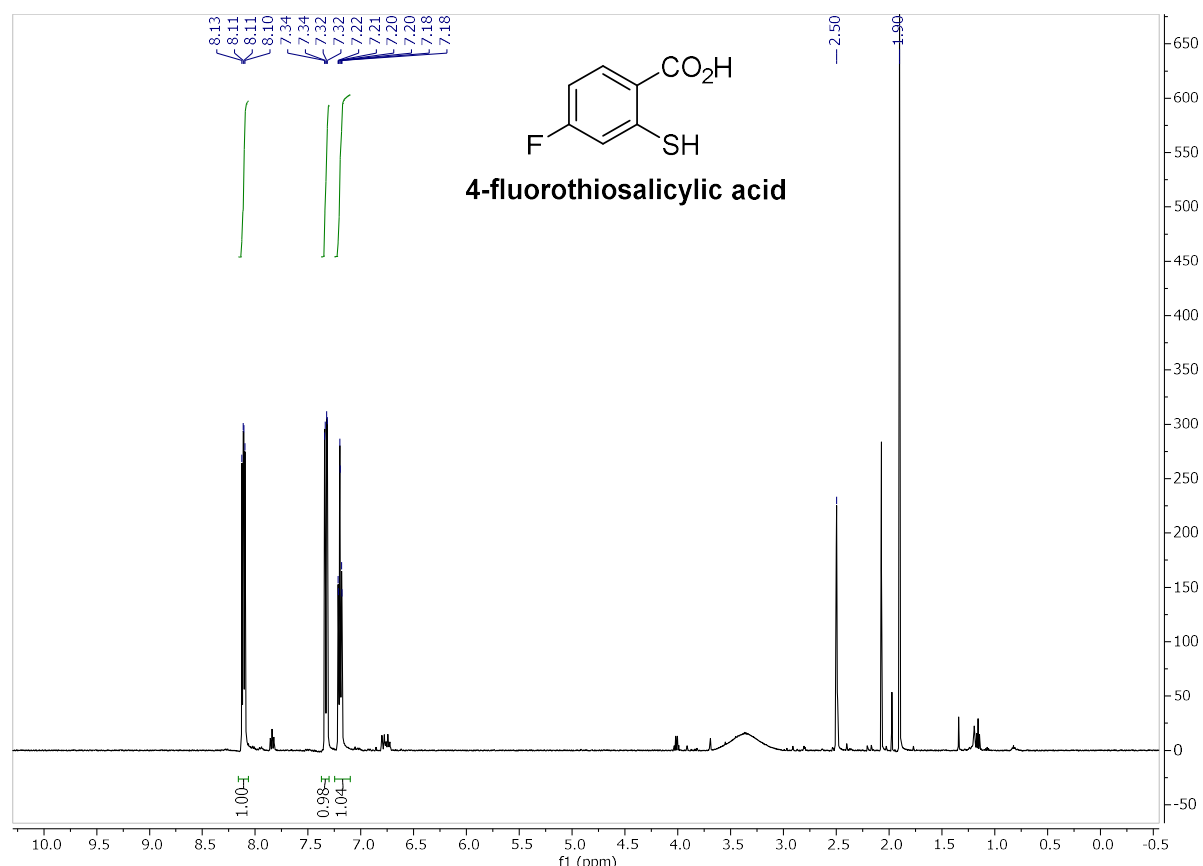

13C-NMR (126 MHz, DMSO-d $\left.{ }_{6}\right)$

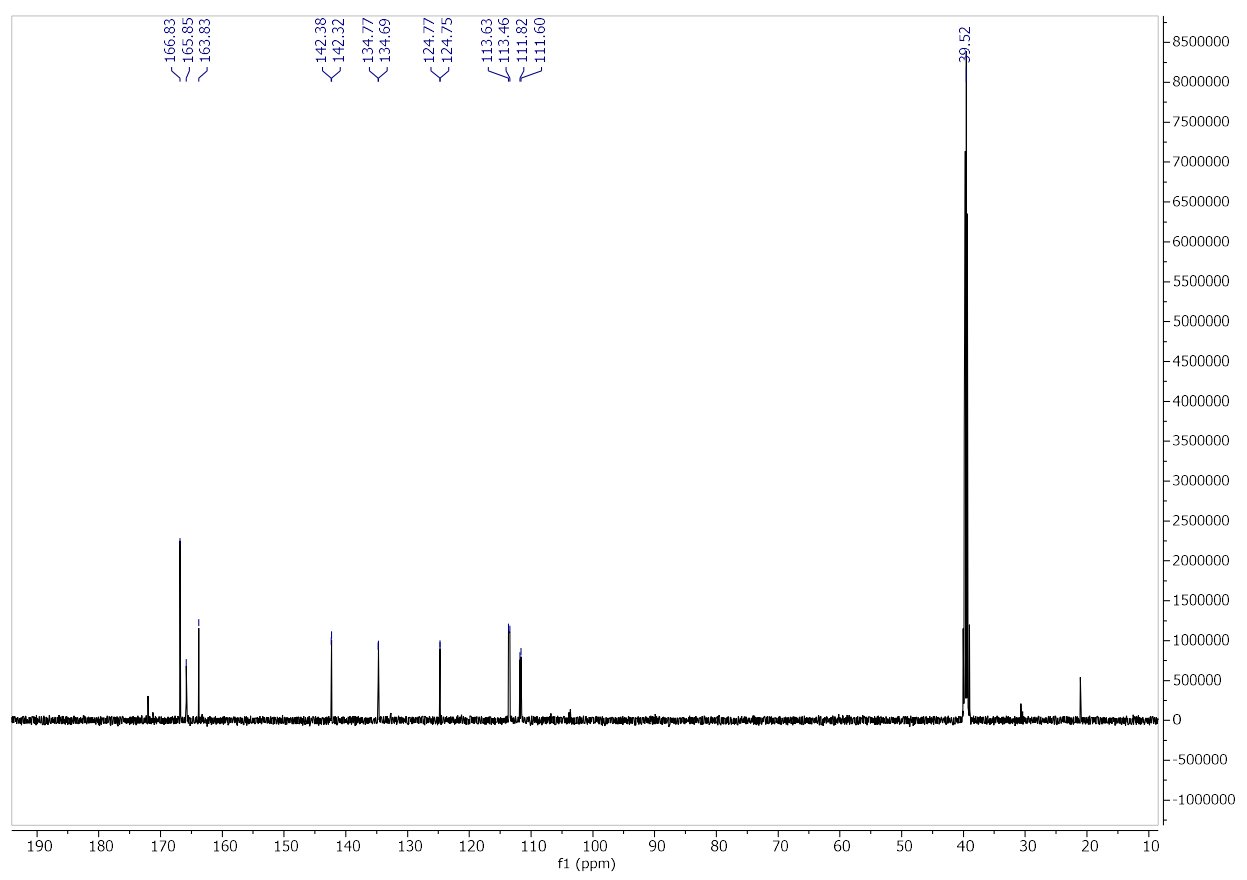




\section{References}

${ }^{1}$ Perkowski, A. J.; Cruz, C. L.; Nicewicz, D. A. An Ambient Temperature Newman-Kwart Rearrangment Mediated by Organic Photoredox Catalysis. J. Am. Chem. Soc. 2015, 137, 15684-15687

${ }^{2}$ Herbicidal sulphonamides, Patent US4632693 (A), 1986

31,3-BENZOTHIAZINONE DERIVATIVES AND USE THEREOF, Patent EP1424336 (A1), 2004

${ }^{4}$ 1,4-benzothiazepine derivatives, Patent US5416066 (A), 1995

${ }^{5}$ Watanabe, M.; Date, M.; Tsukazaki, M.; Furukawa, S. Chem. Pharm. Bull. 1989, 37, 36 - 41

${ }^{6}$ Roberts, K. C.; Smiles, S. CXIII. -Methoxy-derivatives of thioxanthone. J. Chem. Soc. 1929, 863-872

${ }^{7}$ Novel thioxanthene derivatives and salts thereof and a process for the manufacture of same. Patent GB861521 (A), 1961

${ }^{8}$ Brennan, Peter, Michael W. George, Omar S. Jina, Conor Long, Jennifer McKenna, Mary T. Pryce, Xue-Zhong Sun, and Khuong Q. Vuong. Photoinduced $\mathrm{Se}^{-} \mathrm{C}$ Insertion Following Photolysis of $\left(\eta^{5}-\mathrm{C}_{4} \mathrm{H}_{4} \mathrm{Se}\right) \mathrm{Cr}(\mathrm{CO})_{3}$. A Picosecond and Nanosecond Time-Resolved Infrared, Matrix Isolation, and DFT Investigation. Organometallics, 2008, 27, 3671-3680

${ }^{9}$ Gaussian 16, Revision C.01, Frisch, M. J.; Trucks, G. W.; Schlegel, H. B.; Scuseria, G. E.; Robb, M. A.; Cheeseman, J. R.; Scalmani, G.; Barone, V.; Petersson, G. A.; Nakatsuji, H.; Li, X.; Caricato, M.; Marenich, A. V.; Bloino, J.; Janesko, B. G.; Gomperts, R.; Mennucci, B.; Hratchian, H. P.; Ortiz, J. V.; Izmaylov, A. F.; Sonnenberg, J. L.; Williams-Young, D.; Ding, F.; Lipparini, F.; Egidi, F.; Goings, J.; Peng, B.; Petrone, A.; Henderson, T.; Ranasinghe, D.; Zakrzewski, V. G.; Gao, J.; Rega, N.; Zheng, G.; Liang, W.; Hada, M.; Ehara, M.; Toyota, K.; Fukuda, R.; Hasegawa, J.; Ishida, M.; Nakajima, T.; Honda, Y.; Kitao, O.; Nakai, H.; Vreven, T.; Throssell, K.; Montgomery, J. A., Jr.; Peralta, J. E.; Ogliaro, F.; Bearpark, M. J.; Heyd, J. J.; Brothers, E. N.; Kudin, K. N.; Staroverov, V. N.; Keith, T. A.; Kobayashi, R.; Normand, J.; Raghavachari, K.; Rendell, A. P.; Burant, J. C.; Iyengar, S. S.; Tomasi, J.; Cossi, M.; Millam, J. M.; Klene, M.; Adamo, C.; Cammi, R.; Ochterski, J. W.; Martin, R. L.; Morokuma, K.; Farkas, O.; Foresman, J. B.; Fox, D. J. Gaussian, Inc., Wallingford CT, 2016.

${ }^{10}$ Elliott, L. D.; Berry, M.; Harji, B.; Klauber, D.; Leonard, J.; Booker-Milburn, K. I. Org. Process Res. Dev. 2016, 20 1806-1811

${ }^{11}$ Elliott, L. D.; Booker-Milburn, K. I. Photochemically Produced Aminocyclobutanes as Masked Dienes in Thermal Electrocyclic Cascade Reactions. Org. Lett. 2019, 21, 1463-1466

${ }^{12}$ Bruker, SAINT+ v8.38A Integration Engine, Data Reduction Software, Bruker Analytical X-ray Instruments Inc., Madison, WI, USA 2015.

${ }^{13}$ Bruker, SADABS 2014/5, Bruker AXS area detector scaling and absorption correction, Bruker Analytical X-ray Instruments Inc., Madison, Wisconsin, USA 2014/5.

${ }^{14}$ Sheldrick, G. M., SHELXT - Integrated space-group and crystal-structure determination. Acta Crystallographica aFoundation and Advances 2015, 71, 3-8.

${ }^{15}$ Sheldrick, G. M., A short history of SHELX. Acta Crystallographica Section A 2008, 64, 112-122.

${ }^{16}$ Sheldrick, G. M., Crystal structure refinement with SHELXL. Acta Crystallographica Section C-Structural Chemistry 2015, 71, 3-8.

${ }^{17}$ Dolomanov, O. V.; Bourhis, L. J.; Gildea, R. J.; Howard, J. A. K.; Puschmann, H., OLEX2: a complete structure solution, refinement and analysis program. Journal of Applied Crystallography 2009, 42, 339-341. 